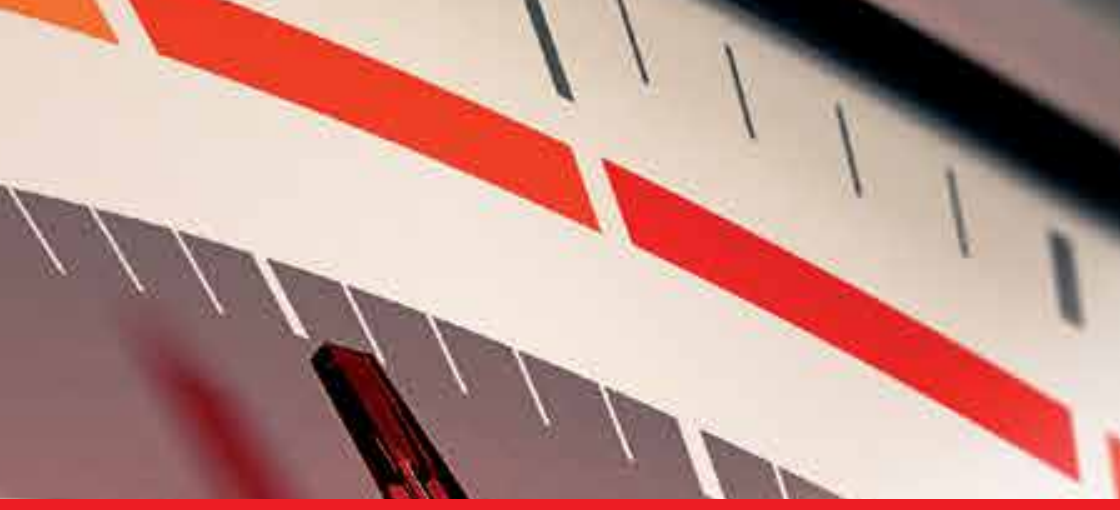

\author{
IntechOpen
}

\title{
Risk Management in \\ Environment, Production and Economy
}

Edited by Matteo Savino

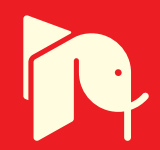





\section{RISK MANAGEMENT \\ IN ENVIRONMENT, \\ PRODUCTION \\ AND ECONOMY}

Edited by Matteo Mario Savino 
Risk Management in Environment, Production and Economy

http://dx.doi.org/10.5772/965

Edited by Matteo Savino

\section{Contributors}

Reza Tavakkoli-Moghaddam, S.M. Mousavi, H. Hashemi, Undram Chinbat, Chris Allan Allan Shisanya, Cush Ngonzo Luwesi, Joy Apiyo Obando, Per Bjarte Solibakke, Massimo Musacchio, Malvina Silvestri, Fabrizia Buongiorno, Sergio Perelli, Sergio Teggi, Sergio Pugnaghi, Eugenio Sansosti, Simona Zoffoli, Chiara Cardaci, Valerio Lombardo, Claudia Spinetti, Stefano Corradini, Luca Merucci, Gabriele Gangale, Lorenzo Guerrieri, Boris Behncke, Angelo Amodio, Hugues Heurtefeux, Provence Lanzellotti, Paul Sauboua, Amandine Bichot, Elena Carrasco, Antonio Valero, Rosa María García-Gimeno, Gonzalo Zurera, Fernando Pérez-Rodríguez, Elvis Pontes, Sergio Kofuji, Adilson Guelfi, Anderson Silva

\section{(c) The Editor(s) and the Author(s) 2011}

The moral rights of the and the author(s) have been asserted.

All rights to the book as a whole are reserved by INTECH. The book as a whole (compilation) cannot be reproduced, distributed or used for commercial or non-commercial purposes without INTECH's written permission. Enquiries concerning the use of the book should be directed to INTECH rights and permissions department (permissions@intechopen.com).

Violations are liable to prosecution under the governing Copyright Law.

\section{(cc) BY}

Individual chapters of this publication are distributed under the terms of the Creative Commons Attribution 3.0 Unported License which permits commercial use, distribution and reproduction of the individual chapters, provided the original author(s) and source publication are appropriately acknowledged. If so indicated, certain images may not be included under the Creative Commons license. In such cases users will need to obtain permission from the license holder to reproduce the material. More details and guidelines concerning content reuse and adaptation can be foundat http://www.intechopen.com/copyright-policy.html.

\section{Notice}

Statements and opinions expressed in the chapters are these of the individual contributors and not necessarily those of the editors or publisher. No responsibility is accepted for the accuracy of information contained in the published chapters. The publisher assumes no responsibility for any damage or injury to persons or property arising out of the use of any materials, instructions, methods or ideas contained in the book.

First published in Croatia, 2011 by INTECH d.o.o.

eBook (PDF) Published by IN TECH d.o.o.

Place and year of publication of eBook (PDF): Rijeka, 2019.

IntechOpen is the global imprint of IN TECH d.o.o.

Printed in Croatia

Legal deposit, Croatia: National and University Library in Zagreb

Additional hard and PDF copies can be obtained from orders@intechopen.com

Risk Management in Environment, Production and Economy

Edited by Matteo Savino

p. cm.

ISBN 978-953-307-313-2

eBook (PDF) ISBN 978-953-51-6051-9 


\section{We are IntechOpen, \\ the world's leading publisher of Open Access books}

Built by scientists, for scientists

\section{$4,000+$ \\ Open access books available \\ $116,000+$ \\ International authors and editors

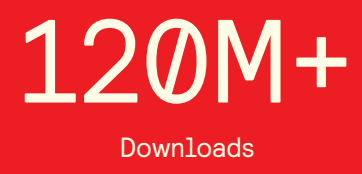

Our authors are among the

151

Countries delivered to

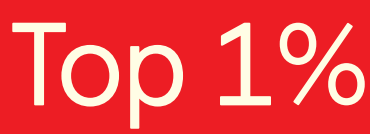

most cited scientists

Contributors from top 500 universities

$12.2 \%$

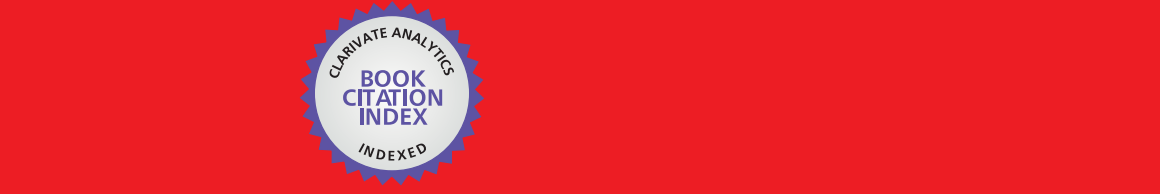

WEB OF SCIENCE ${ }^{\mathrm{M}}$

Selection of our books indexed in the Book Citation Index in Web of Science ${ }^{\mathrm{TM}}$ Core Collection (BKCI)

\section{Interested in publishing with us? \\ Contact book.department@intechopen.com}





\section{Meet the editor}

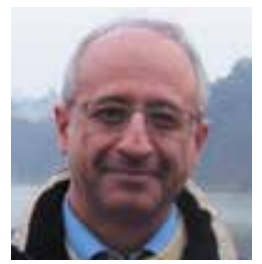

Matteo Mario Savino is a Professor of Industrial Operations and Industrial Management at the University of Sannio. He received a PhD in Industrial plants in 1999 at the University Federico II of Naples, Department of Design and Industrial Engineering. Among his research interests there are Project Management, Risk Assessment, Quality aspects related to industrial production. He has managed several National and EU Funded research and educational projects. Since 2008 he has been a Delegate of the Rector for Quality Assurance and is the President of the University Quality Centre. He is the author of more than 50 Scientific Publications and participates in International Journals and International Peer Review proceedings. 



\section{Contents}

\section{Preface XI}

\section{Part 1 Environment 1}

Chapter 1 Coastal Risk Management Modes: The Managed Realignment as a Risk Conception More Integrated $\mathbf{3}$ Hugues Heurtefeux, Paul Sauboua, Provence Lanzellotti and Amandine Bichot

Chapter 2 Toward a Hydro-Economic Approach for Risk Assessment and Mitigation Planning of Water Disasters in Semi-Arid Kenya 27 Cush Ngonzo Luwesi, Chris Allan Shisanya and Joy Apiyo Obando

Chapter 3 Generation of Added Values Products Supporting Risk Analysis 47

Massimo Musacchio, Malvina Silvestri, Luca Merucci, Stefano Corradini, Claudia Spinetti, Valerio Lombardo, Boris Behncke,Lorenzo Guerrieri, Gabriele Gangale, Fabrizia Buongiorno, Sergio Perelli, Sergio Teggi, Sergio Pugnaghi, Angelo Amodio, Eugenio Sansosti, Simona Zoffoli and Chiara Cardaci

\section{Part 2 Production 75}

\section{Chapter 4 Food Safety Risk Management $\mathbf{7 7}$}

Elena Carrasco, Antonio Valero,Fernando Pérez-Rodríguez, Rosa María García-Gimeno and Gonzalo Zurera

Chapter 5 Risk Analysis in the Mining Industry 103 Undram Chinbat

Chapter 6 A Fuzzy Comprehensive Approach for Risk Identification and Prioritization Simultaneously in EPC Projects 123

R. Tavakkoli-Moghaddam, S.M. Mousavi and H. Hashemi 
X Contents

\section{Part 3 Economy 147}

Chapter 7 A Comprehensive Risk Management

Framework for Approaching the

Return on Security Investment (ROSI) 149

Elvis Pontes, Adilson E. Guelfi, Anderson A. A. Silva and Sérgio T. Kofuji

Chapter 8 Market Risk Management

with Stochastic Volatility Models 171

Per Solibakke 


\section{Preface}

Risk management is nowadays the way to prevent serious damage or critical consequences from dangerous situations in everyday life. Although, for many years, much has been done in terms of prevention and great efforts are continuously invested into it, the concept of risk as an unforeseen event which can cause danger or a great modification of a previous situation is still an issue to be taken into account.

Even if the term "risk" is often negative in its common acceptation, many opportunities can arise from such a situation: not only speculation but, above all, the possibility to be prepared to tackle the events and to use the mind in order to develop new solutions which can convert a possible danger to an unforeseen but positive event.

Unforeseen events are very common not only in natural phenomena but also in human activities: volcanoes, coasts and natural environment rather than projects, food safety, mining and construction industry are examples of the possible application fields of risk management analysis.

This book presents a structured collection of papers dealing with the subject and stressing the importance of an issue such as risk management. The aim is to present the problem in various fields of application of risk management theories, highlighting the approaches which can be found in literature.

The book is organized in three macro parts and their respective chapters referring to three macro areas which can be involved in the risk management analysis.

The first part of the book analyzes risk management methodologies with respect to the environment by introducing approaches to prevent volcano disaster, water disaster or coastal degradation through three representative case studies.

The second part deals with the production field and introduces peculiarities in project management process, food chain and some sectors of industry through the use of new techniques combined with risk analysis. 
The last part discusses the application of risk management in economic sector to face the dynamicity and unforeseen events which can arise and, thus, better understand and tackle the actual global economy.

Prof. Matteo Mario Savino,

Dept. of Engineering, University of Sannio, Italy 


\section{Part 1}

Environment 



\title{
Coastal Risk Management Modes: The Managed Realignment as a Risk Conception More Integrated
}

\author{
Hugues Heurtefeux, Paul Sauboua, \\ Provence Lanzellotti and Amandine Bichot \\ EID Méditerranée, Montpellier,
}

France

\section{Introduction}

Land managers assess the risk by evaluating the probability of hazard occurring and likely damage that would occur to economic assets. There are two types of hazards. The first is caused by wave action, near-shore current and wind effects; which imply erosion and its associated risk of flooding. The second is increased by physical structures that have been built with the aim of protecting the coastline. Storms can induce the destruction of coastal protections as dunes and promote the sea submersion. Sea submersion is a temporary flood of coastal area due to the sea and needing extreme weather conditions. Given the importance of biodiversity and attractive nature of coastal areas, they present different stakes. There are socio-economic stakes as people, amenities, activities and infrastructures. And in the same way, there are natural stakes and cultural heritages as natural areas and historic building.

To anticipate coastal risks, coastal management has always been a major question for land managers. During the XIX ${ }^{\text {th }}$ century, Victor Hugo himself has made speeches to outline the vulnerability of coastal areas to these hazards (Hugo, 1846). For a long time, hard structures were built to hold the line and to provide high level of protection to population. These options more easy to develop were usually used because of absence of knowledge. But in the last twenty years, new approaches to manage coast have been developed.

This shift of coastal management by the decision makers has depended on the appearance of the Integrated Coastal Zone Management (ICZM) concept too. The ICZM is originating from the US and adapted in France via Europe. It replaces a protectionist policy, long based on a naturalistic approach. Taking consideration of the economic, sociological, biological concerns and the democratic, educational and political ones as well, with in addition the relationships between the various partners involved, is a land management way that cannot be ignored these days of sustainable development (Bawedin, 2009).

One of these new approaches to manage coastal areas corresponds to the managed realignment (MR). Different cases of managed realignment exist and constitute a heterogeneous set. Indeed local context differences as the type and the importance of stakes and hazards, of sites topography, but especially of coastal management conceptions into public policies, induce an important diversity of M.R. cases. Thus in a context of thoughts 
about management modes to use into coastal areas, it seems necessary to analyse this emerging notion. This publication will permit to study in a first part (i) the M.R. notion, and the objectives and actions to which they correspond to. Overviews in a second part will permit to evaluate in France (ii) a case where MR seems to be a pertinent option and an other (iii) where MR option has been set up.

\section{Emergence of a coast management mode, the managed realignment (M.R.)}

Land managers have always tried to limit the risks resulting to the interaction between present coastal stakes as population, housing and infrastructures presence, with coastal hazards. This objective has sometimes implicated the obligation to shift some of these stakes because of the evolution of extreme events in their intensity or frequency. Some old marginal cases existed like the Brighton Beach Hotel at Coney Island (New York, United States) which has been shifted during the XIXth century of about 180 meters because of storm wave action (Trevi, 2008). But the majority of M.R. cases are quite recent. The reality proved than for a long time hard structures like seawalls, embankments, groynes, breakwaters were built to hold the line and to provide high level of protection to population. These options more easy to develop were usually used because of absence of knowledge (no strong computers for efficient numerical models, no climate change context) and cultural attitude (coastal lands loss was difficult to accept, whereas dykes increase safety sentiment). In the last twenty years, four global approaches to manage coast have been developed (cf. figure 1):

- The approach by holding the line, as presented above, has persisted to be used. Traditionally, the goal is to protect developed area using hard structures (Klein and al., 2001).

- The "do the minimum" approach. It corresponds to the use of natural processes to reduce risks but permitting coast natural changes. Some of the techniques used with this approach attempt to limit rather than to stop coastal erosion and cliff's retreat;

- The "do nothing" approach, which is rare but can be found. One of the more famous cases of "do nothing" approach is the municipality of Happisburg, in the county of North Norfolk (UK). The storm waves reached the coast with important damages on the bottom of the cliff, the cliff fell with mayor impact on the houses totally destroyed (cf. figure 2). Do nothing is one of policies adopted when it's too late, when any decision has been thought before, when the cost benefit analysis shows than the defence front to the sea exceeds the value of the properties.

- The M.R. approach which is quite recent. Its definitions and its particularities will be presented below.

Climate change would tend to modify coastal hazards. Thus as the $4^{\text {th }}$ evaluation report of the Intergovernmental Panel on Climate Change (IPCC), means sea level will have for the 2090-2099 decade a rise inclusive between 0,18 and 0,59 $\mathrm{m}$ in comparison to the 1980-1999 period (IPCC, 2007). In the same way, as the report of the National Observatory on Climate Change effects, Climate change is happening with several effects directly observed on the coast (ONERC, 2007) :

- Sea level rise,

- Growing of damage by river and sea floods on the coast,

- Trend of more storms but not totally confirmed. 


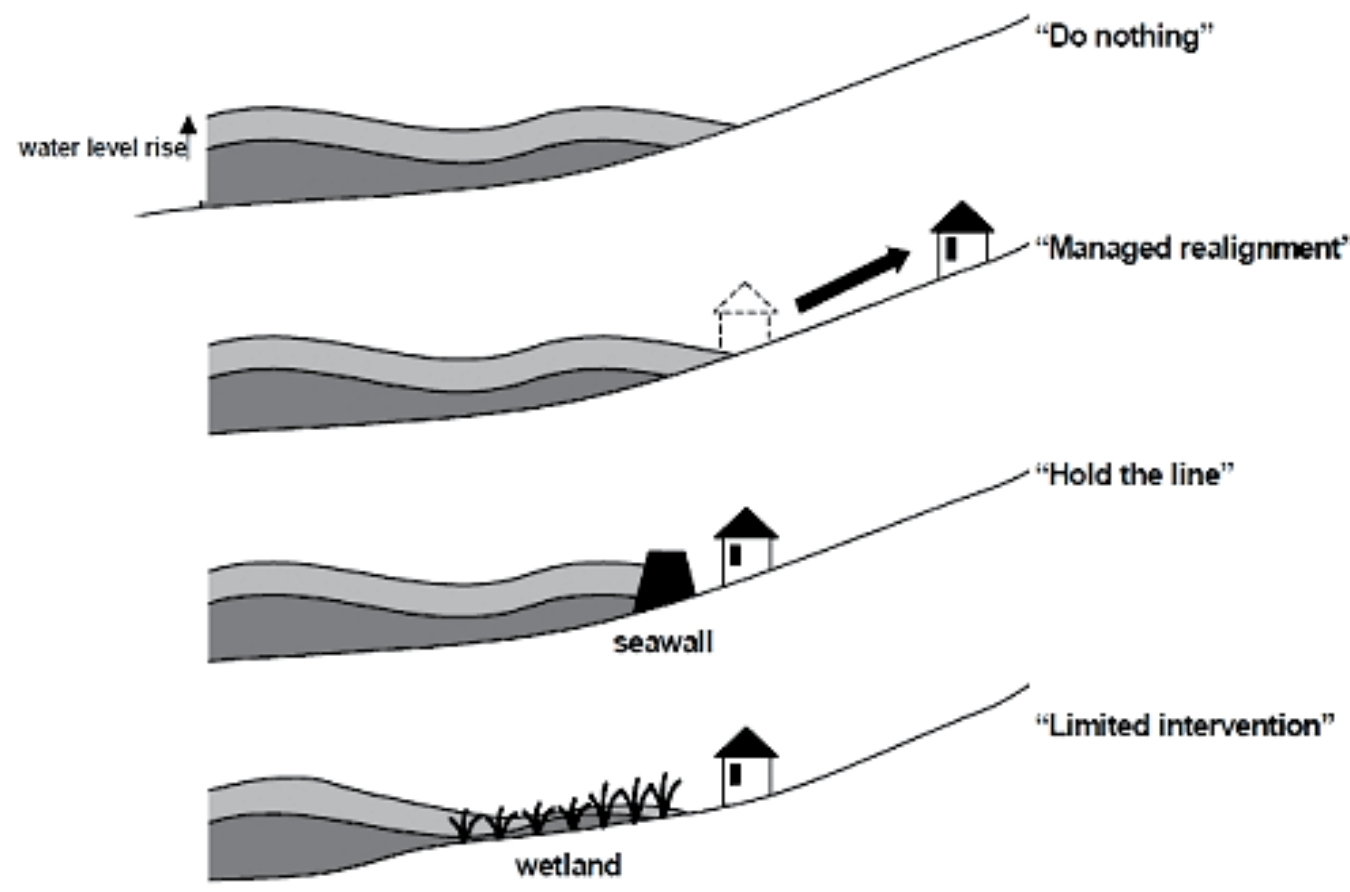

Fig. 1. Policy options for coastal management (European Commission, 2004)

This coastal evolution has an impact on coastal management. In the recent past; land managers were using a different approach in which properties were not moved but instead, protected by hard structures. The use of this holding the line approach has started to be criticized. It has some economic drawbacks (high construction and maintenance costs), environmental drawbacks (breaking of the natural dynamic of the longshore current into the sea sediment cell) and spoils the landscape. Moreover this management mode can be especially questionable into the reasoning. The focus is on the problem of sediment flows rather than on their causes (EID-med, 2010).

An analysis of advantages and disadvantages of the classical management approaches and the evolution of natural hazards have led to a reassessment of these conventional management methods. Thus due to this reassessment, managed realignment projects have been implemented quite recently. One of the oldest (1987) realignments in Europe is Beltringharder Koog, state of Schleswig Holstein, Germany. To compensate for the adverse effects caused by a new polder (land reclamation) built in the Nordstrand Bay, a salt water lagoon and an intertidal habitat were created with a surface area about 1000 ha (ABPmer). M.R. needs political support to make the public aware of the benefits of this approach. That's why this concept has for a long time been difficult to implement

\subsection{Different coastal areas management policies represented by a set of definitions}

For a long time managed realignment used to be called managed retreat. That was the case in England for example. This term has gone out of favour, since it implies negativity in coastal management, and a "retreat in the face of the enemy", rather than a rational management choice (Rupp and Nicholls, 2002). For the British Government, the M.R. of coasts and rivers is defined as a process of establishing a new flood defence line for river 
corridors or coastlines often set back from the existing position, with the aim of improving the long-term sustainability of the defence, or contributing to other aims such as habitat creation (DEFRA, 2005). For Laure Ledoux (Ledoux, 2005), this definition must be understood as the definition of a new defence line, on the coast line but into the estuaries and bank rivers too. So it is in question of a voluntary approach and pro-active, in opposition to "inactive realignment" limited to not look after existing defences. M.R. objectives are numerous. It permits so a diminution of defences costs by the reduction of structures dimensions, and the increase of defences effectiveness and durability due to wave's energy absorbed by the wetlands created. There is an ecosystems creation or restoration too, with sometimes for specific objective to satisfy biodiversity protection criterions as defined by European directive on habitats. Another objective, in the particular case of estuaries, can be the obtaining of a more stable form face to the sea level rise, or to have an influence on sea level and flood risk.

M.R. consists generally in the artificial creation of a breach in existing structures (Dickie, 2010) (cf. figure 3). It permits to water to flood until the next natural relief or the new defence line constructed more into the hinterland. In this case, M.R. is more corresponding to a process of depolderisation. Indeed Western Europe's depolderisation was launched in the 1980's. A lot of different cases exist in United Kingdom where precisely management policies are directed towards M.R. (Goeldner-Gianella, 2007).
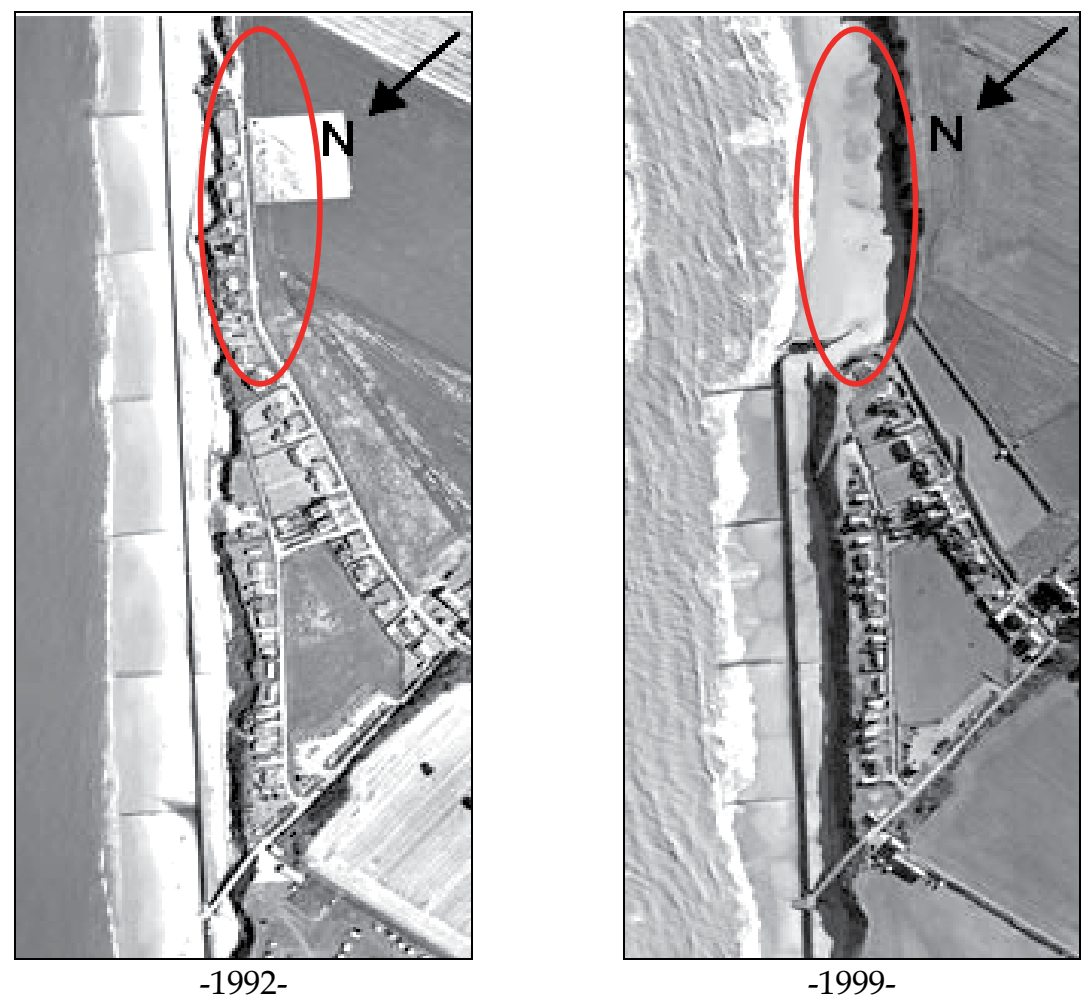

Fig. 2. Case of "do nothing" approach in Happisburgh (UK) (Coastal Concern Action Group) 


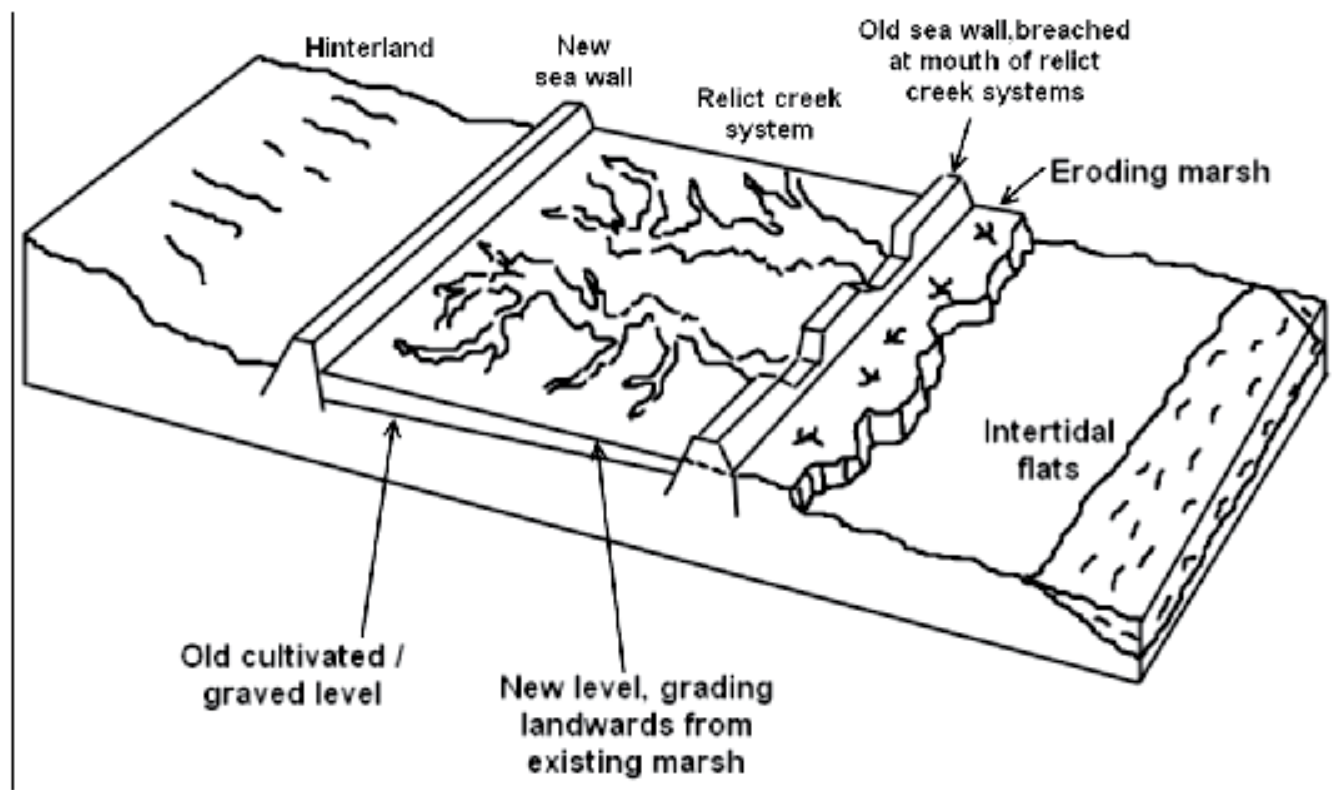

Fig. 3. Representation of strategic realignment (Rupp and Nicholls, 2002)

Since 2005 the management of risks in United Kingdom is concerned by a new strategy called "Making space for water". The main goal of this strategy is to consider environmental and social aspects of floods and coastal protection. It will put forward adaptation recommendations to climate change and promote managed realignment. This strategy includes the recognition of socio-economic, tourist and environmental factors in their totality, the improvement of knowledge relative to hazards, cooperation between stakeholders, development of innovative solutions and the consideration of these risks into land management plans. The same consideration of social, economic and environmental aspects is taken into account in area of flood management in Belgium. In that way, Belgium is a partner with United Kingdom of the project European Spatial Planning: Adapting to Climate Events.

Managed realignment is used in United States too. It is defined in the same way as in United Kingdom but it implies the abandon, the destruction, or the construction shifting on sectors potentially liable to flooding (SFP and URA). In United States, managed realignment is favoured by goods relocation aid and buy-back programs. These programs can be used to promote managed realignment and avoid complaints from sectors where an unconstructible area has been defined. With this coastal management approach, indemnification and relocation possibilities are taken into account.

In France, it is underlined that the process of realignment consists in a switch as a straight line. Thus there is a disappearance of uncertainties areas that make the richness of coastal environments (Léger, 2005). So the term of hindsight is more used in France. It is defined as a backward step or movement. This distant position into the space or into the time permits a better vision and assessment. Hindsight management objective is rather to move back present stakes on the coast towards the hinterland. That corresponds to an integrated management policy. 
Another type of term is used. In Canada retreat is more used to define the shunning of the risk: retreat or shunning consists in avoiding risks so as to eliminate direct impacts. Instead of attempt to protect land against sea encroachment, we give up to development project and we choose rather to abandon threatened land when conditions become intolerable. For example, it is possible to resort to a dissuasive regulation to reduce losses due to erosion. In some cases, restoration can be an alternative solution profitable for coastal constructions. Retreat corresponds to a proactive adaptation form to eliminate a direct impact. Easier retreat form consists in avoiding to buy vulnerable estates, in the case of individual buyers, or to construct in areas with a flood or erosion risk (Canadian Government, 2004).

By this process, the objective is rather to avoid the creation of new coastal stakes than to remove already existing ones. Finally coast line will be abandoned especially if natural hazards are strong but it is not a shifting policy strictly speaking.

The analysis of the different used terms indicates that these differences could be explained in a first part by a difference between expected objectives. These objectives would be to move back the stakes present on the coast to the hinterland, to create a new defence line backwards facing the sea to restore natural areas and a buffer space between sea and stakes, and to avoid the addition of new stakes at existing ones into coastal areas (cf. figure 4). It appears in a second part that these terms aren't used in the same countries. It could be the expression of the existing heterogeneity between countries with coastal line about their strategic orientations of coastal management.

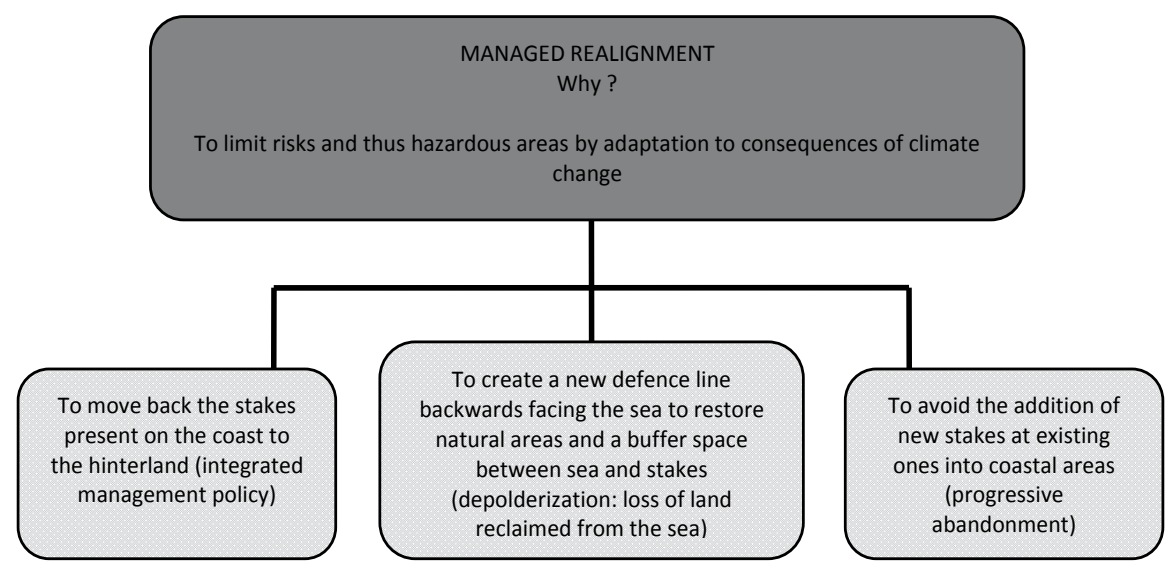

Fig. 4. Strategies diversity linked to managed realignment

\subsection{Overviewes of managed realignement use in the french context \\ 1.2.1 To the European scale}

Managed realignment is discussed by European Commission in order to respond to increasing coastal risks and climate change (European Commission, 2007). Coastal development and management have to be tackle in a strategic, coherent and integrated way. A guide about European Union action in view of climate change has been published in 2008 (European Commission, 2008). Nevertheless these recommendations are more based on the struggle of climate change than on the thorough adaptations. Erosion and marine submersion are analysed only with an economic and speed of execution points of view. Thus M.R. isn't really promoted into this report. 
To present more especially coastal zones, General Direction for Environment has set up the Eurosion program in 2004. The objective was to assess the needs of action in view of erosion at the European Union, the states and region communities scales (European Commission, 2004). According to this program, to European scale, from 1999 to 2002, because of shoreline erosion between 250 and 300 landowners had to leave their house. Four recommendations result from this report:

- To strengthen coastal resistance by the sediment balance restoration

- To take into account coastal erosion coasts in development and investment decisions

- To think ahead at coastal erosion and to plan solutions

- To consolidate knowledge basis concerning management and forward planning of coastal erosion.

M.R. is described as a method to struggle with coastal erosion. To leave risked areas to install stakes into the hinterland is presented as a safe solution in an environmental and economical point of view. Nevertheless only a few case studies of Eurosion program are describing this technique. It is limited and concerns only the areas with limited stakes.

\subsubsection{To the national scale}

In France, development principles of coastal areas used before present some limits into the current context of sea level rise and sediment deficit. Into the most vulnerable sectors, maintain artificially coast line isn't viable in an economic and ecological point of view. The National Observatory on Climate Change Effects (ONERC) has recently reminded the importance of sharing locally the coastal risk culture, especially to set up managed realignment project (ONERC, 2007). Among recommendation made by the ONERC, it is stipulated that M.R., already practised in United Kingdom and in few Conservatoire du littoral's properties, needs to be carefully studied and planned in relation to predictable climate change consequences on the coasts (coastal salt-affected land, coastal erosion, submersion of low coasts, etc.). Moreover M.R. needs to be integrated into the regulatory context to be more efficient. It seems necessary to draw on Risks Prevention Plans, when they exist. It is possible to use existing rules, as the Coastal Law, which should be more implemented, or even strengthened. Communication on climate change can help local authorities to take public interest servitude into account in their choices of coastal strip development or urbanization.

The ONERC considers too that information exchange at an international level about managed realignment is necessary. Thus it is advised to participate at networks such as the European marine outlying regions debate, permitting to capitalize on foreign experiences.

In France M.R. projects are not numerous. Coastal areas managers just begin to set up this type of management method, that is why it is pertinent to analyse the decisive factors and objectives of two of them.

\section{The case of petite camargue : the pertinence of the managed realignment option}

\subsection{Presentation of the PETITE CAMARGUE site}

The Espiguette is an area where a vast dune system spread, unique case in LanguedocRoussillon. Between the Espiguette sandy spit and the Rhône Vif (cf. figure 5), the site orientation is North/South then North-West/South-East and finally West/East: many different attack angles for the local marine winds. The downdrift, oriented from East to 
West, is estimated at more than $200000 \mathrm{~m}^{3}$ of sand per year, which represents one of the most important in Languedoc-Roussillon.

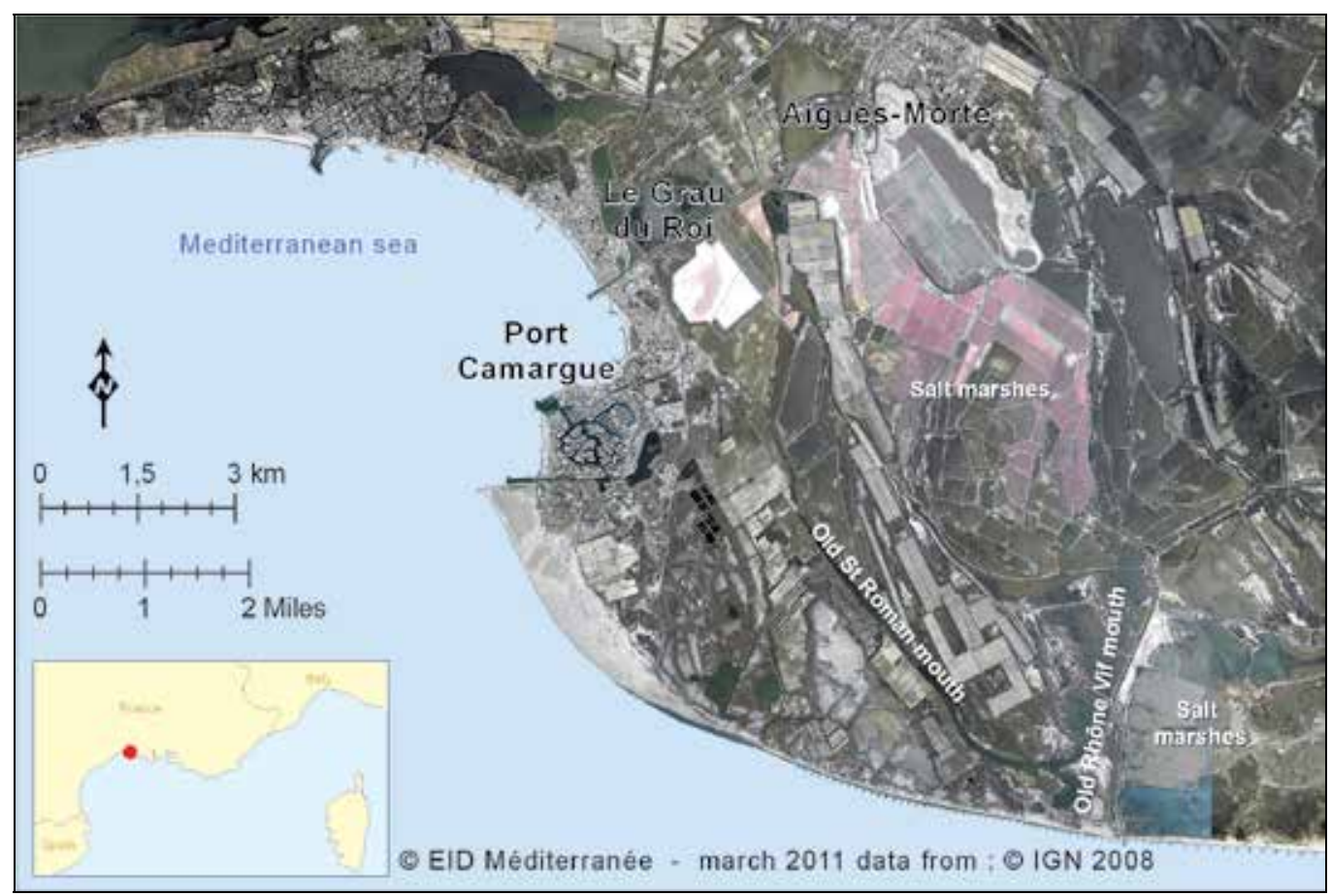

Fig. 5. Espiguette coastal dune slacks location

From the hinterland to the sea, there are dune massifs which the older is alongside the St Roman's Rhône (cf. figure 6). The last-mentioned has been flattened and cultivated, reducing the altimetry ratings and thus weakening the area natural protection. Another production has been developed too. Petite Camargue lagoons have been converted and divided for salt production by the Salins du Midi Company. The old Rhône Vif opening on sea has been equipped with waterworks and provides the whole of Aigues-Mortes salt marshes today (CELRL, 1998).

On this sector, the shore didn't stop to evolve. The main problem is the submersion risk following dune slack rupture during storm events, threatened the commune of Grau-du-Roi (as November 1982) and its sea opening Port Camargue. These coastal facilities have been built at the end of 60 's, at the Espiguette spit extremity, within the sandy strip.

The overall anthropogenic perturbations have produced many disturbances leading the classical arsenal of protection methods setting up, in a period (1960-1980) when "coastal management didn't leave space to technical doubt" (Moulis, 2006). The first works, beachbed rip-raps and groynes, have been realised on Eastern Rhône Vif. There have been set up in 1961 in order to ensure economic stakes protection of salt marshes. On Western Rhône Vif, some groynes of a hundred meters long have been installed in 1963 so as to protect the salt marshes water supply point. Then, they have been expanded further on West until 1997. Finally, it ends up with 46 groynes all $120 \mathrm{~m}$ on 5,5 km long. 
Later, at the end of 1990 to 2000, "dunes came to be opposed to rip raps" (Moulis, 2006) and the dune reconstruction has been preferred. Thus considering the extent of shore line retreat, this protection way by hard structures don't enable to struggle durably against erosion and submersion hazards. This complex and still wild territory permits to address coastal protection notion under a new overview, which makes it reasonable to think that the embankment and hard structures aren't systematic resorts.

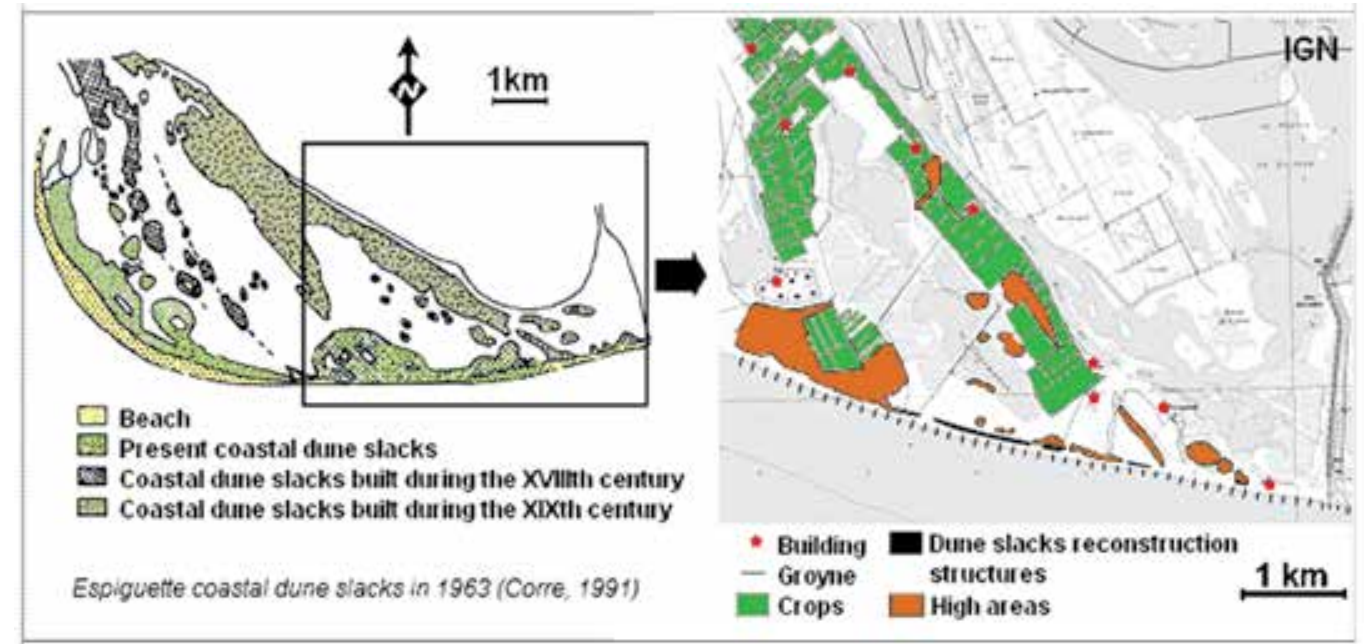

Fig. 6. Coastal dune slacks location and land use

\subsection{Camargue stakes: Economic and heritage interests \\ 2.2.1 Economic and tourist interests}

Espiguette presents several stakes. There are economical stakes, as the agricultural productions: asparagus production, vineyard and salt marshes, and the tourist activities for commune of Grau-du-Roi. Sea encroachments in relation with coastal erosion and sea-level rise constitute a threat for the economic activities. Indeed during high storms, the sea can invade hinterlands (IARE, 1994).

For salt producers, those submersions can cause the loose of harvest of a year, or even to reconsider the next year production. Since the beginning of the 60 's, salt producers have protected their entire coastline with a frontal sea wall and groynes. But the cost of these protection constraints has an influence directly on the price of a ton of salt. It implies consequences on sector profitability too. It's a real handicap in a world competitive market. Nevertheless, salt makers continue to protect their activity against sea encroachments.

In the same way, during exceptional storms, such as in 1982 and 1997, Port Camargue and Grau-du-Roi could be flooded by sea encroachments, coming from slack break. Damages are significant in those urban areas.

Regarding tourism, Espiguette beach knows a relatively moderate daily frequentation. There are 10000 peoples a day, in summer period, for a beach of 11 kilometres-long. Tourism facilities are not really developed. There are only four beach manager installations. However, regarding its wilderness, its environmental quality and its atypical morphology in Languedoc Roussillon, it's one of the most famous and appreciated beaches by peoples who are searching space and nature. 


\subsubsection{Heritage interests}

Espiguette dune slakes are the most conserved and the most spectacular of LanguedocRoussillon. They result from a particular dynamic due to the site situation compared with main winds. Therefore, this site is classed as "landscape title" and the Conservatoire du Littoral (Coastal Conservatory) has acquired 715 hectares here. Moreover this site presents protection areas too, because of Fauna and Flora inventory. It is a stopover for avifauna migratory, and the Petite Camargue coast has a mosaic of priority and community interest habitats in the European directive "Habitats". Furthermore, wooded dunes with Pinus pinea are the only one on the coast. Thus this sector conservation requires mainly a tourist frequenting management.

The Espiguette represents a wealthy succession of natural habitats. Those environments are fragile and sensitive to anthropogenic high pressures. However, their natural evolution and their maintaining require moderate natural disturbances by sea, wind and salt effects.

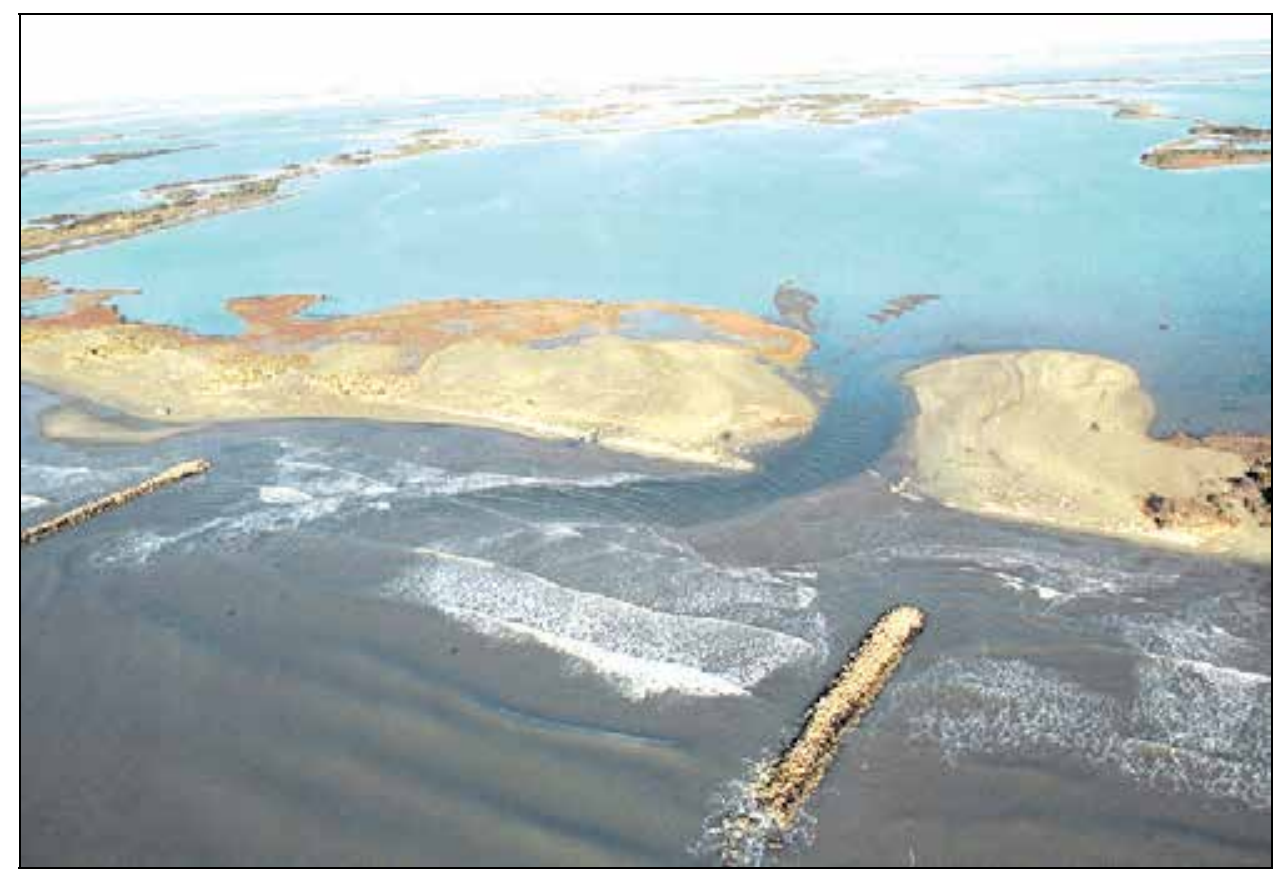

Fig. 7. Sea intrusion due to storm in 1997 (source : EID Méditerranée)

\subsection{From conservation logic to the reflection evolution: a point about conceivable solutions}

\subsubsection{The conservation logic from the 60's to the 90's}

The conservation of the most eroded coastal portion was providing to be necessary to protect salt marshes and avoid farmlands flooding. Started in the 60's, groynes and a frontal seawall setting up had quickly engendered the Grau-du-Roi coast erosion (cf. figure 8). The commune is located downstream from downdrift, immediately on West. So, this sector had been protected with groynes too.

Those settings up allowed to decrease the phenomenon in the set up area, but the erosion had been moved away to the West, by longitudinal sandy transit break off. So, the groynes 
presence just moves away the problem and their local protection role is even illusory, as the marine submersion risk in the back dune is still possible (Heurtefeux and Richard, 2005). Moreover, nowadays the shoreline have a 2 meters a year retreat (Sabatier, 2001).

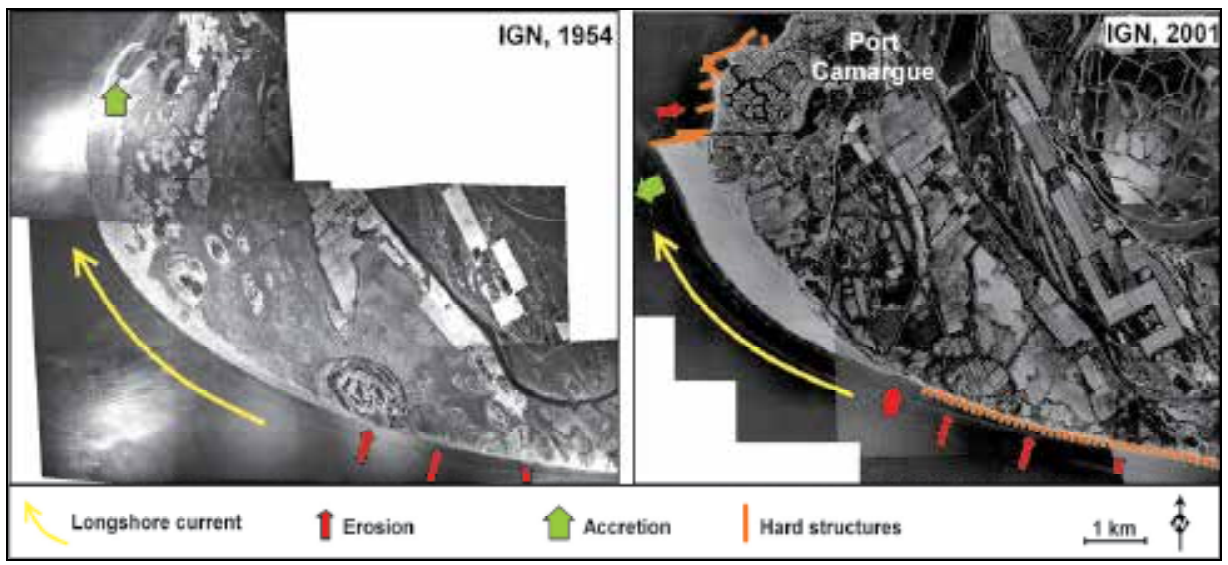

Fig. 8. Coast line evolution from 1954 to 2001

Today, it clearly appears that, on this sector, those kinds of defences do not resolve the erosion hazard and even move it away downstream from downdrift. Its global cost is high with a maintenance cost which is higher than the origin investment.

Therefore, today it's necessary to adapt the action at a local point of view and stop persevering to keep the shoreline, accepting the environment natural evolution.

\subsubsection{Policies and mentalities evolution}

Scientists have early taken the measure of the phenomenon complexity and understood that fight against Nature is illusory. But it is only in the 90's that all the technicians subscribed to this point of view.

In those days, related to the Integrated Coastal Zone Management, on this study site, there are only two possibilities: the "do nothing" approach, or realize a managed realignment. The analysis of different coastal management guidelines (EUROSION, for the European scale, CIADT for the national scale, and Strategic directions for the coastal erosion management in Languedoc-Roussillon for the regional scale) demonstrates that it would exist a consensus on hard structures use. It is advised in all these guidelines to reserve heavy structures (groynes, break-waters...) only for areas which including strong and not moving assets.

Thus in an area like Espiguette, erosion management has to be adapted related to the natural characteristics of this site. Others techniques, as beach nourishments, and dune slakes restoration should be promoted.

\subsubsection{Envisaged solutions}

This logic leads to distinguish between two risks which, even if they are related, lead to different responses:

- Erosion, which suppress a part of the stakes because of beach and dunes destruction : this action is irreversible and spatially limited 
- Submersion, that can hit very important expanses but limited in time. It leads to damages which not necessary cast doubt on area use.

In Grau-du-Roi, the erosion will not really destroy uses. Indeed, the most affected one is the seaside activity, but it can easily re-spread on the area in accretion near the Espiguette seawall. In commune of Saintes Maries, erosion causes more problems for the salt producers because it threatens the salt concentration system.

But in another way, submersion threatens important stakes on Grau-du-Roi sector. Economical stakes as tourist activities and salt marshes could be damaged and environmental ones too such as nature sanctuaries.

Realised analyses demonstrate that the mean risk on Grau-du-Roi territory is submersion, not shoreline retreat. So, it permits to foresee to process differently for the two hazards. For the protections against submersion, the main principle consists to raise roads and trails which surround urban area. As complement, hydraulic works setting up on irrigation canals allow to protect crops and to facilitate soils re-drying up. Regarding erosion management, the objective is not as today: fix the shoreline at any cost. But it evolves toward the restoration of a balance or even toward an acceptable managed realignment. This option depends on its compatibility with salt producers activity. On the long term, heavy structures as groynes are very onerous and that defence cost can exceed the value of assets to protect. An interesting option could consist in rehabilitation in several steps:

- Firstly, the construction of a second line dune on the old slakes built in the 18th century. In the same time, the border dune maintenance could be reduced.

- Secondly, when the back dune will be strengthened, the border dune management could be stopped.

The protective dune location on the old dune slakes disturb not much area functioning, because they have been levelled before (Corre, 1984). Their reconstruction consists more in a habitat restoration than in transformation. Moreover, on old dune slakes level, sand transports are limited and topography stay stable (Corre, 1971) so that makes vegetalisation easier.

Furthemore, the progressive reduction of border dune maintenance could be beneficial for embryonic dunes habitat development. This habitat is not much abundant at the East site because of erosion features observed on the area and the beach-shifting dune direct transition. They are mainly present in openings of shifting dune caused by sea submersion (Favennec and Larroque, 2004). Allow seawater penetrate in a controlled buffer area permits to maintain vegetal communities dynamic dependent on seawater inputs and to protect human stakes situated more in the back.

The ecological stake on Espiguette site is important and it's necessary to find a compromise between important seawater intrusions and a lack of water. Those perturbations maintenance is particularly fundamental for the salty steppe habitat, because seawater intrusions permit the conservation of a low vegetal covering, favourable to the development of rare and protected pioneer species present in this habitat (Favennec and Larroque, 2004). However, fresh water presence in areas protected by dune slake is essential for the maintenance of this site's flora biodiversity (CELRL, 1998). The protection of juniper trees and Pinus pinea priority habitat, sensitive to too high sea influences, pass by controlled sea intrusions.

Nevertheless the sea level rise will prolong backwards, the salty corner influence. In certain depression area, if ground salinity rises, we could find a development of halophilic thickets, non priority habitat but not much present on this site. They have a big value for the 
avifauna, as nesting site and migratory stop (CELRL, 1998). In this context too, the ground salinity increase will more justify dune slake in back to limit increase of salinization.

All these propositions are aimed to avoid heavy structures to respect dune-beach system and its intrinsic transfers in order to not damage ecosystem functionalities. It's necessary to consider dune-beach system in its totality, and thus its natural capacity to return at an initial state after a perturbation. Beach nourishments in the most eroded area, using sand stock along Espiguette's seawall should complete usefully that system.

Today, it's really important to be conscious that the major risk for Grau-du-Roi is the sea submersion. To limit this hazard, concerning the financial and technical points of view it is unrealistic to hope fixing the shoreline and stabilizing dune slack. So, two actions must be realised in the same time:

- A "terrestrial" management of sea submersion by a precise protection of the stakes

- An erosion management with methods adapted to natural characteristic of the study site.

\subsection{Territory complexity, a real palimpsest \\ 2.4.1 A particular territory: The Camargue}

Today, in Camargue, flooding risk or erosion management takes place in a relatively rigid context, inherited from the past, in response at this socio-hydraulic system setting up history (Allard and al., 2005). In 1859, national policies have induced the achievement of frontal seawall closing and the protection of Camargue from seawater intrusions. Those protection systems gave to people from Camargue an impression of absolute protection and the economics activities have prospered (Allard and al., 2005).

Even after the huge floodings in 1993, 1994 and 2002; for certain inhabitants, the recognition of Camargue as potentially liable to flooding territory is not today always an evidence (Allard and al., 2005). The evolution of risk and the limit between acceptable risk and unacceptable risk is above all explained by "the risk perception that has population according to their culture, belief, in their security searches" (Allard and al., 2005).

Believing to control flooding risk, human societies have contributed to increase their vulnerability. Today, a new policy of management emerges, resulting from realization that the natural risk cannot be controlled in its totality: "People can't do anything against Nature. They can protect themselves but not control it" (Allard and al., 2005). However, human can sometimes help Nature or use it, which is the ecological engineering. Thus it is necessary to share lessons resulting from mistakes done in the past about coastal protection and to inform by these experiences decision-makers.

If we want to be optimistic, we could consider that population of Camargue had for a long time learned to live with Rhône fluctuations and sea water intrusions.

The economic restructurings are linked to dynamic instability, and in Bernard Picon's opinion "it is quite vain to wonder about environment and humans' aptitude to change, because adaptation acknowledgement is evident" (Picon, in Bethemont, 2000). But, we may also think that the population, struggling for a long time with those hazards, should not support a return at a previous state: the fear of money loss seems to hide more than an identity loss. The Camargue is a space oriented to change: in a century, farming evolved from a dominance of wheat and sheep to a wine dominance then rice production, to ends currently with a sharing of all those activities (Bethemont, 2000). Today, it's needed to know what it's better to promote for Camargue's inhabitants: tourism or farming activities. 


\subsubsection{A technical and administrative complexity}

The Rhône's delta system has not to be studied only on its seafront. It has to be studied on its entirety, taking into consideration the river-coast interactions. Thus the suggested managements must permit the flood water discharge from rivers too.

In addition, the administrative muddle doesn't make easier the setting up of joint representations. The site is on two different departments the Gard and the Bouches du Rhône, which are French territorial divisions, and it depends on two different communes: Le Grau-du-Roi and Les Saintes Marie de la mer. Moreover there are two different managers of natural areas which are the Camargue Gardoise Association and the Camargue Regional Park.

The number of stakeholders in this case is more important than for a classic case. That is the reason why it is really necessary to define clearly and globally what stakeholders want to protect and what kind of means they are able to do. Communication, between managers, technicians and users is essential in that kind of project with many stakes.

\section{The case of sete sand strip: an example of managed realignement project}

\subsection{Presentation of the Sète-Marseillan sand strip's site}

The sand strip between Sète and Marseillan is a littoral sand line of 11 kilometres long and 1 to 2 kilometres wide, with a dune. It separates Thau lagoon to the Mediterranean sea (cf. figure 9).

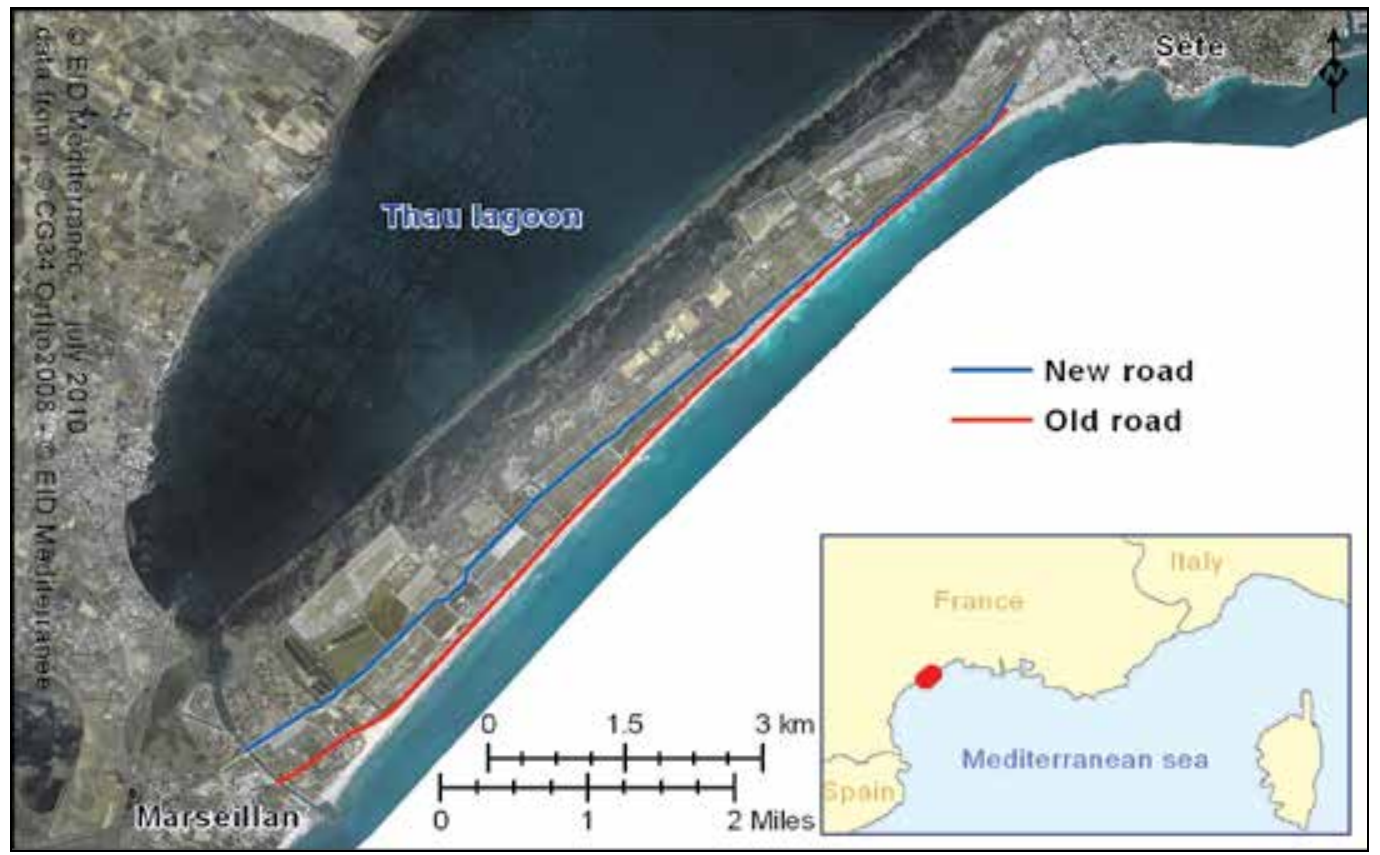

Fig. 9. Sète-Marseillan sand strip

As presented in figure 10, this space presents a lot of different economical stakes. There are a bottle-filling firm which is the main economic actor (120 employees), a four stars camping with 1000 places and two high traffic communication axis: a railroad and a road. 
Furthermore the sand strip's beach corresponds to a real economical stake with the influx of tourists. Its frequenting of tourists is up to 1000000 per year (Thau Agglomération, 2009). The economical stake of the influx of tourists depends also on bars and restaurants located on the beach. For comparison on a smaller beach located at 30 kilometres on the west, the 14 bars and restaurants generate a turnover of 15.2 millions of Euros per year (CCI Montpellier, 2010).

This space comprises a patrimonial stake too, the world conservatory of vine genetic resources with a collection of 7500 plants representing 2250 different grape varieties. Moreover this space presents a high ecological interest, in particular on lagoon's side with the lagoon and wetlands.

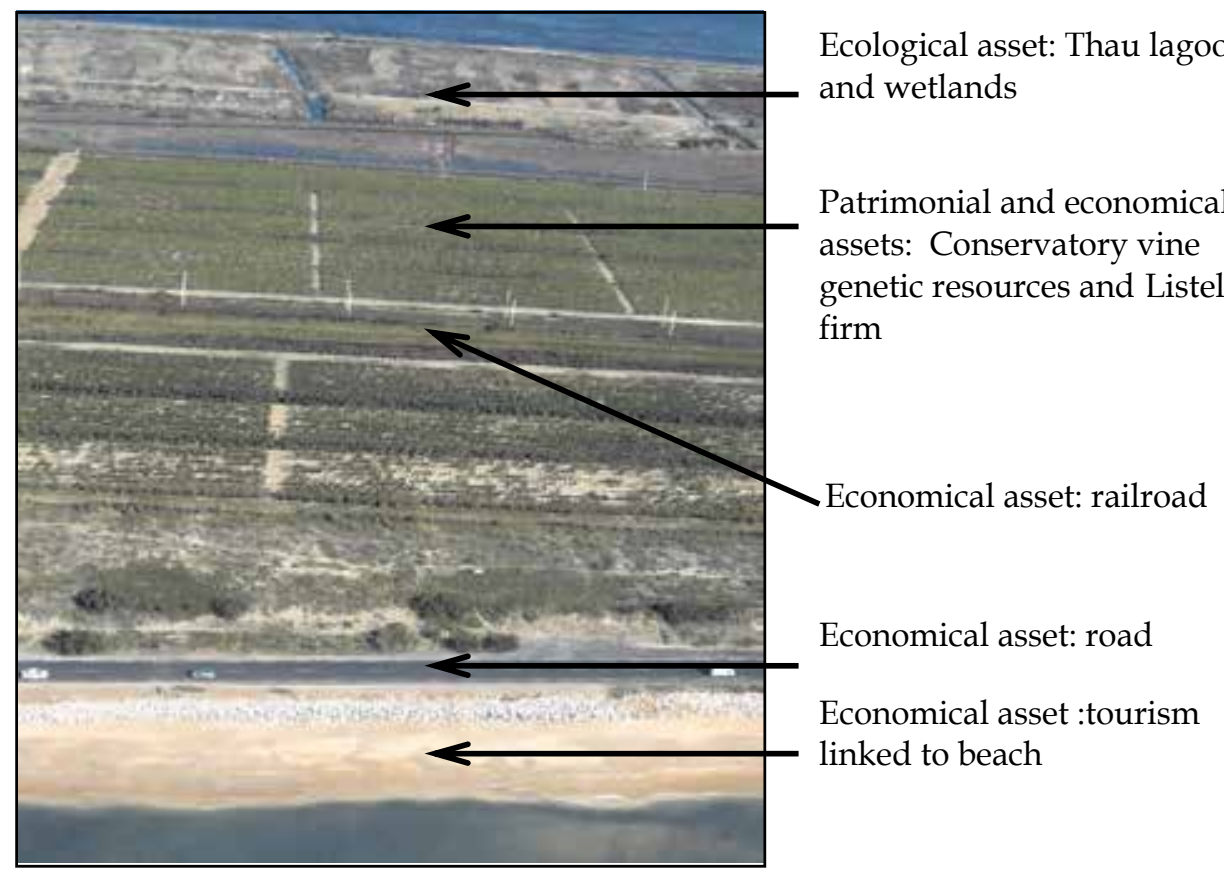

Fig. 10. Assets on Sète-Marseillan lido

But this space is threatened by storm wave action. Thus between 1937 and 1999 the sand strip has been subjected to a slow erosion, in particular at its two edges where observed recessions are longer than 50 meters (Durand, 1999) (cf. figure 11). Since 1954, the sand strip has lost 45 hectares. Nevertheless the threat is not particularly on the mean erosion rhythm, but on the modalities of this erosion. It doesn't exist any wide inter-tidal area in South of France because of microtidal system. Sète-Marseillan sand strip is really more vulnerable during storms, that is to say just a few days, than to the long-term observed evolution. For example, during the four days storm in 1997, with a fifty years period, shoreline recession has been longer than 30 meters in some spots.

Even if the morphology of the beach is reconstituted next a few months following these high erosion events, these high recessions set serious matters. They result notably in more and more frequent breaks of littoral road (cf. figure 12). 
The fragility of Sète-Marseillan sand strip is due to natural factors. The littoral depends directly on South/South-East sectors swells, oriented into the dial $90^{\circ}$ to $180^{\circ}$. These swells can have for expression extremely violent storms with maximum height up to six meters in extreme cases, and with important sea surges up to 1 meter of French General Height. For information maximum astronomical tide isn't up of 0,35 meter of French General Height and the main wave statistics on this coast show that $80 \%$ of significant wave height (Hs) is less than $1 \mathrm{~m}$. In the beginning of 90's, in spite of beachbed rip-raps, the coastal road between Sète and Marseillan was regularly subject to collapse, even by annual occurrence events.

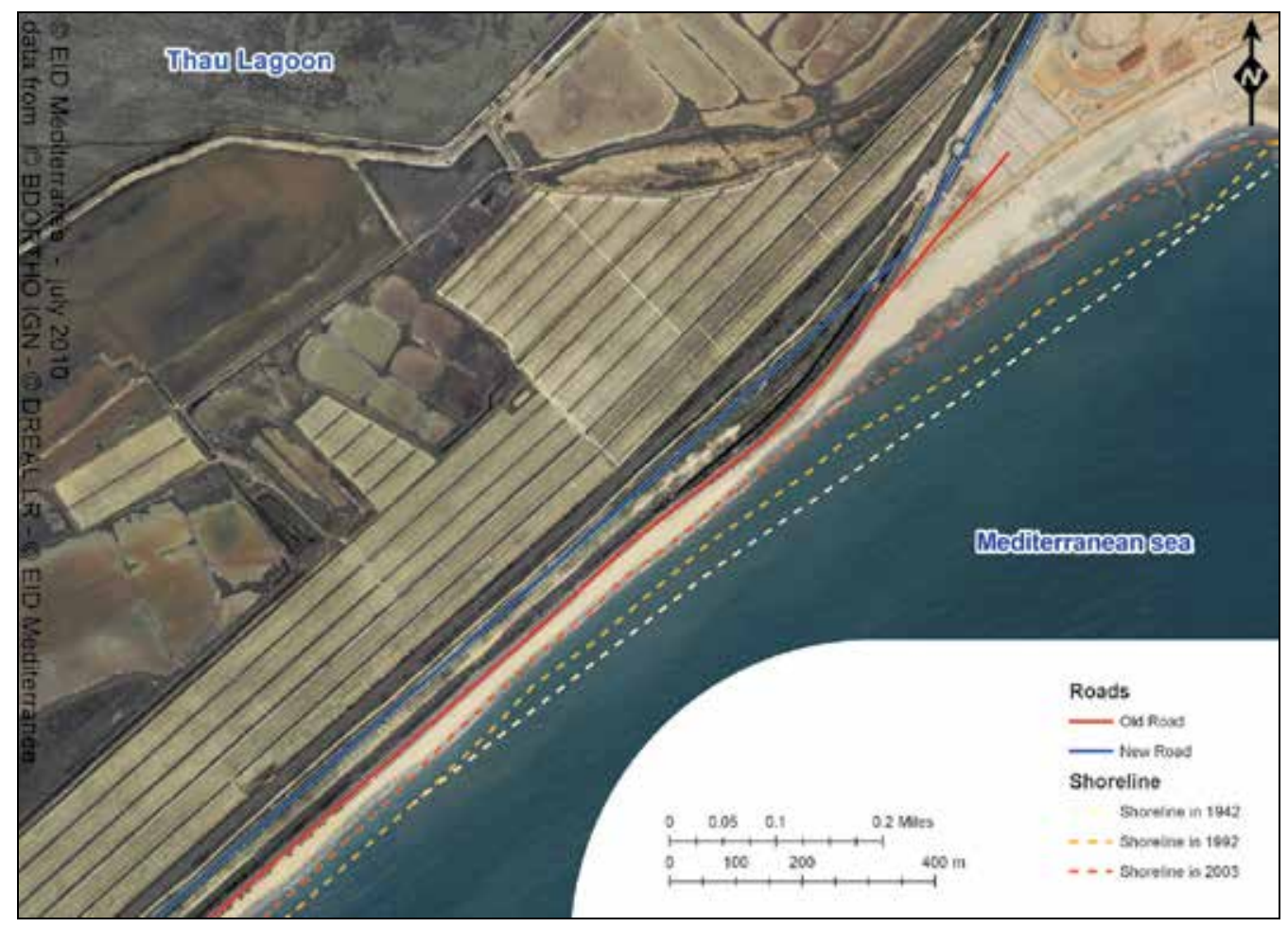

Fig. 11. Shoreline erosion between 1942 and 2003

Moreover the sand strip is separated to adjacent coasts by almost impervious frontiers to sediment transit. As a result the sand strip receives practically no sand supply from nearby sectors (no river mouth in this part). This morphodinamical context is aggravated by Human use of the space. The sand strip is indeed strongly damaged because the fore-dune is truncated on its length by coastal road between Sète and Marseillan. This road, built in the 1920 's on the semi-fixed dune massifs, fixes the littoral system. But a beach and its fore-dune constitute an interdependent system which behaviour is characterized by seasonal variations (Paskoff, 1998). With the construction of the road on the semi-fixed dune massifs, systems lose a part of its natural mobility. During sea storms, the sediment stock constituted 
by the dune isn't mobilized anymore by the wave's effect. The result is a increased erosion on the sand strip. Furthermore, the road presence induces lawless parking practically on the beach of thousands of vehicles and camping-car, which emphasizes the very damaged vision of the site.

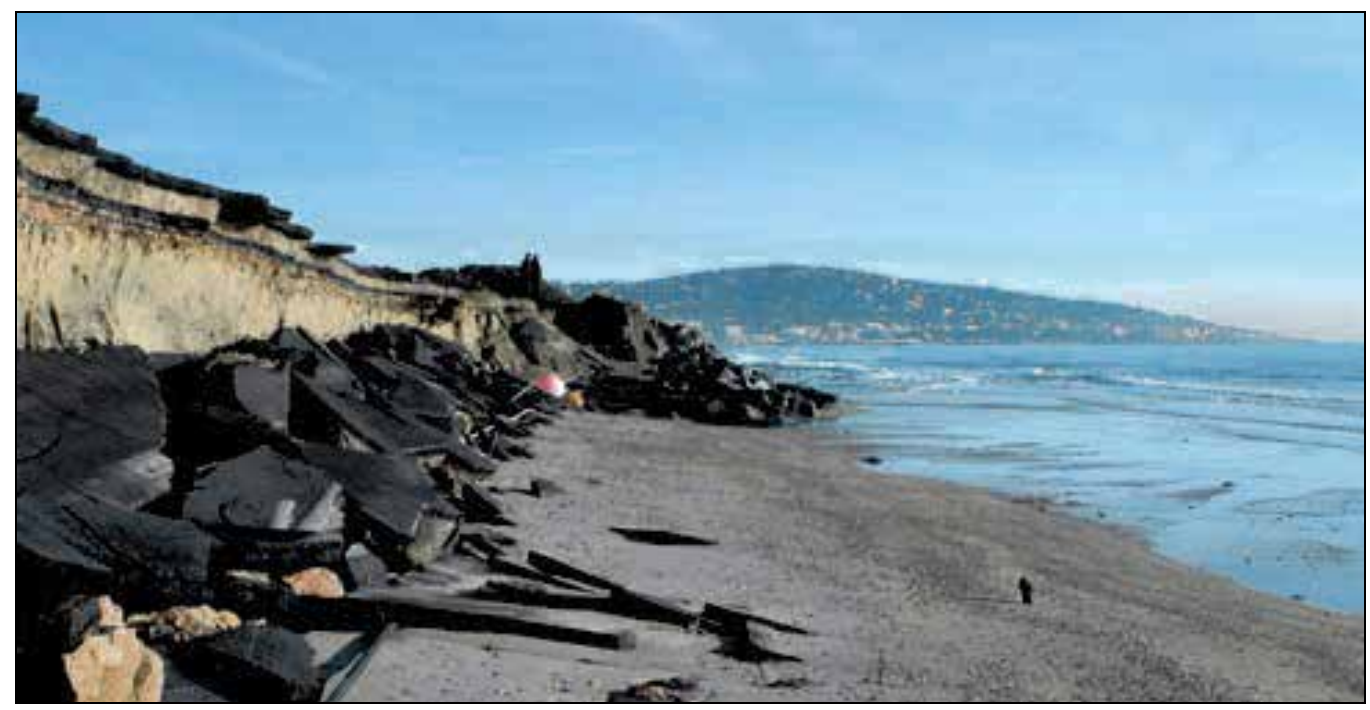

Fig. 12. Frequent destruction of coastal road due to storms (source DREAL LR)

\subsection{Coastal management of Sète-Marseillan sand strip}

To face up to the ineluctable sand strip erosion, and to protect the road to storm wave action, many protective structures have been gradually setting up during last decades. Step by step, the road has been almost completely protected on its length by a line of rip-rap. Two sets of groynes have been constructed at four kilometres on the South-East of SaintClair Mont and a set of breakwaters at Sète, where the road was the most close to the sea. But the problem hasn't been solved by these constructions. In contrary, the line of rip-rap has accelerated the recession of the beach and the groynes and breakwaters have moved and aggravated the erosion in the downdrift sectors.

In fact, used hard protection methods were a failure, in particular to face the catastrophic recession of the Ouest part of the Corniche beach. Coastal services and the Sète municipality have decided to shift backward the road in this sector on a length of 1 kilometre. The operation, achieved in 1990, enabled to solve recurring destruction problems of the road. But it didn't solve the problem of the recession of the beach, here and on the rest of the sand strip. That's why different stakeholders embarked at the beginning of the 90 's in the research of a sustainable solution to the problem of coastal erosion on the whole length of coastal line.

Between 2000 and 2002 a study had been realised about the erosion in the sediment cell from Sète to Marseillan. The scenario of creation that had been selected consisted in the setting up of 11 breakwaters and an associated beach nourishment of $100000 \mathrm{~m} 3$.

Those propositions have been rejected because an economical and environmental realization was emerging in the mind of decision-makers indorsed by technical services, the Interministerial Coastal Development Mission, and the Coastal and Navigation Service. They 
considered that proposed heavy techniques would need the protection of the whole 11 kilometres of the sand strip by these constructions. To avoid that, a project more innovative and more ambitious has started.

The new project started in October 2007 and should last 4 years. At Sète in 2010, 50\% of the project were realised. It is planned the shifting of the road, the parking reogarnization, a new traffic plan, a cycle track and a beach wider with a dune re-created enough far from the shoreline to not be subjected to the storm wave action. The old road and all the others networks have been destroyed and replaced by an equivalent one's less wide with speed constraint, located more into the sand strip. It corresponds to a medium remoteness from the sea of 40 meters into the Easten part and several hundred of meters in its Western part (cf. figure 11). Road shifting has been limited by clear space of the railroad. Frequenting management has been comprehended with an organization with three parking areas along the sand strip, for a total capacity of 2290 places, and the impossibility to park vehicles along the new road. By this project three types of beaches will be defined: wild, semi-natural and urban, relative to their facilities level and their accessibility. Damaged natural areas will be requalified and the conditions to continue wine-growing will be maintained.

In this way, the Sète-Marseillan sand strip's project is a case of managed realignment. The shifting of the road will permit to remove the space necessary to beach and coastal dune restoration. In this case, managed realignment isn't a coastal abandonment but rather the definition more behind of a new shore line, easier to manage.

Considering the scale of this project, with a cost of 55 millions of Euros (Thau Agglomération, 2009) it is a costly project. It corresponds to an investment of 5000 euros.m-1 of coastal line. In comparison, the scenario with the building of hard structures of 2002 would have cost only 2200 euros. $\mathrm{m}^{-1}$ of coastal line. Economically each land development project is considered as an investment for the decision makers. To be validated, this project must be as beneficial as possible for people's interest. In the case of Sète-Marseillan land strip, this project seems to be profitable for many reasons. In a first place it was tried to make sustainable choices for this project. The restoration of sediment dynamic cell will permit to reduce reparation works due to storm wave action. Before this project, the average cost next a storm for the Thau lagoon collectivity was 150000 Euros. With the trend of more extreme events due to climate change, Sète-Marseillan land strip shifting seems profitable. Moreover these storms could damage afterwards others economic stakes like the bottlefilling firm and the camping. It is even more profitable because interests are not only economic but related to road users' security, the rescue mobility and the end of salubrity problems too. In a second place this project is profitable through its resulting effects. It is supposed that with the quality of the landscape and the infrastructures, tourist activity will increase. Besides maintaining this road is a wide economic interest for the Sète and Marseillan towns.

Thus despite its high cost this project seems included in a long term dimension. Its investment was decided to last at least 30 years. With this temporal dimension this project is profitable by the diversity of induced elements too.

As a project of M.R., this project has required several techniques (cf. figure 13) quite recent for some of them and it was a real opportunity for implementing soft-protections technologies. First it has been necessary to restore the coastal dune on 7 kilometres. The objective was to obtain a dune with a slope on the sea side of $23^{\circ}$, a slope of $13^{\circ}$ on the sand strip side and a dune of 14 meters width. A nourishment of 600000 cubic meters has been necessary for the dune and the beach. Then the sand is supplied naturally by the wind. The use of woody fences, an ecological engineering technique, permits to reduce the wind speed 
and to maintain the sand on the dune. On the coastal dune, six woody fences lines were set up to reconstitute the dune. Another line has been built on sea side to put under protection the coastal dune.

In relation with dune restoration, the revegetation was implemented. Vegetation reduces wind erosion and permits to consolidate the dune. 4 kilometres of dunes have been punctually restored with plantings of marasm grass (Ammophila arenaria). To enhace plants survival rate, this technique was combined with the use of geotextiles. Within the framework of biodiversity restoration, a plant nursery of dune plants (Ammophila arenaria, Anthemis maritima, Elymus farctus) was realised. These specific dunes plants will be reintroduced. In the same way, as compensatory measure within the Natura 2000 context, some protected plants that would be damaged during the work have been removed. That is the case of "Jupiter's beard" (Anthyllis barba-jovis). The project damaging habitats too, for each temporary pond destroyed by work, five will be created.

Then the work includes the displacement of the road, to move this stake away of coastal hazards but to let enough places for pre-cited techniques.

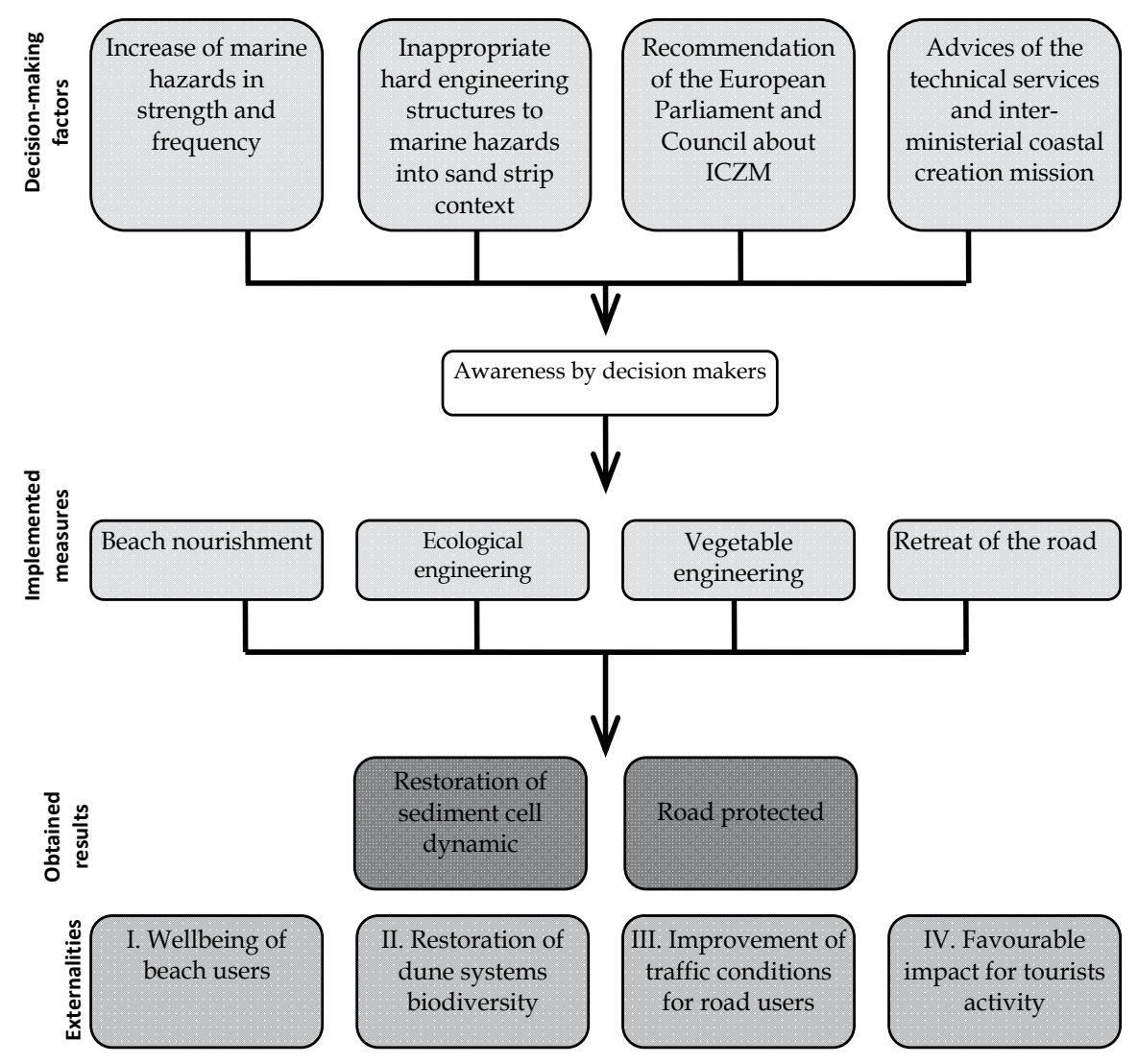

Fig. 13. The framework of Sète-Marseillan sand strip project 


\subsection{Caracteristics of coastal management induced by M.R.}

By these measures, it will permit the restoration of the sediment cell dynamic, and a longterm protection of the road. This project brings about four externalities too. The main externality is the wellbeing of beach users. After the end of the work, the landscape will be nicer and the beach wider. Linked to this externality, that project will have a favourable impact for tourists' activity, which is the fourth externality. Thus by these two externalities, this project will have a social and an economic interests. The second externality is the restoration of dune systems biodiversity. With more space and a better protection for biodiversity, this project presents an environmental interest. Finally, the project will improve the traffic and safety conditions for road users, which is a social and logistical interest.

\section{Discussion}

As the Petite Camargue case demonstrates it, protecting the coast everywhere by fixing the shoreline is not realistic in a technical point of view and in a financial one. It is maybe preferable in current context of climate changes to keep a space of evolution to shoreline and natural functioning. The current realization of problems related to climate changes seems to offer today a hope. This study indicates also that today, it seems necessary to anticipate, and to accept a retreat where the stakes are not directly under sea attacks, and activities reconversion.

This solution is possible only if all the concerned stakeholders share the same diagnosis, and accept to talk without a priori of solutions to give. So, technicians have to be clear and good at explaining, in order to permit everyone to appropriate themselves this complex knowledge. Moreover, landowners and users have to accept an evolution of coastal uses. Nevertheless, private interests in short or mid-term prevail often over the collective interests in long-term.

Concerning the Sète-Marseillan sand strip case, the objectives of this M.R. project were essentially related to logistical and economic aspects. The road was frequently partly destroyed and the construction of hard engineering structures was expensive and not sustainable. These factors have been the determinants of the project and they have permitted the improvement of others points that were corresponding to others aspects. Thus related to the different externalities, social and environmental aspects have been improved. These aspects belong to the scheme but they didn't have the same importance into the decision making process. The environmental aspect could have been more favored. In the French law, Barnier's law relative to environmental protection strengthening defines the precautionary principle. The exposition of this principle is that "Certainty absence, given our current scientific and technival knowledge, mustn't delay the use of measures preventing a risk of large and irreversible damages to the environment" (French Government, 1995). Given the high environmental richness, environmental efforts could have been stronger. This analysis of the importance of each aspect is interesting related to the other European vision of M.R. and their determinants.

Nevertheless this remark must be moderated. Indeed in several points this scheme is innovative. On one hand it is one of the first M.R. implementation in France. In that frame, this is one of the first projects in France mobilizing this kind of ecological and vegetable engineering techniques at a several kilometres scale. The space project has been categorized relatively to its function too: wild, semi-natural and urban. A particular point of M.R. 
projects is to succeed into the structure of the actions to realize between natural and urban areas. On another hand, this plan was integrating into its first phase in 2003 public consultation. During public presentations and meeting, people have been really interested by the scheme and conscious of the urgency in view of coastal erosion (Observatoire du Littoral). By this participative process, social component was an integral part of the project from its beginning. Besides this realization is in line with European orientations of coastal management. Sète-Marseillan sand strip project is an example, in terms of method and contents, of the European Parliament and Council recommendation of the 30th may 2002 relative to the implementation of Integrated Coastal Zone Management. It is linked to erosion management works at European scale into Beachmed Interreg III C and Messina Interreg III C programs. In Beachmed Interreg III C, the objective is to design new coastal management methods taking into account natural and socio-economic aspects. Messina Interreg III $\mathrm{C}$ is intended to mutualize local management knowledge about erosion phenomenon.

\section{Conclusion}

There are many special features of M.R.. One of these features is to move back the economic assets on the coast to the hinterland. It is also to create a new defence line behind the beach and facing the sea to restore natural areas and to create a buffer between the sea and the economic assets. Another feature is to avoid the construction of new economic assets in areas where they would be vulnerable. This diversity of features implies a deepening of the communication among coastal managers. The possible project in Petit Camargue would create a new defence line behind the beach, allowing the restoration of natural areas and a buffer between the sea and the economic assets. It would be a real opportunity for the development of a cost benefit approach.

In the same way, the shift of the Sète-Marseillan coastal sandy beach is a managed realignment case where a major road was moved and a small part of a camping site was destroyed. As a result, this project will limit coastal risks, and also, through a public communication campaign, be a catalyst to increase tourist activity. However, around the same time as this M.R. project, there was a housing development project in the Eastern part of the Sète-Marseillan lido which, unfortunately, ignored the risk of coastal erosion and submersion. Some local surveys show that a majority of people don't have any recollection of storms that have caused considerable damages in this area. This lack of knowledge, together with a pressure from the public and developers to provide more housing, enables such a development to continue.

\section{References}

ABPmer; The Online Managed Realignment Guide - Beltringharder Koog; URL: http://www.abpmer.net/omreg/index.php?option=com_content\&task=view\&id= 64\&Itemid=63; consulted in July 2010.

Allard, P., Picon, B., Claeys-Mekdade, C., Killian S., Astier L., Malangou, S., (2005) - Gestion du risque inondation et changement social dans le delta du Rhône : Les " catastrophes " de 1856 et 1993-1994. Rapport DESMID, CNRS UMR 6012 ESPACE EA 3293 Université de la Méditerranée. 148 pp. 
Bawedin, V. (2009). La gestion intégrée des zones côtières (GIZC) confrontée aux dynamiques territoriales dans le bassin d'Arcachon et sur la côte picarde, thèse de doctorat sous la direction de Alain Miossec, Université de Nantes, 532 pages

Bethemont J., (2000) - Actes du colloque « Le changement climatique et les espaces côtiers » Chapitre 15 : Table ronde : le delta du Rhône et l'élévation du niveau de la mer, p 82 à 86 , Arles.

Bourrelier, P.H. (1997). La prévention des risques naturels, rapport de l'instance d'évaluation. Paris, La Documentation Française.

Canadian Government; Impacts et adaptation liés aux changements climatiques : perspective canadienne, (2004).

Chambre de Commerce et d'Industrie de Montpellier; Le poids économique des plagistes Enquêtes auprès des plages privées de la Grande Motte et de Carnon ; february $2010 ; 9$ p.

CETE / SMNLR, (2002) - Etude sur l'évolution du littoral sableux du golfe du Lion (de 1942 à 1998).

Coastal Concern Action Group ; High altitude aerial photographs courtesy of Environment Agency ; URL: http://www.happisburgh.org.uk/gallery/highalt ; consulted in July 2010.

Conservatoire de l'espace littoral et des rivages lacustres, (1998) - Plan de gestion des domaines de Terre Neuve et de la Capelude, $172 \mathrm{pp}$.

Corre J-J., (1971) - Etude d'un massif dunaire le long du littoral méditerranéen : structure et dynamisme du milieu et de la végétation. Colloques Phytosociologiques, I la végétation des dunes maritimes, p 201 à 225. Paris

Corre J-J., (1984) - La végétation littorale des environs de Montpellier, 34 pp. Institut de botanique-Université Montpellier II.

Department for Environment Food and Rural Affairs; Making space for water, Taking forward a new Government strategy for flood and coastal erosion risk management in England; First Government response to the autumn 2004 Making space for water consultation exercise, March 2005, 47p.

Dickie, I.; Internal communication ; June 2010.

Durand, P.; L'évolution des plages de l'ouest du golfe du Lion au 20ème siècle. Cinématique $\mathrm{du}$ trait de côte, dynamique sédimentaire et analyse prévisionnelle. PhD Thesis, Lumière Lyon II University, 1999, 2 vol., 461p.

Entente Interdépartementale pour la Démoustication ; Rapport d'étude phase 1 : Etat de l'art et diagnostic sur les phénomènes d'érosion et de submersion marine ; 2010, 100p.

European Commission ; Livre vert, (2007).

European Commission; European Union action to struggle against climate change, climate change adaptation, 2008, 22p.

European Commission; Part IV - A guide to coastal erosion management practices in Europe: Lessons learned; 2004, 27p.

European Commission (2004). EUROSION Living with coastal erosion in Europe: Sediment and space for sustainability, 164p.

Favennec J., Larroque B., (2004), ONF - Etude de l'incidence de la création d'un cordon de dune-digue sur le site de Terre Neuve, $30 \mathrm{pp}$. 
French government; LOI no 95-101 du 2 février 1995 relative au renforcement de la protection de l'environnement; Official french government publication $n^{\circ} 29$, 3rd february $1995 ; 43 p$.

Goeldner-Gianella, L., (2007) - Perceptions and attitudes towards de-polderisation in Europe : A comparison of five opinion surveys in France and in the UK; Journal of Coastal Research, 23/5, pp. 1218-1230.

Heurtefeux H., Grosset S., Valantin P.-Y., (2007) - Une approche alternative de la gestion des risques côtiers, $l^{\prime}$ exemple de la petite Camargue, $12 p$.

Heurtefeux H., Richard P., (2005) - Vingt ans de protection des dunes littorales par des techniques douces : bilan et perspectives à travers quelques exemples en Méditerranée française. In Milieux littoraux, nouvelles perspectives d'étude. Ed. l'Harmattan, Paris, p143 à 166.

Hugo, V. (1846). Discours à la chambre des pairs sur la consolidation et la défense du littoral.

Institut des Aménagements Régionaux et de l'Environnement, (1994) - Domaine de TerreNeuve Commune du Grau-du-Roi Gard: Expertise écologique, Inventaire du patrimoine naturel. 12pp.

Intergovernmental Panel on Climate Change; Contribution of working groups I, II and III to the fourth assessment; 2007, 104p.

Klein, RJT, Nicholls RJ, Ragoonadeu S, Capobianco M, Aston J, Buckley EN; "Technological options for adaptation to climate in coastal zones" Journal of Coastal Research; 2001; 17(3):531-543.

Ledoux, L. ; Actes de l'atelier « Chaud froid sur le littoral » ; 2005.

Ledoux L, Cornell S, O'Riordan T, Harvey R, Banyard L, (2003) - Managed realignment:towards sustainable flood and coastal management. CSERGE working paper, forthcoming

Léger, F. ; Actes de l'atelier « Chaud froid sur le littoral » 2005.

Mauger J., (2006) - Quand les enjeux le permettent, organiser le déplacement des équipements, expropriation-indemnisation : Criel-sur-Mer, « de la défense contre la mer à la gestion durable du système côtier ». A.N.E.L., Torreilles.

Moulis D., (2006) - L'évolution des pratiques de lutte contre l'érosion en LanguedocRoussillon. Actes du colloque des journées d'étude « de la défense contre la mer à la gestion durable du système côtier ». A.N.E.L., Torreilles.

Observatoire du littoral ; De la recommandation européenne sur la GIZC à sa mise en œuvre locale : protection et aménagement durable du sand strip de Sète à Marseillan ; URL: http://www.littoral.ifen.fr/Sand strip-de-Sete-a-Marseillan.168.0.html; consulted in July 2010

Observatoire National sur les Effets du Réchauffement Climatique; Stratégie nationale d'adaptation au réchauffement climatique ; La documentation française, 2007, 97p.

Paskoff, R. ; Les littoraux. Impact des aménagements sur leur évolution ; (1998), 3rd edition in A. Colin, 257p.

Rupp, S., and R. J. Nicholls (2002): Managed Realignment of Coastal Flood Defences: A Comparison between England and Germany. In: B. v. Kappel (ed.), Prepared for Proceedings of "Dealing with Flood Risk" An interdisciplinary seminar of the regional implications of modern flood management. Middlesex University, Enfield, $1-11 \mathrm{p}$. 
Sabatier, F., 2001 - Fonctionnement et dynamiques morpho-sédimentaires du littoral du delta du Rhône, Thèse, Université Aix-Marseille III, 272 p.

San Fransisco Planning + Urban Research Association; Strategies for managing sea level rise; URL: $\quad$ http://www.spur.org/publications/library/report/strategiesfor managingsealevel rise_110109; consulted in July 2010.

Thau agglomération; Dossier de presse (2009) - Thau agglomération s'engage dans la protection de ses lidos ; April 2009; 26p.

Trevi, A.; Nomadic hotels and lighthouses; Pruned, on landscape architecture and related fields; URL: http:/ / pruned.blogspot.com, October 2008. 


\title{
Toward a Hydro-Economic Approach for Risk Assessment and Mitigation Planning of Water Disasters in Semi-Arid Kenya
}

\author{
Cush Ngonzo Luwesi, Chris Allan Shisanya and Joy Apiyo Obando \\ Kenyatta University/Department of Geography \\ Kenya
}

\section{Introduction}

Mikhail Gorbachev, President of Green Cross International, once declared: "Water is one of the most important ingredients for development and stability. Without access to basic water supplies, disease and ill-health, poverty, environmental degradation and even conflict may be the result - all of which lead, in turn, to greater water stress. Water-related conflict does not have to take on the attributes of war in order to be debilitating - it can fester between groups, ignite between neighbouring farmers or industrialists, and can cause loss of trust between people and their governments. When water conflict erupts between sovereign states, the victims may not perish on any clearly discernible battlefield, but the people and the watercourse itself will suffer the consequences of the absence of either co-operation or communication between those sharing a basin." (Hartnady \& Hay, 2004). This statement shows the whole importance of the science of management of water and related issues.

In fact, scientists long ago sought to understand the process of water cycle. This understanding helped them monitor the changes in the quantity and the quality of water occurring through the fluxes of water from the atmosphere to the surface of the earth and underground, fluxes of solutes and sediments and the effects of gravity and radiation. Science based knowledge of these hydrological processes assisted in explaining and predicting water-related hazards, notably droughts, floods, tornadoes, cyclones, landslides, mudslides, etc. Yet, due to the high risk associated to environmental changes, traditional scientific postulates and models have become inadequate to controlling water disasters, particularly in the "Arid and semi-arid lands" (ASALs) (Brasington et al., 1998). Under the effect of population pressure on natural resources, water disasters tend to cause agricultural inefficiency resulting in food insecurity and poverty outreach in most ASALs (FAO, 1995; Shisanya, 1996; UNDP, 2007; World Bank, 2007). There is thus need for reviewing traditional premises, hypotheses and theorems of water disaster management to adapt them to environmental changes. Hydro-economic risk assessment offers a novel framework towards sustainable management of agricultural water disaster in ASALs. This study evaluates hydro-geomorphologic risks, and their social and economic impacts associated with farming water use in dry and marginal lands of Kenya.

The risk assessment conducted in Muooni Dam Catchment of Kenya utilized an "hydroeconomic" procedure to assess the risks related to farming water and land use, and served 
as a basis for mitigation planning, implementation, monitoring and evaluation of water disasters in agriculture in that catchment area. This novel approach called "hydro-economic risk assessment and management" (HERAM) assessed farming activities' effects on water and land, social welfare and economic efficiency under three scenarios: that of "Above normal" (ANOR), "Normal" (NOR) and "Below normal" (BNOR) rainfall regimes. Specifically, it sought to highlight hydro-geomorphologic, social and economic risks related to irrational use of farming water and land. The valuation of these externalities coming from the changing environment in Muooni Dam Catchment was done using inventory models. Finally, a risk management approach was suggested for efficient water use in farming in ASALs.

\section{Justification of the approach}

The global warming, El Niño rainfall and wind pressure are critical challenges to water management models built on traditional premises, hypotheses and theorems. Water and soil conservation measures based on these models are vulnerable to important water evaporation and seepage, increased salinity, and obsolescence leading to excessive costs of maintenance (Shakya, 2001; Uitto \& Schneider, 1997). Ecological changes observed in many catchment areas hinder the productivity of natural resources, resulting in increased unit costs per water drop for producing the same quantity of crop or meat (Lal, 1993). An integral assessment of climate and land-use changes related risks on efficient use of natural resources is therefore vital to sustain agriculture efficiency in the course of climate change. It needs a new framework, strategic approach, elaborate hypotheses and comprehensive models to ensure sustainability in the management of both water resources and related disasters (Burdge, 2008; Shisanya \& Khayesi, 2007 ; Vishnudas, 2006).

Brown (2001) stated that "If an economy is to sustain progress, it must satisfy the basic principles of ecology. If it does not it will decline and eventually collapse. There is no middle ground. An economy is either sustainable or it is not." This statement conveys an integration of market based variables of farming water demand within the framework of agro-ecology. Agro-ecological variables are determinants of the farming production optimum. These are bio-physical based variables of plant water leading to evapotranspiration. Yet, when subjected to the market game, to farmers' ignorance, apprehension and false expectations, good bio-physical conditions can easily result in farming inefficiency. Thus, farmers' decision-making, economic power and social dynamics shall be taken into account when assessing water related hazards in farming.

Hydro-economic risk assessment and management (HERAM) is a step of "Integrated watershed management" (IWM). It is a major goal towards sustainable management of water resources, especially designed to improve irrigation planning in the course of climate change within various agro-ecological zones. In effect, HERAM is based on a postulate stating that water efficiency in agriculture can be effectively assessed, planned and evaluated under uncertain conditions of water availability by integrating both agroecological and socio-economic variables (Luwesi, 2009). If that link between the physical and market processes is mended, farmers would naturally balance the fluctuations of water to foster their farming efficiency in a changing environment. Finally, HERAM is in line with the principles adopted during the "IWRM inception conference" in Dublin (1992) and the "Yokohama strategy and plan of action for a safer world" endorsed during the "World conference on natural disaster reduction" (May 1994, Yokohama). The two forums recommended the integration of water resource development within the framework of 
planning and risk assessment as well as the valuation and recognition of the role of natural resources in sustaining life. They recommended the empowerment of local stakeholders to provide alternative and decentralized approaches towards water supply and relief options under conditions of drought or any other disaster.

\section{Hydro-economic risk assessment: Methods and techniques}

Hydro-economic risk assessment and management (HERAM) basically features in the framework of "Environmental risk analysis" (ERA) in a catchment area. Ganoulis \& Simpson (2006) define ERA as "the evaluation of uncertainties in order to ensure reliability in a broad range of environmental issues, including utilization of natural resources (both in terms of quantity and quality), ecological preservation and public health considerations". They provide the following framework for assessing and managing the risk: problem formulation, load-resistance (or exposure-response) characterization, risk quantification, evaluation of incremental benefits against different degrees of risk, and decision-making for risk management. The Risk analysis consists of two procedures: Risk assessment (RA) and Risk management" (RM). Risk assessment deals with the identification of the hazard, the determination of its value (both quantitative and qualitative) and the observable effects it is likely to yield on the people, their environment and economy. Risk management entails the design and implementation of mitigation plans, and their monitoring and evaluation for sustainability. Like ERA, "Hydro-economic risk assessment and management (HERAM) involves a Risk assessment (RA) and a Risk management" (RM). The RA encompasses three other procedures: a "hydro-geomorphologic risk assessment" (HRA), a "social impact assessment" (SIA), and an "Economic inventory" (EI). These three procedures are embedded in the Risk management" (RM). Figure 1 provides the sequence of repeatable steps involved in the conduction of a HERAM.
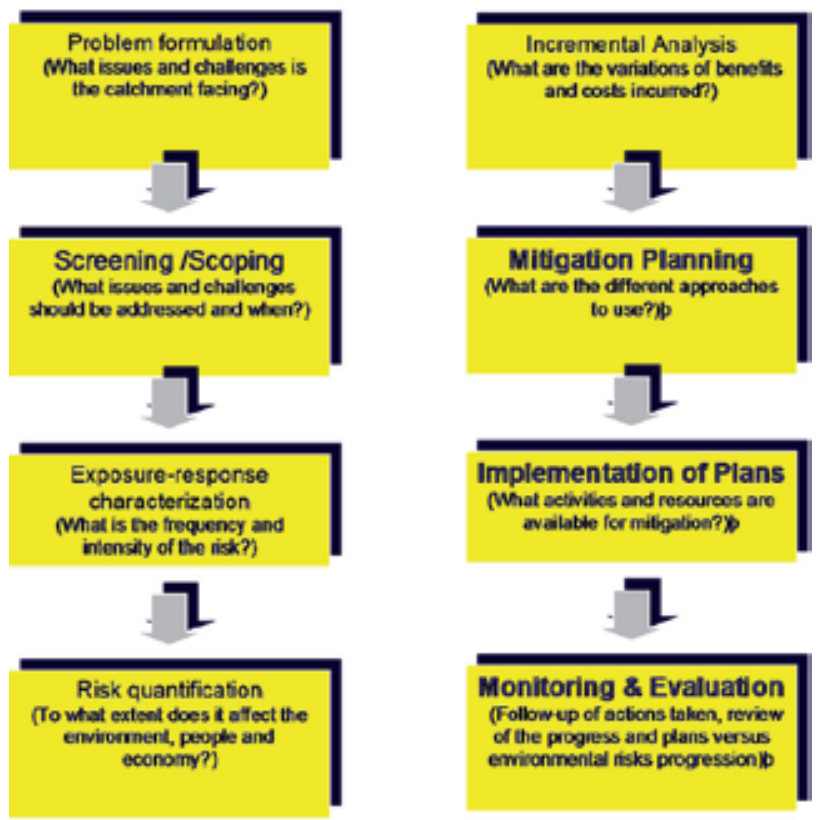

Fig. 1. Hydro-economic risk assessment and management framework 
It shall be noted that "Economic inventory" (EI), which in fact is an incremental analysis of farming water efficiency, makes the particularity of the HERAM. It assesses the effects of water management on its productivity and efficiency in agriculture. It uses hybrid inventory models shaped after Wilson deterministic stock inventory, Baumol deterministic monetary inventory and Beranek dynamic cash inventory, both under above normal (ANOR), normal (NOR), and below normal (BNOR) rainfall regimes (Luwesi, 2010). These models combine internal and external costs incurred in the management of water inventories in order to simulate efficient levels of water use in farming under fluctuating rainfall regimes. Internal costs encompass both the cost of transaction and opportunity cost of water management, while external costs include the cost of water saving under ANOR, and water shortage cost under BNOR. The incremental analysis of the total cost leads to three key indicators of farming water efficiency, namely the "Economic order quantity" (EOQ) - computed under the ANOR, the "Limit average cost" (LAC) - determined under NOR, and the "Minimum efficient scale" (MES) - calculated under the BNOR. Finally, the analytical process assesses the variations of incomes vis-à-vis costs under different hypotheses of the management efficiency (EOQ, LAC and MES) to design strategic guidelines. Table 1 summarizes key outputs of an "Economic inventory" during a HERAM.

\begin{tabular}{|c|c|c|c|c|c|}
\hline \multirow{2}{*}{ Rainfall regime } & \multicolumn{4}{|c|}{ Total Cost of farming water } & \multirow{3}{*}{$\begin{array}{c}\text { Optimum } \\
\text { (First Order } \\
\text { Conditions) } \\
\text { Limit Average Cost } \\
\text { (LAC) }\end{array}$} \\
\hline & \multicolumn{2}{|c|}{ Internal Costs } & \multicolumn{2}{|c|}{ External Costs } & \\
\hline \multirow{2}{*}{ Normal (NOR) } & \multirow{2}{*}{$\begin{array}{c}\text { Cost of } \\
\text { Transaction }\end{array}$} & \multirow{2}{*}{$\begin{array}{l}\text { Opportunity } \\
\text { Cost }\end{array}$} & & & \\
\hline & & & & & $\bar{r}_{n o}=\sqrt{2 \mathrm{q} / Q}$ \\
\hline \multirow{2}{*}{$\begin{array}{l}\text { Above Normal } \\
\text { (ANOR) }\end{array}$} & \multirow{2}{*}{$\begin{array}{c}\text { Cost of } \\
\text { Transaction }\end{array}$} & \multirow{2}{*}{$\begin{array}{l}\text { Opportunity } \\
\text { Cost }\end{array}$} & \multirow{2}{*}{ Saving Cost } & & $\begin{array}{l}\text { Economic Order } \\
\text { Quantity (EOQ) }\end{array}$ \\
\hline & & & & & $\bar{r}_{a n}=\sqrt{2 q /(2 Q-q)}$ \\
\hline \multirow{2}{*}{$\begin{array}{l}\text { Below Normal } \\
\text { (BNOR) }\end{array}$} & \multirow{2}{*}{$\begin{array}{c}\text { Cost of } \\
\text { Transaction }\end{array}$} & \multirow{2}{*}{$\begin{array}{l}\text { Opportunity } \\
\text { Cost }\end{array}$} & & \multirow{2}{*}{$\begin{array}{c}\text { Shortage } \\
\text { Cost }\end{array}$} & $\begin{array}{l}\text { Minimum Efficient } \\
\text { Scale (MES) }\end{array}$ \\
\hline & & & & & $\bar{r}_{b n}=\sqrt{2}$ \\
\hline
\end{tabular}

Table 1. Economic inventory outputs

Note: $r_{n o}, r_{a n}$ and $r_{b n}$ refer to the water demand turnover under NOR, ANOR and BNOR, while $Q$ and $q$ stand for the farming activity output and input, respectively standardized as follows:

$$
\begin{aligned}
& Q=\frac{n^{*} Y}{W_{f}^{*} P} \\
& q=\frac{n^{*} E}{W_{f}^{*} P}
\end{aligned}
$$

Where, $Y$ is the farming income, $E$ is the farming expense, $P$ is water price in the market (per $\left.\mathrm{m}^{3}\right), W_{f}$ is the farmer water demand, and $n$ the number of water withdrawals by the farmer. 
The HERAM conducted in Muooni Dam Catchment sought to evaluate the efficiency of water use in agriculture under hypothesized fluctuations of rainfall in South-East Kenya. It responded to the following research questions: (i) What kind of anthropogenic and environmental factors affect efficient use of Muooni Dam water in farming? (ii) To what extent do land-use activities and environmental externalities influence the active water storage capacity of Muooni Dam? (iii) What variations of farmers' actual water demand and related costs are expected as a result of rainfall fluctuation in South-East Kenya? (iv) What are the efficient levels of farmers' water demand and related costs under fluctuating rainfall regimes? (v) How can farmers improve their water efficiency in the course of climate change?

Zeiller (2000) stratified random sampling was used to select some 66 farms at Muooni Dam site and 60 key informants outside the dam site. The method involved equal chances of selection for all the respondents, both the most accessible ones and those far away from Muooni Dam site. The hydro-geomorphologic impacts sampling was based on Gonzalez et al. (1995) impact assessment technique. The latter aimed to record significant land-use activities and impacts randomly occurring on farmlands. Descriptive statistics, nonparametric tests, and time series analysis assisted in the valuation of impacts assessed, the establishment of their relationship with land-use activities observed, and the prediction of Muooni Dam's active water storage capacity. Spatial data were processed using ArcView GIS mapping for both land-use activities and impacts assessed. Then the analysis proceeded to assess social impacts using mainly descriptive statistics, trend analysis, and a triangulation of both quantitative and qualitative methods. This led to the economic inventory, which totally relied on hybrid inventory models for the computation of farmers' water demand and related costs. It also helped to simulate the optimum levels (EOQ, LAC and MES) of farming water demand and cost under three respective scenarios of rainfall fluctuation (ANOR, NOR and BNOR). These efficiency indicators were computed for each of the three categories of farmers, notably "Large-scale farmers" (LSF), "Medium-scale farmers" (MSF) and "Small-scale farmers" (SSF). Different techniques of "Integrated watershed management" (IWM) were suggested to improve the efficiency of farming water use in Muooni Dam Catchment. The following sections present the sequential analytical steps of the HERAM conducted in Muooni Dam Catchment.

\section{Hydro-economic risk assessment conducted in Kenya}

This section presents the main findings from the HERAM conducted in Muooni Dam Catchment of Kenya. It consecutively outlines the problem formulation, the screening and scoping strategy, the exposure-response characterization, the risk quantification, the incremental analysis, and the strategy for mitigation of water disasters in farming.

\subsection{Problem formulation}

Muooni Dam Catchment is subject to demographic expansion, climate variability, and landuse changes occurring at a large scale. These socio-environmental changes are among key factors leading to soil erosion, the siltation and pollution of drainage channels and water storages, thus affecting water availability and soil fertility in various catchment areas. Pressures on water and soil contribute to the catchment degradation and increased cost of water and land in agriculture in most arid and semi-arid lands of Kenya. Food insecurity, energy disruption and poverty are corollaries of such increased stress of water and land in Muooni Dam Catchment. Therefore, what kind of anthropogenic and environmental factors 
affect efficient use of water and land by farmers in this catchment area? Is there a way to improve the efficiency of farming water use under fluctuating rainfall regimes?

\subsection{Screening and scoping strategy}

This study was based on risks associated to land-use activities going on in Muooni Dam Catchment. The key criterion for screening was the intensity of the hydro-geomorphologic risks assessed on farmlands and Muooni Dam. A scope of most significant risks was determined from their contribution to the degradation of Muooni Dam catchment. As presented in Table 2, the most significant land-use activities and their likely hydrogeomorphologic risks ranged from 1 to 6.

\begin{tabular}{|c|c|c|c|}
\hline Weight & Land-use activity & Weight & Hydro-geomorphologic risk \\
\hline 1 & Tree planting & 1 & Sheet/ rill erosion on farmland \\
\hline 2 & $\begin{array}{c}\text { Intensive cultivation using } \\
\text { water pumps/ tanks }\end{array}$ & 2 & Encroachment on wetland \\
\hline 3 & $\begin{array}{c}\text { Subsistence cultivation with } \\
\text { limited irrigation }\end{array}$ & 3 & $\begin{array}{c}\text { Sand harvesting/ quarrying } \\
\text { impacts on farmland }\end{array}$ \\
\hline 5 & $\begin{array}{c}\text { Subsistence cultivation without } \\
\text { irrigation }\end{array}$ & 4 & Gully erosion on farmland \\
\hline 6 & $\begin{array}{c}\text { Livestock keeping with some } \\
\text { cultivation }\end{array}$ & 5 & Landslide on farmland \\
\hline cultivation
\end{tabular}

Table 2. Land-use and associated risks in Muooni Dam Catchment

This table points out that the catchment degradation was basically defined in terms of soil erosion problems leading to the sedimentation of the dam, and to excess water loss from the dam reservoir. Gonzalez et al. (1995) mapping technique was applied along with GIS spatial modelling to plot each land-use activity and its likely environmental risk. Figure 2 illustrates the distribution of land-use activities assessed on farmlands, while Figure 3 suggests a display of their associated risks. These figures emphasize the fact that agro-forestry and subsistence cultivation and their associated risks (sheets and rills as well as eucalyptus water over-abstraction) had very high significance in their occurrence in the catchment.

Following the depletion of the forest cover, they were propounded to be the key factors hindering water availability in drainage systems and the dam reservoir in Muooni Dam Catchment. These land-use activities and associated risks represented more than three fourths of the total farming area surveyed. Other land-use practices, though not significant, included livestock keeping with some cultivation (12.1\%), intensive cultivation using water pumps and storing devices (10.6\%), and subsistence cultivation with limited irrigation (3\%). Their related hydro-geomorphologic risks were mainly gully erosion, landslides and encroachment of farms on wetlands, which accounted for $8 \%, 3 \%$, and $8 \%$ of farms surveyed, respectively.

This assessment of hydro-geomorphologic risks also looked at environmental externalities affecting water availability and land fertility in Muooni Dam Catchment. Off-site effects of environmental changes on the catchment were highly significant in terms of soil erosion problems and water stress in the catchment. The significance of these environmental 
externalities was elucidated by the effects of El Niño rainfall and heavy wind pressure associated to the siltation of the dam and drainage channels, deforestation, floods, gully erosion, and landslides in the catchment. Table 3 summarizes these externalities and their associated risks.

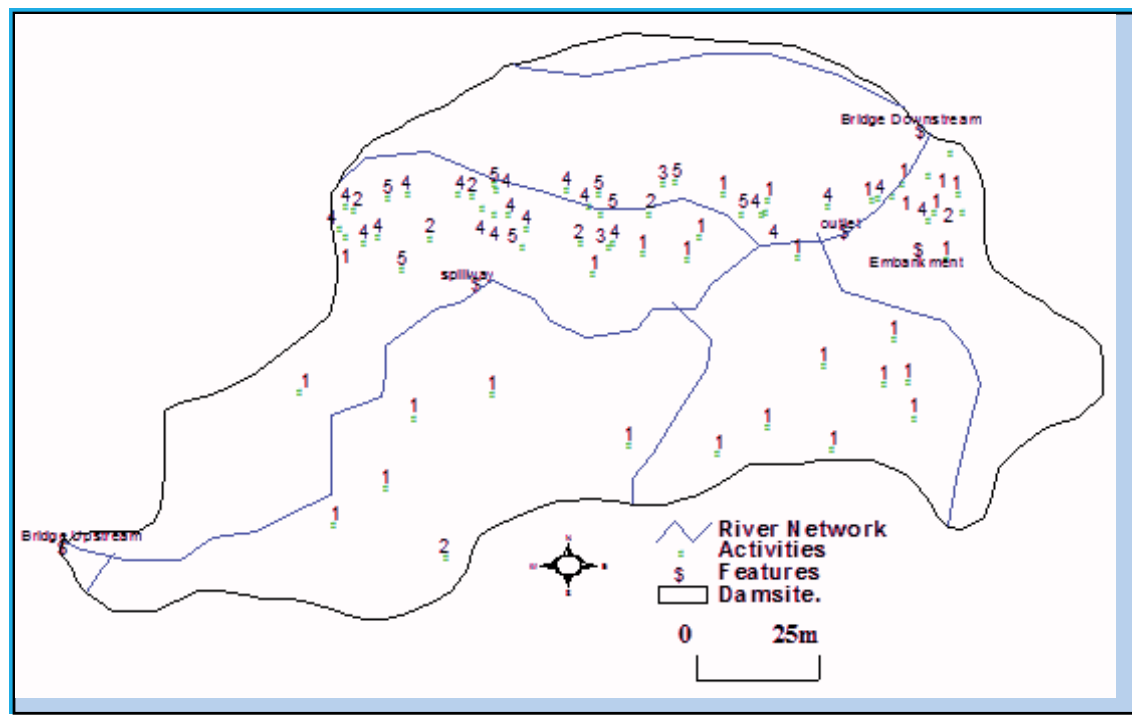

Note: Numbers 1 to 6 refer to the weight of land-use activities found in Table 2.

Fig. 2. Spatial distribution of land-use activities in Muooni Dam Catchment

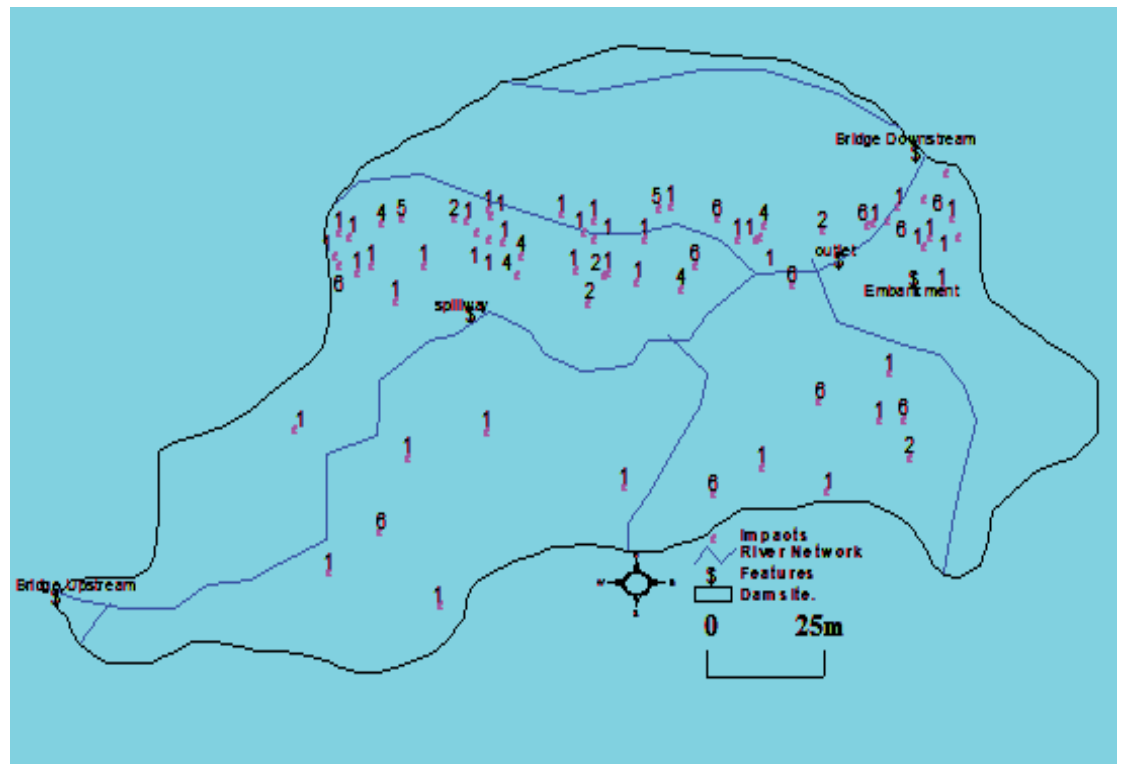

Note: Numbers 1 to 6 refer to the weight of hydro-geomorphologic risks found in Table 2 .

Fig. 3. Spatial distribution of hydro-geomorphologic risks in Muooni Dam Catchment 


\begin{tabular}{|c|l|c|l|}
\hline Weight & \multicolumn{1}{|c|}{ externality } & Weight & \multicolumn{1}{|c|}{ Hydro-geomorphologic risk } \\
\hline 7 & Heavy wind pressure & 7 & Siltation of dams \& drainage systems \\
\hline 8 & Heavy wind pressure & 8 & Deforestation \\
\hline 9 & El Niño rainfall & 9 & Flooding \\
\hline 10 & El Niño rainfall & 10 & Gully erosion in the catchment \\
\hline 11 & El Niño rainfall & 11 & Landslides in the catchment \\
\hline 12 & El Niño rainfall & 12 & Drought \\
\hline
\end{tabular}

Table 3. Environmental externalities and associated risks in Muooni Dam Catchment

It shall be noted that the rainfall regime in South-East Kenya is mainly dominated by two dry "monsoon" seasons and two rainy seasons associated with the movement of the ITCZ. The annual average rainfall fluctuates between 500 and 1,300 mm, with $66 \%$ of reliability, part of it coming from the trade effects of south-eastern winds blowing on slopes (Jaetzold et al., 2007). In such kind of environment, droughts and floods are likely to be recurrent due to the effects of "El Niño southern oscillation" (ENSO) (Shisanya, 1996).

\subsection{Exposure-response characterization}

The hydro-geomorphologic risk assessment conducted in Muooni Dam Catchment revealed a correlation between on-farm management, farmers' level of income and education, and environmental degradation. Most farmers seemed not to be aware of processes going on but complained about soil erosion problems, wetland degradation and farmland infertility. A majority among them got used to enhance their soil protection with terraces, contours, cutoff drains, polyculture and agro-forestry (Tiffen et al., 1994). Yet, eucalyptus and other fast growing alien trees remained the most dominant plant species in the catchment. Accelerated land degradation and acute water stress drove governmental agencies to implement some soil and water conservation measures in this area, especially during the dry season.

In effect, Muooni Dam Catchment area was formerly surrounded by Iveti forest. Demographic pressure, the expansion of farming areas and other economic activities contributed to the encroachment of the forest and to the destruction of more than $25 \%$ of its estimated coverage in 1987 (WRMA, 2008). Thence soil erosion, landslides and water overabstraction by ecosystems, especially by eucalyptus trees planted in the wetlands, thwarted farmers' livelihood and the economic viability of their farming activities. Besides being intensively cultivated, farmlands had poor soils and soil moisture (Lal, 1993; Waswa, 2006). Due to the shortness of the rainy seasons, the fluctuations of rainfall affect efficient use of water and land in agriculture, especially in terms of crop water requirements and crop treatments. In such circumstances, farming incomes are likely to be insignificant, unless supplemented by off-farm incomes. The introduction of "marginal" crops with lower diurnal potential evapo-transpiration (mainly bean and maize species) has proved to be a salvation for farmers under extreme water stress conditions (Jaetzold et al., 2007). Unfortunately, chances for high yields and good incomes are ever reduced as soil moisture declines so quickly due to the smallness of farmlands and to prolonged droughts. 
Consequently, farmers are constrained to adopt unsustainable farming strategies to cope with these poor yields and incomes during unpredictable droughts. Such strategic farming methods included excessive intercropping and multiple cropping of perennial indigenous and alien crop species on small farmlands. Yet, this could not hold their operational costs and losses significantly back. Water over-abstraction by eucalyptus and other alien trees along with off-site effects of El Niño flooding and drought accelerated the risk of soil erosion and water excess loss. Eucalyptus tree planting and subsistence cultivation with irrigation in Muooni Dam Catchment were limited to overland flow and encroached on wetlands. The natural vegetation in those wetlands has been substituted by exotic trees, crops and weeds. These interlopers generally exacerbate the vital functions of the whole ecosystem, owing to the fact that they are not water friendly (Jansky et al., 2005; Kitissou, 2004). Moreover, the practice of overland flow irrigation increases the rate of streamflow evaporation beyond $30 \%$ of the total water resource available (Shakya, 2001). Therefore, soils in farmlands are deprived of most of their resilience, fertility and moisture (Lal, 1993).

Potential rich soils are rare in most Kenyan ASALs, especially where shallow topsoil overlies a light soil. The impact of a raindrop, whether by through-fall or drip from raindrops intercepted by tree canopy, is a necessary and sufficient condition for soil erosion to occur in these areas. Thus, sheets and rills in Muooni Dam Catchment appeared in more than half of the fields surveyed. High rates were recorded in lands managed by full-time farmers and farmers employed in the private sector. The increase of runoff on the surface and the decrease of water infiltration in the soil were likely to cause an "overland flow" and generally resulted in pronounced channels known as "rills" and "inter-rills" (Soilerosion.net, 2007; Thompson \& Scorging, 1995). Inter-rills were to become "gullies", when overflowing massive surface materials (cobbles, stones and grasses) were detached on hillsides during rainstorms and the infiltration capacity of the soil was exceeded. Mass movements were expected in some parts of the catchment, "when obliterated by weathering and ploughing" (Morgan, 1995). No doubt that any farmer, who had not been keen to clear sheets or rills, immediately after their occurrence, had to face acute soil erosion problems. That is why a majority among farmers wanted to cultivate near the riverbanks and other wetlands.

The combined effects of all these factors justify the changes observed in the microclimate of Muooni Dam Catchment through the variation of its temperatures and rainfall regimes. They might also explain the recurrence of droughts and the phenomenon of seasonal water courses in this catchment area. The latter nurtured colossal soil loss and sediment load in the drainage systems of Muooni River and its dam reservoir. This might have led to the decrease of Muooni Dam active water storage capacity. The following section analyzes the relation between land-use activities assessed and their associated risks, and between the risks and Muooni Dam active water storage capacity to establish that assertion.

\subsection{Risk quantification}

The estimate of the risk magnitude was done in three steps. First, the study sought to establish a cause-and-effect relationship between land-use activities assessed and their associated risks. Second, an estimate of the variations of Muooni Dam's active water storage capacity under the effects of risks identified was done to predict its trend. Lastly, the analysis estimated the magnitude of socio-economic impacts. 


\subsubsection{Land-use and associated impacts/ risks}

The hydro-geomorphologic risk assessment did not establish a direct relationship between land-use activities assessed and their likely hydro-geomorphologic impacts. Mann-Whitney U-Test proved with $99.8 \%$ confidence level that land-use activities assessed and their likely impacts on farmlands were randomly drawn from independent populations (Table 4). These findings were reinforced by Spearman's rank correlation (Table 5).

\begin{tabular}{|l|l|l|l|}
\hline No & \multicolumn{2}{|l|}{ Decision Parameters } & Decision \\
\hline 1 & $\mathrm{U}_{1}=2,178$ & $\mathrm{n}_{1}=\mathrm{n}_{2}=66$ & $\begin{array}{l}\text { The deviations around the means of the two } \\
\text { samples are far significant; so are their differences. }\end{array}$ \\
\hline 2 & $\mu_{1}=1,089$ & $\sigma_{1}=219.725$ & \\
\hline 3 & $\mathrm{Z}_{\mathrm{u}}=4.9562$ & $\mathrm{n}=66$ & $\begin{array}{l}\text { Rejection of Ho }\left(\mu_{1}=\mu_{2}\right) \text { stating that there are } \\
\text { significant differences between the populations } \\
\text { from which the two samples were drawn. }\end{array}$ \\
\hline 4 & $\mathrm{Z}_{\rho}=3.99$ & $\mathrm{a}=0.002$ &
\end{tabular}

Table 4. Results of Mann-Whitney U-Test

As displayed on Table 5, Spearman's rank correlation confirmed with $99.8 \%$ confidence level that there was no strong relationship between the two random samples analyzed. Land-use activities assessed in Muooni Dam Catchment and their likely impacts may have originated from diverse sources, within and outside the catchment. These two samples were behaving independently one from another. These hydro-geomorphologic impacts might have been the results of various risks hastening the degradation of the catchment area.

\begin{tabular}{|l|l|l|l|}
\hline No & \multicolumn{2}{|l|}{ Decision Parameters } & Decision \\
\hline 1 & $\sum \mathrm{di}_{2}=52,081.5$ & $\mathrm{n}=66$ & $\begin{array}{l}\text { There is a weak correlation between land-use } \\
\text { activities and impacts assessed. }\end{array}$ \\
\hline 2 & $\mathrm{r}_{\mathrm{s}}=-0.08718$ & $\mathrm{n}=66$ & $\mathrm{n}-1=65$ \\
\hline 3 & $\mathrm{Z}_{\mathrm{u}}=-0.01081$ & $\begin{array}{l}\text { Acceptance of Ho }\left(\rho_{\mathrm{s}}=0\right) \text { stating that there is no } \\
\text { significant relationship between the populations } \\
\text { from which the two samples were drawn. }\end{array}$ \\
\hline 4 & $\mathrm{Z}_{\rho}=-3.99$ & $\mathrm{a}=0.002$ & \\
\hline
\end{tabular}

Table 5. Results of the Spearman's rank correlation

The on-site effects of soil erosion and eucalyptus water over-abstraction may be explained by inadequate soil conservation measures used by farmers (Mutisya, 1997). Off-site effects of soil erosion and high water evaporation from the dam reservoir may be elucidated by the effects of global warming, El Niño floods and droughts, heavy wind pressures, footpaths and roadsides, sand harvesting, deforestation and others forces from outside farming activities. Both on-site and off-site risks were hindering water availability in drainage systems and the dam reservoir in Muooni Dam Catchment (Luwesi, 2009).

\subsubsection{Prediction of Muooni Dam's active water storage capacity}

After identifying the actual risks, the analysis proceeded to estimate the variations of Muooni dammed water and predict its trend. It revealed a decrease of the dam active water storage capacity, since its construction was completed in 1987 (Figure 4). 


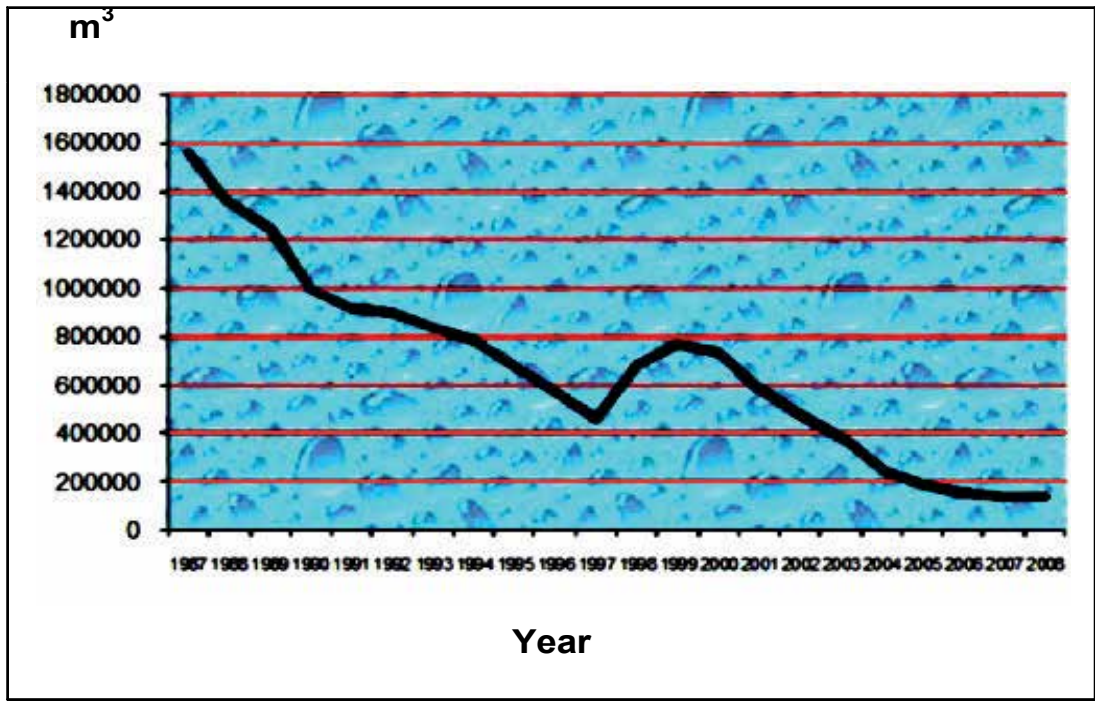

Note: Estimates from various data sources provided by key informants and WRMA (2008)

Fig. 4. Variability of Muooni Dam's active water storage capacity

It was believed by $97 \%$ of public officers and key informants interviewed that soil erosion and landslides were outwitting the Muooni Dam's active water storage capacity under the effects of El Niño floods and wind erosion. The decreasing water storage capacity of the dam was a fact of its siltation by farming activities going on around the dam site. An uplift has been observed in the years 1997-1998 due to the El Niño rainfall, which effects were prolonged until a new descent started in the year 2000. Statistical predictions from Table 6 and Figure 5 emphasize a continuous decreasing trend of the dam's water storage capacity in the near future.

\begin{tabular}{|l|l|}
\hline Year & Dam storage capacity $\left(\mathrm{m}^{3}\right)$ \\
\hline 2009 & 222,190 \\
\hline 2010 & 208,791 \\
\hline 2011 & 196,200 \\
\hline 2012 & 184,368 \\
\hline 2013 & 173,250 \\
\hline 2014 & 162,802 \\
\hline 2015 & 152,984 \\
\hline 2016 & 143,759 \\
\hline 2017 & 135,089 \\
\hline 2018 & 126,943 \\
\hline 2019 & 119,287 \\
\hline
\end{tabular}

Table 6. Prediction of Muooni Dam's active water storage capacity 


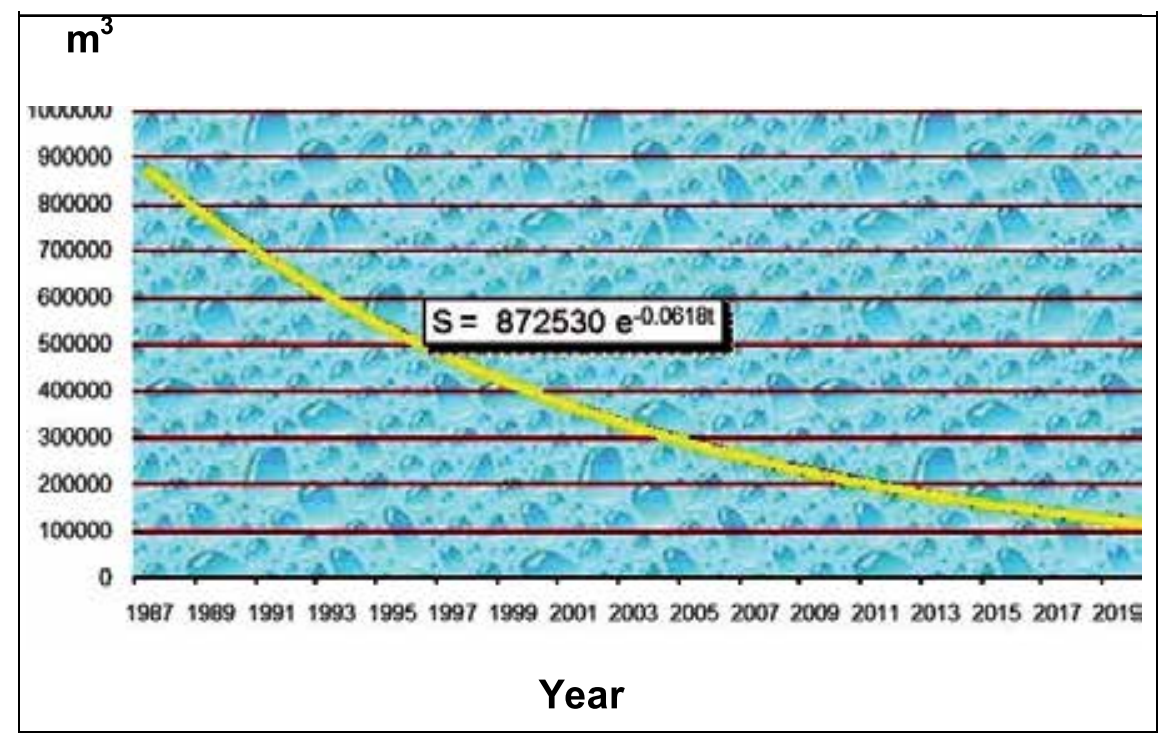

Fig. 5. Trendline of Muooni Dam's active water storage capacity

The maximum capacity of Muooni Dam reservoir that was established to 1,559,400 $\mathrm{m}^{3}$ in 1987 has decreased to an estimate of $196,200 \mathrm{~m}^{3}$ in the year 2011. It will go under its threshold by the year 2019, storing less than $119,400 \mathrm{~m}^{3}$. The analysis also established an annual decreasing rate of $6.2 \%$ of the dam's active water storage capacity (Table 7).

\begin{tabular}{|l|l|l|l|l|}
\hline \multirow{2}{*}{ Model $(\mathrm{St})$} & \multicolumn{2}{|l|}{ Coefficients } & \multirow{2}{*}{ t-statistic } & \multirow{2}{*}{ Sig. } \\
\cline { 2 - 5 } & $\mathrm{B}$ & Std. Error & & \\
\hline 1. $($ Constant) & 872,530 & 316,576 & 2.756 & 0.013 \\
\hline 2. $\mathrm{t}$ & -0.0618 & 0.017 & -3.564 & 0.005 \\
\hline Note: $\mathrm{r}=0.81 ; \mathrm{R}^{2}=0.6565 ;$ Mean $=671,874 \mathrm{~m}^{3} ; \mathrm{ET}=173,400 \mathrm{~m}^{3}$ & \\
\hline
\end{tabular}

Table 7. Significance of Muooni Dam's storage capacity trendline

This table shows that the annual mean water storage capacity was $671,874 \mathrm{~m}^{3}$ with a standard error (SE) of $316,576 \mathrm{~m}^{3}$ and an error term (ET) of $173,400 \mathrm{~m}^{3}$. The fact that the deviations around the mean ( $S E$ and $E T$ ) are far less significant than the sample mean attests that the model is viable for further predictions. The correlation coefficient $(r)$ and the coefficient of determination $\left(R^{2}\right)$ also testify that the regression model is sufficiently strong to explain the variations of the dam's active water storage capacity $\left(S_{t}\right)$ by the time $(t)$. In fact, the correlation coefficient shows that $81 \%$ of the variations of the active water storage capacity of Muooni Dam reflect its old age. The fluctuations of the dam's active water storage capacity have thence the same bearing as the depreciation of its reservoir infrastructure. The coefficient of determination confirms this result by attributing $65.7 \%$ of the total variation of the dam's active storage capacity to its logistics obsolescence. Spearman's Rho test certifies these assertions (Table 8). 


\begin{tabular}{|l|l|l|}
\hline \multicolumn{2}{|l|}{ Statistical Parameters } & Decision \\
\hline 1. $\mathrm{r}=0.81$ & $\mathrm{a}=0.005$ & $\begin{array}{l}\text { There is a strong correlation between } \mathrm{S} \\
\text { and } \mathrm{t}\end{array}$ \\
\hline 2. $\mathrm{S}_{\mathrm{r}}=0.134$ & $\mathrm{n}-2=20$ & $\begin{array}{l}\text { The correlation coefficient is good } \\
\text { Rejection of } \mathrm{H}_{0}(\rho=0): \mathrm{S} \text { is explained by } \mathrm{t} . \\
\text { So, the decreasing trend of the dam's } \\
\text { storage capacity is related to its logistics } \\
\text { old age. }\end{array}$ \\
\hline 3. $\mathrm{t}_{\rho, \mathrm{n}-2}=4.651$ & $\mathrm{t}_{\mathrm{a} ; \mathrm{n}-2}=2.84$ & \\
\hline
\end{tabular}

Table 8. Results of the Spearman's Rho test

This table highlights the fact that the prediction model was sufficiently strong to explain the decreasing trend of Muooni Dam's active water storage capacity by its logistics old age. It reveals with $99.5 \%$ confidence level and 20 degrees of freedom that $81 \%$ of the variations of the dam's active water storage capacity were reflected in the changes of its infrastructure resistance over years. However, only $65.7 \%$ of its total variation could be explained by the dam's logistics old-age. The decreasing active water storage capacity of Muooni Dam might have been a consequence of its reservoir logistics depreciation, either by destruction or by lack of maintenance. Therefore, the study needed to explain the remaining $34.3 \%$ of the total variation of the dam's active storage capacity not attributed to its logistics obsolescence. This proportion of the total variation of Muooni dam's active storage capacity might be due to the hydro-geomorphologic risks identified earlier, and which were degrading the dam's catchment area. Both the dam's logistics obsolescence and hydro-geomorphologic risks associated to land-use activities and environmental externalities were threatening the social welfare and economic stability of farmers, as demonstrated in the following subsection.

\subsubsection{Magnitude of social and economic impacts}

The decrescendo of Muooni dam's active storage capacity may have severed smallholder farming water security, and farmers' yields and incomes. Due to excess water costs, it could therefore not be surprising to see farmers using water inefficiently. These inefficient practices thwarted the economic viability of farmers'activities and led to poverty. Farmers' poverty in this area was likely due to an accumulation of losses over years, and as a result of water stress and lack of potential agricultural lands (Table 9).

This table suggests that most farmers surveyed were at the brink of poverty since they were incurring losses over years due to the decreasing productivity of their farming water and land resources. The Social impact assessment (SIA) confirmed that poverty was a reality in the study area. The distribution of farmers by level of income disclosed that $30 \%$ of farmers in Muooni Dam Catchment had a daily average income of less than US \$1, with an annual income averaging US\$ 231 (for $\$ 1=$ KES 60). Accordingly, the distribution of farmers by class of income was dominated by small and Medium-scale farmers (SSF and MSF) earning a monthly income below KES 3,000, and between KES 3,000 and 5,999, respectively. Hence, the study needed to assess the variations of actual farmers' water costs in Muooni Dam Catchment vis-à-vis the optimum levels of farming water (EOQ, LAC and MES) to establish their efficiency under fluctuating rainfall regimes. 


\begin{tabular}{|c|c|c|c|c|}
\hline $\mathrm{N}^{\circ}$ & Operations & LSF (KES) & MSF (KES) & SSF (KES) \\
\hline 1 & Farming Income & 428,400 & 273,600 & 55,800 \\
\hline 1.1 & Total Income & 428,400 & 273,600 & 55,800 \\
\hline 1.2 & Average Income/m ${ }^{3}$ & 85.84 & 65.68 & 51.62 \\
\hline 2 & Farming Expenditures & 569,000 & 276,500 & 63,530 \\
\hline 2.1 & Seeds & 10,000 & 17,500 & 2,110 \\
\hline 2.2 & Fertilizers & 23,000 & 0 & 1,900 \\
\hline 2.3 & Pesticides & 8,000 & 16,000 & 0 \\
\hline 2.4 & Water & 0 & 0 & 12,000 \\
\hline 2.5 & Water Pumps Fuel & 360,000 & 135,000 & 0 \\
\hline 2.6 & Wages & 108,000 & 81,000 & 0 \\
\hline 2.7 & Transport & 60,000 & 27,000 & 11,520 \\
\hline 2.8 & Food & 0 & 0 & 36,000 \\
\hline 2.9 & Total Cost & 569,000 & 276,500 & 63,530 \\
\hline 2.10 & Average Cost / ${ }^{3}$ & 114.9065 & 66.3773 & 58.7648 \\
\hline 3 & Farming Profit & $-140,600$ & -8.111 & $-7,730$ \\
\hline 3.1 & Total Profit & $-140,600$ & -8.111 & $-7,730$ \\
\hline 3.2 & Average Profit/m ${ }^{3}$ & -28.1725 & -0.701 & -7.1502 \\
\hline
\end{tabular}

Note: KES stands for Kenya Shillings

Table 9. Farmers' annual income and expenses distribution

\subsection{Incremental analysis}

Results of the "Economic inventory" (EI) show that increased shortage costs of farming water and the cost of fertile soil excess loss constrained farmers to order less farming water $\left(W_{f}\right)$ than required by their crops $\left(W_{c}\right)$. Large-scale (LSF), Medium-scale (MSF) and Smallscale farms (SSF) could just afford ordering 28.9\%, 12.2\% and $4.4 \%$ of their actual crop water requirements, respectively (Figure 6). In such conditions, operational costs of farming water soared by $175 \%, 518 \%$ and $1,420 \%$ of the actual total costs under the ANOR, NOR and BNOR scenarios, respectively (Figure 7). This underscored a progressive accumulation of farming losses by a majority of farmers over years.

An analysis of the optimum levels of farming water demand (EOQ, LAC and MES) revealed that farmers operating in Muooni Dam Catchment recorded high water productivities from 1987 to 2003, under the ANOR rainfall regime. Their unit cost per $\mathrm{m}^{3}$ averaged KES 197, 188 and 159 for LSF, MSF and SSF, respectively. This water cost was assorted to an "Economic order quantity" (EOQ) of farming water demand in a very profitable economic conjuncture at Muooni Dam Catchment. 


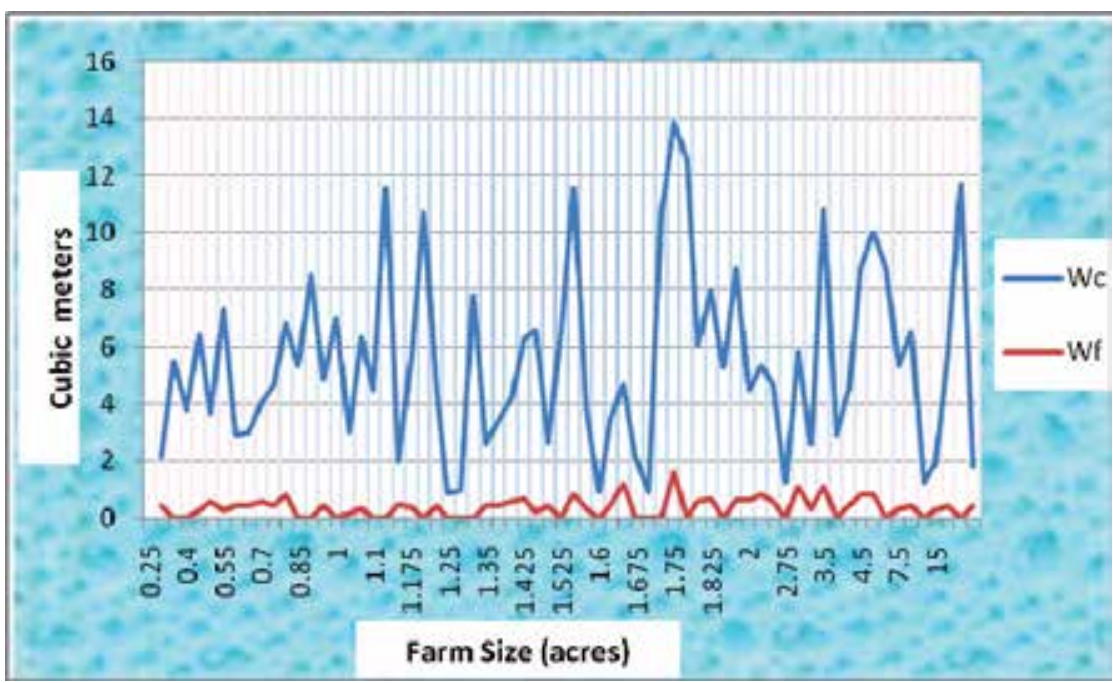

Fig. 6. Farmers' water demand and crop water requirements

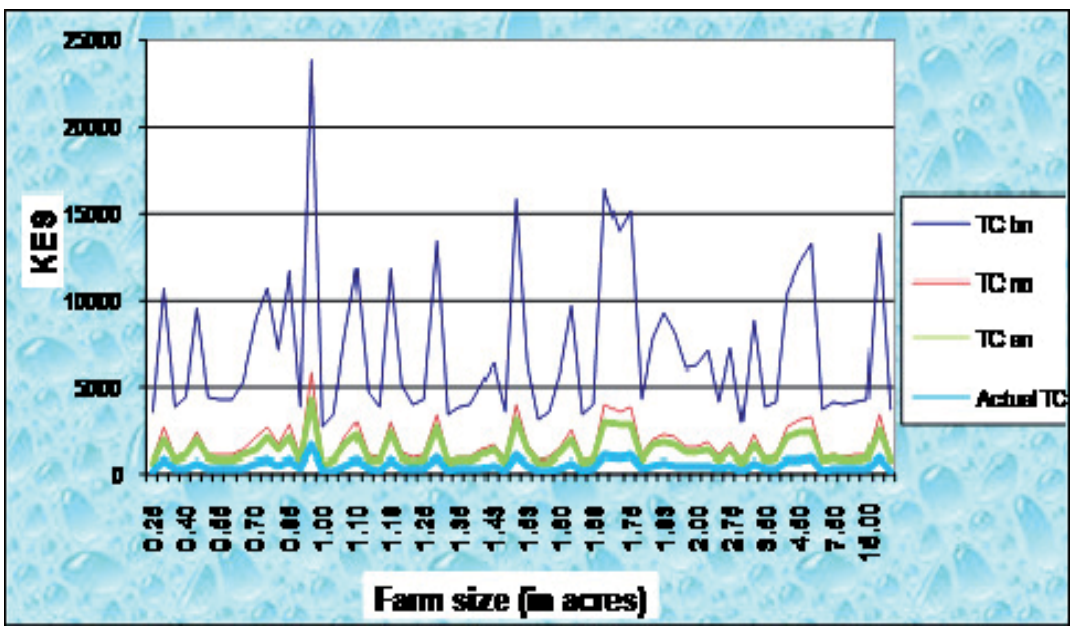

Fig. 7. Farming water costs under fluctuating rainfall regimes

From 2004 to date the loss of farming profitability under the NOR scenario is the most important economic incentive that leads farmers to subdivide their lands. Their average costs having become significantly high, older farmers have to limit their farming water costs to a "Limit average cost" (LAC) of KES 444, 415 and 361 for LSF, MSF and SSF, respectively. Many farmers have adopted inadequate practices such as eucalyptus tree planting, leasing or even sale of part of their farmlands to new comers in order to limit their farming water costs. Others have left their farmlands under fallow for several years.

By the year 2019, when the active water storage capacity of Muooni Dam will have gone under its threshold, a majority will be obliged to abandon their farming activities and adopt off-farm activities. Some will even embrace small-scale businesses, or jobs in the private and public sectors. The "survivors" will have to sacrifice their short-term benefits by adjusting 
their farming water demands to a "Minimum efficient scale" (MES) of KES 831, 769.3 and 676.7, for LSF, MSF and SSF, respectively. Using the minimum efficient farming water demand (MES), farmers will be able to secure more water than their actual water demand (Actual $W_{f}$ ) and crop water requirements $\left(W_{c}\right)$ (Figure 8). This will allow them mitigate the high risk of crop failures under fluctuating rainfall regimes, particularly under drought.

For efficiency, farmers need to increase their respective actual water demand by at least $42 \%$ to meet their optimal farming water levels under the scenario of ANOR rainfall regime (EOQ ), NOR rainfall regime (LAC) and BNOR rainfall regime (MES), respectively. By so doing, they would expect a fall of their farming water costs up to $36 \%, 78 \%$ and $232 \%$ under the three respective scenarios. Such optimization of their farming water demand would result in a decrease of their operational average costs by a range of $30 \%$ to about $100 \%$. This fall of operational costs would be accompanied by an increase of water productivities due to high farming yields and good incomes under the ANOR rainfall regime, if the EOQ was to be respected. This would allow farmers to meet their crop water requirements and ensure the economic viability of their farming activities in time of water stress and scarcity.

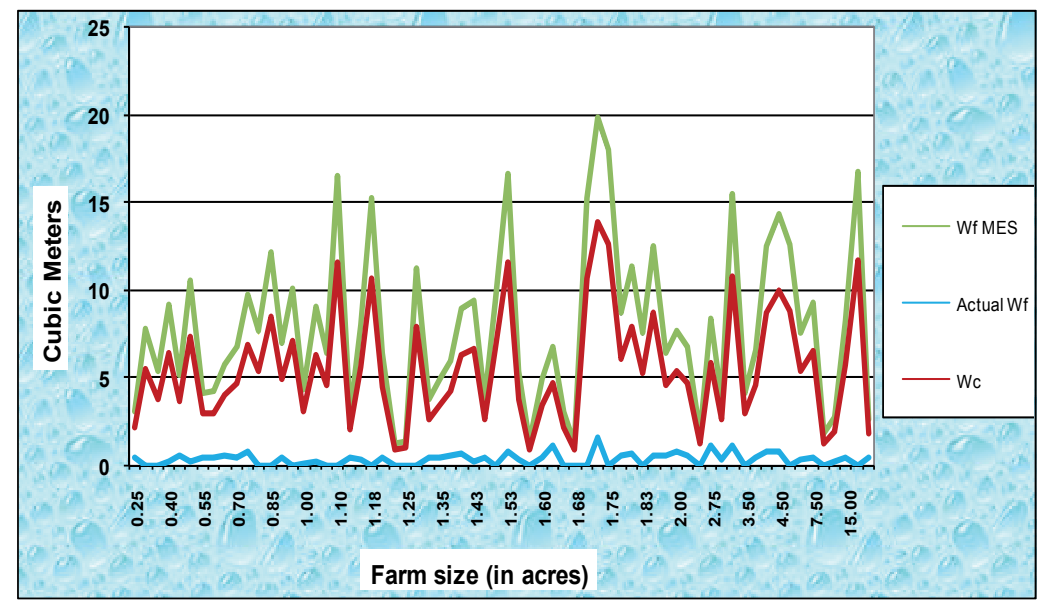

Fig. 8. Minimum farming water demand under rainfall fluctuations

There is not yet a prospect of significant increase of farming yields and incomes under the NOR rainfall regime, and more less under the BNOR scenario, even where the LAC and the MES can be applied with scrutiny. Farmers are particularly expecting a significant decrease of their farming profitability under the BNOR rainfall regime due to farmland subdivisions and poor soil moisture. This soil moisture decrease is particularly attributed to both the change of the catchment microclimate and the global climate change. Therefore, how would farmers ensure the sustainability of their farming efficiency in view of such disasters? The following subsection presents the strategy that farmers need to apply in order to mitigate the high risk of crop failures due to water disasters in the course of climate change.

\subsection{Strategy for water disasters mitigation in farming}

"Water crises are not about too little water but about managing water badly such that billions of people and the environment suffer badly"(Water Vision, 2000, as cited in Mati, 2006). To curve the trend of water stress and scarcity, the Government of Kenya set a major goal of implementing an "Integrated Watershed Management" (IWM). The overall 
implementation of IWM includes the creation of "Water resource users' associations" (WRUAs) in all the catchments to ensure that the "Water resources management authority" (WRMA) implements the new water policy in consultation with the public (GWP, 2000; UNDP, 2007). Talking about such implementation of IWM in Kenya, Förch et al. (2008) suggest that the government speeds up the process by enforcing key regulations of the water sector reforms. These include water quality control, water use allocation and metering, and irrigation schemes and dams coordination. Farmers need to comply with these rules by paying relevant water charges. Nevertheless, they shall factor these water charges in their marginal profit calculations by adopting the right crop type and production method, and by using efficient farming water saving techniques to achieve high profits through "more crops per drop". The authors urge farmers to understand that fees are used to manage the water rationally, up to the end tap, for the benefit of all stakeholders. However, Ellis (1993) firmly encouraged farmers to make some tradeoffs between on-farm and off-farm income-generating activities, if efficiency was to achieve. This meant that they could adopt off-farm activities if their farming water opportunity costs were higher than elsewhere. They would thus avoid running deficient farming enterprises.

Finally, the incremental analysis showed that farmers' efficiency was tied to the adjustment of their crop water requirements with the level of soil moisture. If they could specialize to less than three water friendly crop species for instance, they would improve their productivity (GoK, 2007). Yet, they have also to minimize their farming water costs by using other effective agronomic technologies and efficient on-farm management techniques such as rational crop treatments and selection, and application of improved farming inputs (fertilizers, pesticides, fungicides, and rodenticides). Finally, making good use of hydropolitical strategies in the context of "Integrated Watershed Management" (IWM) will also help them. These include water consumption metering, evapo-transpiration quotas allocation, green water saving and rainwater harvesting, payment for watershed services, virtual water import and etc.

\section{Conclusion}

Traditional soil conservation methods having become rudimentary to control climate change related risks, the Kenyan government needs to support programmes dealing with disaster mitigation and adaptation to climate change. This involves making new adaptation policies and direct investments in water projects, including strategic action plans for dredging dams and irrigation schemes, and designing early warning systems for preparedness to ENSO, among others. But prior to implementation of such policies and schemes, the government needs to conduct a serious risk assessment that encompasses both environmental and socio-economic risks. This study offered a novel approach for achieving sustainability in a watershed and mitigating recurrent water shortages in farming. This hydro-economic risk assessment and management would assist the government to foster the implementation of "Integrated watershed management" (IWM) in different catchments of the country. This would curve the trend of food shortages and energy crises in ASALs. The government shall also encourage public-private partnerships through institutional linkages between the "Water resources management authority" (WRMA), the "Water services providers" (WSP), the "Water resource users' associations" (WRUA) and associations of farmers (Cooperatives, Mutuals, NGOs, CBOs, etc). Thence, the government's task will 
become easier, as farmers strive to improve their farming efficiency in the course of climate change using efficient hydro-political strategies, and innovative agronomic technologies.

\section{References}

Brasington, J., El-Hames, A. \& Richards, K. (1998). Hydrological Modelling In Humid Tropical Catchments. David Harper \& Thomas Brown, Chichester, UK

Brown, L.R. (2001). Eco-Economy: Building an Economy for the Earth. W.W.Norton \& Company Ltd., New York, USA

Burdge, R.J. (2008). The focus of impact assessment (and IAIA) must now shift to global climate change. Environmental Impact Assessment Review, No 28, (2008), pp. 618-622

Ellis, F. (1993). Peasant Economics: Farm Households and Agrarian Development. Cambridge University Press, ISBN 052145711 4, Cambridge, UK

FAO. (ed.).(1995). Planning for Sustainable Use of Land Resources: Towards a New Approach. FAO Land and Water Bulletin, No 2, (1995), pp. 25-46

Förch, G., Winnegge, R. \& Thiemann, S. (2008). DAAD Alumni Summer School 2008: Water Demand in Participatory Watershed Management - Ngaciuma-Kinyaritha Watershed, Kenya - Final Report (Unpublished). Universität Siegen \& Kenyatta University, Meru, Kenya

Ganoulis, J. \& Simpson, L. (2006). Environmental Risk Assessment and Management: Promoting Security in the Middle East and the Mediterranean Region - Report of the Working Group on Environmental Risk Assessment and Management. In: Environmental Security and Environmental Management: The Role of Risk Assessment, B. Morel \& I. Linkov, (eds.), Springer, Dordrecht, The Netherlands

GoK. (2007). Kenya Vision 2030. Retrieved from

<http://www.investmentkenya.com/Documents/Publications/vision_2030_BRO

CHURE_July_2007.pdf>

González, A., Díaz de Terán, J.R., Francés, E. \& Cendrero, A. (1995). The Incorporation of Geomorphological Factors into Environmental Impact Assessment for Master Plans: A Methodological Proposal. In: Geomorphological and Land Management in a Changing Environment, F. Duncan, M. McGregor \& D.A. Thompson, (Eds.), pp. 179193, John Wiley \& Sons, Chichester, UK

GWP. (ed.).(2000): Integrated Water Resources Management. Global Water Partnership TAC, No $4,(2000)$

Hartnady, C. \& Hay, R. (2004). Integrated Water Resource Management (IWRM) and Disaster Reduction. Paper presented during the Africa Regional Consultation on Disaster Reduction Workshop, (2-3 June 2004), Johannesburg, RSA

Jaetzold, R., Schmidt, H., Hornetz, B. \& Shisanya, C. (2007). Farm Management Handbooks of Kenya, Vol. 2, Part C East Kenya, Subpart C1 Eastern Province. Ministry of Agriculture \& GTZ, (eds.), pp. 1-571, Nairobi, Kenya

Jansky, L., M. Haigh \& H. Prasad. (eds.).(2005). Sustainable Management of Headwater Resources: Researches from Africa and India. United Nations University Press, ISBN 92-808-1108-8, Tokyo, Japan

Kitissou, M. (2004). Hydropolitics and Geopolitics: Transforming Conflict and Reshaping Cooperation in Africa. Africa Notes, (Nov-Dec. 2004)

Lal, R. (1993). Agricultural Sustainability and Soil Resilience. Desertification Control Bulletin, No. 23, pp. 26-43 
Luwesi, C.N. (2009). An Evaluation of Efficient Use of Agricultural Watershed Resources under Fluctuating Rainfall Regimes at Muooni Dam Catchment, Machakos District, Kenya. Masters' Thesis (Unpublished). Kenyatta University, School of Pure and Applied Sciences, Nairobi, Kenya

Luwesi, C.N. (2010). Hydro-Economic Inventory in a Changing Environment - An Assessment of the Efficiency of Farming Water Demand under Fluctuating Rainfall Regimes in Semi-Arid Lands of South-East Kenya. Lambert Academic Publishing AG \& CO.KG, ISBN 978-3-8433-7607-5, Saarbrüken, Germany

Mati, B. (2006). Regional Perspective of Green Water Management. In: ISRIC First Green Water Credits Workshop, ISRIC - World Soil Information,(ed.). Retrieved from <http://www.isric.org/UK/About+ISRIC/Projects/Current+Projects/Green+Wat er+Credits.htm>saving and rainwater harvesting

Morgan, R.P.C. (1995). Soil Erosion and Conservation. Longman Group, Essex, UK

Mutisya, D. (1997). Socio-Economic and Agronomic Factors Influencing Soil Erosion in the Masinga Dam Catchment. PhD Thesis (Unpublished). Kenyatta University, Faculty of Arts, Nairobi, Kenya

Shakya NM (2001). Impact of Forest Clearing on Hydrology: Mathematical Modelling of Khageri River Mathematical modelling of Khageri River. In: Ecohydrology, V. Subramanian \& A. Ramanathan, (eds.), pp. 355-368, Capital Publishing Company, New Delhi, India

Shisanya, C.A. (1996). Chances and Risks of Maize and Bean Growing in the Semi-Arid Areas of SE Kenya during Expected Deficient, Normal and Above Normal Rainfall of the Short Rainy Seasons. Materialien zur Ostafrika-Forschung, Heft 14, ISBN 3-921-599-19-9, Trier, Germany

Shisanya, C.A. \& Khayesi, M. (2007). How is Climate Change Perceived in Relation to Other Socio-Economic and Environmental Threats in Nairobi, Kenya. Journal of Climate Change, Vol. 85 (2007), pp. 271-284

Soilerosion.net. (2007). Water Erosion and Rainsplash Redistribution. Retrieved from $<$ http://www.soilerosion.net/doc/water_erosion.html>

Tiffen, M., Mortimore, M. \& Gichuki, F. (1994). More People Less Erosion: Environmental Recovery in Kenya. ACTS Press, Nairobi, Kenya

Thompson, D.A. \& Scoging, H.M. (1995). Agricultural Terrace Degradation in South-East Spain: Modelling and Management Strategies". In: Geomorphological and Land Management in a Changing Environment, F. Duncan, M. McGregor \& D.A. Thompson, (eds.), pp. 153-175, John Wiley \& Sons, Chichester, UK

Uitto, J.I. \& Schneider, J. (1997). Freshwater Resources in Arid Lands. United Nations University Press, ISBN 92-808-0982-8, Tokyo, Japan

UNDP. (2007). Integrated Water Resources Management Plans. Retrieved from $<$ http://www.undp.org/mdg/>

Vishnudas S. (2006). Sustainable Watershed Management: Illusion or Reality? A Case of Kerala State, India. Eburon Academic Publishers, ISBN-10: 90-5972-154-3, Delf , The Netherlands

Waswa, P.F. (2006). “Opportunities and Challenges for Sustainable Agricultural Land Management in Kenya". In: Environment and sustainable development: A guide for higher education in Kenya, Vol. 1, F. Waswa, S. Otor \& D. Mugendi, (eds.), Kenyatta 
University, School of Environmental Studies \& Humaine Sciences, ISBN 9966-77634-6, Nairobi, Kenya

World Bank. (2007). Water Topics: Monitoring and Evaluation. Retrieved from <http://www.worldbank.org/html/fpd/water/topics/m\&e.html>

WRMA. (2008). Athi Water Resources Management Authority Report on Muooni Dam (Unpublished). Machakos, Kenya.

Zeiller, M. (2000). Methods of Socio-Economic Analysis of Rural Development. Universität Göttingen, Institute of Rural Development, Göttingen. Retrieved from <http://www.childinfo.org/files/chap06.pdf> 


\title{
Generation of Added Values Products Supporting Risk Analysis
}

\author{
Massimo Musacchio et al. ${ }^{*}$ \\ Istituto Nazionale di Geofisica e Vulcanologia, Rome \\ Italy
}

\section{Introduction}

Active volcanoes are spread all over the world and are located in specific areas correlated to geologic structures. In the last 10,000 years more than 1300 volcanoes have erupted, but only half of the eruptions have been reported in historical texts. It has been estimated that every year 50 volcanic eruption may occur threating about $10 \%$ of the worldwide population. Considering the constant increase in human population and that many major cities are placed in the proximity of active volcanoes, the number of people subjected to the risks caused by volcanic eruptions is also increasing. Stated the problem dimension, it shall be defined the method to counter act the crisis scenario. A volcanic eruption can be faced under different point of view, on one side it can be deeply studied in order to improve the knowledge of geophysical mechanism which drives the eruption itself, on the other hand it is important to set up a service based on the integration of different dataset and aimed to deliver added values products toward whose are in charge to manage the risk associated. One response to last sentence is the Sistema Rischio Vulcanico (ASI-SRV) project funded by the Italian Space Agency (ASI) in the frame of the National Space Plan 2003-2005 under the Earth Observations section for natural risks management. The ASI-SRV Project is coordinated by the Istituto Nazionale di Geofisica e Vulcanologia (INGV) which is responsible, in Iyaly, at national level for the volcanic monitoring. The main goal of the ASISRV project is to define, develop and demonstrate tools and products, based on the integration Earth Observation data (EO) with data coming from the ground monitoring network developed at national and local level, to support the risk management decision procedures. The project philosophy is to implement, by incremental versions, specific modules which allow to process, store and visualize through a dedicated Web-GIS tools, added value information derived by EO and No EO data.

\footnotetext{
* Malvina Silvestri ${ }^{1}$, Luca Merucci ${ }^{1}$, Stefano Corradini ${ }^{1}$, Claudia Spinetti ${ }^{1}$, Valerio Lombardo ${ }^{1}$, Boris Behncke$^{1}$, Lorenzo Guerrieri ${ }^{3}$, Gabriele Gangale ${ }^{3}$, Fabrizia Buongiorno ${ }^{1}$, Sergio Perelli², Sergio Teggi ${ }^{3}$, Sergio Pugnaghi ${ }^{3}$, Angelo Amodio ${ }^{4}$, Eugenio Sansosti ${ }^{5}$, Simona Zoffoli ${ }^{6}$ and Chiara Cardaci ${ }^{7}$

IIstituto Nazionale di Geofisica e Vulcanologia, Rome, Italy

${ }^{2}$ Advanced Computer System S.p.A, Rome

3Università degli Studi di Modena e Reggio Emilia, Modena, ${ }^{4}$ Galileian plus, via Vito Giuseppe Galati Rome,

${ }^{5}$ Istituto per il Rilevamento Elettromagnetico dell'Ambiente-CNR, Naples,

${ }^{6}$ Agenzia Spaziale Italiana, Agenzia Spaziale Italiana, Rome

${ }^{7}$ Dipartimento della Protezione Civile Rome, Italy
} 


\section{Rationale and goals}

The "Volcanic Risk System (ASI-SRV)" is a three year (2007-2010) project, funded by the Italian Space Agency (ASI), aimed at defining, developing and demonstrating (at a preoperational stage) a set of functionalities in support of a decisional system for volcanic risk management based on the use of Earth Observation (EO) data. Moreover, this pilot project supports research activities to fill in the gaps between the user needs and the available technology. The Civil Protection organism represents the National Authority which will get benefit from the space technology derived products for Volcanic Risk management and monitoring. During the project lifetime a great effort was dedicated to understand the organization of Department of the Civil Protection (DPC) in order to get specific requirements for services and products to be developed in this pre-operational project taking into account that the DPC is a division of the Italian Presidenza del Consiglio dei Ministri, and represents the national authority charged for civil protection activity; It addresses and coordinates all the forces operating on the Italian territory, during the emergency phases through the National warning system provided by DCP and Regions by the Functional Centres National Network. The main purpose of CFRV is to collect, share and synthesize data related to volcanic hazard provided by the monitoring centres (e.g. INGV). Functional Centres are the operative support units, which are able to collect, elaborate and exchange every kind of data provided from Competence Centres. These are Institutions which provide services, information, data, elaboration, technical and scientific contributions for specific topics.

During the volcanic emergency phases the functional centres for volcanic risk is supported by Synthesis Group. This group includes volcanologist of the High Risks Committee, the researchers of Competence Centre involved in the monitoring activities and a civil protection manager/officer expert in the risk evaluation. The Office "General Direction of Prevision, Evaluation, Prevention and Mitigation of Natural Risks" takes part in many European projects and participated in civil protection interventions in foreign countries. Operative Centre for Volcanic Risk is the scientific decision-support section of the DPC. For that reasons the End User is the Italian Department for Civil Protection (DPC).

The ASI-SRV system and products have been defined through a detailed User requirement survey that has been started in the Feasibility Study, funded by ASI in 2004 and integrated with information acquired in other project such as FP6-PREVIEW (2005-2008). The system architecture is based on different modules that could be activated depending of the Volcanic Phase (figure 1) addressed by the Italian Civil Protection Department (DPC):

- $\quad$ Early Warning (Knowledge and Prevention)

- Crisis

- Post-Crisis

Moreover the system is able to add new modules in order to have the flexibility to improve its performance by using new algorithms or new sensors. ASI-SRV has developed, in its final version, a centralized HW-SW system located at INGV which will control two complete processing chains, one located at INGV for Optical data, and the other located at CNR-IREA for SAR data. The produced results will be disseminated through a Web-GIS interface which will hallow the End User to overview and assimilate the products in a compatible format respect to local monitoring needs in order to have an immediate use of the provided information. 


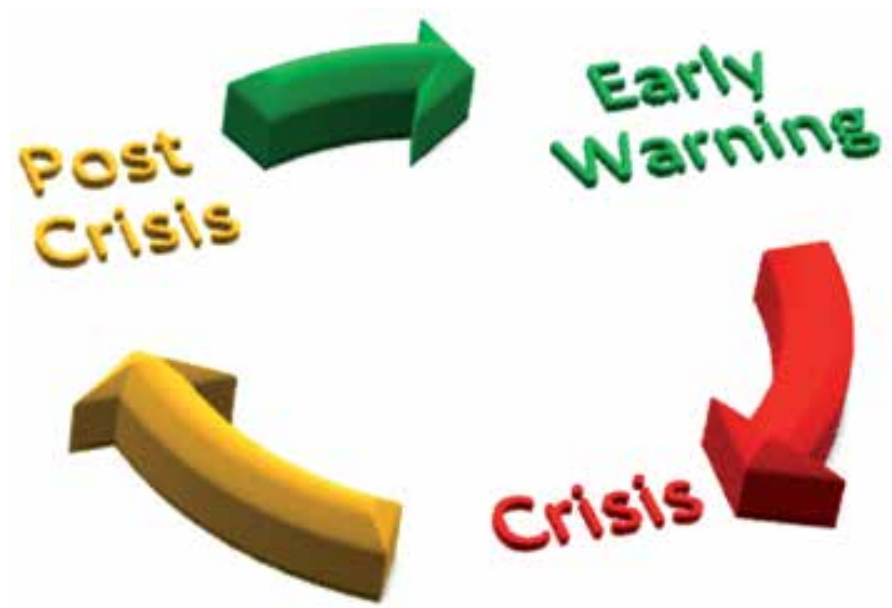

Fig. 1. Synthetic risk cycle diagram

The ASI-SRV project has developed data processing modules dedicated to the generation of specific products meeting the user needs and to the dissemination of the information by means of dedicated Web-GIS. ASI-SRV system provides the capability to manage the import many different EO data into the system, it maintains a repository where the acquired data are stored and generates selected products which are functional to the phases described above. All technical choices and development of ASI-SRV are based on flexible and scalable modules which will take into account also the new coming space sensors, new processing algorithms considering the national and international scenario in the space technologies. An important step of the project development regards the technical and scientific feasibility of the provided products. In fact the technical feasibility depends on the data availability, accuracy algorithms and models used in the processing and of course the possibility to validate the results by means of comparison with other independent measurements (EO and non-EO). Archived series and near real time (NRT) acquisition of EO optical and radar data are used to derive information on surface and plume characteristics building the knowledge for the two volcanic systems composing the test sites, respectively Etna and Vesuvio Campi Flegrei. Considering the different type of volcanic activities characterizing the investigated volcanic complexes, different stacks of products type are necessary to the User considering also the product feasibility. Each product is generated by a specific modules based on algorithm developed by the researcher during last decade. All these modules can process in parallel EO optical data generating huge volume of products to be stored in the ASI-SRV main database, building a very long catalogue of geophysical parameters suitable for back analysis but also for better understand a complicate natural system as a volcano is. The generated and delivered products are divided according to the following paradigm: before a crisis, in order to recognize small variation of any geophysical parameter, high spatial resolution sensors have to be used, whilst during a crisis, in order to daily follow the ongoing eruption, sensors characterized by multi-acquisition per day are necessary. According to the sentence stated above the following products with respect to the test site have been chosen and generated:

Moreover the system is able to add new modules in order to have the flexibility to improve its performance by using new algorithms or new sensors. ASI-SRV has developed, in its final version, a centralized HW-SW system located at INGV which will control two complete processing chains, one located at INGV for Optical data, and the other located at 
CNR-IREA for SAR data. The produced results will be disseminated through a Web-GIS interface which will hallow the End User to overview and assimilate the products in a compatible format respect to local monitoring needs in order to have an immediate use of the provided information.

\begin{tabular}{|c|c|c|}
\hline Phase & Product & Test Site \\
\hline \multirow[t]{4}{*}{ Early Warning } & Multi-parametric Analysis & $\begin{array}{l}\text { Mt.Etna, Vesuvio - Campi } \\
\text { Flegrei }\end{array}$ \\
\hline & $\begin{array}{l}\text { Ground deformation velocity map and } \\
\text { time series based on radar data }\end{array}$ & $\begin{array}{c}\text { Mt.Etna and Vesuvio - Campi } \\
\text { Flegrei }\end{array}$ \\
\hline & $\begin{array}{l}\text { Temperature Map, } \\
\text { Thermal Flux }\end{array}$ & Mt.Etna, Campi Flegrei \\
\hline & $\begin{array}{c}\text { SO2 Columnar, } \\
\text { Water Vapour Columnar Content, } \\
\text { AOT Concentration map }\end{array}$ & Mt.Etna \\
\hline \multirow[t]{4}{*}{ Crisis } & Deformation Map based on radar data & Mt.Etna \\
\hline & $\begin{array}{l}\text { Ground deformation velocity map and } \\
\text { time series based on radar data }\end{array}$ & Mt.Etna \\
\hline & $\begin{array}{l}\text { Temperature Map, } \\
\text { Thermal Flux } \\
\text { Effusion Rate }\end{array}$ & Mt.Etna \\
\hline & $\begin{array}{l}\text { SO2 Columnar Content and flux, } \\
\text { Water Vapour Columnar Content, } \\
\text { AOT Concentration map }\end{array}$ & Mt.Etna \\
\hline \multirow[t]{3}{*}{ Post Crisis } & $\begin{array}{l}\text { Ground deformation velocity map and } \\
\text { time series based on radar data }\end{array}$ & $\begin{array}{c}\text { Mt.Etna and Vesuvio - Campi } \\
\text { Flegrei }\end{array}$ \\
\hline & Lava thickness & Mt.Etna \\
\hline & $\begin{array}{l}\text { Ash distribution map } \\
\text { Lava distribution map }\end{array}$ & Mt. Etna \\
\hline
\end{tabular}

Table 1. List of the products generated and delivered within ASI-SRV project. The background color is coherent with the risk phase indicating in figure 1

Moreover the system is able to add new modules in order to have the flexibility to improve its performance by using new algorithms or new sensors. ASI-SRV has developed, in its final version, a centralized HW-SW system located at INGV which will control two complete processing chains, one located at INGV for Optical data, and the other located at CNR-IREA for SAR data. The produced results will be disseminated through a Web-GIS interface which will hallow the End User to overview and assimilate the products in a compatible format respect to local monitoring needs in order to have an immediate use of the provided information. 


\section{Processing chain}

The ASI-SRV system has been thought as a semi-automatic system able to operate in unsupervised mode for all the modules where the human interaction is useless. It doesn't imply that the scientists role is negligible on the contrary this method will allow to gain time to spent in the processing and validation processes.

These "unsupervised" modules concern the automatic calibration, georeferencing, mosaiking, atmospheric and topographic correction. These modules start with the radiometric calibration, cut and mosaiking and atmospheric correction tool [1,2] and after the core data processes represented by scientific algorithm dedicated to the extraction of added value products and end with the publication of the vector layer via GIS Tool Analyst (GTA) via a dedicated MMI. The selected products (table 1) after the feasibility study have been transformed to functional requirements of the system. On the base of the functional requirements the system will have the following main sub-systems (Figure 2)

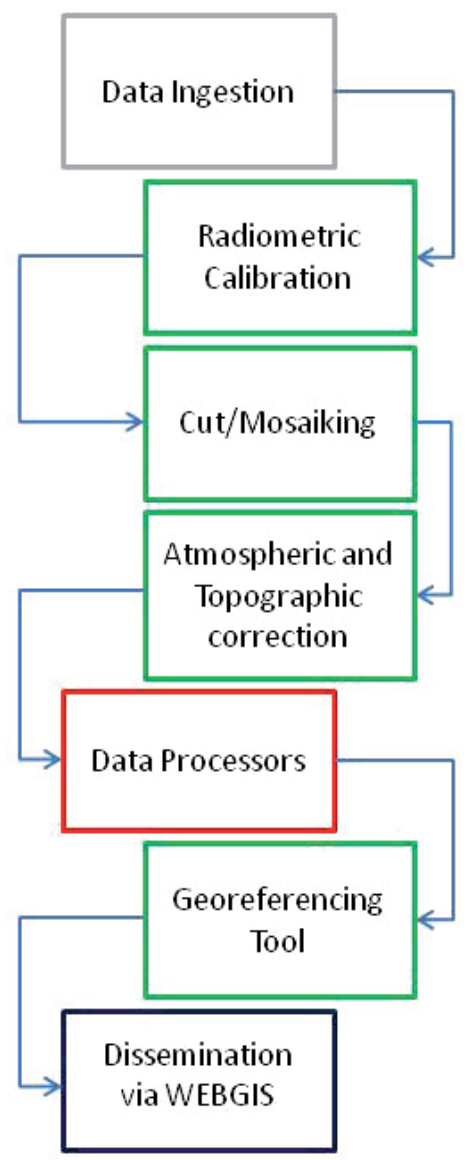

Fig. 2. ASI-SRV end to end processing flow; green boxes contain "general purposes" module (which are remote sensed data independent), red boxe contains the core of the ASI-SRV system (module based on the integration of scientific alghorithm), dark blue box represents the Web-GIS interface. 
All data are ingested into ASI-SRV system and are available to the processing functionality installed into main ASI-SRV Infrastructure. This system has been developed enabling the ingestion of different EO data sensors that can be processed contemporaneously. This processing chain requires that the ASI-SRV system is able to run in parallel allocating more than one parallel instances. One of the aim of the GP modules is to prepare the EO data in a specific file format including all attributes needed by each different processors and then the publication of the results. Considering that ASI-SRV architecture is based on a distributed and scalable client/server architecture this imply that different processors need to ingest data set characterized by a constant and common structure.

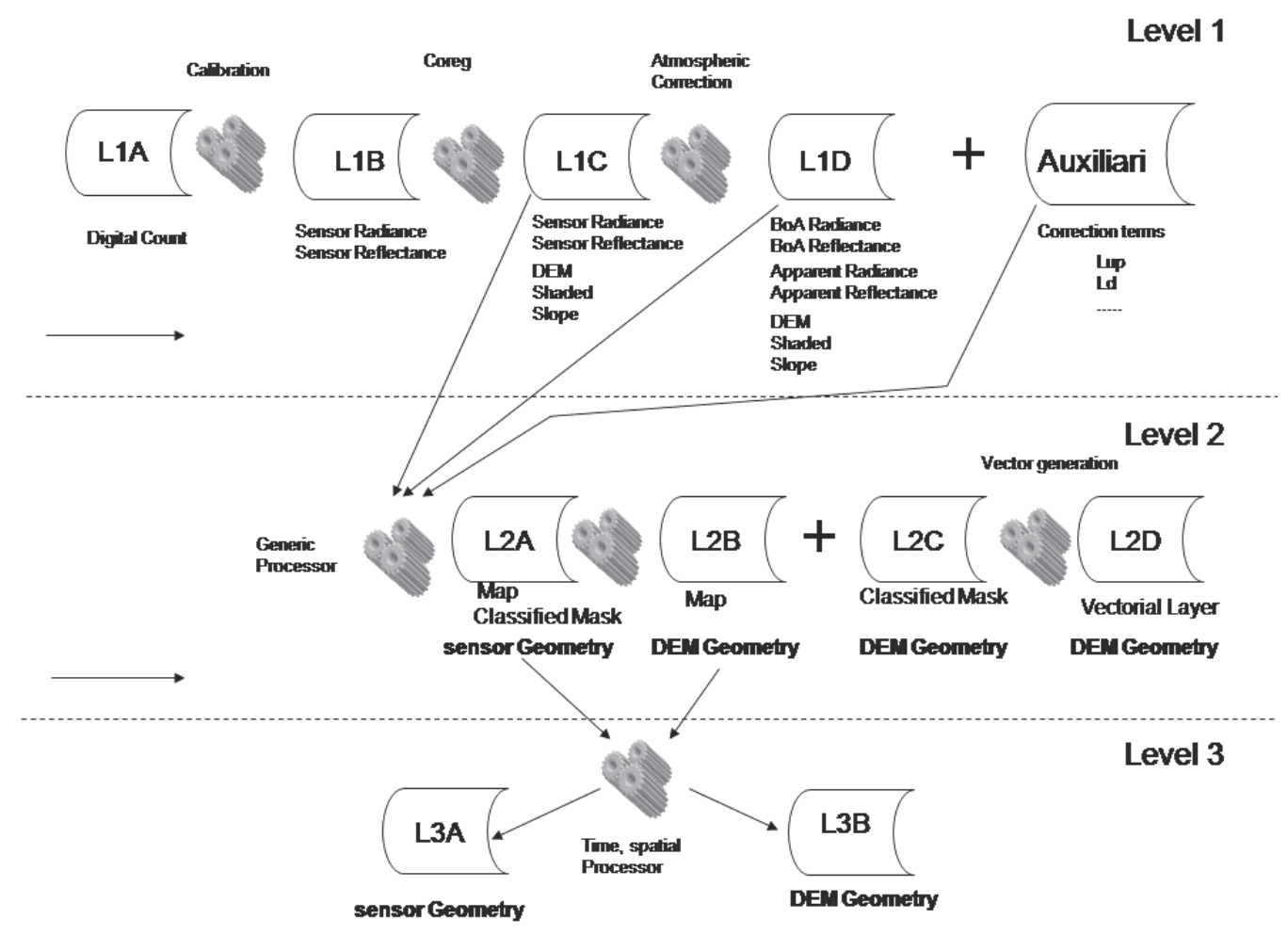

Fig. 3. ASI-SRV production chain. The General Purpose modules are dedictaed to the production of all Level 1 dataset

The ASI-SRV production chain produce three level of product and the GP module is dedicated to the generation of all the L1 and to the L2D products (Figure 3). In the ASI-SRV project the EO data used have been classified with different level depending on the information contained. The level definition of processing is inspired to the CEOS standard (1992) with few differences. The definitions are the following:

- Level 1A: ingested data derived from the spaceborne. They do not contain information on calibration

- Level 1B calibrated data containing radiance/reflectance measured at the sensor

- Level 1C spatial resizing on the geographical windows; on these data DEM, Shaded Relief, Slope and Aspect are contained 
- Level 1D equivalent to 1C level but containing the bottom of atmosphere radiance/reflectance and the apparent reflectance obtained using coefficients computed by atmospheric correction module

- Level 2A raster products; they contains geographical variables in the sensor geometry. Typically they can be divided in: :

- A-1 containing the output derived from the processor module (i.e. map with results of algorithm implemented in the processing module)

- A-2 containing the classified results according to criteria defined by the responsible of processing module

- $\quad$ Level 2B raster products equal to 2A-1 products projected in DEM geometry

- Level 2C raster products equal to 2A-2 products projected in DEM geometry

- Level 2D products in vector format (lines, curves, points) obtained using level 2C products

- Level 3 products obtained combining two or more products of level 2 resampled/processed in the space and time.

According to this level of classification each different step is represented by an HDF file format containing increased scientific dataset (Figure 3) with respect to the former.

\section{Test sites}

According to the necessity of the Users and with the objectives of demonstrate the suitability of the defined products three different test sites have been chosen, two test sites are located in the Napoli Bay area (Mt. Vesuvius volcano and the Campi Flegrei Caldera) and one in Sicily, near Catania (Mt. Etna) (Figure 4). Those areas are characterized by different volcanic activity and surface phenomena enabling the capability to analyze the geophysical parameters useful to investigate the pre-crisis (early warning) the crisis and post crisis phases.

These three test sites have been selected by considering the present state of the volcanic activity and therefore ensure the demonstration of the selected products for each phase (Early Warning, Crisis and Post Crisis). Moreover second parameter used to selected the test areas has been the observability by space of the different volcanic phenomena. Mt. Etna volcano is characterized by an almost persistent volcanic activity, allowing the generation of products related to the sin-eruptive and post-eruptive phase. For this volcano it is possible to provide products also if no eruptive events have occurred, using EO data acquired during the eruptive events in the last years. Vesuvio and Campi Flegrei volcanoes are representative to quiescent phase products analysis, especially regarding the surface deformation map. Moreover the sites selection is compatible with the spatial resolution of EO operative systems and the frequent monitoring with ground networks permits the system to validate and integrate $\mathrm{EO}$ products

\section{Etna test site}

Mount Etna is Europe's largest volcano (its volume is at least $350 \mathrm{~km} 3$ ), and one of the most active (in the sense of "productive" and eruption frequency) volcanoes on Earth, with frequent periods of intermittent to persistent activity in the summit area and major eruptions from new vents on its flanks every 1-20 years. The main feature of Etnean activity is voluminous lava emission, but strong explosive activity occurs occasionally, mostly from its presently four summit craters. Some of the eruptions from its flanks also show high 
degrees of explosivity, such as those in 1669, 1879, and 2002-2003. Etna lies near the eastern (Ionian) coast of Sicily and occupies a surface area of around $1200 \mathrm{~km} 2$ with a perimeter exceeding $135 \mathrm{~km}$. Its summit height varies frequently in function of eruptive activity or minor collapse events at the summit craters: through the early 1980s it showed a net increase by nearly $100 \mathrm{~m}$ to an unprecedented $3350 \mathrm{~m}$ in 1981 . This growth was concentrated at the Northeast Crater, a feature that was born in 1911; nearly constant activity at this crater since the mid-1950s lead to the growth of a large cone around it. Activity of the Northeast Crater became rather infrequent since the mid-1980s, and since then the height of its cone has decreased to $3330 \mathrm{~m}$ as of 2007. The cone of the youngest of the four summit craters, the Southeast Crater, which was born in 1971, underwent a period of dramatic growth between 1998 and 2001 but remained 40 lower than the highest point at the summit, the Northeast Crater. Etna is particular for a number of reasons. First, it has the longest record of historical eruptions (see Volcanoes of the World, 1994 edition) among all volcanoes on this planet, its first historically documented eruption occurring at about $1500 \mathrm{BC}$. The total number of eruptions is 209 (18 among them questionable) through late 1993 (Volcanoes of the World). To these, there have now to be added the spectacular and vigorous summit eruptions of 1995-2001, the flank eruptions of 2001, 2002-2003, 2004-2005, and 2008-2009, plus a period of intermittent summit activity in 2006-2008. Certainly we will not have to wait long to add yet more eruptions, either at the summit or somewhere on the flanks, to this impressive record.

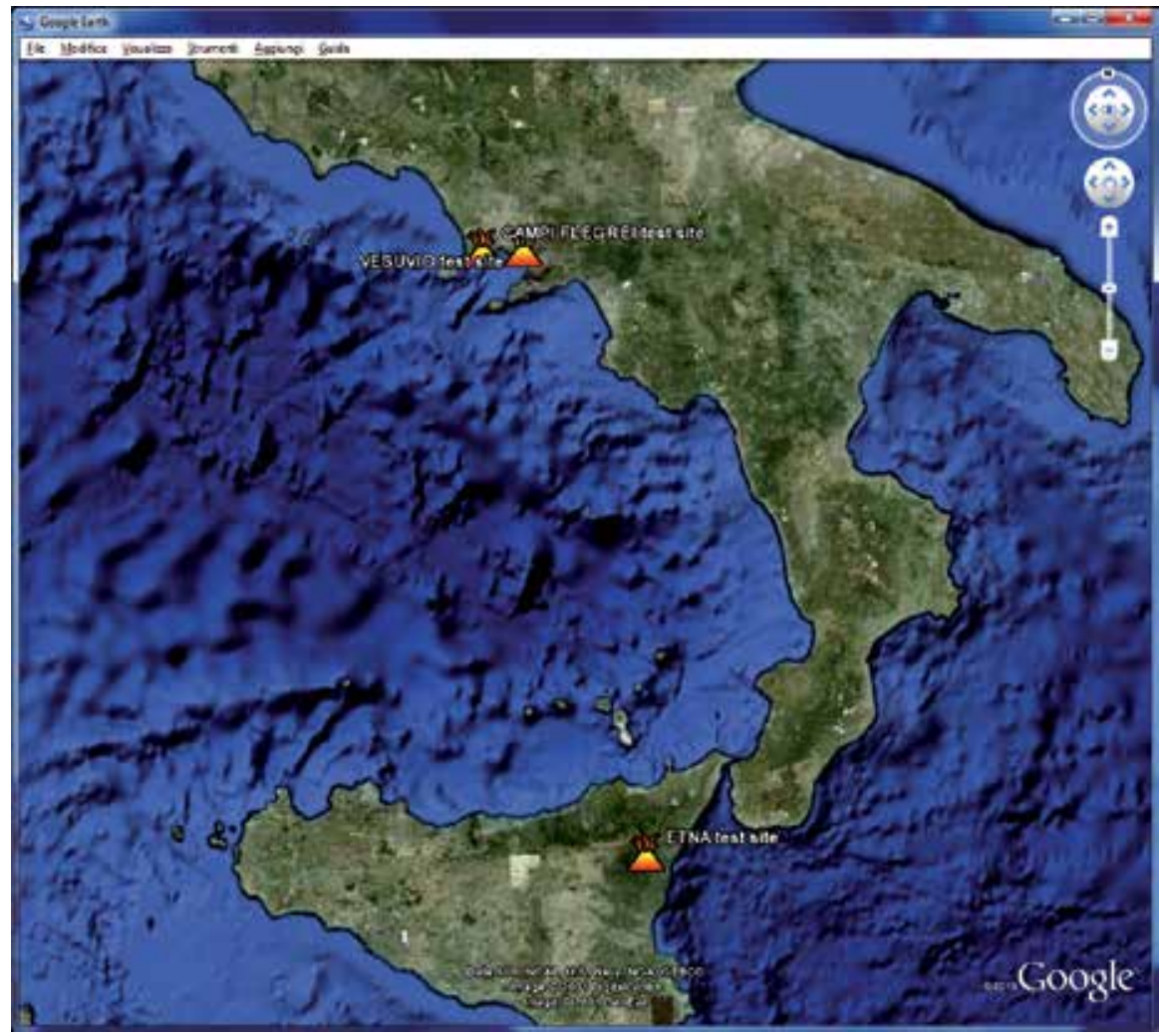

Fig. 4. Localization of the project test sites, from North to South Campi Flegrei, Veuvio and Etna respectivel (from Google Earth) 
Etna lies in an area that is still not well understood from a geological standpoint. While some scientists relate, in a broader sense, the Etnean volcanism to subduction of the Ionian oceanic seafloor beneath the Calabrian Arc (with volcanism on the Aeolian Islands as one consequence), others postulate a hot spot beneath Etna, thus explaining its high lava production and fluid mafic magmas. Still another hypothesis sees Etna in a complex rifting environment, due to the inhomogeneous nature of convergence between the African and Eurasian plates with subduction of the oceanic Ionian sea floor underneath the Calabrian Arc, and much lower convergence rates on Sicily where both colliding margins are continental lithosphere. Among the few things which are quite well understood is the fact that the volcano lies at the intersection of several major regional fault systems, and this probably facilitates the uprise of magma right in this place. It is evident that Etna lies in a very complex geodynamic environment hardly comparable to any other region on Earth. There is some evidence that Etna is but the most recent manifestation of volcanism fed from a very long-lived mantle source, having caused numerous earlier phases of mafic volcanism in the Monti Iblei, SE Sicily, from the late Triassic to the early Pleistocene.

The geological history of Mount Etna.

Mount Etna is a large basaltic composite volcano lying near the eastern coast of Sicily, in a complex geodynamic environment characterized by the collision of the African and Eurasian continental lithospheric plates. This setting contains numerous faults, including the distensive Malta-Iblei escarpment, an important structural boundary between the continental lithosphere of Sicily and the oceanic lithosphere of the Ionian sea floor. Volcanism in the area has been continuing episodically for more than 230 million years, first in the Monti Iblei, in the southeast portion of Sicily, on the foreland of the African plate promontory, and, during the past half million years, in the Etnean area.

The geological history of Etna is subdivided into four main periods (Branca et al., 2004).

a. Basal Tholeiites

The start of eruptive activity has been dated at about 500,000 years, during the midPleistocene. At that time the current Etna area was occupied by a broad bay corresponding to the sedimentation base of the foredeep, and the first eruptions took place under the sea. The products of this phase of activity occur in outcrops in the area of Acicastello, Ficarazzi, and Acitrezza on the Ionian coast to the north of Catania, forming intercalations in foredeep sediments represented by grayish-blue clays of the lower to mid Pleistocene. The most famous of these outcrops is the castle rock of Acicastello, which is composed of pillow lavas and associated hyaloclastite (pillow breccias). These originally submarine products have been subjected to isostatic uplift.

b. The Timpe phase

From no less than 220,000 years ago until about 110,000 years ago, volcanic activity concentrated along the Ionian coast along a fault system known as the "Timpe" (the steps), which represents the northern continuation of the Malta-Iblei escarpment (Azzaro, 1999). The Timpe faults are marked by conspicuous morphological scarps, and terminate to the NNW near Moscarello and Sant'Alfio. During this phase, numerous fissure eruptions occurred in this relatively restricted elongate belt along the Ionian coast, and led to the growth of a NNW-SSE elongated shield volcano about $15 \mathrm{~km}$ long. The internal structure of this shield volcano is today exposed in the Timpe fault scarps between Acireale and Moscarello. During this eruptive period, sporadic volcanism also occurred along the valley of the Simeto river, constructing, amongst others, the large 
scoria cone that constitutes the hill of Paternò and a number of thin, strongly eroded, lava flows like those cropping out in the northern periphery of Catania at LeugatiaFasano.

c. Valle del Bove eruptive centers

About 110,000 years ago, the focus of volcanism shifted from the Ionian coast into the area now occupied by the Valle del Bove. In this period, the character of Etna's activity underwent a profound change, from sporadic fissure eruptions as during the first two phases, to a more centralized activity of both effusive and explosive character. This activity led to the construction of the first composite volcanic edifices in the Etna region, the Rocche and Tarderia volcanoes. The products of these eruptive centers crop out along the base of the southern flank of the Valle del Bove at Tarderia and Monte Cicirello. Subsequently, the activity concentrated in the southeastern sector of the Valle del Bove, at Piano del Trifoglietto, where the main eruptive center of this phase was built up, Trifoglietto volcano, which reached a maximum elevation of about $2400 \mathrm{~m}$. Three minor eruptive centers formed subsequently on the flanks of Trifoglietto, which are named Giannicola, Salifizio and Cuvigghiuni; their activity continued until about 60,000 years ago. This phase marks the formation of a stratovolcano structure in the Etna edifice and the superposition of different eruptive centers.

d. Stratovolcano phase

About 60,000 years ago, a further shift in the focus of eruptive activity toward northwest marks the end of the Valle del Bove centers, and the start of the building of the largest eruptive center of Etna, now named Ellittico (the elliptical), which constitutes the main structure of the volcano. The Ellittico volcano produced intense effusive and explosive activity, constructing a large edifice, whose summit may have reached a height of 3600-3800 m. Numerous flank eruptions generated lava flows that reached the Simeto river valley to the west of Etna. About 25,000 years ago, the Alcantara river was deviated from its former valley closer to Etna (in correspondence with the towns of Linguaglossa and Piedimonte Etneo) into the present-day Alcantara valley (Branca, 2003). Much of the Ellittico lavas and pyroclastics are present in outcrops in the northern wall of the Valle del Bove. The Ellittico stage ended about 15,000 years ago with a series of powerful explosive (Plinian) eruptions (Coltelli et al., 2000), which destroyed the summit of the volcano leaving a caldera about $4 \mathrm{~km}$ in diameter. Intense eruptive activity continued during the past 15,000 years, largely filling the Ellittico caldera, and building up a new summit cone. This current summit edifice is called Mongibello. About 9000 years ago, a portion of the upper east flank of Etna underwent gravitational collapse, generating a catastrophic landslide (the Milo debris avalanche), and forming the huge collapse depression of the Valle del Bove, which still today bites deeply into the eastern sector of the volcano (Calvari et al., 2004). Following the Valle del Bove sector collapse, remobilization of the debris avalanche deposit by alluvial processes led to the generation of a detritic-alluvional deposit, known as Chiancone, which crops out between Pozzillo and Riposto along the Ionian coast. This huge collapse of the eastern flank of the Mongibello edifice has exposed a large portion of the internal structure of both the Valle del Bove eruptive centers and of the Ellittico volcano, which crop out in the walls of the depression. The eruptive activity of the Mongibello is strongly controlled by structures of weakness in the volcanic edifice, where most intrusions occur along a number of main trends. These are characterized by three main rift zones, the NE, $S$ and $W$ rift zones. Although much of 
the activity of the Mongibello volcano is effusive, numerous strongly explosive events are known as well, mostly from the summit craters. The most powerful eruption of this eruptive phase occurred in historical time, in 122 B.C. (Coltelli et al., 1998). This eruption, which occurred from the summit of the volcano, produced a large volume of pyroclastics (ash and lapilli), which fell in a sector on the southeast flank of the volcano, causing heavy damage in the city of Catania.

\section{Vesuvio test site}

Vesuvio (Vesuvius) is probably the most famous volcano on Earth, and certainly one of the most, if not the most dangerous. It is also notable for having produced the first eruption of which an eyewitness account is preserved, in AD 79. Geologically, Vesuvio is particular for its unusual versatility, its activity ranging from Hawaiian-style emission of very liquid lava, fountaining and lava lakes, over Strombolian and Vulcanian activity to violently explosive, Plinian events that produce pyroclastic flows and surges. These different eruptive styles are due to changes in the magma compositions but also to magma-water interaction (phreatomagmatic activity). Certainly the most notable aspect of Vesuvio's eminence among Earth's volcanoes is the dense population surrounding it and climbing higher and higher up its slopes. More than half a million people live in a near-continuous belt of towns and villages around the volcano, in the zone immediately threatened by future eruptions. The situation is still more peculiar as Vesuvio is not the only volcano looming above that area and its people - there is, on the other side of the city of Napoli (Naples), the caldera of Campi Flegrei, renowned for some cataclysmic ash-flow forming eruptions in the all-toorecent geologic past and signs of unrest during the past three decades. There is also the historically active volcanic complex of Ischia, not threatening to Vesuvio inhabitants but to those on Ischia island itself. Pyroclastic deposits laid down by past eruptions of Vesuvio continue to be mobilized during heavy rainfalls and can develop into catastrophic debris flows such as those of May 1998, which killed more than 150 people in the Sarno area. To complete this ensemble of geologic hazards, the area forms the nucleus of a much vaster zone that is seismically vulnerable; its most recent disastrous earthquake, on 23 November 1980, killed more than 3,000 people.

Three types of eruption are generally distinguished in the modern literature:

a. Plinian (AD 79, Pompeii type) events with widespread airfall and major pyroclastic surges and flows;

b. sub-Plinian to Plinian, more moderately sized eruptions (AD 472, 1631) with heavy tephra falls around the volcano and pyroclastic flows and surges;

c. small to medium-sized, Strombolian to Vulcanian eruptions (numerous events during the 1631-1944 cycle, such as 1906 and 1944) with local heavy tephra falls and major lava flows and small pyroclastic avalanches restricted to the active cone itself.

To these three types there should be added a fourth one, though it is of the smallest dimensions of all eruption types observed at Vesuvio. It is the persistent Strombolian to Hawaiian style eruption that characterizes almost all of an eruptive sub-cycle (see below), such as was the case during the period 1913-1944. Activity of this kind is mainly restricted to the central crater where one or more intracrateral cones form, and to the flanks of the cone. Lava flows from the summit crater or from subterminal vents may extend beyond the cone's base. A somewhat particular kind of persistent activity is the slow effusion of large volumes of lava from subterminal fractures to form thick piles of lava with little lateral extension, such as the lava cupola of Colle Umberto, formed in 1895-1899. 


\section{Campi Flegrei test site}

The name "Campi Flegrei" itself - "burning fields", derived from Latin and Greek words indicates that the volcanic nature of the area has been well known since antiquity. Campi Flegrei is a volcano that you will not easily recognize at first sight when looking at it from the ground. It is a caldera, a vast volcanic collapse depression, formed during possibly more than one cataclysmic explosive eruptions, which blanketed extensive areas in the Campania region with thick deposits, mainly laid down by ground-hugging currents of gas and fragmented volcanic rocks known as pyroclastic flows. The caldera has a relatively flat floor dotted with a number of low younger volcanic features, which are mostly broad cones (tuff cones), explosion craters, and other minor features. None of these evokes the classical image of a volcano, although each one of them bears testimony to violent volcanic events in the not-too-distant past. Campi Flegrei may not look very much like a classical volcano, but it is among the most dangerous volcanoes on Earth. The highest point is barely $458 \mathrm{~m}$ above sea level (a portion of the caldera rim), and it largest cone, Monte Gauro, rises to a height of 331 $\mathrm{m}$. Yet, while Vesuvius enjoys a status of being maybe the most famous volcano worldwide, and very much everybody knows it is close to the city of Naples, much less people know there is another volcano on the other (western) side of the megacity, and that actually a significant portion of Naples stands within the caldera of Campi Flegrei, besides the town of Pozzuoli and numerous smaller population centers. The caldera has a diameter of approximately $14 \times 16 \mathrm{~km}$, and shows two nested rims that are poorly defined on most sides of the volcanic complex, but instead are conspicuous on its eastern margin, where they intersect the urban area of Naples. The origin of the caldera is still subject to debate - it certainly is related to a voluminous explosive eruption about $15 \mathrm{ka}$ (thousands of years) ago, the so-called Neapolitan Yellow Tuff (NYT) eruption, whereas scientists disagree whether it has also been the site of the much more voluminous "Campanian Ignimbrite" eruption about $40 \mathrm{ka}$ ago. Approximately 70 smaller eruptions have occurred since the $12 \mathrm{ka}$ Campanian Ignimbrite eruption, including a few dozen only during the past 4000 years. The latest eruptions, in historical time, occurred in 1198 (possibly a minor steam-blast explosion at the Solfatara) and 1538, when the small cone of Monte Nuovo (the "new mountain") was built up. Although in the past 3800 years volcanism has been at a low level - the only known events being the 1198 and 1538 eruptions - the Campi Flegrei system remains highly dynamic and restless. Long-term vertical movement of the caldera floor, that is, uplift alternating with subsidence, has been observed since antiquity, and sometimes been punctuated by episodes of accelerated uplift. Rapid uplift preceded the 1538 Monte Nuovo eruption, and occurred again during two well-documented episodes in 1969-1972 and 19821984, without culminating in renewed volcanism - thus far. These latest episodes of unrest, which were accompanied by increased seismic activity, have triggered intense studies of the Campi Flegrei volcanism and related hazards. At present (2011), the Campi Flegrei volcano shows relatively low levels of unrest, although minor episodes of ground uplift and slightly elevated seismic activity have occurred repeatedly since the end of the most recent major crisis in the mid-1980s. However, in a recent publication Isaia et al. (2004) note that about 4000 years ago a series of 15 eruptions occurred during an interval of 150 years, sometimes simultaneously in the western and eastern portions of the caldera. They furthermore found evidence for several tens of meters of ground uplift in the caldera prior to this intense eruptive period and speculate that the renewed unrest observed since 1969 might be a precursor of similar activity in the future. 


\section{ASI-SRV pre-operative processors}

The efforts to satisfy the requests for operative support expressed by the Italian DPC by means of spaceborne and airborne image data is at the base of all technical design and development of ASI-SRV by producing a system concept based on flexible modules which are needed to take into account the new coming space sensors, new processing algorithms and Web-GIS interfaces considering the national and international scenario in the space technologies. Starting from the modular approach the system should be able to produce all the requested in formation relative to the volcanic activity phases corresponding to the end user operative protocols which are:

1. Early Warning: it identify and measure variations in the state of the volcanic area before the eruption

2. Crisis: it support organizations involved in the management of emergency situations in order to activate the planned procedures in the case of a possible emergency in the volcanic areas

3. Post Crisis: it analysis of effects produced by the eruption

The Project has included a long and continuous demonstration phase during which time series for all the EO data, both optical and radar have been systematically used to generate upgraded added values product as soon as a new acquisition is available. Considering that an important step of the project development regarded the technical and scientific feasibility of the selected products a technical feasibility has been executed highlighting the dependencies from the data availability (in terms of spectral channel, satellite revisit time, accuracy algorithms and models used in the processing).

The algorithms selected for the EO processing modules have been analyzed during the last decade and have the following characteristics:

- Robust with a well proved scientific background

- High Adaptability to new space sensor

- Portability into an integrates system

- The algorithms were developed in house (INGV, CNR-IREA, University of Modena and Reggio Emilia) which ensure the possibility to upgrade the procedures and adapt them to ASI-SRV system

- Products partially tested in other Projects or INGV surveillance Procedures

- $\quad$ Suitability of the generated products for the selected test sites

In general two classes of products are generated respectively concerning radar and optical remote sensed data. A first important class of products regard the characteristics derived by active sensors such as the deformation maps retrieved by SAR interferometry which is based on consolidated techniques [Lanari et al. 2004], and the accuracy has been analyzed in the past years. Moreover the selected test sites have well developed GPS network that ensure a suitable validation for the SAR maps produced by the system. Nevertheless the usability of the deformation maps in the Crisis Phase (Sin-eruptive) is restricted by the low revisit time of the current systems. Within the ASI-SRV project since the availability of new mission (eg. COSMO-SKYMED) the improvement of the revisit time as well as the ground resolution of SAR systems in a prototype procedures have been developed and tested. A second class of product regards the analysis products derived by passive sensors. The available algorithms allow to extract information, such as the surface thermal characteristics, during both the Early Warning phase and during the Crisis phase, In the Early Warning phase the thermal analysis is directed to the identification of temperature variation on 
volcanic structure which may indicate a change in the volcanic activity state [Realmuto , 1990]. The feasibility of this product depends from the availability of bands the TIR region and from the accuracy of the atmospheric corrections applied to the images. A major operative limitation for this product is the very low spatial resolution in the TIR channels for space sensors with an high revisit time $(>1 \mathrm{~km}$ pixel). At the moment the only sensor that present good technical characteristics for the Early Warning is the ASTER sensor $(90 \mathrm{~m}$ pixel) on NASA satellite TERRA, the lack of future missions with high spatial resolution in the TIR region may prevent an effective support in the early warning phase of volcanic activity by space sensors. The product regarding the Crisis stage is mainly finalized to the estimation of the effusion rate for active lava flows, the algorithms for this product are well consolidated and could be applied to the low spatial resolution space sensors (eg. AVHRR, MODIS, MSG) [Lombardo et al. 2004]. Moreover the analysis of the emitted gas species from degassing plume is usually performed trough ground networks of instruments based on the spectral behaviour of the gas species, although many volcanoes in the world do not have such permanent networks. The ASI-SRV system will produce information on the concentration and flux of sulphur dioxide (SO2) [Realmuto et al., 1994] water vapour and volcanic aerosol optical thickness [Spinetti et al., 2003] by means of ASTER, MODIS and HYPERION data on Etna test site. The analysis of ash clouds will be made by means of already consolidated procedures [Searcy et al., 1998, Corradini et al., 2006, Constantine et al., 1999] which uses low spatial resolution sensors with an high revisit time (eg. AVHRR, MODIS). For the Post Crisis phase the required products will be obtained through classification algorithms and spectral analysis.

\subsection{ASI-SRV: Early warning phase products}

\subsubsection{Ground deformation analysis using SAR time series}

The algorithm selected for ground deformation analysis via the use of SAR data is the Small BAseline Subset (SBAS) approach described in details in Berardino et al., 2002 and Lanari et al., 2004. This algorithm has the unique capability to work at both low and full spatial resolution scales. While full resolution scale has an impact in monitoring single structures (which are generally not visible at the larger spatial scale), it has been demonstrated in the literature that the low spatial resolution scale results (100 m pixel spacing) are well suited to characterize and monitor volcanic phenomena (Figure 5). This has the big advantage of reducing the amount of data to be handled, thus making the whole processing chain more efficient with respect to the full resolution one. The achievable accuracy has also been extensively tested by comparison with classical geodetic measurements (levelling, continuous GPS, alignment arrays, etc.). For a typical data set of 40-50 ESA SAR images in a time span of 10 years the calculated accuracies are generally lower than: $2 \mathrm{~mm} /$ year on the mean velocity and $10 \mathrm{~mm}$ on the ground deformation time series; more details can be found in Lanari et al., 2007 and Casu et al., 2006.

\subsubsection{Surface temperature, emissivity and thermal flux}

The surface temperature and emissivity processing module gives as output result the surface temperature map and the spectral emissivity image. The spectral radiance emitted by a body having a kinetic temperature Ts can be expressed as a function of the spectral emissivity $\varepsilon$ of its surface and of the Plank function B:

$$
L\left(\lambda, T_{s}\right)=\varepsilon(\lambda) \cdot B\left(\lambda, T_{s}\right)
$$




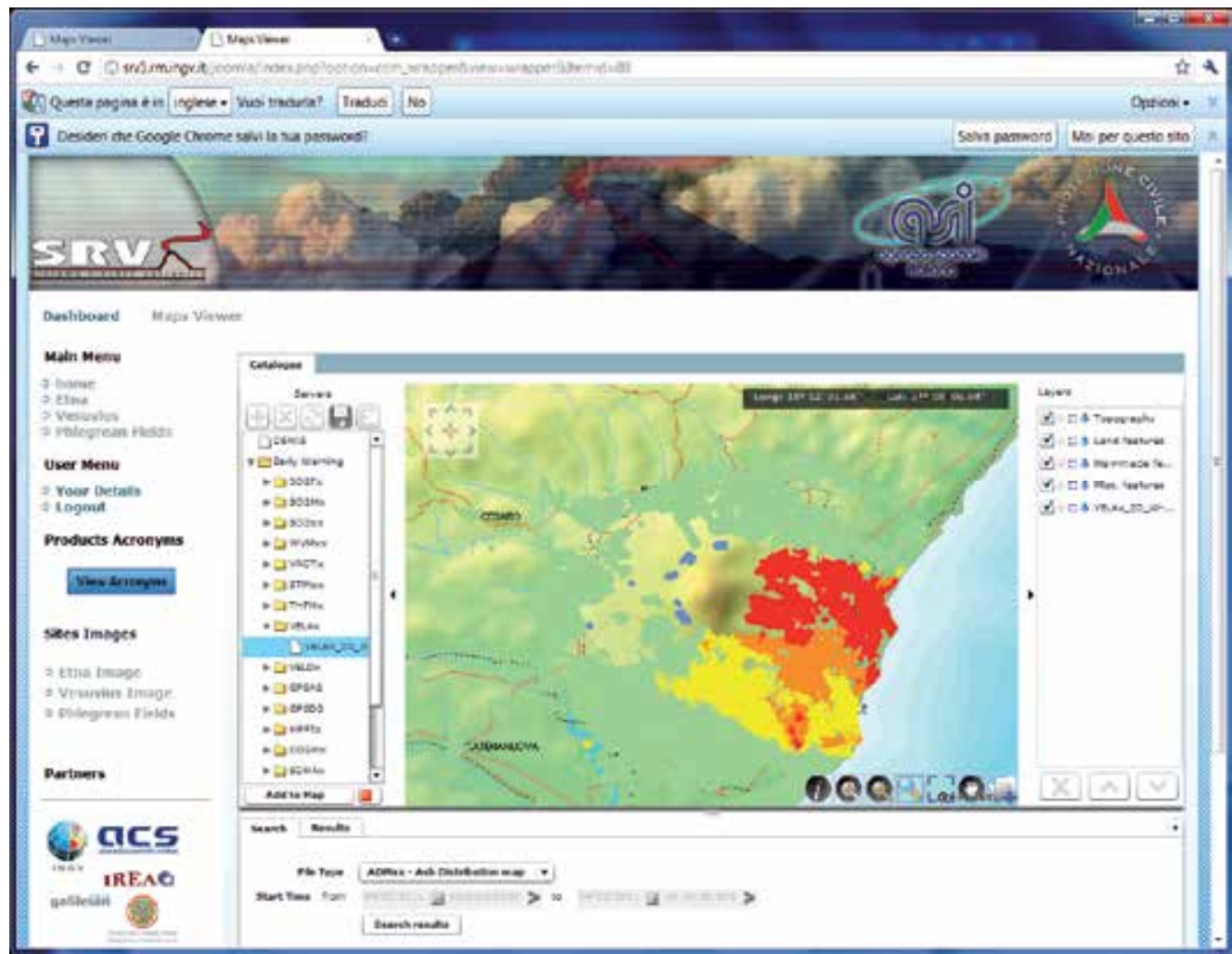

Fig. 5. Example of ground deformation product that is provided for all test sites and for both orbit (ascending and descending)

If the radiance $\mathrm{L}$ is measured at $\mathrm{N}$ wavelengths $\lambda$, the relation is expressed by a system of $\mathrm{N}$ equations with $\mathrm{N}+1$ unknowns, i.e. the $\mathrm{N}$ values of spectral emissivity and the temperature. This makes difficult the estimation of surface temperature and emissivity from remote sensing data because the equation system is not closed. In the literature, different "nonexact" solutions are given to this problem, called Temperature and Emissivity Separation (TES). Details of the different algorithms that have been proposed so far are discussed in [Gillespie, 1998, ; Li et al., 1999]. In this project we use the TES algorithm [Gillespie, 1998] and where not possible the well established method of the Emissivity Spectrum Normalization (ESN) [Gillespie, 1985; Realmuto, 1990]. These methods are robust and have demonstrated a good capability to maintain the spectrum shape, that is the most important feature in applications of spectral analysis and mapping.

During the monitoring and early warning phases the thermal flux can be estimated from ASTER images. Input to the module are the surface temperature and emissivity retrieved by the TES module and the output is the estimated thermal flux map.

The surface temperature and emissivity retrieved by means of the TES module allow the estimate of the surface emitted thermal flux and the production of the related maps. The radiant flux Qrad emitted by a surface element of area A at given temperature and emissivity is

$$
\text { Qrad }=\varepsilon \sigma \mathrm{AT}^{4}
$$


where $\sigma$ is the Stefan-Boltzmann constant. Inputs to the module that estimates the thermal flux are thus the TES module surface temperature and emissivity, while the output is the Qrad image. (Figure 6)

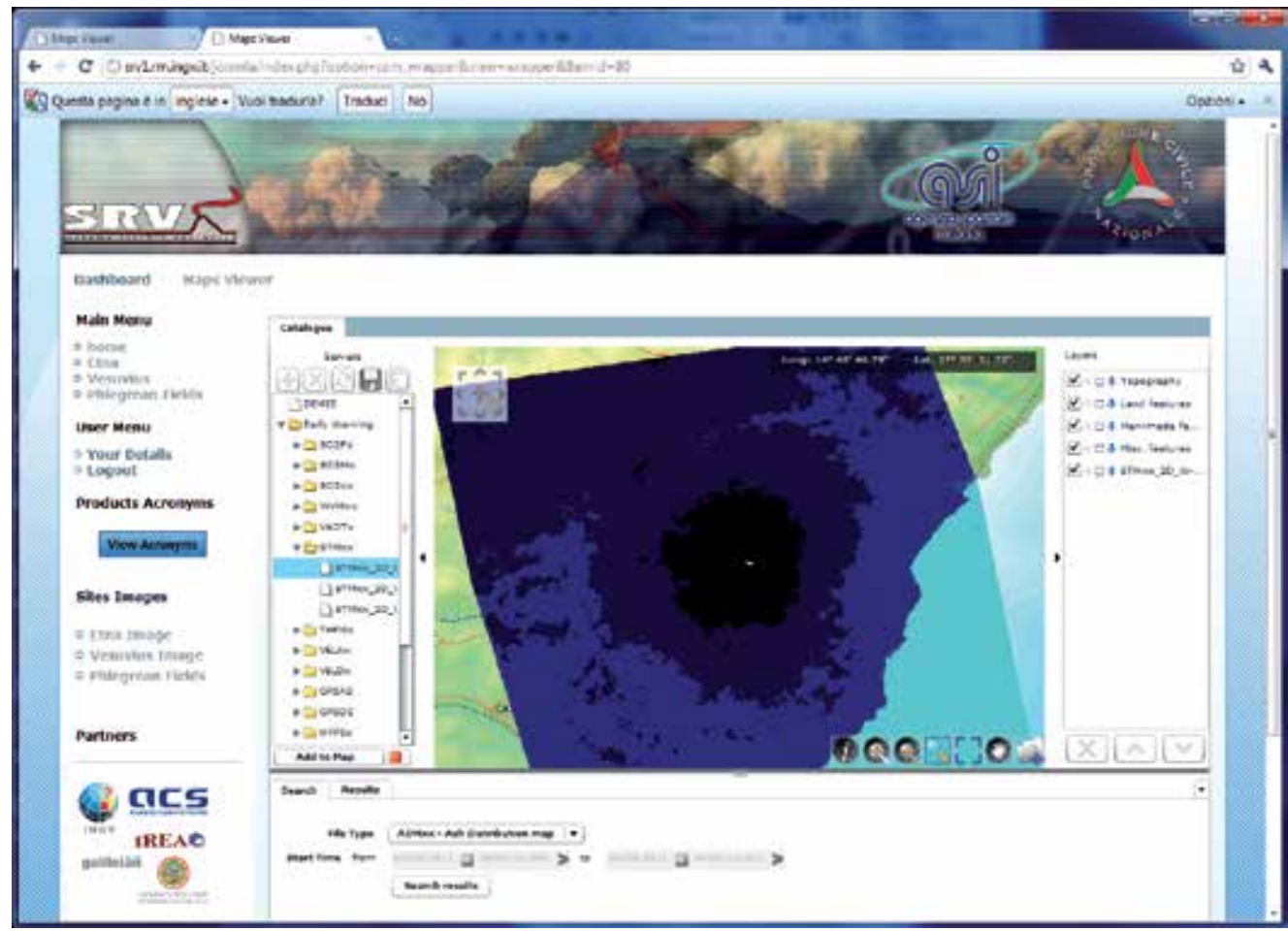

Fig. 6. Example of surface temperature product. It can be obtained by ASTER (nightime in figure) by MODIS and AVHRR.

\subsubsection{VAOT Volcanic aerosol optical thickness estimation}

The VAOT has been developed at INGV [Spinetti et al., 2003, Spinetti et al., 2004, Spinetti and Buongiorno 2007], and represents the first algorithm that has been developed following the theoretical basis of atmospheric aerosol estimated from space, published by [Kaufman 1997] Purpose of this algorithm is the estimation of the volcanic aerosol optical thickness (AOT) during the prevention and early warning phase therefore VAOT technique has been used in ASI-SRV to estimate AOT at medium-high resolution in early warning phase. The algorithm to estimate the AOT parameter is based on the inversion of the radiative transfer equation using the $6 \mathrm{~S}$ [Vermote 1997] radiative transfer code. (Figure 7)

\subsubsection{Water vapour estimation}

The used algorithm to estimate the volcanic water vapour in a volcanic plume has been developed at INGV [Spinetti et al., 2003, Spinetti et al., 2004]. This has been developed on the well consolidated theoretical basis of atmospheric water vapour estimation published by [Carrere and Conel, 1993]. Purpose of this algorithm, which is based on the fitting of the simulated radiance to the effectively one measured, is the estimation of the volcanic plume 
water vapour.. The band used is the $1130 \mathrm{~nm}$ as the $940 \mathrm{~nm}$ band shows a problem in overlapping signals. (Fig. 1)

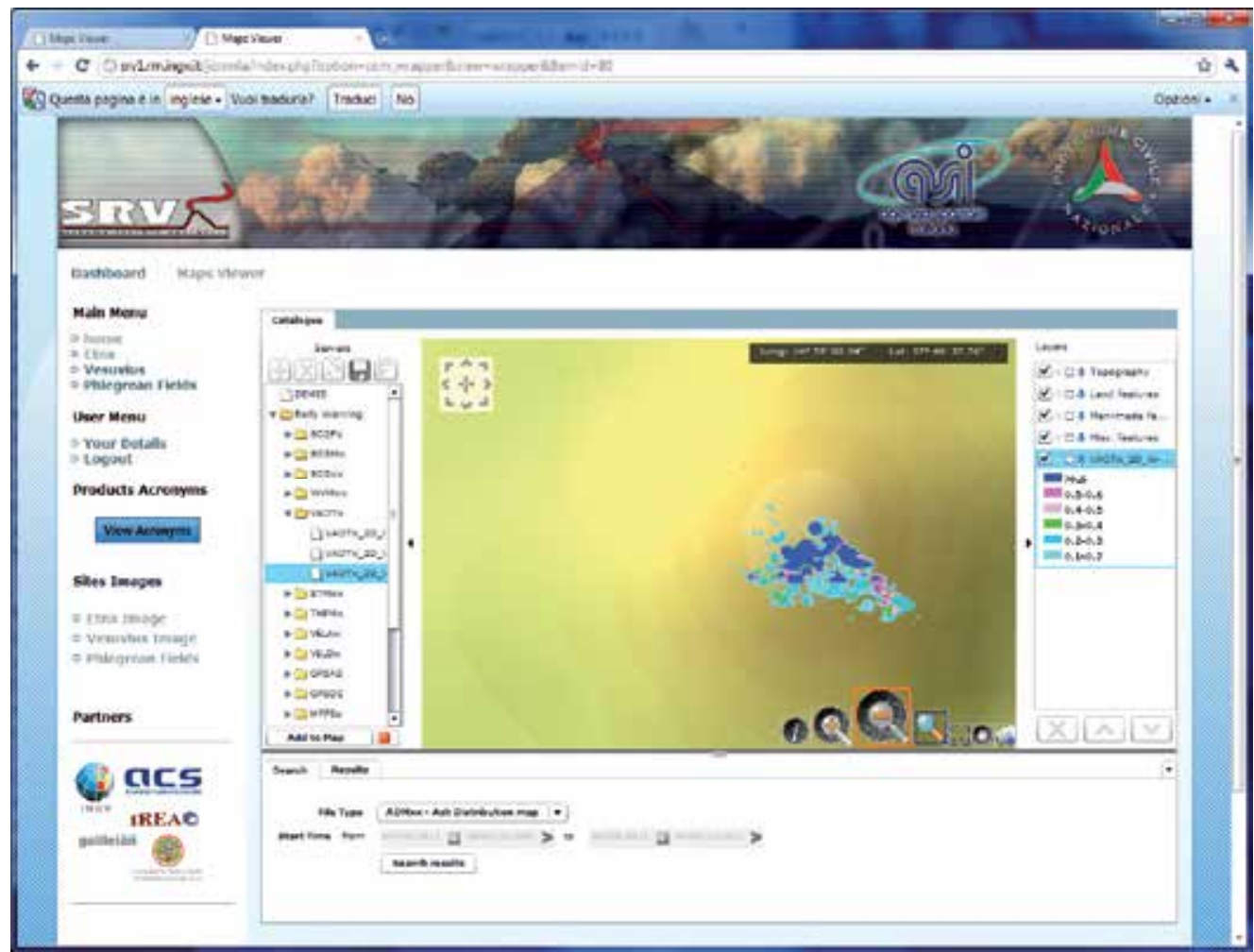

Fig. 7. Example of aerosol optical depth provided by means of official gateway. During early warning phase this prodcut is generated by high spatial resolution sensor

\subsection{ASI-SRV sin eruption phase}

\subsubsection{SAR deformation map production using interferogram couple module}

For measuring ground deformations during sin-eruptive phase, the ASI-SRV will use the Two-Pass interferometric process (Zebker \& Goldstein, 1986; Massonet \& Feigl 1998). This choice allows measuring ground deformations by using a single SAR image pairs, provided by any SAR sensor. This approach does not require minimum critical dimension of the number of images in the database and, furthermore, allows using SAR data provided from different sensors (e.g. ENVISAT, RADARSAT, etc.). The only constraint in applying this method is to have a good correlation between the image pairs. (Fig. 2)

\subsubsection{Thermal flux and effusion rate computation modules}

For the estimation of the Effusion Rate the dual band algorithm has been implemented. The dual-band technique allows a realistic estimate of the energy flux radiated from active lava flows and fumaroles [Pieri et al., 1990, Wright et al., 2000]. The thermal model for active lava flows considers the thermal flux as a function of the fractional area of two thermally distinct radiant surfaces. Within this model, the larger surface area corresponds to the cooler crust of 
the flow and the other, a much smaller area, to fractures in the crust. These cracks are at much higher temperatures then the crust and are closer to the temperature of the molten or plastic flow interior. Interior temperatures for active lava flows are typically about a factor 2-4 higher than that of the crust [Calvari et al., 1994, Flynn et al., 1993]. The dual-band method requires two distinct SWIR bands $(\alpha$ and $\beta$ ) to formulate a system of two equations from the simultaneous solution of the Planck equation in each band. Solution of these simultaneous equations allows calculation of the 'sub-pixel' coverage and temperature of the crusted and hot components. The dual-band general formula is written as:

$$
\begin{aligned}
& \operatorname{Rad} \alpha=\text { fh }(\operatorname{Rh} \alpha)+(1-\mathrm{fh}) \operatorname{Rc} \alpha \\
& \operatorname{Rad} \beta=\text { fh }(\operatorname{Rh} \beta)+(1-\mathrm{fh}) \operatorname{Rc} \beta
\end{aligned}
$$

where $\operatorname{Rad} \alpha$ and $\operatorname{Rad} \beta$ are respectively the total radiance detected by the sensor in band $\alpha$ and $\beta, R h x$ is the radiance of the hot crack component in band $x(x=\alpha$ or $\beta$ in our case), Rcx is the radiance of the cooler crust component in band $x$ and fh is the fractional area of the pixel with hottest temperature Th. Following [Oppenheimer, 1991, Harris et al., 1998, Flynn et al., 2000] we can solve the system by assuming a value for $\mathrm{Th}$, to obtain values for the two unknowns.

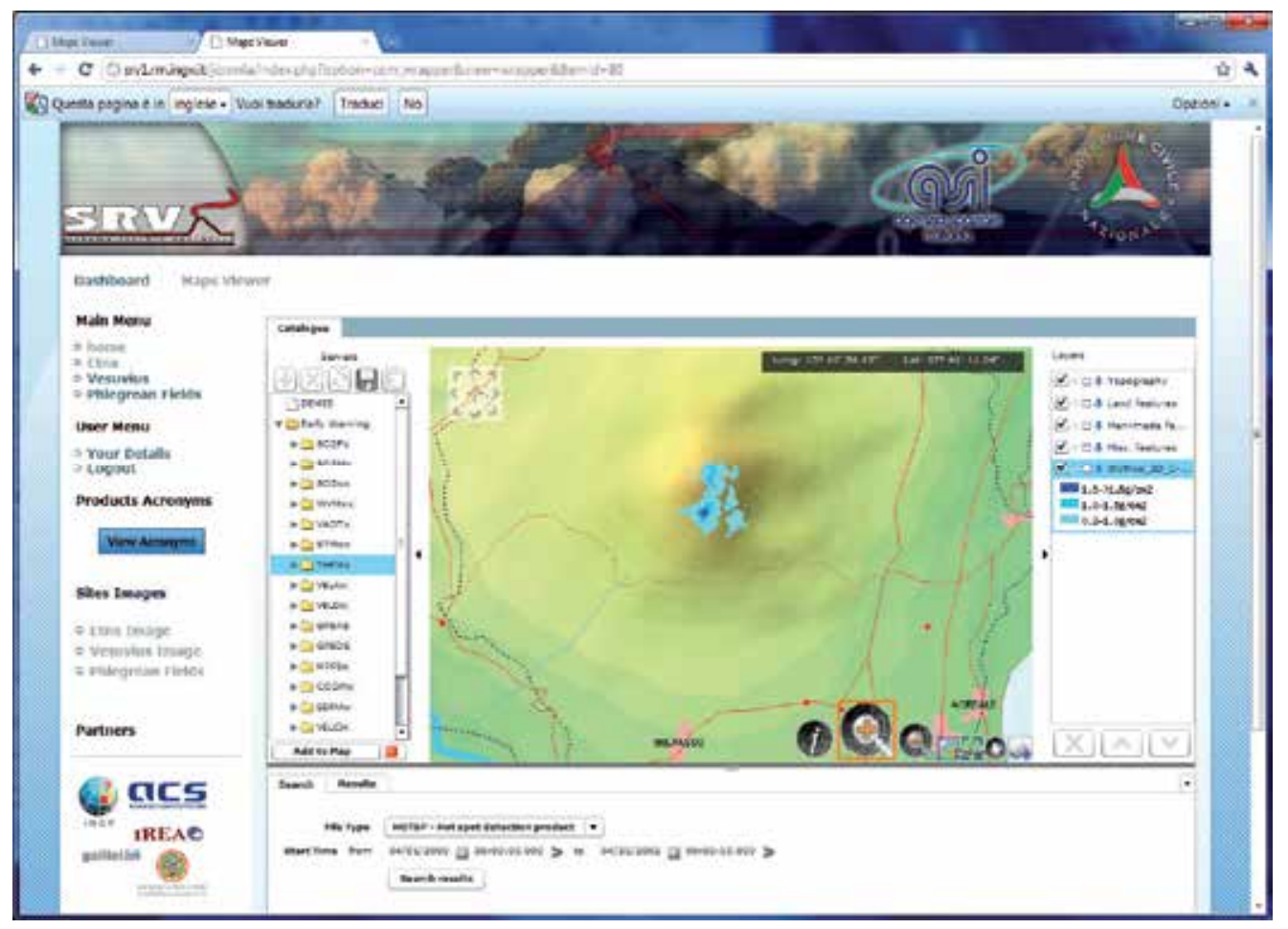

Fig. 1. Example of water vapour content provided by means of official gateway 


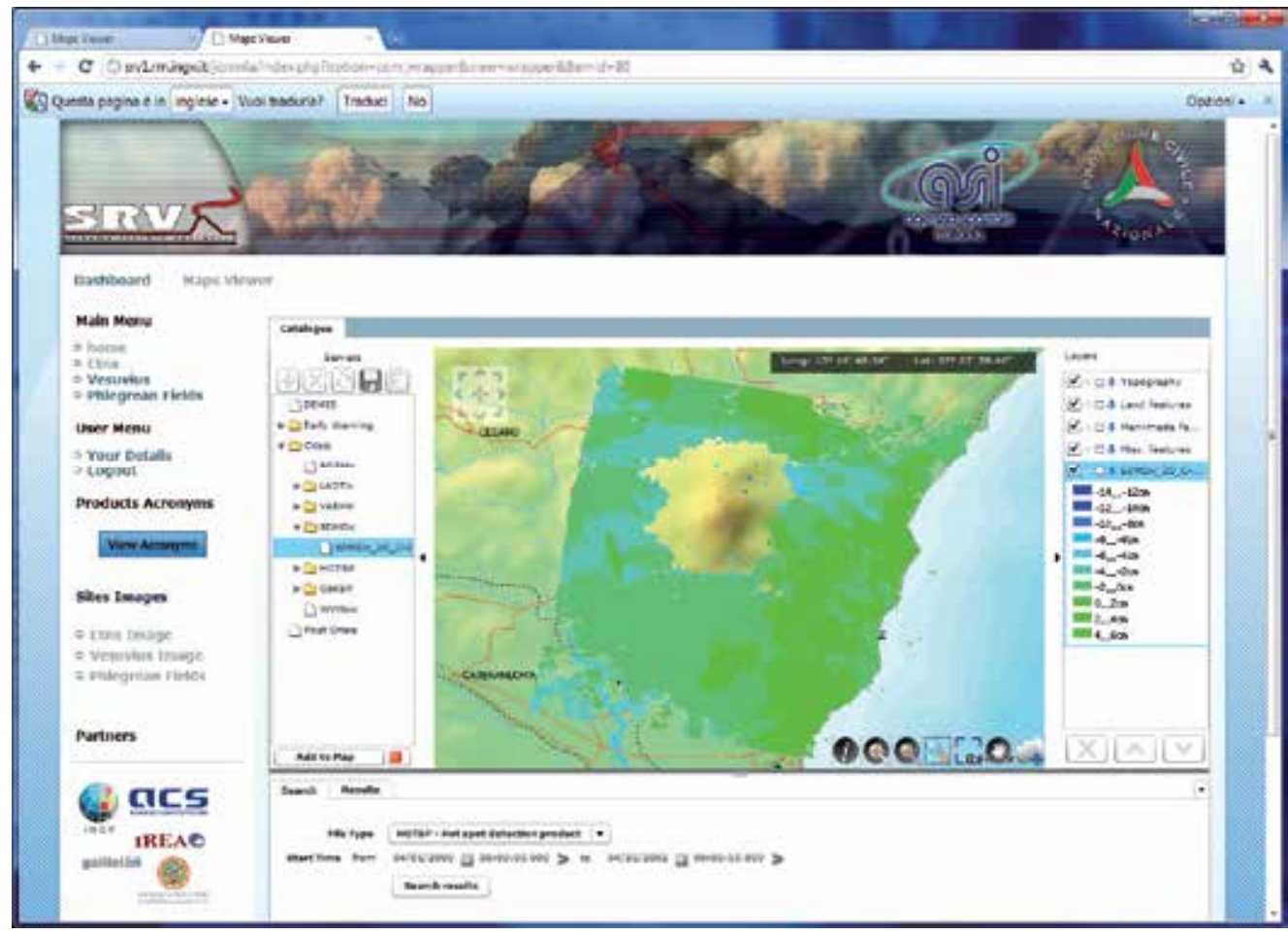

Fig. 2. Example of sin eruptive deformation map provided by means of official gateway

The main information layer is the temperature of the thermal anomaly and its spatial location. The thermal flux map is derived from the temperature maps retrieved using the dual-band technique and it is expressed in watt. Thermal flux roughly represents the energy emitted by the hot-spot when the image has been acquired. Effusion rate appears to control the basic flow dynamics and the manner of emplacements of active flows. Therefore measurements of the effusion rate are of great interest. Reliable estimations of Er imply the knowledge of rheological and geological parameters such as the lava density, the specific heat capacity, the temperature drop throughout the moving portion of the flow and the mass fraction of crystal grown through the cooling process. These parameters are typical of each different volcano and must be separately estimated or derived from literature. (Fig. 3)

\subsubsection{Sulphur dioxide retrieval modules}

Three different procedure are able to estimate the sulphur dioxide from a volcanic source: LUT [Realmuto et al., 1997],FUN [Teggi et al., 1999] SW [Pugnaghi et al., 1999,Pugnaghi et al., 2002] which doesn't require the DEM. All these three mentioned procedures have been implemented in the ASI-SRV system to estimate the sulphur dioxide emitted from Mt. Etna. The routinely measurements of the $\mathrm{SO} 2$ volcanic flux is important because its variation from the standard baseline can be used as precursor of possible start or end of an eruption [Caltabiano et al., 1994]. In the thermal infrared (TIR) portion of the electromagnetic spectrum a common and good assumption, in absence of clouds, is that scattering is negligible. If there is no scattering, the spectral radiance at the sensor, in the $8-14 \mu \mathrm{m}$ atmospheric window, depends on the radiance from the surface (which mainly depends on 
temperature and emissivity) and on the effect of the atmospheric path between the target and sensor.

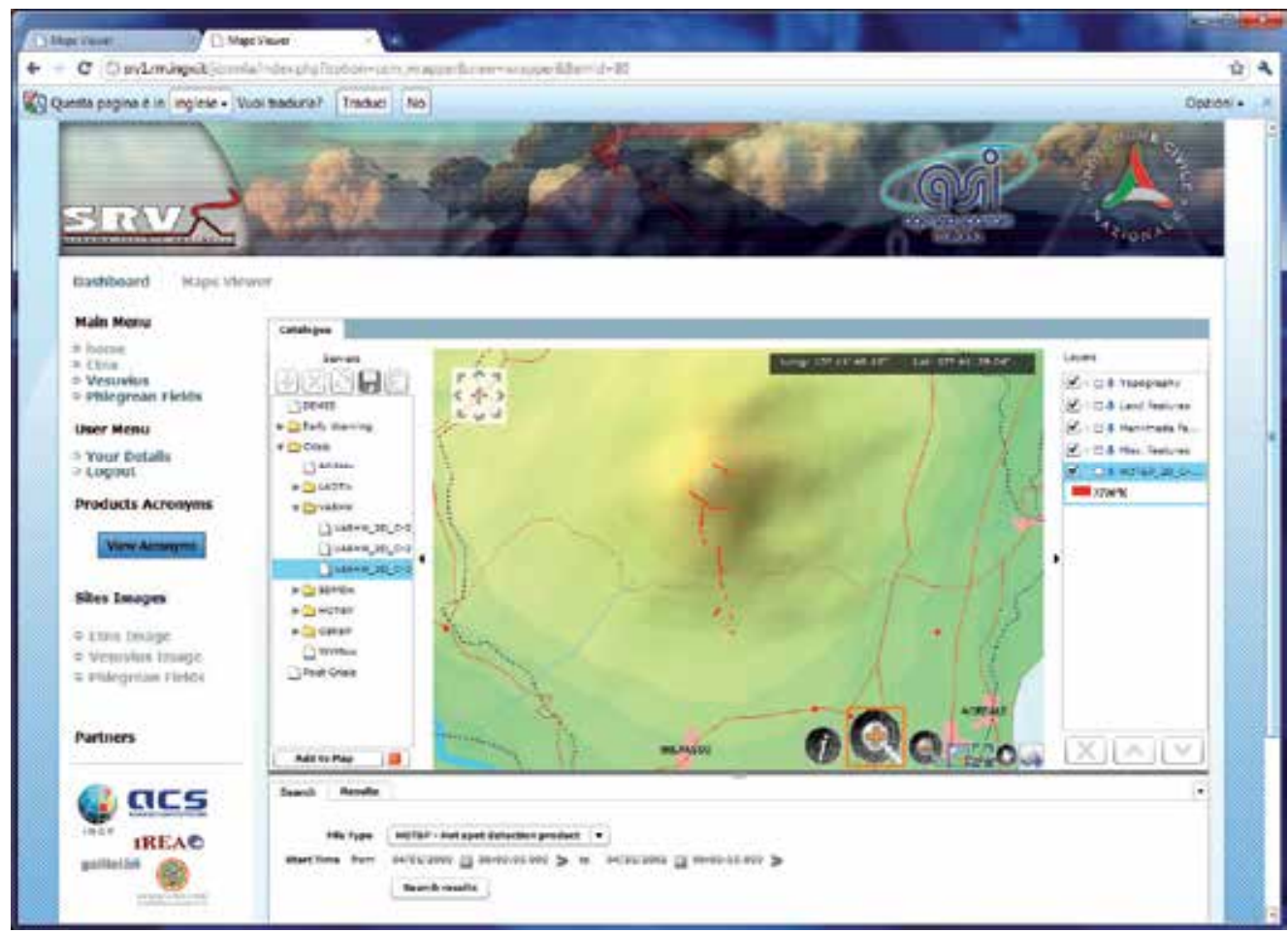

Fig. 3. Example of sin eruptive surface thermal map map provided by means of official gateway

To compute the sulphur dioxide flux (F) emitted from the volcano vents, the map of the columnar content of SO2 $\left(c_{s}\right)$, computed from the remotely sensed image, and the wind speed $(v)$ measured at the plume altitude are required. The plume axis and the transect length (or plume width) have to be chosen by the user on the sulphur dioxide map, which is the result of the previous algorithm (Fig. 4).

$$
F=v \cdot \int c_{s} \cdot d s
$$

\subsubsection{Low aerosol pptical thickness (LAOT) estimation}

In order to estimate the Volcanic Aerosol Optical Thickness in a volcanic plume during crisis, an algorithm called LAOT based on low spatial resolution image has been implemented in the ASI-SRV system. This algorithm based on the same approach described in VAOT has been developed at the Univeristy of Modena [Remitti et al., 2006]. This algorithm is based on the work of [Kaufman 1993, Kaufman et al., 1997 and Remer et al., 2005] (Fig. 5). 


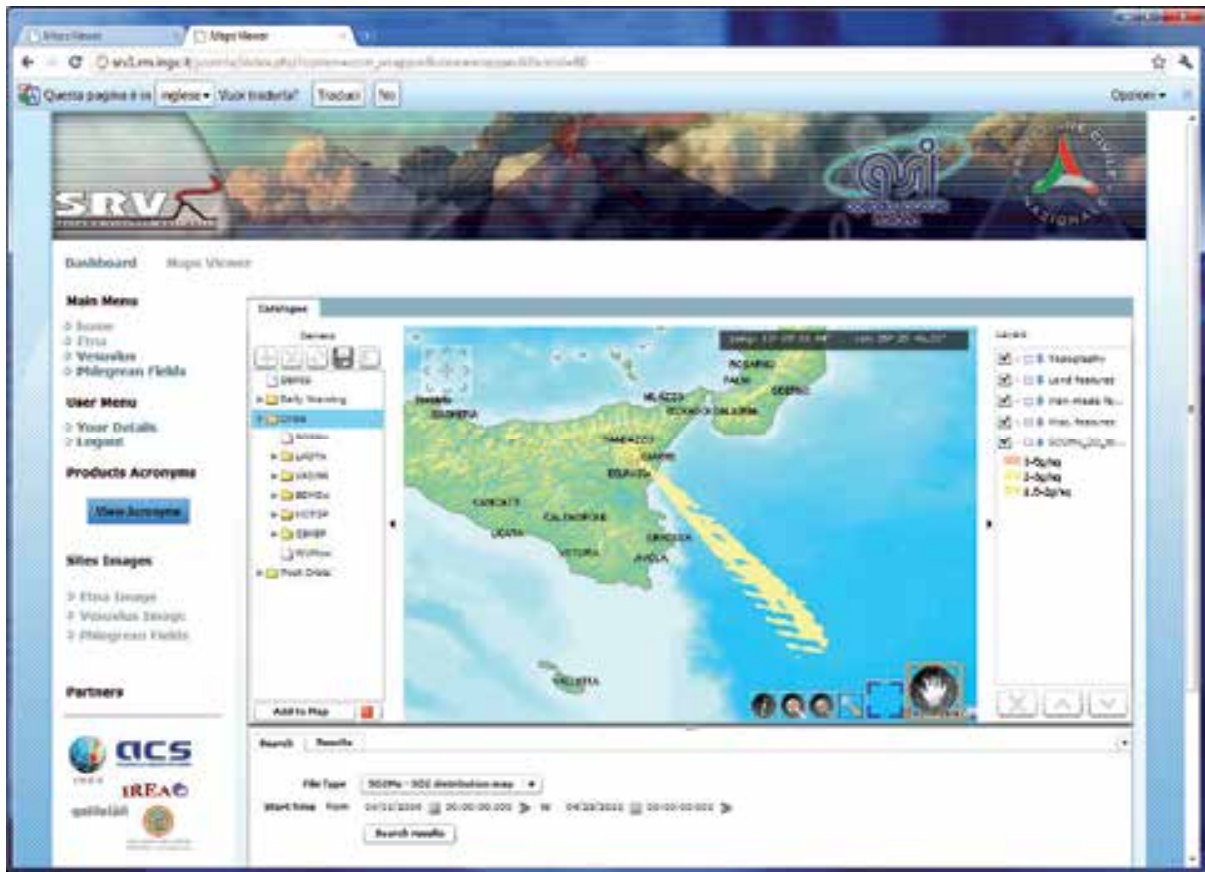

Fig. 4. Example of SO2 map product generated and delivered by means of dedicated gateway

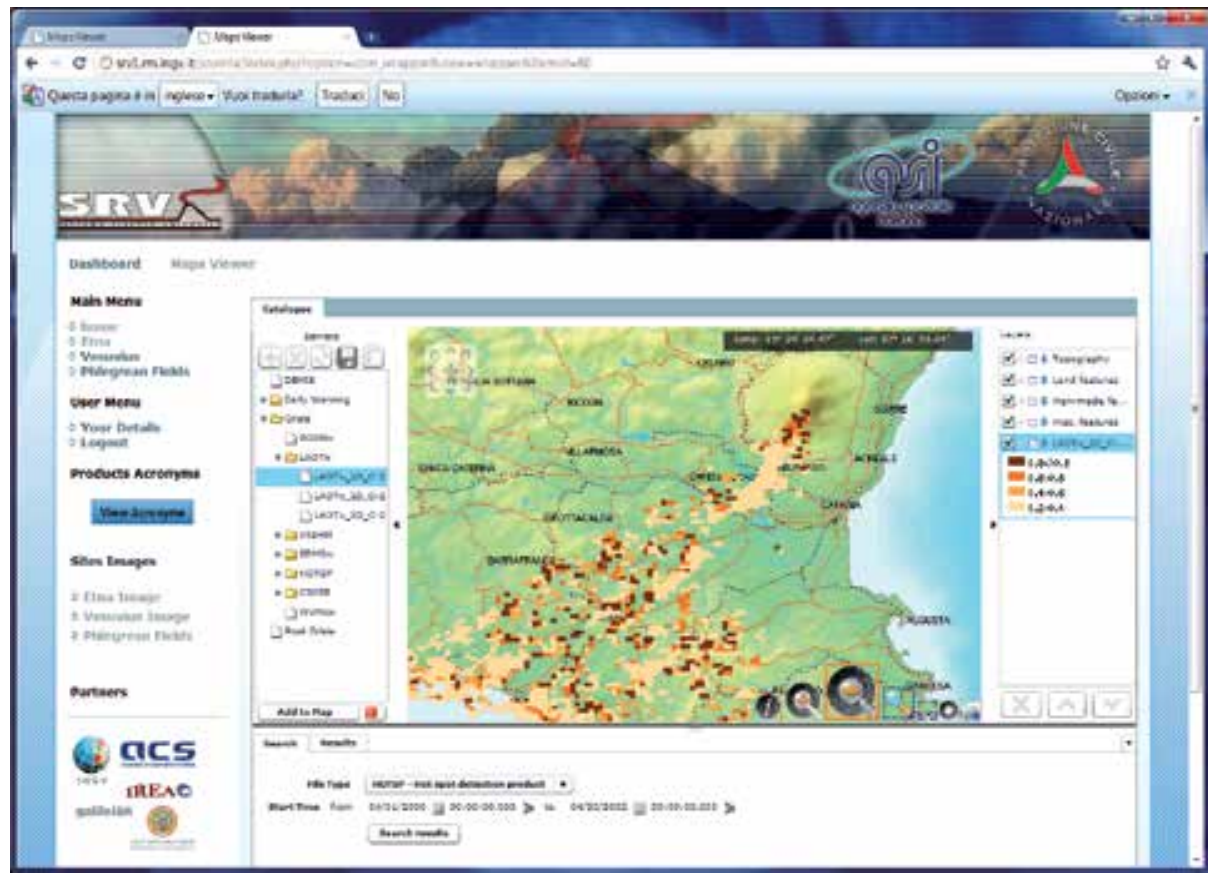

Fig. 5. Example of aerosol optical depth provided by means of official gateway. During crisis phase this prodcut is generated by low spatial resolution sensor 


\subsubsection{Volcanic ash loading map (VAMP)}

Purpose of this algorithm is the volcanic ash detection and loading retrieval from MODIS spaceborne measurements in Thermal InfraRed (TIR) spectral range. The algorithm is based on Brightness Temperature Difference (BTD) procedure [Prata and Barton, 1989] applied on MODIS channels 31 and 32. The ash detection is realized inverting the Plack function, computing the brightness temperatures for the cited channels and making the difference. The ash detection is obtained showing the BTD map $\left[{ }^{\circ} \mathrm{C}\right]$ and identifying the negative values. The ash loading map retrieval [tons] is performed using the effective radius (reff) and aerosol optical thickness (AOT) retrieval obtained by a double linear interpolation from the AOT-reff curves computed using the simulated Top Of Atmosphere (TOA) radiances [Wen and Rose, 1994]. The simulated radiances will be estimated from MODTRAN Radiative Transfer Model (RTM) [Berk et al., 1989], using as input the atmospheric profiles (pressure, temperature, humidity), surface characteristics (temperature, emissivity) and ash optical properties (extinction coefficient, absorption coefficient, asymmetry parameter). The total plume ash loading is computed as sum of the retrieved ash loading of each pixel. (Fig. 6).

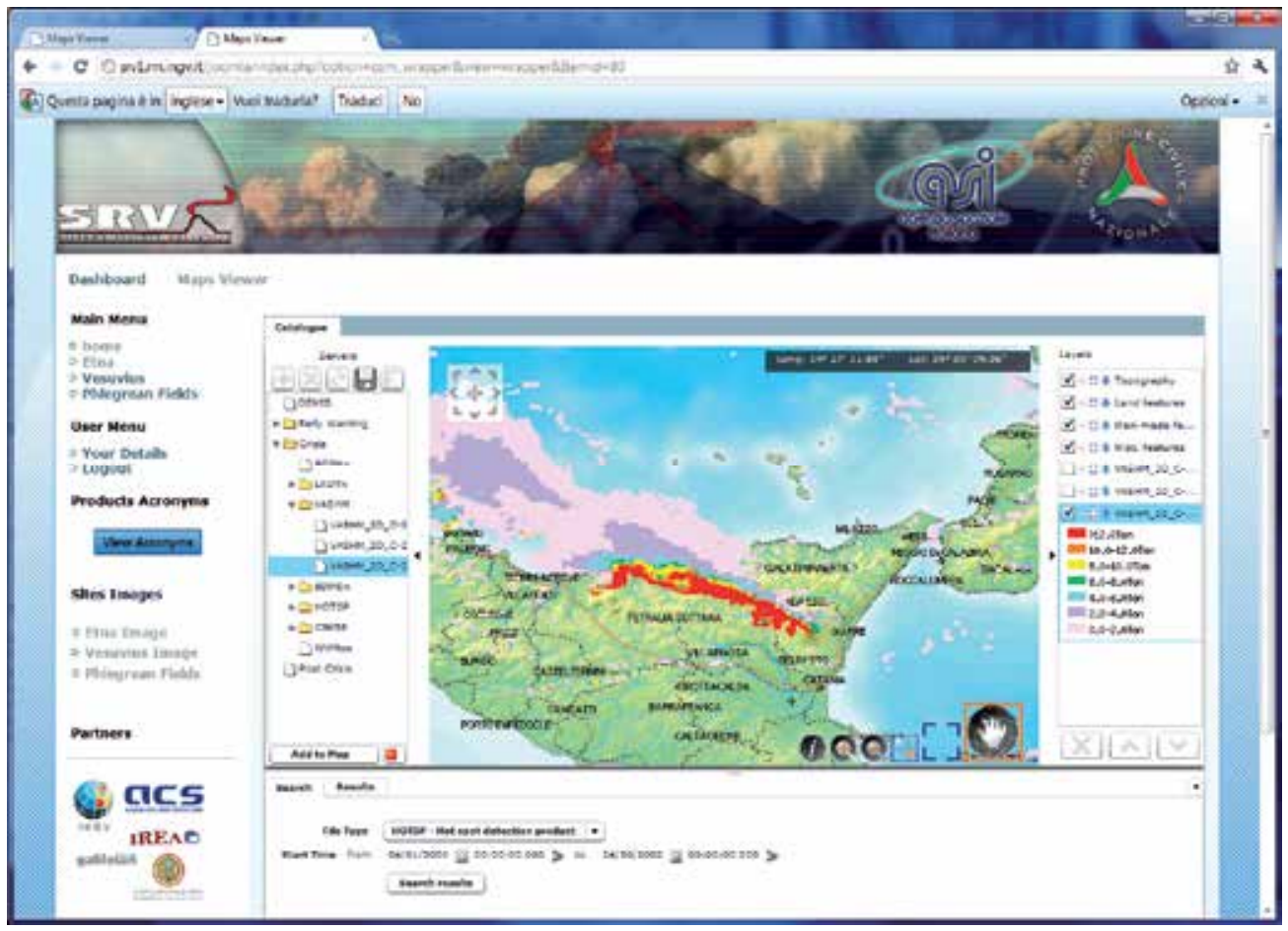

Fig. 6. Example of ASH map product generated and delivered by means of dedicated gateway

\subsection{ASI-SRV POST ERUPTION PHASE}

Active volcanoes that erupt frequently constantly change in shape and volume. Mount Etna produces major lava flows about once per year, and more explosive activity is nearly always accompanied by growth of pyroclastic cones, whereas inter-eruptive intervals may be marked by collapse of portions of the summit cones. These morphological changes strongly 
influence the distribution of future eruptive products (namely lava flows) and need to be carefully mapped and measured for the assessment of the hazard from future eruptions.

The new distribution of ash and lava flow have been evaluated by means of spectral classification using supervised and unsupervised technique. Beside this surface classification an evaluation of the thickness of eruptive products will be carried out in the field, using hand-held GPS to create a model of the new, post-eruptive surface morphology in areas affected by the eruptive activity. GPS is the instrument most suitable for obtaining a high quantity of data at a resolution comparable to that of the satellite images used for the project This new morphology will be superimposed on the pre-eruptive morphology to reveal the approximate $( \pm 5 \mathrm{~m})$ thickness of the new products in any site, and obtain volume estimates (Fig. 7).

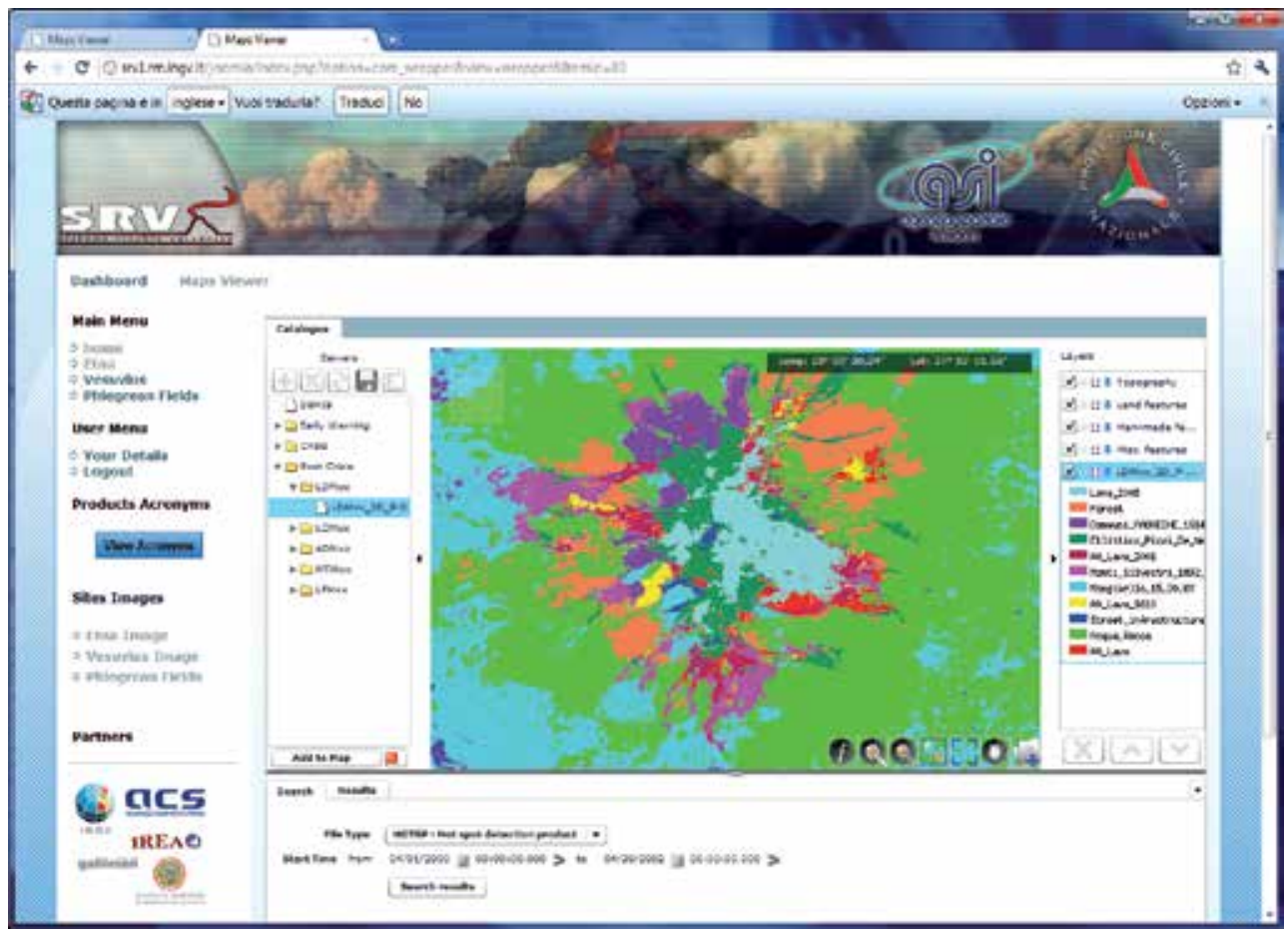

Fig. 7. Example of post eruptive lava distribution map product generated and delivered by means of dedicated gateway

\subsubsection{Multiparametric analysis}

All the above mentioned early-warning products have been used to verify the capability of dedicated statistical model to support the monitoring activities. ASI-SRV project has implemented a well-known model called Bayesian Event Tree - Eruption Forecast (BET-EF) (Marzocchi et al., 2009) which is an already developed algorithm for the eruption model, and has been adapt, as it is, to the ASI-SRV needs. The BET-EF model represents a flexible tool to provide probabilities of any specific event at which we are interested in, by merging any kind of available and relevant information, such as theoretical models, a priori beliefs, monitoring measures, and real time and past data. It is mainly based on a Bayesian 
procedure and it relies on the fuzzy approach to manage monitoring data. The method deals with short- and long-term forecasting, therefore it can be useful in many practical aspects, as land use planning, and during volcanic emergencies. Besides BET-EF a multivariate analysis allows to perform multiple comparisons in order to have a first idea of which variables are largely preferentially or rather rarely distributed, also considering their geographic localization, and then a cross correlation will allow to define the weight of each product that will be used as input in the BET-EF model (Fig. 8).

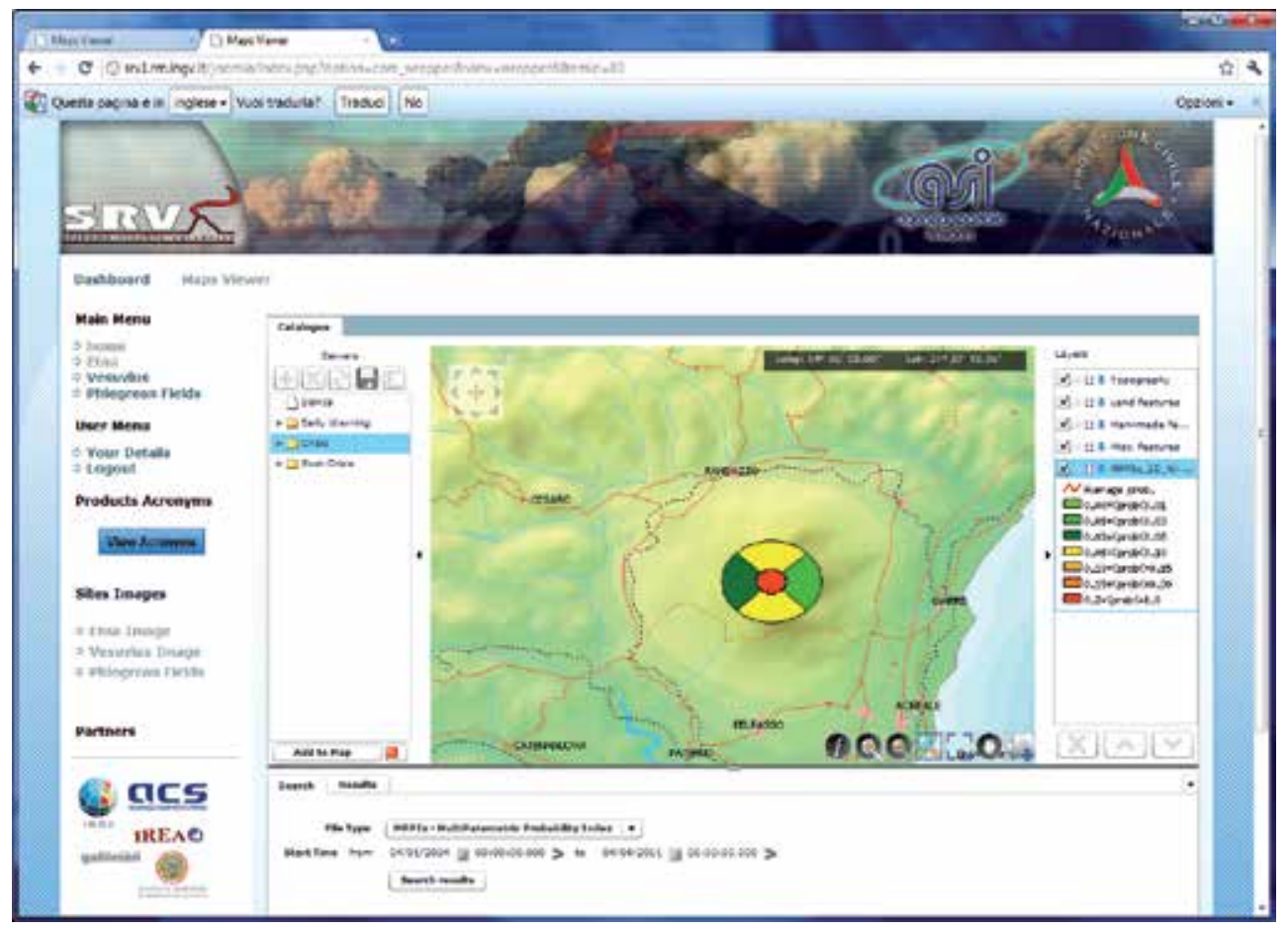

Fig. 8. Example of ASH map product generated and delivered by means of dedicated gateway

\section{Conclusion}

Technologies and services provided by ASI-SRV are developed for provide added value information in case of Volcanoes eruption, but also during the pre-event (early warning) phase and post-event enabling an improved support for risk management and assessment. In order to let remote sensed data available to the core processes as soon as they are received selected processors operating in un-supervised mode generate advanced L1 data.

The processing chains has been delocalized ensuring the fastest updating rate for the newest generated products. The processing chain for radar data has been located and operated at IREA premises and the processing results will be transferred to the main system via ftp connection as soon as they are generated. This choice is justified essentially its high complexity, the algorithm must be supervised during the whole processing phase by an expert operator who is also responsible for setting a number of important parameters that 
affect the quality of the final result: Expert personnel operate the module throughout the project lifetime.

The processing chain dedicated to the develop of product by optical remote sensed data has been located and operated at INGV premises and the processing results are transferred to the project gateway by means of dedicated procedure for validation and dissemination as soon as they are generated.

The availability of a set of instrument dedicated to the harmonization and pre-processing of EO data represents an important tool for a complex system as ASI-SRV is. A well structured production chain, that manage the ingestion, pre processing, processing and publication of EO derived product in a semi-automatic process, allow to compare a wide volume of data using the same standard. All the validated ASI-SRV products produced by processing modules and data processor software are stored in the ASI-SRV main database, in order to be published by Web-GIS and then made available to the end-user.

SRV project has finished the development of architectural design of modules and interfaces and it is now ready to operate according the User's request.

\section{Acknowledgment}

This study was supported by Agenzia Spaziale Italiana Progetto Sistema Rischio Vulcanico project (ASI-SRV ref ASI I/091/06/0). The active contribute of the Italian DPC has been very important in order to meet the requirement requested especially regarding the delivery time of the products in the Crisis Phase.

\section{References}

Azzaro R. (1999) Earthquake surface faulting at Mount Etna volcano (Sicily) and implications for active tectonics. J. Geodyn., 28, 193-213.

Berardino, P., Fornaro, G., Lanari, R., and Sansosti, E. (2002), A new Algorithm for Surface Deformation Monitoring based on Small Baseline Differential SAR Interferograms, IEEE Transactions on Geoscience and Remote Sensing, 40, 11, 2375-2383.

Berk A., Bernstein L.S. e Robertson D.C..( 1989) MODTRAN: a moderate resolution model for Lowtran7, GL-TR-89-0122, AFG Lab., Hanscom Air Force Base, MA 01731-5000, USA.

Branca S. (2003) Geological and geomorphologic evolution of the Etna volcano NE flank and relationships between lava flow invasions and erosional processes in the Alcantara Valley (Italy). Geomorphology, 53, 247-261.

Branca S., Coltelli M., De Beni E., Wijbrans J. (2008) Geological evolution of Mount Etna volcano (Italy) from earliest products until the first central volcanism (between 500 and $100 \mathrm{ka}$ ago) inferred from geochronological and stratigraphic data. Intern. J. Earth Sci., 97:135-152

Branca S., Coltelli M., Groppelli G. (2004) Geological evolution of Etna volcano. In: “Etna Volcano Laboratory" Bonaccorso, Calvari, Coltelli, Del Negro, Falsaperla (Eds), AGU (Geophysical monograph) 143, pp 49-63.

Caltabiano T., Romano R., Budetta G., (1994). SO2 flux measurements at Mount Etna (Sicily). Jour. Geoph. Res., 99, D6, 12.809-12.819 
Calvari S., Neri M., Pompilio M., Scribano V., (1994). Etna: Eruptive activity. In: "Data related to eruptive activity, unrest phenomena and other observations on the Italian active volcanoes - 1992", L. Villari (Ed.), Acta Vulcanol., 6, 1-3

Calvari, S., Tanner, L.H., Groppelli, G., Norini, G. (2004) A comprehensive model for the opening of the Valle del Bove depression and hazard evaluation for the eastern flank of Etna volcano. In: "Etna Volcano Laboratory" Bonaccorso, Calvari, Coltelli, Del Negro, Falsaperla (Eds), AGU (Geophysical monograph) 143, pp 65-75.

Coltelli M., Del Carlo P., Vezzoli L. (2000) Stratigraphic constrains for explosive activity in the last $100 \mathrm{ka}$ at Etna volcano. Italy. Inter. J. Earth Sciences 89: 665-677.

Coltelli, M., Del Carlo, P., Vezzoli, L. (1998) The discovery of a Plinian basaltic eruption of Roman age at Etna volcano, Italy. Geology, 26, 1095-1098.

Flynn LP, Harris AJL, Rothery DA, Oppenheimer C (2000) High-Spatial resolution thermal remote sensing of active volcanic features using Landsat and hyperspectral data. Remote Sensing of Active Volcanism AGU Geophysical Monograph Series 116: 161177.

Flynn, L., P. Mouginis-Mark, J. Gradie, and P. Lucey, (1993) Radiative Temperature Measurements at Kupaianaha Lava Lake, Kilauea Volcano, Hawaii, J. Geophys. Res.,98, 6461 - 6476

Gillespie, A., Rokugawa, S., Matsunaga, T., Cothern, J.S., Hook, S. And Kahle, A. (1998): A temperature and emissivity separation algorithm for Advanced Spaceborne Thermal Emission and Reflection Radiometer (ASTER) images, IEEE Trans. Geosci. Remote Sensing, 36 (4),1113-1126

Gillespie, A.R. (1985): Lithologic mapping of silicate rocks using TIMS, in The TIMS Data User's Workshop, JPL Publication 86-38, Jet Propulsion Lab., Pasadena, CA, 29-44

Harris, A.J.L., Flynn, L.P., Keszthelyi, L., Mouginis-Mark, P.J., Rowland, S.K., Resing, J.A., (1998). Calculation of lava effusion rates from Landsat TM data, Bull. Vucanol. 60, 52-71.

Isaia R., M. D'Antonio, F. Dell'Erba, M.A. Di Vito and G. Orsi, (2004) The Astroni volcano: the only example of close eruptions within the same vent area in the recent history of the Campi Flegrei caldera (Italy), Journal of Volcanology and Geothermal Research 133, pp. 171-192.

Kaufman Y.J., Tanre' D., Remer L.A., Vermote E.F., Chu A., Holben B.N., (1997). Operational remote sensing of tropospheric aerosol over land from EOS moderate resolution imaging spectroradiometer. Journal of Geophysical Research, Vol. 102, No. D14, pp. 17,051-17,067, July 27.

Kaufman, Y. J. (1993) "Measurements of the aerosol optical thickness and the path radiance - Implications on aerosol remote sensing and atmospheric corrections", Journal of Geophysical Research, 98, 2677-2692, (b)

Kaufman, Y.J. Wald, A.E. Remer, L.A. Bo-Cai Gao Rong-Rong Li Flynn, L. (1997) The MODIS 2.1- $\mu \mathrm{m}$ channel-correlation with visible reflectancefor use in remote sensing of aerosol Geoscience and Remote Sensing, IEEE Transactions onPublication Date: Sep Volume: 35, Issue: 5

Lanari, R., De Natale, G., Berardino, P., Sansosti, E., Ricciardi, G. P., Borgstrom, S., Capuano, P., Pingue, F., and Troise, C. (2002), Evidence for a peculiar style of ground deformation inferred at Vesuvius volcano, Geophysical Research Letters, 29 
Lanari, R., Lundgren, P., Manzo, M., and Casu, F., (2004b), Satellite radar interferometry time series analysis of surface deformation for Los Angeles, California, Geophysical Research Letters, 31, L23613, doi:10.1029/2004GL021294.

Lentini F., Carbone S., Catalano S., Grasso, M. (1996) Elementi per la ricostruzione del quadro strutturale della Sicilia orientale. Mem. Soc. Geol. It., 51, 179-195.

Li, Z., Becker, F., Stoll, M. And Wan, Z. (1999): Evaluation of six methods for extracting relative emissivity spectra from thermal infrared images, Remote Sens. of Env., 69, 197-214.

Lundgren, P., Casu, F., Manzo, M., Pepe, A., Berardino, P., Sansosti, E., and Lanari, R. (2004), Gravity and magma induced spreading of Mount Etna volcano revealed by satellite radar interferometry, Geophysical Research Letters, 31, L04602, doi:10.1029/2003GL018736

Manzo M., Ricciardi, G. P., Casu, F., Ventura, G., Zeni, G., Borgström, S., Berardino, P., Del Gaudio, C. and Lanari, R. (2006), Surface deformation analysis in the Ischia island (Italy) based on spaceborne radar interferometry, Journal of Volcanology and Geothermal Research, 151, 399-416, doi:10.1016/j.jvolgeores.2005.09.010.

Marzocchi,W., Sandri, L., Selva J., (2009) BET_EF: a probabilistic tool for long- and short term eruption forecasting , Bull. Volcanol. , doi:10.1007/s00445-007-0157-y,

Massonet D., K. Feigl, (1998) Radar Interferometry and its application to changes in the Earth's surface, Reviews of Geophysics, 36, 4 / November 1998, pag. 441-500,

Oppenheimer, C., (1991). Lava flow cooling estimated from Landsat Thematic Mapper infrared data: The Lonquimay eruption (Chile, 1989), Journal of Geophysical Research 96, 21865-21878.

Pepe, A., E. Sansosti, P. Berardino and R. Lanari (2005), On the Generation of ERS/ENVISAT DinSAR Time-Series via the SBAS technique, IEEE Geoscience and Remote Sensing Letters, 2, 3, pp. 265-269.

Pieri, D.C., Glaze, L.S., Abrams, M.J., (1990). Thermal radiance observation of an active lava flow during th June 1984 eruption of Mt. Etna, Geology, v.18, 1018-1022

Prata A. J., I. J. Barton, (1989) “Detection and discrimination of volcanic clouds by infrared radiometry - I:theory", Proc. of the first international symposium on Volcanic ash and aviation safety, 305-311.

Pugnaghi S., Gangale G., Corradini S., Buongiorno M.F. (2006), Mt. Etna sulfur dioxide flux monitoring using ASTER-TIR data and atmospheric observations, Journal of Volcanology and Geothermal Research, 152, 74-90.

Pugnaghi, S., Teggi, S., Corradini, S., Buongiorno, M.F., Merucci, L., Bogliolo, M.P., (2002). Estimation of SO 2 abundance in the eruption plume of Mt. Etna using two MIVIS thermal infrared channels: a case study from the Sicily-1997 Campaign. Bull Volcanol 64, 328-337.

Realmuto, V.J. (1990): Separating the effects of temperature and emissivity: emissivity spectrum normalization, in Proc. 2nd TIMS Workshop, JPL Publication, 90-55, Jet Propulsion Lab., Pasadena, CA.

Realmuto, VJ, AJ Sutton and T Elias (1997) Multispectral thermal infrared mapping of sulfur dioxide plumes - a case study from the East Rift Zone of Kilauea volcano, Hawaii, Jour. Geophys. Res., 102: 15057-15072

Remer, L. A. Kaufman, Y. J. Tanrè, D. Mattoo, S. Chu, D. A. Martins, J. V. Li, R.-R. Ichoku, C. Levy, R. C. Kleidman, R. G. Eck, T. F. Vermote E. and Holben, B. N. (2005) “The 
MODIS Aerosol Algorithm, Products and Validation", Journal of Atmospheric Science, Special Section, 62, 947-973.

Remitti M., Pugnaghi S., Teggi S., Parmiggiani F., (2006). Retrieval of tropospheric ash clouds of mt. etna from AVHRR data Quaderni di Geofisica n. 43.

Spinetti C. and M.F. Buongiorno, (2007). Volcanic Aerosol Optical Characteristics of Mt. Etna Tropospheric Plume Retrieved by Means of Airborne Multispectral Images. Journal of Atmospheric and Solar-Terrestrial Physics Volume 69, Issue 9, pp. 981994 doi:10.1016/j.jastp.2007.03.014.

Spinetti C., Buongiorno M.F., Lombardo V., Merucci L. (2003) - Aerosol optical thickness of Mt. Etna volcanic plume retrieved by means of the Airborne Multispectral Imaging Spectrometer MIVIS. Annals of Geophysics, 46 (2).

Spinetti, C. Buongiorno, M.F. Volcanic water vapour abundance retrieved using hyperspectral data Geoscience and Remote Sensing Symposium,. IGARSS '04. Proceedings. (2004) 2004 IEEE International Publication Date: 20-24 Sept. 2004 Volume: 2, On page(s): 1487- 1490 vol.2

Synthetic Aperture Radar Computer Compatible Tape Format Specifications", (CEOS SAR CCT Iss/Rev: 2/1) by CEOS WGD on SAR data Standards, March 1989, revision 1 January 1992

Teggi. S., Bogliolo MP, Buongiorno MF, Pugnaghi S., Sterni A. (1999), Evaluation of SO2 emission from Mount Etna using diurnal and nocturnal IR and visibile imaging spectrometer thermal IR remote sensing images and radiative transfer models, Journal of Geophysical Research, vol. 104, n. B9, pp. 20069-20079

Tizzani, P., P. Berardino, F. Casu, P. Euillades, M. Manzo, G. P. Ricciardi, G. Zeni and R. Lanari (2007), Surface deformation of Long Valley caldera and Mono Basin, California, investigated with the SBAS-InSAR approach, Remote Sensing of Environment, doi: 10.1016/j.rse.2006.11.015e.

Vermote E., D. Tanre', J. L. Deuze', M. Herman, and J. J. Morcrette.( 1997) "Second simulation of the satellite signal in the solar spectrum, 6S: an overview," IEEE Trans. Geosci. Remote Sens. 35, pp. 675-686

Wen S., W. I. Rose, (1994) "Retrieval of sizes and total masses of particles in volcanic clouds using AVHRR bands 4 and 5", J. of Geoph. Res., 99, D3, 5421-5431

Wright R., Rothery, D.A., Blake, S., Pieri, D.C., (2000). Improved remote sensing estimates of lava flow cooling: a case study of the 1991-1993 Mount Etna eruption, Journal of Geophysical Research, 105, B10, 23,681-23,694.

Zebker, H.A. Goldstein, R.M. (1986) Topographic mapping from interferometric SAR observations, J. Geophys. Res., 91 4993- 5001. 
Part 2

Production 



\title{
Food Safety Risk Management
}

\author{
Elena Carrasco, Antonio Valero, Fernando Pérez-Rodríguez, \\ Rosa María García-Gimeno and Gonzalo Zurera \\ University of Cordoba \\ Spain
}

\section{Introduction}

It is a principal aim of governments to assure the safety of societies in all sectors. In the food field, safety has been dealt with for a long time by making decisions in an empirical manner. Recently, risk management has been appointed as the formal scientific-based approach to address food safety issues.

From a global perspective, food safety risk management can be described "as the process of weighting control alternatives by government (and international standard-setting bodies) in consultation with interested stakeholders, taking into account scientific information on risks to consumers as well as other relevant inputs (e.g. economics, technical feasibility, societal preferences), and choosing and implementing food safety measures as appropriate" (Food Agriculture Organization/World Health Organization [FAO/WHO], 2006b). Indeed, governments must make decisions, whose effects are especially noted during food crises. Nevertheless, other stakeholders should also manage food risks, for example, at manufacture or consumer level. Nowadays, manufacturers and other operators involved in the food chain are aware of the importance of producing and assuring food safety, as well as the devastating consequences of supplying contaminated food products. However, at consumer level, the relevance of consumer's hygiene practices in the home may not always be evident in order to avoid foodborne conditions.

Food safety risk management should be based on risk assessment, as proposed by the Regulation (EC) No. 178/2002 of 28 January 2002, laying down the general principles and requirements of food law, establishing the European Food Safety Authority and laying down procedures in matters of food safety. Currently, risk assessment is being gradually introduced at governmental level as a systematic practice. In the case of manufacturers and other food business operators, only big food enterprises have adopted risk assessment procedures; risk management in medium and small food companies is based on the implementation of Hazard Analysis and Critical Control Point (HACCP) systems, which is in fact compulsory. Hygiene practices in homes are out of the control of Health Authorities; nevertheless, for example, a risk management option mandated by governments may consist of developing educational programs which could enhance a positive attitude among consumers towards a more hygienic preparation of foods.

Food safety risk management has been proved to be useful in making science-based decisions. In this chapter, food safety risk management is addressed from various perspectives, together with management metrics to facilitate its implementation. Also, a review of risk assessment is included. A promising future can be envisaged for food safety risk management activities. 


\section{Perception of risk}

Any attempt to manage risk begs the question: 'What is risk?' The dominant conception views risk as 'the chance of injury, damage, or loss' (Webster, 1983). The probabilities and consequences of adverse events are assumed to be produced by physical and natural processes in ways that can be objectively quantified by risk assessment. Much social science analysis rejects this notion, arguing instead that risk is inherently subjective (Pidgeon et al., 1992; Slovic, 1992; Wynne, 1992). In this view, risk does not exist "out there', independent of our minds and cultures, waiting to be measured. Instead, human beings have invented the concept risk to help them understand and cope with the dangers and uncertainties of life. Although these dangers are real, there is no such thing as 'real risk' or 'objective risk'. The nuclear engineer's probabilistic risk estimate for a nuclear accident or the toxicologist's quantitative estimate of a chemical's carcinogenic risk are both based on theoretical models, whose structure is subjective and assumption-laden, and whose inputs are dependent on judgment. As we shall see, nonscientists have their own models, assumptions, and subjective assessment techniques (intuitive risk assessments), which are sometimes very different from the scientists' models.

\begin{tabular}{|c|c|}
\hline \multicolumn{2}{|c|}{ Acceptability of risk } \\
\hline More if: & Less if: \\
\hline Voluntary & Involuntary \\
Natural & Artificial \\
Familiar & Unfamiliar \\
Fair & Unfair \\
No dread & Dreaded \\
Trustworthy sources & Untrustworthy \\
Good process & Poor process \\
\hline
\end{tabular}

Table 1 . The acceptability of risk varies depending on features that affect our perception of risk. (Trautman, 2001).

Not only are there differences in people, in the way they approach risks, but there are also dramatic differences in risks. Table 1 lists some perceptual features of risk that reflect a risk's acceptability. Risks are more likely to be accepted if they have more of the features shown on the left in Table 1, e.g. if they are voluntary or familiar. So driving a car or even smoking cigarettes are readily accepted risks. Increased controversy surrounds those risks that have more features on the right, perhaps genetically modified foods or hormones in beef. It is probable that the communication gap between scientists and the public is only accentuated when several of these right-side features are in play.

Recently, the European Commission et al. (2010) has published a special Eurobarometer 354 report called "Food-related risks". The European Food Safety Authority (EFSA) surveyed consumers across Europe about how their views on food-related risks have evolved since an earlier survey carried out in 2005 (European Commission et al., 2005, as cited in European Commission et al., 2010). It was conducted through face-to-face interviews with consumers in their mother tongue from 9 to 30 June 2010. With regards to the public perception of food and food-related risks the survey shows that the majority of respondents associate food and eating with pleasure, such as selecting fresh and tasty foods (58\%) and with enjoyment of meals with friends and family (54\%). Food safety (37\%) is less commonly associated with 
food and eating as such. Similarly, in the context of other potential risks which are likely to affect them personally, the economic crisis (20\%) and environmental pollution (18\%) are viewed by more respondents as risks that are much more likely to affect their lives than food-related problems (11\%). When it comes to public concerns about food-related risks, the survey shows that there is no single, widespread concern mentioned spontaneously by a majority of respondents; $19 \%$ of citizens spontaneously cite chemicals, pesticides and other substances as their major concern. This concern is confirmed by prompted responses: when offered a list of possible issues associated with food, 3 out of 10 Europeans mention chemical residues from pesticides (31\%), antibiotics (30\%) and pollutants such as mercury and dioxins $(29 \%)$, together with cloning animals for food products $(30 \%)$, as risks to be "very worried" about; fewer citizens are "very worried" about health and nutrition risks like putting on weight $(15 \%)$ or not having a healthy / balanced diet $(15 \%)$. In terms of personal effectiveness to avoid food-related risks, EFSA found that EU citizens feel the most confident about being able to personally take steps to avoid diet and health-related issues (e.g. high fat intakes and heart disease) and bacterial contamination (e.g. salmonella in eggs); a more divided opinion is found with regard to possible risks from animal infections or diseases which could be transmitted to humans, as a larger proportion of respondents $(52 \%)$ claims not to be confident in avoiding these risks; citizens feel less confident in being able to personally deal with possible problems of chemical contamination $(<40 \%)$ and new technologies $(<30 \%)$. With this information, one could relate these numbers with the facts showed in Table 1. For instance, campylobacteriosis is the most commonly reported zoonosis in the European Union, with 198,252 confirmed human cases in 2009 (European Food Safety Authority [EFSA] \& European Centre for Disease Prevention and Control [ECDC], 2011). At the same level, the harmful consumption of alcohol is estimated to be responsible for approximately 195.000 deaths a year in the EU due to e.g. accidents, liver disease, cancers, etc. However, the harmful consumption of alcohol, which is a voluntary act and perceived as not dreaded probably due to its popularity, is underestimated by the general population, and in fact, is not included as a food-related risk in the above survey.

Slovic (1998) supported the contexualist conception of risk, which is conceived as a game. Games have time limits, rules of play, opponents, criteria for winning or losing, and so on, but none of these attributes is essential to the concept of a game, nor are any of them characteristic of all games. Similarly, a contextualist view of risk assumes that risks are characterized by some combination of attributes such as voluntariness, probability, intentionality, or equity, but that none of these attributes are essential. The bottom line is that, just as there is no universal set of rules for games, there is no universal set of characteristics for describing risk. The characterization must depend on which risk game is being played.

Often referred to as a risk management options assessment, this is the process by which different options for controlling a hazard to an "appropriate level of protection" (ALOP) are evaluated and compared. This is typically done by developing a risk assessment model that establishes mathematically the various factors that contribute to the current level of risk associated with a product/pathogen pair. Once this model is established, the model is augmented with additional parameters representing the different control strategies being considered (Buchanan, 2002).

To make decisions wisely, individuals need to understand the risks and the benefits associated with alternative courses of action. They also need to understand the limits to their 
own knowledge and the limits to the advice proffered by various experts (Fischhoff et al., 1993). Some of the key questions that have to be asked when considering an optimal risk management option are: to whom it is optimal and what criteria are used to make that determination. Buchanan (2002) illustrated this with a hypothetical example. Let's consider an instance where is it necessary to achieve a reduction of pathogens on the surface of citrus fruit. In an industrialized country where labor costs are high, the use of advanced, highspeed steam surface pasteurization technologies may be the optimal system for achieving the desired reduction. However, in a developing country where labor costs are low but capital costs are high, it may be more effective to hand wash the fruit in an appropriate sanitizing solution. Thus, if the criterion for what constitutes optimal is minimal labor cost and speed then the former is optimal whereas if the criterion were minimization of capital expenditures and full employment, then the latter would be the desired approach. "Optimal", like beauty, is in the eyes of the beholder. Buchanan (2002) conceived risk assessment options assessments as a combination of two processes: risk management and assessment. Risk managers have a general idea of the degree of public health protection they are trying to achieve. Risk assessors then examine the impacts of different control options and approaches, providing the risk managers with data that allows them to more objectively evaluate proposed options. The risk managers then provide alternative management options to be evaluated. This iterative process continues until one or more risk management options achieving the desired level of protection are identified.

Risk perception and risk communication are strongly related, the former being markedly influenced by the latter. Risk communication should always have an objective, i.e. an expected attitude by the public. Usually, such an objective is set by risk managers. Some of the key points for successful risk communication are as follows (Trautman, 2001):

- Early inclusion of major stakeholders in the risk evaluation process is best. It helps avoid the appearance of trying to hide something, provides transparency, and may help identify potential pitfalls.

- Being open, honest, sincere and appreciative of other views.

- Recognizing biases and differences that are not likely to change (or only slowly), but must be expressed as part of the process.

- Finally, enlisting professional help for risk communication techniques.

\section{Producer's and consumer's risk}

Food producers and wholesalers/retailers' efforts are focused on earning money by selling their products, primarily. There are many factors which can influence the volume of sales: the dependence of quality/quantity of the product on weather, governmental policy such as economic support or marketing of a food sector, diet fashion, complying with new legislation (e.g. on emerging risks) or food crisis.

Nowadays, consumers expect high quality from a food (frequently associated with freshness), pleasure, convenience, good price-quality balance, reasonable consume-by-date margins, and of course, safety. Usually, the safety of a product on the market is taken for granted, and in fact, consumers do not usually make their choice based on safety, but rather on other issues. In fact, the EU survey mentioned previously (European Commission et al., 2010) revealed that the majority of respondents associate food and eating with pleasure, such as selecting fresh and tasty foods (58\%) and with enjoyment of meals with friends and family (54\%); food safety (37\%) was less commonly associated with food and eating as such. 
Nevertheless, both producers and wholesalers/retailers do know that the safety of a food product is basic, and the consequences of unsafe food in the market could be devastating, consumers being the most-harmed stakeholders.

Todd (1989) estimated the economic impact of the acute bacterial food-borne disease in Canada and United States. Medical costs and lost income were easier to determine than losses to food companies, legal awards and settlements, value of lost leisure time, pain, grief, suffering and death. The evaluation of costs at the national level for Canada and the United States based on all available costs for 61 incidents showed that company losses and legal action are much higher than medical/hospitalization expenses, lost income or investigational costs. It was reckoned that on an annual basis an estimated 1 million cases of acute bacterial food-borne illness in Canada cost nearly after $\$ 1.1$ billion and 5.5 million cases in the United States cost nearly $\$ 7$ billion. The value of deaths was a major contributor to the overall costs especially for diseases like listeriosis, salmonellosis, Vibrio infections, and haemorrhagic colitis. Nowadays, food companies are responsible for the safety of their products in accordance to food hygiene legislation, irrespective of the official inspection. This means that, when an outbreak or an individual case is reported, legal responsibility inevitably falls on food companies.

In food microbiology, producer's and consumer's risks are those derived from sampling lots. It is not feasible to analyze all units of a lot (by destructive analysis techniques), so a sampling scheme must necessarily be designed for all hazards indentified in a food. Microbiological criteria applied for different foods and hazards should include a sampling plan. For example, the EC Regulation No. 2073/2005 on microbiological criteria for foodstuffs, establishes for Salmonella in different meat products a sampling plan consisting of analyzing 5 samples, from which none may exceed the microbiological limit established. When a lot is sampled, a probability of accepting "good" or "bad" lots is associated. What is more, a probability of accepting a lot when it is actually "bad" and a probability of rejecting a lot when it is actually "good" is also associated. These probabilities are the so-called consumer's risk and producer's risk, respectively. Table 2 shows the different samplingbased decisions.

In general, risk management at consumer level includes important issues such as good hygiene practices at home, proper heating of foods or adequate refrigerated storage of chilled foods. Risk management at producer/wholesaler/retailer's level include a wide range of aspects such us the application of Good Manufacturing Practices, Good Hygiene Practices or the correct implementation of Hazard Analysis and Critical Control Point systems.

\begin{tabular}{|c|c|c|c|}
\hline \multicolumn{2}{|c|}{} & \multicolumn{2}{c|}{ Hygiene quality of a lot } \\
\cline { 2 - 4 } \multicolumn{2}{|c|}{} & “Good" & "Bad" \\
\hline $\begin{array}{c}\text { Hygiene quality } \\
\text { detected at } \\
\text { sampling }\end{array}$ & “Good" & $\begin{array}{c}\text { Acceptance of a lot: right } \\
\text { decision }\end{array}$ & $\begin{array}{c}\text { Acceptance of a lot: wrong } \\
\text { decision (consumer's risk) }\end{array}$ \\
\cline { 2 - 4 } & “Bad" & $\begin{array}{c}\text { Rejection of a lot: wrong } \\
\text { decision (producer's risk) }\end{array}$ & Rejection of a lot: right decision \\
\hline
\end{tabular}

Table 2. Decisions made at sampling of food lots. 


\section{Management measures to reduce risks throughout the food chain}

Optimization of food control measures in terms of efficiency, effectiveness, technological feasibility and practicality at selected points throughout the food chain is the generalized goal of food businesses.

Food safety and its management has been a matter of concern to humans since the dawn of history. FAO/WHO (n.d.) described the traces of the development of the food control from Ancient History, the Middle Ages and the Industrial Revolution until the 19th and 20th centuries. Many rules and recommendations advocated in religious or historical texts are evidence of the concern to protect people against food-borne diseases and food adulteration. Modern countries have traditionally attempted to improve food safety by setting microbiological criteria for raw or for finished processed products. However, the frequency and extent of sampling used in traditional food testing programs may not provide a high degree of consumer protection.

In the 1960s, the United States Army and the United States National Aeronautics and Space Administration (NASA) developed a system to guarantee the safety of the foods that astronauts would consume in space based on prevention and not on end-product inspection and testing, from which emerged the Hazard Analysis Critical Control Points (HACCP) concept. HACCP emphasizes the control of the process as early as possible in the processing system by using operator control and/or continuous monitoring techniques at critical control points. The HACCP system can be applied throughout the food chain, from the primary producer to final consumer. The use of HACCP principles in the promulgation of regulations for low-acid canned food was completed in 1974 by the United States Food and Drug Administration (US-FDA). In the early 1980s, the HACCP approach was adopted by other major food companies and the experiences gained indicate that application of HACCP systems leads to more efficient prevention of food-borne diseases (International Commission of Microbiological Specifications for Foods [ICMSF], 1988).

Recognizing the importance of HACCP to food control, the US-FDA published a guidelines for Hazard Analysis Critical and Critical Control Point Principles and Application (US-FDA, 1997) defining HACCP as "a scientific, rational and systematic approach to the identification, evaluation, and control of food safety hazards". With this system, food safety control is integrated into the design of the process rather than the ineffective system of endproduct testing. Therefore, it provides a preventive and thus a cost-effective approach to food safety. While it was originally developed to ensure microbiological safety of foodstuffs, it has been further broadened to include chemical and physical hazards in foods. (FAO/WHO, 1997a).

Sometimes a level of microbiological criteria stricter than the international level for foods in trade (based on Codex recommendations) imposed by national governments for different foods have been viewed by other countries as barriers to international trade. Because of this, more than 100 countries have signed the General Agreement on Tariffs and Trade (GATT), and "Sanitary and Phytosanitary Agreement" (SPS Agreement) of the World Trade Organization (WTO). This agreement states that, although each country has the sovereign right to decide on the degree of protection it wishes for its citizens, levels of criteria demanded for imported food must be based on scientific evidence, consideration of risk and societal issues. It also established that a country must not ask for a higher degree of safety for goods than it does for goods produced in its own country. The work of Codex through its standards, guidelines and recommendations, is recognized as the reference or 'yard stick' 
for national requirements in food safety and has played an important role in facilitating international trade. (FAO/WHO, 1997a).

In Europe, the Regulation (EC) No. 178/2002, laying down the general principles and requirements of food law, establishing the European Food Safety Authority and laying down procedures in matters of food safety, incorporated Risk Analysis as a tool to provide a systematic methodology for the determination of effective, proportionate and targeted measures or other actions to protect health. Also, several Regulations force the implementation of HACCP system by food business operators, based on Risk Analysis criteria, and the adequate establishment of official control systems (Regulation (EC) No. 852/2004; Regulation (EC) No. 853/2004; Regulation (EC) No. 854/2004; Regulation (EC) No. 2074/2005).

The HACCP concept has provided great improvements in the production of safe foods. The goal of HACCP is to focus on the hazards in a particular food commodity that are reasonably likely to affect public health if left uncontrolled, and to design food products, processing, commercialization, preparation and use conditions that control those hazards. HACCP involves an assessment of hazards in a particular production sequence and defines steps where control measures that are critical for the safety of a product should be taken. Also, it states limits, monitoring procedures and corrective actions. To be successful, HACCP needs to build on a prerequisite programs and good practices such as good agricultural practices (GAPs), good manufacturing practices (GMPs) and good hygienic practices (GHPs), which minimize the occurrence of hazards in the product and the production environment (ICMSF, 2005). The main elements of the HACCP system are: a) identify potential hazards; b) determine the Critical Control Points (CCPs); c) establish the criteria that must be met to ensure that a $\mathrm{CCP}$ is under control; d) establish a monitoring system; e) establish the corrective action when CCP is out of control; f) establish procedures for verification; and $\mathrm{g}$ ) establish documentation and record-keeping.

An ongoing assessment following the implementation of a HACCP system can be achieved at two levels; with internal audits carried out by those responsible for the system or by independent external audits. In HACCP and food safety there are several standards from a variety of sources such as legislative standards, national or international standards like International Organization for Standardization (ISO), or standards from customer-driven expert groups or food industry sectors. When standards are verified by a professional external audit and certification, the effectiveness of food safety programs can be demonstrated. Within certification, we can mention as examples the British Retail Consortium Global Standard (BRC), Global Food Safety Initiative (GFSI), ISO 22000:2005 "Food Safety Management Systems- Requirements for any organization in the food chain" and Dutch HACCP-code (Wallace et al., 2011).

Risk Management can be defined as the process of weighing policy alternatives in the light of the results of risk assessment and, if required, selecting and implementing appropriate control options, including regulatory measures. The report elaborated by $\mathrm{FAO} / \mathrm{WHO}$ (1997b) considers 8 general principles of food safety risk management. The first principle states that risk management should follow a structured approach which is: risk assessment, risk management option assessment, implementation of management decision, and monitoring and review. The second principles highlights that the protection of human health should be the primary consideration in risk management decisions and arbitrary or unjustified differences in the risk levels should be avoided. The third principle deals with 
risk management decisions and points out that practices should be transparent, that is to say, they should include the identification and systematic documentation of all elements of the risk management process including decision-making, so that the rationale is transparent to all interested parties. The fourth principle states that the determination of risk assessment policy should be included as a specific component of risk management. The fifth principle underlines the functional separating of risk management and risk assessment which ensures the scientific integrity. The sixth principle reminds us to take into account the uncertainty of the risk assessment in decision-making. The seventh principle states that risk management should include clear, interactive communication with consumers and other interested parties in all aspects of the process. The last principle proposes that risk management should be a continuing process that includes all newly generated data in the evaluation and review of risk management decisions. Monitoring and other activities will likely be necessary to carry out the review effectively.

Almost all the progress in the development of HACCP and other standards like effective food safety management programs and their global acceptance and use has been accomplished by the voluntary efforts of global food companies. Involvement of all stakeholders in food safety issues is crucial in order to assure food safety in our rapidly changing global food market. We need more knowledge throughout the food chain, common standards and science-based regulations, and a global infrastructure to provide global strategy and oversight (Wallace et al., 2011).

\section{Risk assessment in foods}

In the food safety field, the performance of Microbiological Risk Assessment (MRA) methodology has been developed as a standardized approach to integrate and evaluate information from diverse sources concerning the origin and fate of pathogens in the food chain and to determine the magnitude of public health risks. The SPS Agreement of the WTO recognized the necessity of scientific basis for evaluating food safety. Based on this consideration, principles and guidelines for food safety risk analysis were defined by the Codex Committee on Food Hygiene (FAO/WHO, 1995).

\subsection{General principles for conducting MRA}

The principles and guidelines for the conduct of MRA are described in Codex Alimentarius (Codex Alimentarius Commission [CAC], 1999). A formal MRA consists of four steps:

i. Hazard identification;

ii. Hazard characterization;

iii. Exposure assessment; and

iv. Risk characterization.

The definition of each step as well as their relationships are described in Figure 1.

The general principles for the conduct of MRA (CAC, 1999) can be summarized as follows:

- $\quad$ MRA should be soundly based upon science.

- There should be a functional separation between risk assessment and risk management.

- MRA should be conducted according to a structured approach that includes hazard identification, hazard characterization, exposure assessment, and risk characterization.

- $\quad$ MRA should clearly state the purpose of the exercise, including the form of risk estimate that will be the output. 
- $\quad$ The conduct of MRA should be transparent.

- Any constraints that impact on the risk assessment such as cost, resources or time, should be identified and their possible consequences described.

- The risk estimate should contain a description of uncertainty and where the uncertainty arose during the risk assessment process.

- Data should be such that uncertainty in the risk estimate can be determined; data and data collection systems should, as far as possible, be of sufficient quality and precision that uncertainty in the risk estimate is minimized.

- MRA should explicitly consider the dynamics of microbiological growth, survival, and death in foods and the complexity of the interaction (including sequelae) between human and agent following consumption as well as the potential for further spread.

- Wherever possible, risk estimates should be reassessed over time by comparison with independent human illness data.

- $\quad$ MRA may need reevaluation, as new relevant information becomes available.

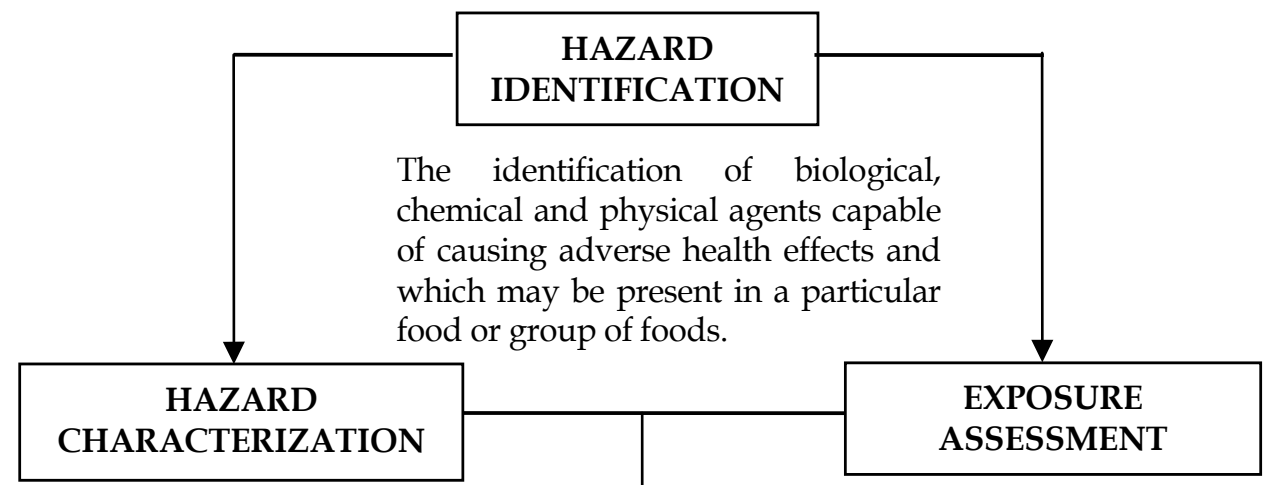

The qualitative and/or quantitative evaluation of the nature of the adverse health effects associated with biological, chemical and physical agents, which may be present in food. For biological or physical agents, a dose-response assessment should be performed if data are available.

ASSESSMENT

The qualitative and/or quantitative evaluation of the likely intake of biological, chemical and physical agents via food, as well as exposures from other sources if relevant.

The qualitative and/or quantitative estimation, including attendant uncertainties, of the probability of occurrence and severity of known or potential adverse health effects in a given population based on hazard identification, hazard characterization and exposure assessment.

Fig. 1. Scheme of the four steps of MRA. Adapted from FAO/WHO (2006a). 
These principles highlight the importance of developing a systematic and scientific methodology in order to serve as main guidance for decision-making process in the food safety field.

\subsection{Uses of risk assessment outputs}

Some of the final uses of risk assessment outputs are:

- Characterization of the most important factors influencing the risk of hazards identified in the food chain.

- Identification of strategies for risk mitigation.

- Establishment of guidelines for ranking priorities to be addressed in public health and food safety programs.

With regard to this, it is worth mentioning that risk assessment of foods is part of the risk analysis framework. The Regulation (EC) No. 178/2002 laying down the general principles and requirements of food law, establishing the European Food Safety Authority and laying down procedures in matters of food safety states in its Article 17 that "Where food law is aimed at the reduction, elimination or avoidance of a risk to health, the three interconnected components of risk analysis - risk assessment, risk management, and risk communication - provide a systematic methodology for the determination of effective, proportionate and targeted measures or other actions to protect health.".

For risk assessment issues, the World Health Organization (WHO) and the Food and Agricultural Organization of the United Nations (FAO) are coordinated by the establishment of the Joint Expert Meetings on Microbiological Risk Assessment. This group has initiated a process to produce guidelines on four steps of the MRA process and has produced several international risk assessments, based mainly on a combination of modules developed for national risk assessments. Since the mid-90s, several MRA have been developed for different food/risk combinations. Some of the main purposes of conducting MRA are focused on providing a response to questions such as:

- Which foods pose a higher risk for the selected pathogen?

- Which interventions can effectively control the pathogen?

- How can corrective measures be implemented in food industries?

- Which is the effectiveness of testing and sanitation of food contact surfaces on mitigating product contamination and reducing the subsequent risk of illness?

- How effective are alternative pre- and post-processing interventions in mitigating product contamination and reducing the subsequent risk of illness?

The most important significance of MRA (even more than the estimation of the human health risk) is that it allows an "a priori" assessment of the effect of intervention measures throughout the whole food chain, or combinations of intervention measures, on public health (Havelaar et al., 2008). Thus, risk managers can request the development of MRA in order to provide a clear scientific methodology to support decisions regarding food safety and apply control measures with, as ultimate objective, food safety assurance. In this sense, it is important to be sure that a clear mandate is transmitted to risk assessors and that the MRA satisfies the risk manager actual needs. Once established, the MRA should be further examined by the scientific community and, if necessary, by the general public.

The results obtained in the MRA may be well described for their utilization by risk managers in order to adequately select the most convenient options to improve food safety. In fact, risk assessment may also involve judgments and choices that are not entirely 
scientific, and risk managers need a sound understanding of scientific approaches used by risk assessors.

\subsection{Risk profiles and quantitative approaches in MRA}

A scientific-structured MRA often needs a large number of data and time. However, this fact mainly depends on the complexity of the questions proposed and the degree of certainty required. If the question is simple (such as establishing a risk ranking for different food matrices and microbiological risks) a point-estimate approach will suffice (Ross \& Sumner, 2002).

To better understand the MRA process, the Australian Food Safety Centre of Excellence developed a semi-quantitative spreadsheet (Risk Ranger) in which the user can introduce some information organized in three modules:

A. Susceptibility of the host and severity of the hazard.

B. Probability of exposure to contaminated food.

C. Probability that a given food contains an infectious dose.

As a result, the spreadsheet calculates the risk ranking derived from the inputs introduced within each item (A-C) ranging from 0 (low risk) to 100 (high risk). Later on, the tool was applied to selected food commodities like seafood (Sumner \& Ross, 2002) or meat products (Sumner et al., 2005).

Risk ranking tools were further developed by the US-FDA (US-FDA, 2009), which has been recently working on fresh produce commodities. A semi-quantitative tool was created to identify priority pathogen-produce commodity combinations based on explicit data-driven risk criteria. The epidemiological information available was used to prioritize risk combinations in four dimensions: strength of the epidemiological association between the pathogen and the commodity; severity of disease; pathogen characteristics that affect disease, risk or severity; and food characteristics that affect pathogen prevalence, pathogen behavior, and likelihood of exposure by the consumers.

The main results of the model revealed that the combination leafy greensenterohemorrhagic Escherichia coli O157:H7 (EHEC) consistently ranked first, followed by tomatoes-Salmonella enterica.

The New Zealand Food Safety Authority (NZFSA) has focused on the development of risk profiles in soft cheeses for Listeria monocytogenes (NZFSA, 2005a). The purpose of a risk profile is to provide contextual and background information relevant to a food/hazard combination so that risk managers can make decisions and, if necessary, take further action. In this document, MRA was conducted based on epidemiologic information, prevalence and concentration of pathogens, consumption data and dose-response relationships. A similar approach was performed for L. monocytogenes in ready-to-eat (RTE) salads (NZFSA, 2005b). Risk profiles have been also determined for pork and poultry products (Mataragas et al., 2008). According to Codex Alimentarius (CAC, 2007), the main information to be included in a risk profile should cover these aspects:

- Define the food-pathogen combinations that could be more important to be investigated.

- Description of the public health concern (biological hazard, illness symptoms, epidemiology of the disease, economical costs etc.).

- Production, dispatch and consumption of foods (a formal description of the farm-tofork chain, a summary of the risk management measures and their efficacy on the food production control etc.). 
- $\quad$ Risk assessment needs and questions for risk assessors.

- Available information and data gaps (include other previous related MRA and additional information sources to be considered in the new MRA).

A simplified deterministic MRA was addressed by Evers \& Chardon (2010) for all combinations of Campylobacter spp. and Salmonella spp. with chicken fillet, filet americain (raw minced beef with mayonnaise) and table eggs in order to compare the magnitude of risks associated to each combination. The predicted risk was highest for Salmonella spp. in table eggs and Campylobacter spp. in chicken fillet. These kinds of instruments can assist to quickly determine the relative risks associated to specific food hazards, thus making decisions more efficiently. Nevertheless, when applying a simplified model, the resulting public health risk in terms of number of human cases must be interpreted in a relative sense, that is, comparing it with a reference study or other simplified pathogen-product calculations. It is advisable not to use simplified models when trying to produce an estimation of the number of cases due to the ingestion of a pathogen present in a food.

When economics is taken into consideration, a cost-utility analysis can be performed (Mangen et al., 2007). In this way, quantitative risk assessments have the additional advantage of being able to model the effects of different interventions and their associated costs.

Inclusion of variability and uncertainty in quantitative risk assessments is crucial for a more accurate determination and interpretation of risk outputs. Despite this, it should be highlighted that estimation of uncertainty is, in many cases, very difficult or even impossible when the model is complex and when a notorious lack of data is detected.

One of the earliest quantitative MRA performed at international scale was published by FAO/WHO (2002b,) which proposed MRA of Salmonella spp. in egg and broiler chickens. The main observations in broiler chickens were that a $50 \%$ reduction in prevalence of contaminated flocks influenced the reduction in the final risk of Salmonella spp. per serving until reaching 99.75 \% risk reduction. Another MRA was extended to Campylobacter spp. in broiler chickens and Vibrio parahaemolyticus and V. vulnificus in shellfish (FAO/WHO, 2002c).

The risk assessment developed in 2003 by the US-FDA and the Food Safety Inspection Service (FSIS) regarding Listeria monocytogenes in different Ready-to-Eat food categories, identified deli meats as the most risky products in relation to food-borne listeriosis in the USA. It is interesting to note that high population risks can be related to consumption of high-risk foods (e.g. pâté and meat spreads) but also to high consumption of foods with relatively low risks per serving (e.g. pasteurized milk).

FAO/WHO (2004) has also performed a MRA for L. monocytogenes in RTE foods: ice cream, fermented meats, cold-smoked and vacuum-packed fish. Risk estimates ranged from 1 case per 20 million servings for smoked fish to 0.4 cases per 1 million servings for fermented meats. An important finding of the risk assessment was that, based on the predictions of the models developed, nearly all cases of listeriosis resulted from the consumption of high numbers of the pathogen. Conversely, the models predicted that the consumption of low numbers of L. monocytogenes had a low probability of causing illness.

Risk estimation of Salmonella enteritidis in shell eggs and Salmonella spp. in egg products (liquid pasteurized egg) was performed by USDA-FSIS in two different MRA (USDA-FSIS, 1998; USDA-FSIS, 2005). Pasteurization was predicted to be effective for reducing illnesses from S. enteritidis in shell eggs and from Salmonella spp. in egg products. If all eggs produced in the US were pasteurized for $3 \log _{10}$ units reduction of $S$. enteritidis, the annual number of 
illnesses would be reduced from 130,000 to 41,000 cases. Also, if all liquid egg products produced in the US were pasteurized for $6 \log _{10}$ units reduction of Salmonella, the annual number of illnesses would be reduced from 5,500 to 3,200 cases. Finally, storage time, temperature, initial levels of Salmonella in unpasteurized egg products and the way in which products are prepared for consumption, had the greatest impact on human health in the risk assessment of Salmonella spp. in egg products.

As explained above, the more complex the MRA is, the less understandable for risk managers, probably leading to misinterpretation and wrong decision-making. Nevertheless, MRA was mainly addressed to include a more extensive analysis of risk factors and to assess the effectiveness of potential management strategies to reduce microbial risks. One of the most representative examples is the MRA developed by Ross et al. (2009) for $L$. monocytogenes in RTE meats. The predictions obtained were based on data describing initial contamination levels of both lactic acid bacteria and L. monocytogenes, product formulation, times and temperatures of distribution and storage prior to consumption, and consumption patterns. The risk output indicated that processed meats could be responsible for up to $\sim 40 \%$ of cases of listeriosis in Australia, a level that could be in line with the available epidemiological data. Application of risk management measures for L. monocytogenes in ready-to-eat lettuce salads was made by Carrasco et al. (2010). They showed that the most effective measures to reduce the risk of listeriosis were the use of specific mixture of gases in packages, the reduction of shelf-life to four days and the prevention of high-risk population from consuming ready-to-eat lettuce salads. Other methodologies are based on the implementation of advanced sensitivity techniques in MRA (Pérez-Rodríguez et al., 2007). This latter study revealed that the extremes at the right side of the dose distribution ( 9 to $11.5 \log$ cfu per serving at consumption) were responsible for most of the cases of listeriosis simulated. Other approaches developed for L. monocytogenes in RTE meats (Mataragas et al., 2010) propose different strategies to be considered by risk managers. They applied a structured methodology using risk-based metrics such as Food Safety Objectives (FSO), Performance Objectives (PO) and Process Criteria (PC) defined by the International Commission of Microbiological Specifications for Foods (ICMSF) (ICMSF, 2002) (see Section 7 for more details). They demonstrated that by extracting useful information from a risk assessment model, practical risk management strategies and intervention steps can be developed for reducing the number of cases. Further approaches should be addressed to implement these risk-based metrics into HACCP systems.

\section{Variability and uncertainty in the propagation of risks throughout the food chain}

\subsection{Considering variability and uncertainty for food risk management}

There may be different approaches to carrying out a quantitative risk assessment. In essence, the process can be addressed from two different approaches: point-estimate and probabilistic. The first approach concerns the use of point-estimate values to describe variables of the model (Øvreberg et al., 1992). In the second approach, variables are distributions of probability which describe uncertainty and/or variability of inputs. Both approaches support adequate decisions in decision-making processes; however, by including variability and uncertainty, insight into the level of accuracy is gained. An increasing number of probabilistic risk assessments studies have been observed during the last few years for microbial and chemical hazards (Pérez-Rodríguez et al., 2007; Fairbrother 
et al., 2007; Tressou et al., 2004; US-FDA et al., 2003). Although the concepts of variability and uncertainty may be easily confused, they remain distinct in a decision-making context (National Research Council [NRC], 1994). Variability refers to temporal, spatial or interindividual differences (heterogeneity) in the value of an input (Cullen \& Frey, 1999). For example, variability might refer to differences in the body weights between individuals, or in the consumption of specific dietary items of those individuals. In general, variability cannot be reduced by additional study or measurement. The existence of variability in the population implies that a single action or strategy may not emerge as optimal for each of the individuals, and consequently any decision made will go too far for some and not far enough for others. Uncertainty differs significantly from variability. Uncertainty may be thought of as a measure of the incompleteness of one's knowledge or information about an unknown quantity whose true value could be established if a perfect measuring device were available (Cullen \& Frey, 1999). Uncertainty arises from our lack of perfect knowledge, and it may be related to the model used to characterize the risk, the parameters used to provide values for the model, or both. In some cases, we can reduce uncertainty by obtaining better information, but this may not always be possible. Uncertainty implies that we might make a non-optimal choice because we may expect one outcome but something quite different might actually occur.

\subsection{Propagation of variability and uncertainty in risk assessment}

Uncertainty can be originated from a number of sources which may go from specification of the problem, formulation of conceptual and computational models, estimation of input values and calculation, interpretation, and documentation of the results. However, only input values may be quantified with variance propagation techniques. Uncertainty coming from the model structure, erroneous assumptions or misspecification of the model can only be analyzed by decision trees based on expert elicitation (Vose, 2000; WHO, 1995).

Variability is a result of the natural variation of the observed system. This may be spatial, temporal or inter-individual variation. Examples of this may be the distribution of a certain hazard in a specific food batch (i.e. special variation) or between different batches over time (i.e. temporal variation). Variability also exists between and within strains in the microbial response (e.g. growth, death, or survival) to environmental conditions (e.g. temperature, $\mathrm{pH}$, etc.), which is named biological variability. In some cases, there may be several subpopulations which are more nearly homogenous than the overall population. In such cases, the observed variability may be well described by a mixture of frequency distributions for various subpopulations (Cullen \& Frey, 1999). Both variability and uncertainty may be quantified using distributions. However, the interpretation of the distributions differs in each case. Usually, variability is represented as distributions of frequencies which provide the relative frequency of values in a specific interval. In turn, uncertainty probability distributions reflect the degree of belief, or subjective probability that a known value is within a specified interval. Figure 2 shows the uncertainty and variability of a hypothetical variable.

The most used techniques to propagate uncertainty and variability in a probabilistic food risk assessment model comprises classic statistics and numerical methods (Vose, 2000). The method of moments is a classical method that can be applied to propagate information regarding uncertainty and variability based on the properties of mean and standard deviation of input values. However, this method is only valid when input values are distributed normally. By contrast, algebraic methods can be applied even when other types 
of distributions than the normal distribution are used to characterize uncertainty and variability; this method, though, is limited to specific distributions which are not usually used in risk assessment studies. The Monte Carlo analysis is a numerical method which allows propagating numerous types of probability distributions in risk assessment studies based on the random sampling processes of each distribution. This method has become quite popular among food risk assessors and managers as the existence of commercial software enables easy application by users who are not advanced practitioners in numerical methods.

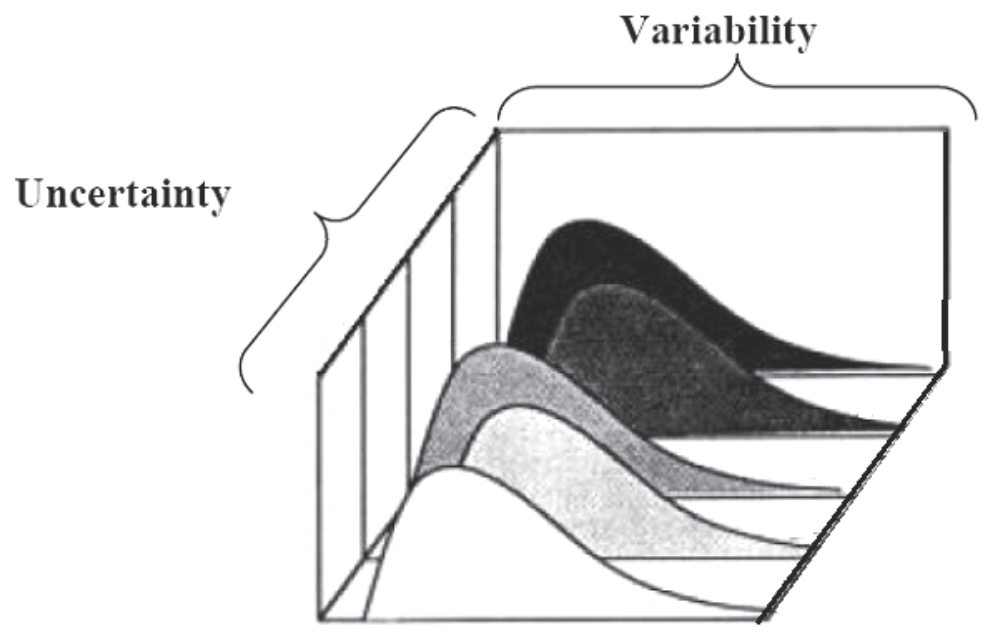

Fig. 2. Representation of variability and uncertainty for a hypothetical variable. Adapted from Hoffman \& Hammonds (1994).

Although the specification of distributions for all or most variables in a Monte Carlo analysis is useful for exploring and characterizing the full range of variability and uncertainty, sometimes it is unnecessary and not cost-effective. The study by PérezRodríguez et al. (2007) pointed out that certain inputs (e.g. serving size) in MRA studies might be described by point-estimate values provided they are not significant sources of uncertainty or variability within the risk estimate. Similarly, Leeuwen \& Hermens (1995) stated for chemical hazards that the results of simple model calculations are easier to communicate and, therefore, may serve to better support the decision. In conclusion, uncertainty and variability components should be applied when necessary, and a previous analysis should be carried out by risk assessors in order to determine which inputs are more relevant as uncertainty and variability sources in the risk estimate. Based on results, simpler models could be better understood and applied by food risk managers to make decisions.

\subsection{Separation of variability and uncertainty improves food Risk Management}

Variability and uncertainty have different ramifications in the decision-making process. By confronting variability and uncertainty, risk managers can better understand how variability affects the distributions of exposure or risk, the impact of various assumptions, data gaps or model structures on decision-making. Uncertainty forces decision-makers to judge how probable it is that risk will be overestimated or underestimated for every 
member of the exposed population, whereas variability forces them to deal with the certainty that different individuals will be subjected to risks both above and below any reference point chosen. Some studies have demonstrated how better characterization of variability and uncertainty in the risk assessment may lead not only to better risk management, but also to better risk communication (Pérez-Rodríguez et al., 2007). In exposure assessment of food hazards, the common source of variability resides in the different characteristics between individuals (e.g. intake rates, activity patterns, geographical distribution) and/or the spatial and temporal distribution of contaminants in foods. However, uncertainty could be present in such characteristics or in the contamination distribution, for example, due to measurement errors or sampling of lots. In these cases, the resultant variability distribution would also be uncertain. Inference to the whole population from the observed distribution could lead to uncertainty; hence the contaminant distribution may account for both uncertainty and variability. However, sometimes, separation between both uncertainty and variability is not clear. In these cases, the final decision about which part of the input corresponds to uncertainty and variability will depend on the interpretation made by the risk assessor or manager.

Considering separately both components can be crucial to better guide risk managers in the decision-making process thereby resulting in more adequate food policies. Understanding variability can help to identify significant subpopulations which are more relevant to risk. Uncertainty in the observed values for specific characteristics or parameters can be used to elucidate whether further research or alternative methods are needed to reduce uncertainty.

\section{Risk management metrics}

\subsection{Appropriate Level of Protection (ALOP)}

The SPS Agreement (WTO, 1995) states that Members States are autonomous to adopt SPS measures to achieve their health protection level. This level, called Appropriate Level of Protection (ALOP) is defined as "The level of protection deemed appropriate by the Member establishing a sanitary or phytosanitary measure to protect human, animal or plant life or health within its territory." An ALOP represents the current public health status and not a goal to be achieved in the future. The ALOP is strongly influenced by aspects such as the capacity of the consumer to control it, the severity of the hazard, and level of alertness among consumers raised by the hazard. In short, ALOP choice greatly depends on the perception of the risk with regard to the hazard and food associated. This concept has been incorporated by organizations like FAO and ICMSF as a basis to develop a new global risk management schemes. FAO/WHO (2002a, 2006b) and CAC (2007) develop in more detail the role of the ALOP in a formalized and global process of Microbiological Risk Management. According to FAO/WHO (2002a), an ALOP is specified as a statement of the impact of the illness (e.g. number of cases/100,000 population/year) associated with a hazard-specific food product combination in a country, it being common to frame it in a context of continuous improvement in relation to the reduction of the illness.

The ALOP is usually expressed as the impact level of an illness in the population (e.g. annual number of cases). Nevertheless, Havelaar et al. (2004) proposed the use of integrated public health measures. Specifically, they proposed the index "Disability Adjusted LifeYear" (DALY), which has been considered by WHO (2008) as the basis for the establishment of public health goals for the quality of drinking-water (Havelaar \& Melse, n.d.). Such a proposal is based on the fact that the ALOP expressed as impact does not seem to be 
appropriate to represent illnesses associated with a microbial hazard of multiple nature (e.g. gastroenteritis, syndrome of Guillain-Barré, reactive arthritis and mortality caused by Campylobacter spp. ,Campylobacter thermophilus) (Havelaar et al., 2004). Other decisions such as the distinction between different population groups (e.g. high risk populations), the selection of one or more foods as vehicles of hazards for ALOP establishment, or the inclusion of other ways of transmission (e.g. from person to person or from water to person), etc., still have to be discussed for a better application of the ALOP.

Determining the ALOP may be considered a complex task. Information from health surveillance systems is crucial to undertake the ALOP determination. However, the confirmed-cases reported by surveillance systems represent only a small fraction of the total disease incidence, and additional information should be applied to calibrate the so-called surveillance pyramid. The sensitivity of the surveillance may be another important factor to be considered since this can vary between countries and within one country over time. Because most food-borne pathogens can also be transmitted by other routes (e.g. the environment or direct contact with animals), it is also necessary to establish the fraction of all cases that is attributable to food, and within food categories which food types are associated with exposure. For that purpose, information from various sources such as outbreak studies, analytical epidemiology, microbial subtyping and risk assessment can be applied; this process is called source attribution (Batz et al., 2005). FAO/WHO (2006b) pointed out that Microbiological Risk Assessment can contribute, in a fundamental way, to an elucidation of the ALOP.

\subsection{Public health goal}

The public health goal concept, different from ALOP, is intended to derive strategies to improve the future public health status and reduce disease burden (FAO/WHO, 2006b). Public health goals are usually set by government or public health bodies, with a varying degree of input from stakeholders, and imply some consideration of the current health status and disease burden (in the population as a whole or in vulnerable sub-populations). In setting goals, consideration may also be given to possible interventions and how achievement of the goal is to be measured. The public health goal can be specified following two approaches. Establishing an objective of reduction of illness (e.g. from 10 to 5 in the rate of population/year) assuming that the objective is feasible; or else, modifying such objectives as function of management capacities. Both approaches have strengths as well as weaknesses. For example, in the first case, more resources are destined to management, offering greater flexibility and promoting innovation, although it is more probable that the objective is unrealistic and impossible to be achieved. On the other hand, the second approach, based on the actual technical status, is more likely to succeed in achieving the goal. Nevertheless, for this, the industry has to accomplish technological requirements and/or adapt methods to help reach the objective of public health.

\subsection{Food safety objective (FSO)}

The ALOP is not the most adequate concept for developing and implanting the necessary control measurements throughout the food chain (Havelaar et al., 2004). The terms in which the ALOP is expressed do not form part of the "language" that the industry or other operators of the food chain use for food safety management (Gorris, 2005). Therefore, the creation of a new concept was proposed (ICMSF, 2002), i.e. Food Safety Objective (FSO), which aims to establish a link between the ALOP and the "hazard" status of a food at the time of consumption. 
The ICMSF (2002) defined FSO as "The maximum frequency and/or concentration of a hazard in a food at the time of consumption that provides or contributes to the ALOP". The FSO allows a high level of flexibility to design and implement control measurements throughout the food chain (Zwietering, 2005).

FSO differs from microbiological criteria. FSO is the hazard level providing an ALOP, and specifies a goal which can be incorporated into the design of control measurements in the food chain (van Schothorst, 2005). In turn, microbiological criteria are used to verify analytically the acceptance of a batch or a group of batches. Besides, microbiological criteria may be established for quality as well as safety concerns (CAC, 2003).

\subsection{FSO in the framework of microbiological food safety risk management}

According to CAC (2008), FSO could be well established on the basis of epidemical data which describe the current status of public health for a hazard or by the application of a Risk Characterization curve. In the latter case, the curve relates FSO with an ALOP (ICMSF, 2002), the FSO being linked to a quantitative risk assessment in which variables can be related to the FSO and finally to an ALOP. Nevertheless, the literature is not clear about the consideration of the ALOP in order to establish an FSO. In practice, an FSO could be established without using an ALOP. As a matter of fact, microbiological criteria and other control measures have been raised through history mainly based on decisions of experts' panels. Nevertheless, firstly, it should be considered whether an FSO is feasible or not, and if the food business operators have the means to fulfill it.

Risk Management systems based on the FSO may be structured in five fundamental facts according to Swarte \& Donker (2005): risk assessment; establishment of an ALOP and FSO; translating the risk management to processes of management; interaction between risk assessment and risk management ; and start of a new cycle or consolidation

The ICMSF (2002) does not specify the way of application of the Risk Characterization curve, since it does not address how, by means of a dose-response model (hazard characterization), an FSO value can be estimated from a value of the impact of the illness in the population (ALOP). We should keep in mind that a dose-response model deals with individual risk (individual probability of getting ill) and not population risk (e.g. number of cases/100.000 population).

The FSO can be understood as a more or less complex system of "quantifiable" objectives that food business operators use as a criterion to select and develop the most adequate control measures. To achieve an FSO, the ICMSF (2002) and CAC (2008) have proposed different concepts to be applied throughout the food chain:

- Performance Objective: "The maximum frequency and/or concentration of a hazard in a food at a specified step in the food chain before the time of consumption that provides or contributes to an FSO or ALOP, as applicable".

- Performance Criteria: "The effect in frequency and/or concentration of a hazard in a food that must be achieved by the application of one or more control measures to provide or contribute to a Performance Objective or an FSO".

These terms and concepts must again be translated to others that food operators may understand, i.e. process criteria and product criteria. Van Schothorst (2002) defined process criteria as the control parameters (e.g. time, temperature, etc.) at a step that may be applied to reach efficiency criteria. In a HACCP context, these would correspond with the control limits of a process (Jouve, 1999). Product criteria (e.g. pH, water activity, etc.) are defined as the parameters of a food product which are essential to assure that an FSO will be reached 
(van Schothorst, 2002, 2005). This set of objectives, criteria and limits can be considered in HACCP systems and Good Manufacture Practice/Good Hygiene Practice guides to finally achieve an FSO (van Schothorst, 2005).

ICMSF (2002) proposed an inequation which considers the effect of different processes and subprocesses in the food chain (growth, inactivation, etc.) to reach an FSO:

$$
H_{0}+\sum I+\sum R \leq F S O
$$

where $H_{o}$ is the initial population of microorganisms, $I$ is a factor of increase and $R$ is a factor of reduction. All terms are expressed in $\log _{10}$.

For validation of control measures in a food chain, the FSO concept can be used to structurally combine the initial level, reduction and increase of contaminants. The impact of taking into consideration both the level and the variability of these factors on the proportion of product meeting the FSO has been investigated by Zwietering et al. (2010), working out whereabouts in the process the main factors are found to control the proportion of product meeting the FSO.

Verification of activities into Food Safety Management system based on the ALOP/FSO and other related management metrics can be performed by using information from epidemiological surveillance systems (Walls \& Buchanan, 2005). In some cases a public health goal may not be reached because the factors considered in risk assessment (basis to establish the FSO) have changed or because other important factors have not been included in risk assessment. Verification process should be considered as crucial after the implementation of Food Safety Management systems. Verification process would permit discernment between those changes in public health status produced by the implementation of FSO and those due to natural fluctuations. Currently, FAO is working on the elaboration of guidelines for the validation process of food hygiene control measures (FAO/WHO, 2006b).

\section{Future and prospective research}

Efforts are continuously being made to improve food safety in consonance with modern technologies. Intelligent packaging or labels are examples of the most recent advances in the food safety field. Genomics and proteomics are disciplines which are being increasingly applied in food safety in order to explain microorganism behavior, such as the virulence of different strains, adaptability to environmental conditions or quorum sensing. In this line, the biotechnology industry has benefitted from a major development of biosensors able to, for example, detect virulence genes in pathogens.

Food safety risk management at the food industry level has evolved from final product testing to risk prevention by application of HACCP systems. However, the development of non-destructive technology, such as image analysis, near infrared spectroscopy or radio frequency identification tags, may bring back final product testing, which should require the adaption of the management systems currently implemented.

Just as quantitative risk assessment is preferred for providing more information, HACCP systems could also include quantification of the different processes, i.e. how and to which extent different process affect hazards. In this way, HACCP would be "connected" to risk management based on risk assessment and with health official control, which increasingly demand quantitative justification for different practices and processes. 
The continuous development of alternative food standards, specifications, formulations and novel foods, together with increasing international trade, would require more sophisticated risk management measures. Jacxsens et al. (2009) proposed the implementation of microbial assessment schemes as a tool for the (yearly) verification of a food safety management system in food industries, as required by CAC (2003). The structure of these kind of system is susceptible to be in share among food enterprises to identify and agree on microbiological safety issues and risk management measures.

Environmental sustainability of food production is also an important issue to be considered when managing food risks. A way of evaluating the environmental impact of a certain product, process or related activity is through the so-called Life cycle assessment (Roy et al., 2009). Life cycle assessment is a tool for evaluating environmental effects of a product, process, or activity throughout its life cycle or lifetime, which is known as a 'from cradle to grave' analysis. Environmental awareness influences the way in which legislative bodies such as governments, will guide the future development of agricultural and industrial food production systems. A collaborative framework should be established by risk assessors and managers, food business operators and governmental authorities to couple life cycle assessment with risk management based on risk assessment. International standardization on how to use these tools would broaden their practical applications, improve the food safety and reduce human health risk.

\section{Acknowledgments}

CTS-3620 Project of Excellence from the Andalusia Government, AGL 2008-03298/ALI project from the Spanish government, FP7-KBBE-2007-2A n 222738 project from the VII Framework Programme and European ERDF funding are greatly acknowledged for providing material and specially human resources, making possible the continuation of risk assessment and management activities at national and European level by our research group AGR170 “HIBRO”.

\section{References}

Batz, M.B.; Hoffmann, S.A.; Krupnick, A.J.; Morris, J.G.; Sherman, D.M.; Taylor, M.R. \& Tick, J.S. (2004). Identifying the most significant microbiological foodborne hazards to public health: a new risk ranking model. In: Food Safety Research Consortium, 15.02.2011, Available from: http://www.thefsrc.org/Discussion\%20Papers/FRSCDP-01.pdf

Buchanan, R. (2002). The role of quantitative microbiological risk assessment in risk management options, In: FAO, 15.02.2011, Available from:

ftp:/ /ftp.fao.org/es/esn/jemra/kiel_paper4.pdf

Carrasco, E.; Pérez-Rodríguez, F.; Valero, A.; García-Gimeno, R.M. \& Zurera, G. (2010). Risk assessment and management of Listeria monocytogenes in ready-to-eat lettuce salads. Comprehensive Reviews in Food Science and Food Safety, Vol. 9, No. 5, (August 2010), pp. 498-512, ISSN 1541-4337

Codex Alimentarius Commission (1999). Principles and Guidelines for the Conduct of Microbiological Risk Assessment. CAC/GL-30, In: Codex Alimentarius, 15.01.2011, Available from:

http://www.codexalimentarius.net/web/standard_list.do?lang=es 
Codex Alimentarius Commission (CAC). (2003). Recommended International Code of Practice - General Principles of Food Hygiene. CAC/RCP1-1969, Rev. 4-2003, In: Codex Alimentarius, 15.01.2011, Available from: http://www.codexalimentarius.net/web/standard_list.do?lang=es

Codex Alimentarius Commission (CAC). (2007). Principles and guidelines for the conduct of microbiological risk management (MRM). CAC/GL 63-2007. In: Codex Alimentarius, 15.02.2011, Available from:

http://www.codexalimentarius.net/web/standard_list.do?lang=es

Codex Alimentarius Commission (CAC). (2008). Guidelines for the validation of food safety control measures. CAC/GL 69-2008. In: Codex Alimentarius, 15.02.2011, Available from: http://www.codexalimentarius.net/web/standard_list.do?lang=es

Cullen, A.C. \& Frey, H.C. (1999). Probabilistic Techniques in Exposure Assessment- A Handbook for dealing with variability and uncertainty in models and inputs, Plenum Press, ISBN 0-306-45956-6, New York, USA

European Commission; EFSA; TNS Opinion \& Social (November 2010). Special eurobarometer 354. Food-related risks, In: EFSA, 15.02.2011, Available from: http://www.efsa.europa.eu/en/riskcommunication/riskperception.htm

European Food Safety Authority \& European Centre for Disease Prevention and Control (EFSA \& ECDC). (2011). The European Union Summary Report on Trends and Sources of Zoonoses, Zoonotic Agents and Food-borne Outbreaks in 2009, EFSA Journal, Vol. 09, No. 3:2090, (March 2011) ISSN 1831-4732

Evers, E.G, \& Chardon, J.E. (2010). A swift Quantitative Microbiological Risk Assessment (sQMRA) tool. Food Control, Vol. 21, No. 3 (March 2010), pp. 319-330, ISSN 09567135

Fairbrother, A.; Wenstel, R.; Sappington, K. \& Wood, W. (2007). Framework for Metals Risk Assessment. Ecotoxicology and Environmental Safety, Vol. 68, No. 1, (November 2007), pp. 145-227, ISSN 0147-6513

Fischhoff, B.; Bostrom, A. \& Jacobs Quadrel, M. (1993). Risk perception and communication. Annual Review of Public Health, Vol. 14, (May 1993), pp. 183-203, ISSN 0163-7525

Food Agriculture Organization/World Health Organization (FAO/WHO). (1995). Application of Risk Analysis to Food Standards Issues. Report of the Joint FAO/WHO Expert Consultation, In: World Health Organization, 15.02.2011, Available from: http://www.who.int/foodsafety/publications/micro/en/march1995.pdf

Food Agriculture Organization/World Health Organization (FAO/WHO). (1997a). HACCP - An Introduction to the Hazard Analysis and Critical Control Point System, In: World Health Organization, 15.02.2011, Available from: https://apps.who.int/fsf/Codex/IntroducingHACCP.pdf

Food Agriculture Organization/World Health Organization (FAO/WHO). (1997b). Risk Management and Food Safety. Report of a Joint FAO/WHO Consultation, Publications Division, Food and Agriculture Organization of the United Nations, ISBN 92-5103980-1, Rome, Italy

Food Agriculture Organization/World Health Organization (FAO/WHO). (2002a). Principles and guidelines for incorporating microbiological risk assessment in the development of food safety standards, guidelines and related text, World Health Organization, ISBN 92-5-104845-2, Rome, Italy 
Food Agriculture Organization/World Health Organization (FAO/WHO). (2002b). Risk assessments of Salmonella in eggs and broiler chickens. Technical report. Microbiological risk assessment series 2. Food and Agriculture Organization of the United Nations, ISSN 1726-5274, Rome, Italy

Food Agriculture Organization/World Health Organization (FAO/WHO). (2002c). Risk assessment of Campylobacter spp. in broiler chickens and Vibrio spp. in seafood. Technical report. FAO Food and Nutrition Paper 75. Food and Agriculture Organization of the United Nations, ISBN 92-5-104886-X, Rome, Italy

Food Agriculture Organization/World Health Organization (FAO/WHO). (2004). Risk assessment of Listeria monocytogenes in ready-to-eat foods. Technical report. Microbiological risk assessment series 5, World Health Organization, ISSN 1726-5274, Rome, Italy

Food Agriculture Organization/World Health Organization (FAO/WHO). (2005). Understanding the Codex Alimentarius. Food and Agriculture Organization of the United Nations, ISBN 978-92-5-105332-42, Rome, Italy

Food Agriculture Organization/World Health Organization (FAO/WHO). (2006a). Food Safety Risk Analysis. A guide for national food safety authorities. FAO Food and Nutrition Paper No. 87. Food and Agriculture Organization of the United Nations, ISBN 97892-5-105604-2, Rome, Italy

Food Agriculture Organization/World Health Organization (FAO/WHO). (2006b). The Use of Microbiological Risk Assessment Outputs to Develop Practical Risk Management Strategies: Metrics to improve food safety, In: FAO, 15.01.2011, Available from: ftp://ftp.fao.org/ag/agn/food/kiel.pdf

Food Agriculture Organization/World Health Organization (FAO/WHO). (n.d.). Assuring food safety and quality: guidelines for strengthening national food control systems. In: World Health Organization, 15.02.2011, Available from:

http://www.who.int/foodsafety/publications/capacity/en/Englsih_Guidelines_F ood_control.pdf

Gorris, L.G.M. (2005). Food safety objective: An integral part of food chain management. Food Control, Vol. 16, No. 9, (November 2005), pp. 801-809, ISSN 0956-7135

Havelaar, A.H. \& Melse, J.M. (n.d.). Quantifying public health risk in the WHO guidelines for drinking-water quality. A burden of disease approach, In: World Heath Organization, 15.02.2011, Available from:

http://www.who.int/water_sanitation_health/dwq/quantifyinghealthrisks/en/i ndex.html

Havelaar, A.H.; Nauta, M.J. \& Jansen, J.T. (2004). Fine-tuning food safety objectives and risk assessment. International Journal of Food Microbiology, Vol. 93, No. 1, (May 2004), pp. 11-29, ISSN 0168-1605

Havelaar, A.; Evers, E.G. \& Nauta, M.J. (2008). Challenges of quantitative microbial risk assessment at EU level. Trends in Food Science E Technology, Vol. 19, Supplement 1, (November 2008), pp. S26-S33, ISSN 0924-2244

Hoffman, F.O. \& Hammonds, J.S. (1994). Propagation of uncertainty in risk assessments: the need to distinguish between uncertainty due to lack of knowledge and uncertainty due to variability. Risk Analysis, Vol. 14, No. 5, (October 1994), pp. 707-712, ISSN 0272-4332

International Commission on Microbiological Specifications for Foods (ICMSF). (1988). Microorganisms in Foods 4: Application of the Hazard Analysis Critical Control Point 
(HACCP) System to Ensure Microbiological Safety and Quality, Oxford: Blackwell Scientific Publications, ISBN 0632021810, Oxford, UK

International Committee on Microbiological Specifications for Foods (ICMSF). (2002). Microorganisms in foods. 7. Microbiological testing in food safety management, Kluwer Academic/Plenum Publishers, ISBN 0306472627, New York, USA

International Commission on Microbiological Specifications for Foods (ICMSF). (2005). A simplified guide to understanding and using Food Safety Objectives and Performance Objectives, In: International Commission on Microbiological Specifications for Foods, 15.02.2011, Available from: http://www.icmsf.iit.edu/pdf/Simplified\%20FSO9nov05.pdf

Jacxsens, L.; Kussaga, J.; Luning, P.A.; van der Spiegel, M.; Devlieghere, F. \& Uyttendaele, M. (2009). A Microbial Assessment Scheme to measure microbial performance of Food Safety Management Systems. International Journal of Food Microbiology, Vol. 134, No. 1-2, (August 2009), pp. 113-125, ISSN 0168-1605

Jouve, J.L. (1999). Establishment of food safety objectives. Food Control, Vol. 10, No. 4-5, (August-October 1999), pp. 303-305, ISSN 0956-7135

Lammerding, A.M. (1997). An overview of microbial food safety process. Journal of Food Protection, Vol. 60, No. 11, (November 1997), pp. 1420-1425, ISSN: 0362-028X

Leeuwen, C.J. \& J.L.M Hermens. (1995). Risk assessment of chemicals: An introduction. Kluwer Academic Publishers, ISBN 0-7923-3740-9, Dondrecht and Boston

Mangen, M.J.; Havelaar, A.H.; Poppe, K.P. \& de Wit, G.A. (2007). Cost-utility analysis to control Campylobacter on chicken meat dealing with data limitations. Risk Analysis, Vol. 27, No. 4 (August 2007), pp. 815-830, ISSN 0272-4332

Mataragas, M.; Skandamis, P.N. \& Drosinos, E.H. (2008). Risk profiles of pork and poultry meat and risk ratings of various pathogen/product combinations. International Journal of Food Microbiology, Vol. 126, No. 1-2, (August 2008), pp. 1-12. ISSN 01681605

Mataragas, M.; Zwietering, M.H.; Skandamis, P.N. \& Drosinos, E.H. (2010). Quantitative microbiological risk assessment as a tool to obtain useful information for risk managers - Specific application to Listeria monocytogenes and ready-to-eat meat products. International Journal of Food Microbiology, Vol. 141, Supplement 1, (July 2010), pp. S170-S179, ISSN 0168-1605

National Research Council (NRC). (1994), Science and Judgment in Risk Assessment. National Academy Press, ISBN 0-309-04894-X, Washington, DC

New Zealand Food Safety Authority (NZFSA). (2005a). Risk Profile: Listeria monocytogenes in soft cheeses. In: New Zealand Food Safety Authority, 15.02.2011, Available from: http://www.foodsafety.govt.nz/elibrary/

New Zealand Food Safety Authority (NZFSA). (2005b). Risk Profile: Listeria monocytogenes in ready-to-eat salads. In: New Zealand Food Safety Authority, 15.02.2011, Available from: http://www.foodsafety.govt.nz/elibrary/

Øvreberg, O.; E. Damsleth \& Haldorsen, H.H. (1992), Putting error bars on reservoir engineering forecasts. Journal of Petroleum Technology, Vol. 44, pp. 732-738, ISSN 0149-2136

Pérez-Rodríguez, F.; van Asselt, E.D.; García-Gimeno, R.M.; Zurera, G. \& Zwietering, M.H. (2007). Extracting additional risk managers information from a risk assessment of 
Listeria monocytogenes in deli meats. Journal of Food Protection, vol. 70, No. 5, (May 2007), pp. 1137-1152, ISSN 0362-028X

Pidgeon, N.; Hood, C.; Jones, D.; Turner, B. \& Gibson, R. (1992). Risk perception, In Risk: Analysis, Perception and Management, Royal Society Study Group, (Ed.), pp. 89-134, The Royal Society, ISBN 0854034676, London, UK

Ross, T. \& Sumner, J. (2002). A simple, spreadsheet-based, food safety risk assessment tool. International Journal of Food Microbiology, Vol. 77, No. 1-2, (July 2002), pp. 39-53, ISSN: 0168-1605

Ross, T. ; Rasmussen, S. ; Fazil, A. ; Paoli, G. \& Sumner, J. (2009). Quantitative risk assessment of Listeria monocytogenes in ready-to-eat meats in Australia. International Journal of Food Microbiology, Vol. 131, No. 2-3, (May 2009), pp. 128-137, ISSN 01681605

Roy, P.; Nei, D.; Orikasa, T.; Xu, Q.; Okadome, H.; Nakamura, N. \& Shiina, T. (2009). A review of life cycle assessment (LCA) on some food products. Journal of Food Engineering, Vol. 90, No. 1, (January 2009), pp. 1-10, ISSN 0260-8774

Slovic, P. (1992). Perception of risk; reflections on the psychometric paradigm. In: Social Theories of Risk, S. Krimsky and D. Golding, (Eds.), pp. 117-152, Praeger, ISBN 0275-94168-X, Westport CT, UK

Slovic, P. (1998). The risk game. Reliability Engineering and System Safety, Vol. 59, pp. 73-77, ISSN 0951-8320

Sumner, J. \& Ross, T. (2002). A semi-quantitative seafood safety risk assessment. International Journal of Food Microbiology, Vol. 77, No. 1-2, (July 2002), pp. 55-59, ISSN 0168-1605

Sumner, J.; Ross, T.; Jenson, I. \& Pointon, A. (2005). A risk microbiological profile of the Australian red meat industry: Risk ratings of hazard-product pairings. International Journal of Food Microbiology, Vol. 105, No. 2, (November 2005), pp. 221-232, ISSN 0168-1605

Swarte, C. \& Donker, R.A. (2005). Towards an FSO/ALOP based food safety policy. Food Control, Vol. 16, No. 9, (November 2005), pp. 825-830, ISSN 0956-7135

Todd, E. (1989). Costs of acute bacterial foodborne disease in Canada and the United States. International Journal of Food Microbiology, Vol. 9, No. 4, (December 1989), pp. 313-326, ISSN 0168-1605

Trautman, T.D. (2001). Risk communication-the perceptions and realities. Food Additives and Contaminants, Vol. 18, No. 12, (February 2001), pp. 1130-1134, ISSN 0265-203X

Tressou, J.; Crepet, A.; Bertail, P.; Feinberg, M.H. \& Leblanc, J.C.H. (2004). Probabilistic exposure assessment to food chemicals based one extreme value theory. Application to heavy metals from fish and sea products. Food Chemistry and Toxicology, Vol. 42, No. 8, (August 2004), pp. 1349-1358, ISSN 0278-6915

United States Department of Agriculture-Center for Food Safety and Applied Nutrition (USDA-CFSAN), (2009). Fresh produce risk ranking tool summary: Identification of priority pathogen- commodity combinations for quantitative microbial risk assessment. In: RTI International, 15.02.2011, Available from:

http://www.foodrisk.org/exclusives/RRT/downloads/Produce_RRT_report_RTI .pdf 
United States Department of Agriculture-Food Safety Inspection Service (USDA-FSIS). (1998). Salmonella enteritidis risk assessment: shell eggs and egg products. In: Food Safety Inspection Service, 15.02.2011, Available from: http://www.fsis.usda.gov/ophs/risk/

United States Department of Agriculture-Food Safety Inspection Service (USDA-FSIS). (2005). Risk assessments of Salmonella enteritidis in shell eggs and Salmonella spp. in egg products, In: Food Safety Inspection Service, 15.02.2011, Available from: http://www.fsis.usda.gov/PDF/SE_Risk_Assess_Oct2005.pdf

United States Food and Drug Administration (US-FDA). (1997). Hazard Analysis and Critical Control Point Principles and Application Guidelines, In: Food and Drug Administration, 15.02.2011, Available from:

http://www.fda.gov/Food/FoodSafety/HazardAnalysisCriticalControlPointsHA CCP/HACCPPrinciplesApplicationGuidelines/default.htm

United Stated Food and Drug Administration; United States Department of Agriculture \& Centers for Disease Control and Prevention (US-FDA; USDA \& CDC). (2003). Quantitative assessment of relative risk to public health from foodborne Listeria monocytogenes among selected categories of ready-to-eat foods. In: United Stated Food and Drug Administration, 15.02.2011, Available from:

http://www.fda.gov/Food/ScienceResearch/ResearchAreas/RiskAssessmentSafe tyAssessment/ucm183966.htm

van Schothorst, M. (1998). Principles for the establishment of microbiological food safety objectives and related control measures. Food Control Vol.9, No. 6, (December 1998), pp. 379-384, ISSN 0956-7135

van Schothorst, M. (2002). Implementing the results of a microbiological risk assessment: pathogens risk management. In: Microbiological risk assessment in food processing, $\mathrm{M}$. Brown \& M. Stringer (Ed.), 175-192, Woodhead Publishing Limited, ISBN 1-85573585-7, Cambridge, UK

van Schothorst, M. (2005). A proposed framework for the use of FSOs. Food Control, Vol. 16, No. 9, pp. 811-816, ISSN 0956-7135

Vose, D. (2000). Risk Analysis: A Quantitative Guide. John Wiley \& Sons, Inc, ISBN 0-47199765-X New York, NY.

Wallace, C.; Sperber, W. \& Mortimore, S. (2011). Food Safety for the 21st Century: Managing HACCP and Food Safety throughout the Global Supply Chain, Wiley-Blackwell, ISBN 978-1-4051-8911-8, Oxford, UK

Walls, I. \& Buchanan, R.L. (2005). Use of food safety objetives as a tool for reducing foodborne listeriosis. Food Control, Vol. 16, No. 9, (November 2005), pp. 795-799, ISSN 0956-7135

Webster, N. (1983). Webster's New Twentieth Century Dictionary (2nd edn), Simon \& Schuster, ISBN 067141819X, New York, USA

World Health Organization (WHO). (2008). Guidelines for Drinking-water Quality. 3rd Edition. Volumen 1. Recommendations. In: World Health Organization, 15.02.2011, Available from:

http://www.who.int/water_sanitation_health/dwq/GDWPRecomdrev1and2.pdf

World Trade Organization (WTO). (1995). The WTO agreement on the application of sanitary and phytosanitary measures (SPS Agreement). In: World Trade Organization, 15.02.2011, Available from: 
http://www.wto.org/english/tratop_e/sps_e/spsagr_e.htm

Wynne, B. (1992). Risk and social learning: reification to engagement. In: Social Theories of Risk, S. Krimsky and D. Golding, (Eds.), pp. 275-300, Praeger, ISBN 0-275-94168-X, Westport CT, UK

Zwietering, M. (2005). Practical considerations on food safety objectives. Food Control, Vol. 16, No. 9, (November 2005), pp. 817-823, ISSN 0956-7135

Zwietering, M.H. (2009). Quantitative risk assessment: Is more complex always better? Simple is not stupid and complex is not always more correct. International Journal of Food Microbiology, Vol. 134, No. 1-2, (August 2009), pp. 57-62, ISSN 0168-1605

Zwietering, M.H. \& Nauta, M.J. (2007). Predictive models in microbiological risk assessment. In: Modelling Microorganisms in Food, S. Brul; S. van Gerwen \& M.H. Zwietering (Eds.), 110-125, CRC press, ISBN 084931237X, Boca Raton, USA

Zwietering, M.; Stewart C.M. \& Whiting, R.C. (2010). Validation of control measures in a food chain using the FSO concept. Food Control, Vol. 21, No. 12, (December 2010), pp. 1716-1722, ISSN 0956-7135 


\title{
Risk Analysis in the Mining Industry
}

\author{
Undram Chinbat \\ School of Economic Studies, National University of Mongolia \\ Mongolia
}

\section{Introduction}

People in different societies and different economic, political environments perceive and evaluate risks of large and complex projects in significantly distinctive ways. This chapter demonstrates ways of identifying and analyzing risks in large projects using case studies of mining projects in Mongolia.

According to the Project Management Body of Knowledge (PMBOK), composed by the Project Management Institute (PMI), the largest professional organization dedicated to the project management (PM) field, risk management (RM) has been designated as one of the nine main areas (the other eight being integration, scope, time, cost, quality, human resources, communications, and procurement management). Consequently, RM is considered as an important activity of the PM process. The need to identify a project's uncertainties, estimate their impact, analyze their interactions and control them within a risk-management structure has only in recent years been realized, mainly within the defense, construction and oil industries (Williams, 1995).

The chapter explaines risk management processes through a research on mining project risks. For clarity, the chapter will start from explaining about mining projects, providing a simple process flow chart. The next step was to identify risks based on this flow chart and seen in the mining projects implemented in Mongolia. The long-list of the risks may occur during mining project implementation was completed through literature review and discussion with mining engineers and project managers with experience working in Mongolia. Construction project risk and oil and petroleum project risk studies were widely used. The list of identified risks was short-listed by the criteria, which has the most impact to mining project failure during an implementation process in the country. The short-listed risks were assessed and prioritized based on a questionnaire response from the expertise working in the Mongolian mining industry. Finally, a study on project risk information database, methods to create and use the database were formulated.

\section{Project risk}

All projects carry certain level of risk and how this is dealt with affects project success (Gardiner, 2005). Project risk is, defined by the PMI:

Project risk is an uncertain event or condition that, if it occurs, has positive or negative effects on at least one project objective, such as time, cost, scope or quality (Project Management Institute [PMI], 2008). 
Risks can have either positive or negative effect on projects. A recent survey of IT managers reflecting on the idea that risk can have a positive effect revealed that although 49 percent of respondents regarded risk as a negative event, 22 percent of respondents held the view that risk can include positive consequences of some event as well as negative aspects (Charette, 2002). Therefore, all risks cannot be considered as negative. According to Gardiner (2005), there are essentially two categories of risk:

- Speculative risk: meaning a chance of a loss or chance of a profit. For example, an established business could expand and make more profit or it could go bankrupt, so buying stock in this company is a speculative risk. Most projects carry speculative risk.

- $\quad$ Pure risk: meaning only a chance of a loss. For example, jumping out of a moving car involves only the chance of an accident. Pure risks are insurable.

The classification of risks creates a common framework for grouping risks, although different cultures could classify the same risk differently (Wyk et al., 2008). Edwards and Bowen (2005) suggests two primary categories for classifying risks:

- Natural risk: those from systems "beyond human agency" which include risks from weather, geological, biological and extraterrestrial systems.

- Human risk: risks from social, political, cultural, health, legal, economic, financial, technical and managerial systems.

In this chapter all the risks considered as pure risks, and will be written in the text using a term "risk". Furthermore, propositions for managing several human risk were suggested in the chapter.

\subsection{Project risk management}

The need for project risk management (PRM) has been widely recognized. This is particularly so in the case of 'major projects' (Williams, 1995). Fraser (1984) says that 'Normal' projects have the characteristics (amongst others) that "risk assessment can follow well established procedures as all risks are visible"," "there are no catastrophic risks", "the scale of individual risks is small compared with the size of the parties involved and therefore there is no completion problem", but that "none of these characteristics is true of the largest projects"; "in general, beyond a certain size, the risks of projects increase exponentially and this can either be appreciated at the beginning or discovered at the end".

Risk management (RM) provides a structured way of assessing and dealing with future uncertainty (Cooper et. al., 2005). PRM is applied in all project phases to identify significant risks and develop measures to address them and their consequences. Once the project starts, RM needs to be an on-going process (Ward \& Chapman, 1991). Implementing a RM process earlier in the project life cycle is useful if it is done effectively (Chapman, 1997). PRM includes the following set of processes (Figure 1):

- $\quad$ Risk identification - process of determining risks that may affect the project;

- Risk analysis - process of assessing risks' probability of occurence and impact on project sucess;

- $\quad$ Risk evalutaion - process of prioritizing risks based on the probability of occurence and impact on project sucess;

- $\quad$ Risk mitigation - process of developing actions to reduce the occurance and/or impact of the negative risks.

- $\quad$ Risk monitoring - process of implementing risk mitigation plans, tracking identified risks, monitoring residual risks, identifying new risks, and evaluating overall risk management process effectiveness throughout the project. 
- $\quad$ Risk learning - process of documenting lessons learned from the PRM activities.

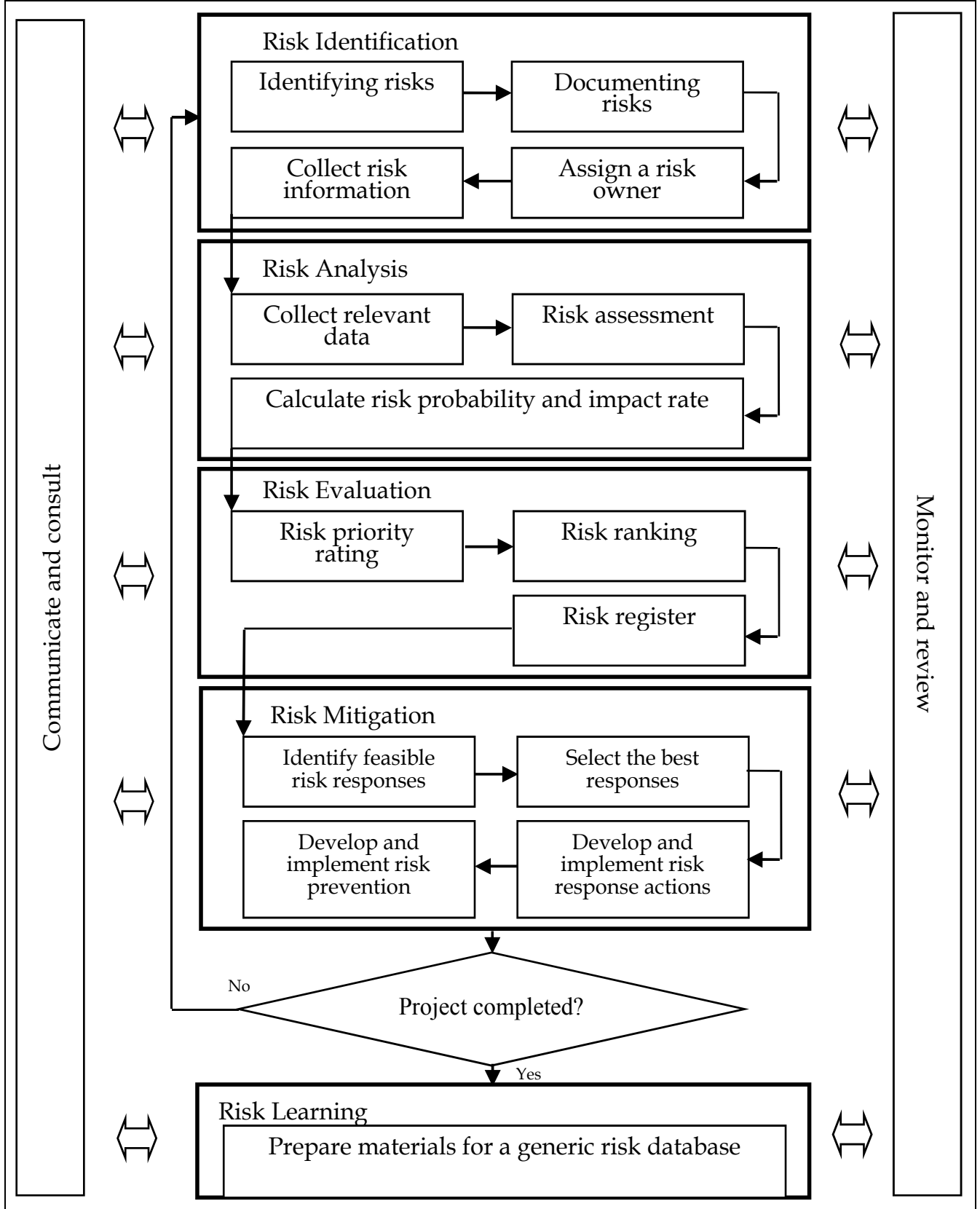

Fig. 1. Risk management process model

The objective of PRM is to reduce the probability and impact of negative risks of a project. The RM is an iterative process throughout the project's life, because new risks may evolve or become known as the project progresses. 


\section{Project risk management in the mining industry}

Up to date, mining industry has not performed well in its ability to deliver projects according to the financial and physical parameters forecast in the feasibility study process. For example, the pace and scale of current developments in Australia's mineral resources sector is worldwide known as unprecedented. A study of eighteen mining projects covering period of 1965 to 1981 showed an average cost overrun of 33 percent compared to their feasibility study estimates (Castle, 1985). A study of sixty mining projects covering the period from 1980 to 2001 showed average cost overruns of 22 percent with almost half of the projects reporting overruns of more than 20 percent (Gypton, 2002). A review of sixteen mining projects carried out in the 1990s showed an average cost overrun of 25 percent, attributed to overly optimistic feasibility studies and poor cost estimation (Anon, 2000, as sited in Noort \& Adams, 2006). Therefore, a standard approach to mining project management, effective tools that can be utilized to meet the project objectives, and studies regarding risk factors associated with mining projects, are required to develop the current project management status of the mining industry.

Mining project activity is subject to high risks because of its size, uncertainty, complexity, and high costs. Large engineering projects are high-stakes games characterized by substantial irreversible commitments, skewed reward structures in case of success, and high probabilities of failure (Miller \& Lessard, 2001). Floricel and Miller (2000) suggested that large scale projects such as power plants, highways, bridges, tunnels, and airports developed in the last 20 years have become increasingly characterized by turbulence resulting from radical shifts in institutional frameworks, political and economic discontinuities, environmental and social activism and, to a lesser extent, technological changes and innovations. Risks caused by these turbulences ought to be considered by project managers for a successful project implementation. The extent of risk and uncertainty associated with construction projects, particularly in remote locations is considerable and should not be underestimated (Perry, 1986). Mining projects are commonly implemented in distant locations, which explicate its need for careful RM. RM becomes an integral part of PM and plays such an important role that its application goes beyond the traditional scope which normally center on the construction phase (del Cano \& de la Cruz, 2002). In the development of an oil field enormous number of issues involved and a lot of risks are associated to them. The limited knowledge about the characteristics of the geological formation, technical facilities, and human behavior results in considerable uncertainty about the oil and gas wells drilling operations (Jacinto, 2002).

A review of the extant literature shows that excluding the numerous studies on construction PRM in various countries, very few studies have been conducted specifically on mining PRs. Several risk analysis studies has been carried on oil field, petroleum exploration. However, only number of studies relevant to PRM based on the geographical uniqueness of the mining industry had been found. Therefore, in this study, besides the oil and petroleum project risk researches, construction project risk researches have been used widely for a review.

\subsection{Operational sequence of mining projects}

To understand the roots of a project risk, one must consider the characters of the project process. Project characteristics differ due to the industry uniqueness. Major mining projects 
generally have six distinct phases; scoping studies, prefeasibility studies, definitive feasibility studies, design and construction, operations, and closure (Figure 2).

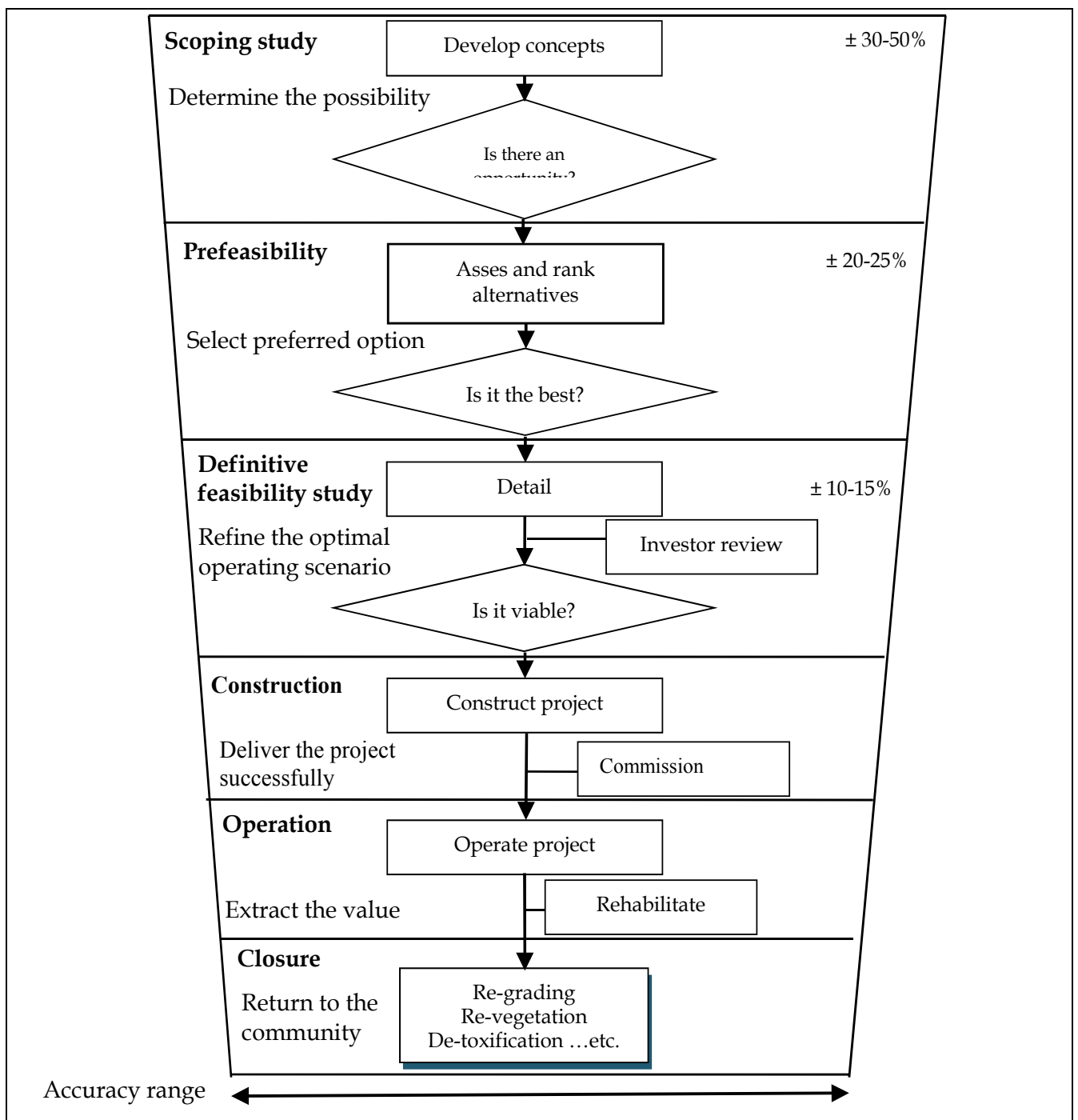

Fig. 2. The mining project development framework

The above Figure (2) was developed based on the original mining project development framework of Mackenzie \& Cusworth (2007). Each of these project phases serve an important purpose and requires a specific set of management skills. Furthermore, the framework recognizes that the feasibility study process is repetitive and indeed not all projects will progress through all the phases. At the end of each primary three phases, a decision is made whether to stop the project or progress to the next phase. It is usually difficult for the team to reach such a conclusion after spending considerable time, effort and resources on the study. Thus, the studies often do not progress smoothly through the study phases. The framework provides clear decision points after the completion of each phase, 
though in practice, a decision to reassess a project or abandon a study can be made at any time. As the project advances through, the accuracy of each phase improves. The typical accuracies of cost estimates for the study levels are illustrated on the top right corners of each box.

The framework in Figure 2 may be applied slightly different in each countries due to their legal policy and characteristics. To demonstrate the uniqueness, mining project process framework in Mongolia was developed and explained.

\subsubsection{Mining projects in Mongolia}

A process flow chart for mining projects was developed by interviewing experienced professionals working in the Mongolian mining industry (Figure 3).

A typical process generally consists of exploratory, planning, construction, operational, and a closure phase. These phases can have several stages as follows:

1. The exploratory phase. Under Mongolian law (Ашигт малтмалын тухай хууль, [Minerals Law] 2003), the national government maintains ownership of all mineral reserves. Private parties receive license for exploration and mining rights from the government. A contract agreement between the government and the mining company stipulates the terms of the license. Companies, after indicating a specific territory which is believed to have certain amount of a particular type of mineral deposit, start to negotiate the "exploration license" from the government agency if the land is available. Occasionally, companies that has an exploration license and no fund for exploration work, does consider selling the license or transforming certain percentage of it. Subsequently, the exploration phase begins with a team of several geology engineers, who usually work for months, during the summer, to identify the possible amount of resource under the territory along with its quality. Sometimes the mining companies hire other companies that specifically carry exploration work on a contract basis. The exploration work consists of three main fractions including detailed, definitive and mining. After the exploration work, the exploration team prepares a report that includes the assays, geological pictures, resource calculation and the type of technology and machines required for operating the mining work. If the company decides that the resource amount is sufficient, they will further perform a cost-benefit analysis. Clearly, if the management sees the possible benefits in implementing the project, they will proceed further with the project.

Environmental monitoring process starts as soon as the exploration work starts and it is continued until ownership of the territory is returned to the local community when the exploration work is finished or when the mine is closed.

2. The planning phase. Based on the set of exploration work, the company will submit it's exploration work report to the Minerals' Committee of Mongolia for assessment. Once the exploration report is approved, the company will provide set of documents such as the technical and economical feasibility study report, enivronmental monitoring work plan in order to register the mineral deposit data in the National Mineral Resource Book. The reason for this is to obtain the "mining license" from the government agency. Companies can also acquire a "mining license" from a seller who currently is in hold of the license or buy a share of the company that holds the "mining license“. By analyzing the exploration reports, which demonstrate the information about the territory mineral resources, companies can make a decision to purchase the mining license. Furthermore, there are territories which was explored previously with the government fund. The "mining license's" for these territories can be obtained based on an exclusive contract with the government. 


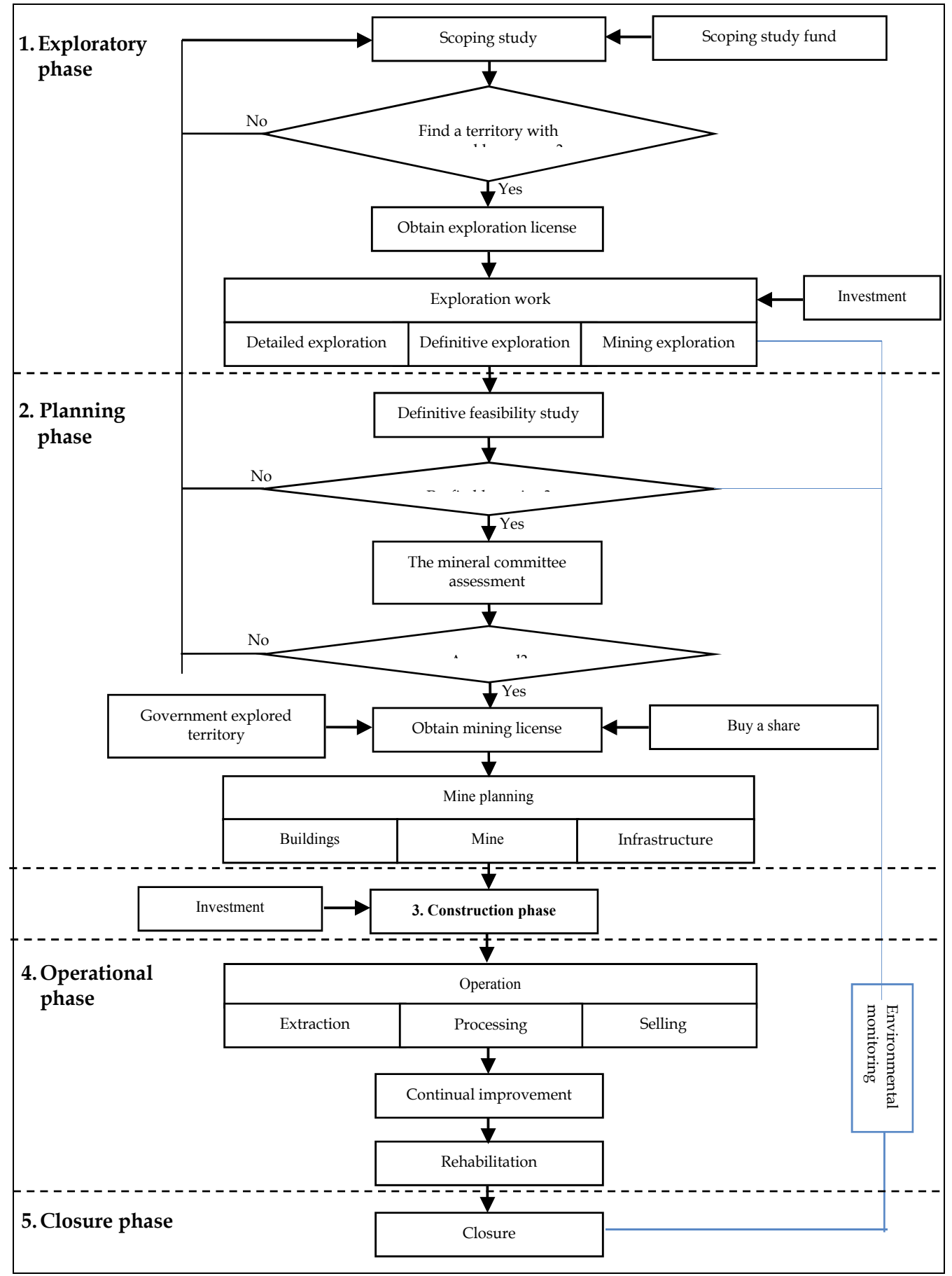

Fig. 3. Mining project process flow chart (Mongolian case) 
Once all the legal aspects are in place, the company will starts it's mine planning, including the buildings and infrastructure that is required to be built. These set of plans are often refered as the master plan of the mine.

3. The construction phase. The construction phase will start in accordance to the master plan of the mine. If necessary, companies can acquire investments from an outside resource such as financial institutions. Frequently, one of the sources for investment is to sell the project share or bond through broker companies at the stock exchange market. Large international investments in the mining field are regularly held in the Canadian, British and Australian stock exchange markets.

4. The operational phase. This phase will begin under the following condition:

- The main constructions for the mine, such as the enrichment factory (if necessary) assembly, accommodation facilities for the manpower, are completed;

- $\quad$ All machines and equipments had arrived on site;

- The necessary manpower is acquired and trained.

A typical mining operation involves extraction process where the mineral is extracted from the ground, processing of the mineral and selling. The selling process may include transportaion to the buyer's market.

During operational process a continious improvement is very important to lower bottlenecks, reduce cost and increase efficiency. Furthermore, in this phase, the rehabilitation process is intensified.

5. The closure phase. The permanent closure of a mine involves re-grading and revegetation, removal and disposal of stored fuels and chemicals, structure tear down, removal of roads and ditches, capping of tailings, waste detoxification, and reestablishment of drainage ways (United States Environmental Protection Agency, 1997). Many features of mines such as open pits, waste dumps, and impoundments of tailings are permanent and can degrade long after the mine has been closed, causing further environmental damage (Miranda et. al., 2003).

\subsection{Risk identification}

Risk identification is a process of determining which risks may affect the project and documenting their characteristics (PMI, 2008). Risk may be identified by understanding and reviewing the project plans, brainstorming with and interviewing experts, looking into previous risk related experiences and a database.

\subsubsection{Literature review}

Large construction projects and mining projects may share risks with similar characteristics because both are uncertain, complicated and costly. Therefore, number of researches on construction risks in several countries was conducted. However, no PRM study of Mongolia has been found up to date.

Construction project risk studies conducted in countries such as Hong Kong (Shen, 1997), Kuwait (Kartam \& Kartam, 2001), Vietnam (Luu et. al., 2009), China (Fang et. al., 2004; de Camprieu et. al., 2007), India (Ling \& Hoi, 2006), United Arab Emirates (UAE) (El-Sayegh, 2007), Palestine (Enshassi \& Mosa, 2008), Australia (Lyons \& Skitmore, 2004) and Taiwan (Wang et. al., 2003) was found and used to create a long-list of possible risks of the mining projects implemented in Mongolia. Some of the risks which were considered to share a similar effect on mining projects implemented in Mongolia were gathered in Table 1. 


\begin{tabular}{|c|c|c|c|c|c|c|c|c|c|}
\hline \multirow[t]{2}{*}{ Risk description } & \multicolumn{9}{|c|}{ Countries of the study } \\
\hline & Vietnam & Kuwait & China & Palestine & UAE & India & Australia & $\begin{array}{l}\text { Hong } \\
\text { Kong }\end{array}$ & Taiwan \\
\hline Owners' financial difficulties & 1 & 1 & 2 & 8 & 14 & & & & \\
\hline $\begin{array}{l}\text { Owners' unreasonably imposed tight } \\
\text { schedule }\end{array}$ & & & & & 2 & & & & \\
\hline Unmanaged cash flow & & & & 30 & & & & & \\
\hline Inadequate experience & 2 & & & 23 & & & & & \\
\hline $\begin{array}{l}\text { Lack of capable and responsible site } \\
\text { supervisors }\end{array}$ & 11 & & & & & $\mathrm{n} / \mathrm{a}$ & & & \\
\hline Subcontractors' poor management & & & 9 & & & & & & \\
\hline $\begin{array}{l}\text { Shortage in manpower supply and } \\
\text { availability }\end{array}$ & & 3 & & & 7 & & 2 & 3 & \\
\hline Shortage of skills/techniques & 14 & & & & & & 3 & 5 & \\
\hline Varied labor and equipment productivity & & & & 32 & & & & & \\
\hline Lack or departure of qualified staff & & & & & 9 & & & & \\
\hline Labor strikes and disputes & & & 45 & & 34 & & & & \\
\hline Low productivity of labor and equipment & 16 & 6 & 12 & & 20 & & & 6 & \\
\hline Human/organizational resistance & & 26 & 41 & & & & 6 & & \\
\hline Accidents during construction & & 23 & 20 & 3 & 33 & & & & \\
\hline $\begin{array}{l}\text { Breakdown of special machinery } \\
\text { equipment }\end{array}$ & & & 39 & & & & & & $\mathrm{n} / \mathrm{a}$ \\
\hline $\begin{array}{l}\text { Shortage in material supply and } \\
\text { availability }\end{array}$ & & & & 12 & 10 & & & 4 & \\
\hline Shortage in equipment availability & & & & 16 & 18 & $\mathrm{n} / \mathrm{a}$ & & & \\
\hline Late delivery of materials and equipments & & & 28 & & & & & & $\mathrm{n} / \mathrm{a}$ \\
\hline Lack of information & & & & & & & 4 & & \\
\hline Regulatory risks & & 19 & & & & $\mathrm{n} / \mathrm{a}$ & & & \\
\hline Changes in laws and regulations & & 22 & 25 & 28 & 35 & & & & $\mathrm{n} / \mathrm{a}$ \\
\hline Government's improper intervention & & & 11 & & & & & & \\
\hline Corruption and bribes & & & 23 & & 37 & & & & \\
\hline Delays in approvals & & & & & 8 & & & & \\
\hline Inclement weather & 12 & 21 & 26 & 33 & 40 & & & 2 & \\
\hline Environmental factors & & 24 & & 24 & & $\mathrm{n} / \mathrm{a}$ & & & $\mathrm{n} / \mathrm{a}$ \\
\hline
\end{tabular}

Table 1. List of construction project risks in various countries

The risk descriptions are listed in the left side column, and the risk rankings based on their impact on project failure according to the literatures was positioned next to each risk. Finally, the countries, which the risks are considered as significant during project implementation, are noted in the second row of the table.

The list of risks in Table 1 was used as a long-list for the risk identification process in the Mongolian mining industry. Countries in the table were chosen because they presumed to have certain similar characteristics with Mongolia. For example, Vietnam, China, Hong Kong, India and Taiwan are all among the developing economies in Asia and the selected risks were considered that it has a matching impact rate in projects implemented in 
Mongolia. Some of the characteristics such as political instability, corruption, lack of managers with the appropriate level of PM know-how of Mongolia are analogous with the above mentioned countries. However, the case of Australia was used to observe the risks in more developed counties. A number of risks were similar with the less developed countries which can be seen in Table 1 .

\subsubsection{Brainstorming and interviewing}

Brainstorming and interviewing was performed with mining engineers and project managers with an experience working in Mongolia. Flow chart (Figure 3) is a very useful tool in risk identification, as each process can be talked through with cause and effect diagram. Based on the long-list and further discussions with experienced project managers and researchers the following list in Table 2, of MPRs in Mongolia were selected as the most common and significant to the project success. The risks were divided into two segments, risks that derive from an internal and an external environment.

\begin{tabular}{|r|l|l|}
\hline & List of risks (internal) & List of risks (external) \\
\hline 1 & Incorrect mineral resource calculation & Diesel shortage in the country \\
\hline 2 & Owner's financial difficulties & Railway transportation delay \\
\hline 3 & Incorrect financial resource calculation & Unpredicted environmental damages \\
\hline 4 & $\begin{array}{l}\text { Not enough fund for the environmental } \\
\text { recovery }\end{array}$ & Boycotting \\
\hline 5 & $\begin{array}{l}\text { Unsufficient employement safety } \\
\text { substances }\end{array}$ & $\begin{array}{l}\text { Government bureaucracy for obtaining } \\
\text { licenses }\end{array}$ \\
\hline 6 & Technical problem (breakdown) & Pressure from the government inspectors \\
\hline 7 & $\begin{array}{l}\text { Shortage of skilled manpower for the } \\
\text { mining machinery }\end{array}$ & $\begin{array}{l}\text { Changes in laws and regulations (negative } \\
\text { effect case only) }\end{array}$ \\
\hline 8 & $\begin{array}{l}\text { Unsufficient skills of the project } \\
\text { managers }\end{array}$ & $\begin{array}{l}\text { Price fluctuation of minerals (negative effect } \\
\text { case only) }\end{array}$ \\
\hline 9 & $\begin{array}{l}\text { Accidents during construction and } \\
\text { operation }\end{array}$ & $\begin{array}{l}\text { Foreign exchange rate fluctuation (negative } \\
\text { effect case only) }\end{array}$ \\
\hline 10 & Poor management & Shortage of experts \\
\hline 11 & Irresponsibility of the workers & Shortage of local manpower \\
\hline 12 & Shortage of equipments & Poor infrastructure \\
\hline 13 & Poor internal communication & Demand fall of the mineral \\
\hline 14 & Shortage of machinery & Political instability \\
\hline 15 & Employee strike & Incrase of competition \\
\hline
\end{tabular}

Table 2. List of mining project risks in Mongolia

The identified risks (Table 2), were determined based on the mining industry characteristics, as well as the country's unique features. For example, in petroleum explorations, as economical and technological resources are limited, managers of these companies frequently face important decisions regarding the best allocation these scarce resources among exploratory ventures that are characterized by substantial financial risk and geological uncertainty (Roisenberg et. al., 2009). Uncertainty is intrinsically involved in all petroleum venture predictions, and particularly in chance of discovery. Resource calculation is where the mining resources are discovered during the exploration process and risk from an 
incorrect resource calculation has a significant impact to project failure. Thus, the risk was included in the long-list of risks created. Furhtermore, Mongolia has its own unique characteristics because of its geographical position. The country is land locked and located between Russia and China. Therefore, transportation of goods such as equipments and machinery is carried by railway or trucks. The railway transportation is overly utilized and delays occur frequently. Furthermore, a mass of diesel is consumed by mining companies for the machineries such as bulldozers, excavators and trucks for transportation. The country is heavily dependent on diesel import from Russia, and occasionally the supply of diesel stops due to indefinite reasons. Thus diesel shortage is considered as a great risk of various projects implemented in the country.

\subsection{Risk analysis}

To analyze the risk which were identified in the previous section, a questionnaire was developed, to obtain perceptions of other mining project experts in Mongolia. An indication of the relative importance of these risks in the local mining practice is given by examining observations and judgments of those in the field. Based on employment position and work experience, the study inferred that the respondents have adequate knowledge of the activities associated with mining and related risks, as shown on Table 4.

\begin{tabular}{|c|c|c|}
\hline \multirow[t]{2}{*}{1} & \multicolumn{2}{|c|}{$\begin{array}{l}\text { Number of years worked in the } \\
\text { industry }\end{array}$} \\
\hline & $0-3$ years & $39 \%$ \\
\hline & $4-6$ years & $26 \%$ \\
\hline & 7 - 9 years & $15 \%$ \\
\hline & More than 10 years & $19 \%$ \\
\hline & Not answered & $1 \%$ \\
\hline 2 & $\begin{array}{l}\text { Knowledge of risk } \\
\text { management }\end{array}$ & \\
\hline & Excellent & $8 \%$ \\
\hline & Good & $36 \%$ \\
\hline & Moderate & $42 \%$ \\
\hline & A little & $10 \%$ \\
\hline & None & $3 \%$ \\
\hline & Not answered & $1 \%$ \\
\hline
\end{tabular}

Table 3. Respondent's profile

The questionnaire's readability, lucidity and effectiveness was tested by a reveiw of the preliminary questionnaire of two practitioners working in the mining sector of Mongolia. Their comments were contemplated in the contents of the final questionnaire. The 
questionnaire forms were distributed by the senior students of the School fo Economic Studies, National University of Mongolia. The students asked each respondent orally and filled the form on behalf of them. In total 200 questionnaires were filled by the employees of 58 mining companies operating in Mongolia. Data analysis software SPSS 12 was used for assessing the questionnaire data. The software made available to check the reliability of results and the validity.

The practitioners were asked to assess the previously defined 30 risks based on their probability of occurence and impact on projects (Table 4). Risk probability assessment investigates the ilkelihood that each specific risk may occur. Risk impact assessment investigates the potential effect on a project objective such as time, cost or quality.

In the left hand column of Table 4 is the list of 30 risks identified previously are ranked based on their probability of occurence. The probability rates evaluated by the respondents are shown in the following column. Furthermore, in the right hand column, the 30 risks were listed according to their magnitude of impact on project success, from starting from the most signifacant risk. The impact rate of each risk is listed in the fourth column from the left. In the survey, respondents were asked to circle the factors using two scales with numbers from 0 to 10. A value of 10 indicated the highest impact to project failure or probability of occurance, while 1 indicated the lowest. Respondents had to circle numbers from 0-10 which best indicated their opinion. The value 0 indicates that the practitioner believes that there is no impact of the risk to project failure.

The analysis showed that the respondents perceived "Incorrect mineral resource calculation" as the highest risk that contributed to project failure with the highes probability of occurence. Inaccurate geological reports, drilling and assay result and magnetic works of exploration bring high risk to mining projects. The exact geological layers and the metal dispersion system are extremely difficult to predict. Therefore, mineral resources can be estimated incorrectly or the average ore concentration can be inconclusive. However, the estimated resource is the main objective for implementing the project, which is the main income that will pay back the project investment and make profit. Thus, it is one of the most important aspects in mining project development to calculate the resource precisely as possible. Incorrect resource calculation reflects one of the largest contributions to a project failure.

Furthermore, risks from the changes in laws and regulation has a high ranking in probability of occurence due to the several changes in the Mineral law of Mongolia for the last number of years.

Moreover, it has been revealed that a majority of project owners do not effectively plan the financial segment of the project, which usually does not include any cost from the risk factors that may occur during the project implementation.

According to further interview, when managers, in Mongolia, calculate the project budget, typically include contingency amount which equals to 8 percent of the total project funds. The contingency fund is usually spent for an alternative features along the project implementation, and is nonexistent when the designated requisite arises. However, the interviewed participants supposed that the project owners do realize that the industry has exceptionally high risk, especially when the project implementation requires a lot of investment throughout all of its phases. Thus, the following high ranking risks such as "owner's financial difficulty" is apparent. 


\begin{tabular}{|c|c|c|c|c|}
\hline $\begin{array}{l}\text { Risks prioritizing based on the } \\
\text { probability of occurance }\end{array}$ & Probability & Ranking & Impact & $\begin{array}{l}\text { Risks prioritizing based on the } \\
\text { impact on project success }\end{array}$ \\
\hline Incorrect mineral resource calculation & 6.15 & 1 & 7.86 & Incorrect mineral resource calculation \\
\hline $\begin{array}{l}\text { Changes in laws and regulations } \\
\text { (negative effect case only) }\end{array}$ & 5.76 & 2 & 6.69 & $\begin{array}{l}\text { Incorrect financial resource } \\
\text { calculation }\end{array}$ \\
\hline $\begin{array}{l}\text { Price fluctuation of minerals (negative } \\
\text { effect case only) }\end{array}$ & 5.63 & 3 & 6.45 & Owner's financial difficulties \\
\hline Owner's financial difficulties & 5.51 & 4 & 6.27 & Diesel shortage in the country \\
\hline Political instability & 5.49 & 5 & 6.16 & $\begin{array}{l}\text { Price fluctuation of minerals (negative } \\
\text { effect case only) }\end{array}$ \\
\hline Technical problem (breakdown) & 5.47 & 6 & 6.13 & $\begin{array}{l}\text { Changes in laws and regulations } \\
\text { (negative effect case only) }\end{array}$ \\
\hline Poor infrastructure & 5.44 & 7 & 5.95 & Poor management \\
\hline $\begin{array}{l}\text { Shortage of skilled manpower for the } \\
\text { mining machinery }\end{array}$ & 5.40 & 8 & 5.90 & Technical problem (breakdown) \\
\hline $\begin{array}{l}\text { Foreign exchange rate fluctuation } \\
\text { (negative effect case only) }\end{array}$ & 5.31 & 9 & 5.87 & Railway transportation delay \\
\hline Shortage of local manpower & 5.28 & 10 & 5.86 & $\begin{array}{l}\text { Shortage of skilled manpower for the } \\
\text { mining machinery }\end{array}$ \\
\hline Incorrect financial resource calculation & 5.25 & 11 & 5.76 & Demand fall of the mineral \\
\hline $\begin{array}{l}\text { Government bureaucracy for obtaining } \\
\text { licenses }\end{array}$ & 5.18 & 12 & 5.75 & $\begin{array}{l}\text { Unsufficient skills of the project } \\
\text { managers }\end{array}$ \\
\hline Shortage of equipments & 5.16 & 13 & 5.70 & Shortage of equipments \\
\hline $\begin{array}{l}\text { Unsufficient skills of the project } \\
\text { managers }\end{array}$ & 5.16 & 14 & 5.54 & Irresponsibility of the workers \\
\hline $\begin{array}{l}\text { Pressure from the government } \\
\text { inspectors }\end{array}$ & 5.03 & 15 & 5.53 & Shortage of machinery \\
\hline Irresponsibility of the workers & 4.90 & 16 & 5.43 & $\begin{array}{l}\text { Foreign exchange rate fluctuation } \\
\text { (negative effect case only) }\end{array}$ \\
\hline $\begin{array}{l}\text { Not enough fund for the environmental } \\
\text { recovery }\end{array}$ & 4.88 & 17 & 5.32 & $\begin{array}{l}\text { Accidents during construction and } \\
\text { operation }\end{array}$ \\
\hline Shortage of machinery & 4.74 & 18 & 5.23 & $\begin{array}{l}\text { Government bureaucracy for } \\
\text { obtaining licenses }\end{array}$ \\
\hline Poor management & 4.71 & 19 & 5.12 & Boycotting \\
\hline Demand fall of the mineral & 4.70 & 20 & 5.11 & Unpredicted environmental damages \\
\hline Poor internal communication & 4.64 & 21 & 5.06 & Poor infrastructure \\
\hline Railway transportation delay & 4.59 & 22 & 5 & $\begin{array}{l}\text { Not enough fund for the } \\
\text { environmental recovery }\end{array}$ \\
\hline $\begin{array}{l}\text { Unsufficient employement safety } \\
\text { substances }\end{array}$ & 4.46 & 23 & 4.95 & Political instability \\
\hline Boycotting & 4.41 & 24 & 4.79 & $\begin{array}{l}\text { Unsufficient employement safety } \\
\text { substances }\end{array}$ \\
\hline $\begin{array}{l}\text { Accidents during construction and } \\
\text { operation }\end{array}$ & 4.39 & 25 & 4.77 & $\begin{array}{l}\text { Pressure from the government } \\
\text { inspectors }\end{array}$ \\
\hline Incrase of competition & 4.38 & 26 & 4.71 & Employee strike \\
\hline Unpredicted environmental damages & 4.28 & 27 & 4.68 & Poor internal communication \\
\hline Diesel shortage in the country & 4.18 & 28 & 4.37 & Incrase of competition \\
\hline Shortage of experts & 4.02 & 29 & 4.13 & Shortage of experts \\
\hline Employee strike & 3.40 & 30 & 3.91 & Shortage of local manpower \\
\hline
\end{tabular}

Table 4 . Risk probability and impact assessment 


\subsection{Risk evaluation}

To properly evaluate project risks, one must consider both the probability of risk occurrence and the impact on project objectives once the risk event occurs. This is achieved best by plotting the risk probability - impact matrix (El-Sayegh, 2007). The identified thirty risks were positioned on the probability and impact matrix, as shown in Figure 4 . In the matrix, the $x$-axis represents the probability value while the $y$-axis represents the impact value. Both scales are $1-10$ (one being very low to 10 being very high). For a clearer view of the figure, only scales from 3 to 7 for the $x$-axis and 3 to 8 for the $y$-axis were shown in Figure 4 . The probability and the impact values were calculated based on the average scale provided by the respondents.

It was assumed, in this study, that if the average probability and impact of the risk is more than five, then the risk is considered as significant wich is in need of high attention. The matrix shows that risks within the circle of priority number 1 are the ones with highest probability and impact. Risks in the circle of priority number 2 are the ones with high probability but medium impact on project failure. Conversely risks in the circle of priority number 3 are the ones with medium probability and high impact to project failure. Finally, risks in the circle of priority number 3 are the ones with medium probability and medium impact.

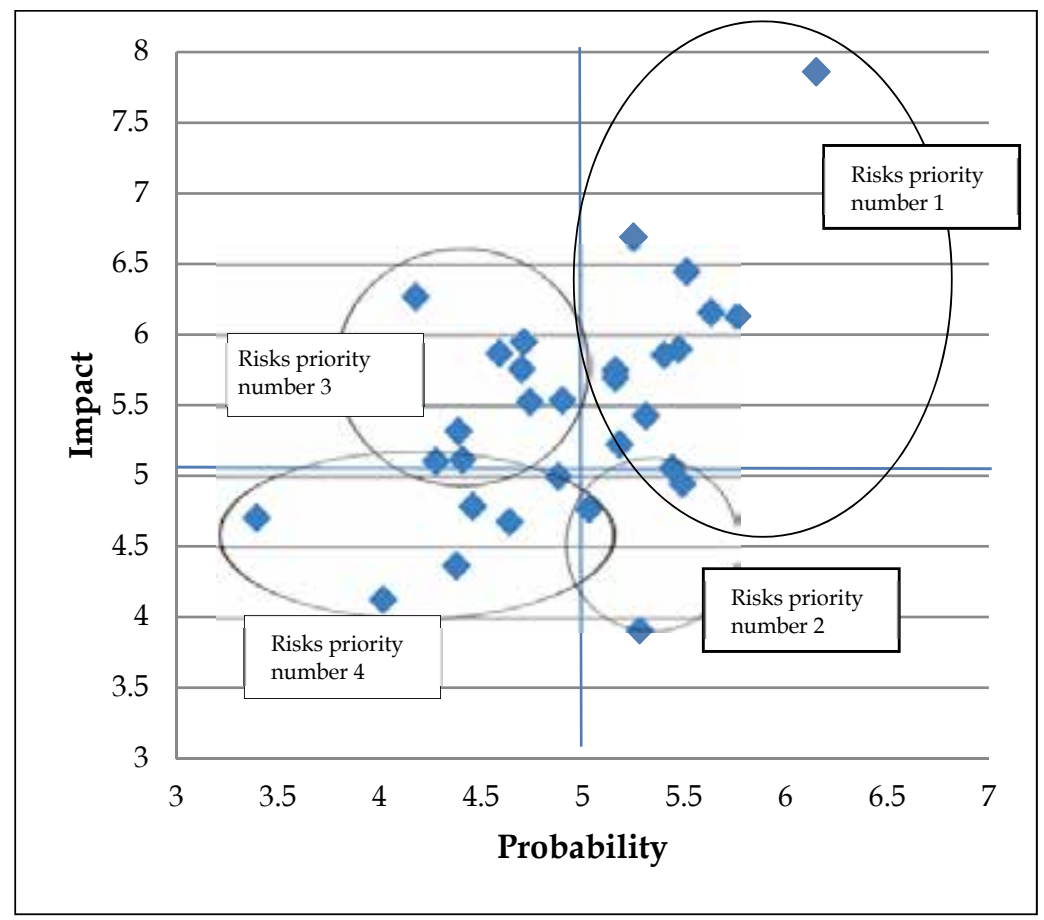

Fig. 4. Probability and impact matrix

\subsection{Risk mitigation}

Risk mitigation actions are adopted by practitioners to respond to various risks that threats the project objectives. This process follows the risk evaluation process so that the risk mitigation is concentrated on the most significant risks in the higher priority. 
The final part of the survey in this study was designed to identify if the practitioners in the Mongolian mining sector perform risk mitigation plan. The results from the survey were shown in Figure 5.

According to Figure 5, the majority of respondents answered that they do perform risk mitigation plan. Therefore, it can be assumed that most companies in Mongolia make an effort to perform their risk mitigation plans.

Finally, the usage of risk management tools by practitioners in the mining industry of Mongolia were evaluated (Figure 6). The two tools used mainly by the practitioners

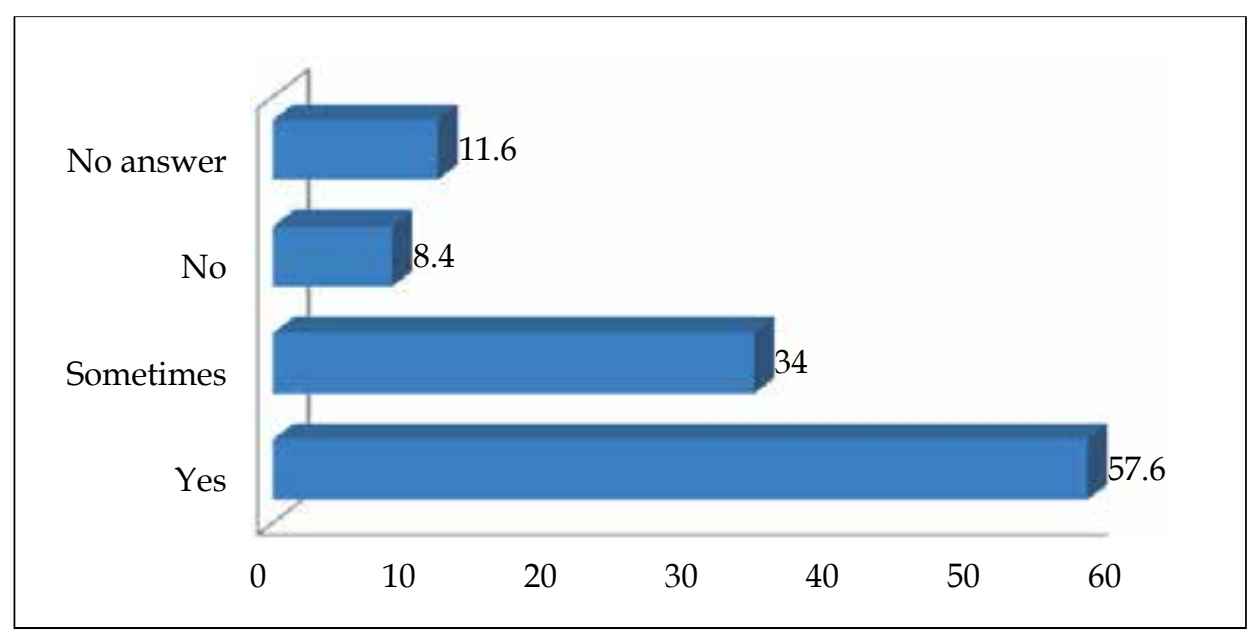

Fig. 5. The performance level of a risk mitigation plan

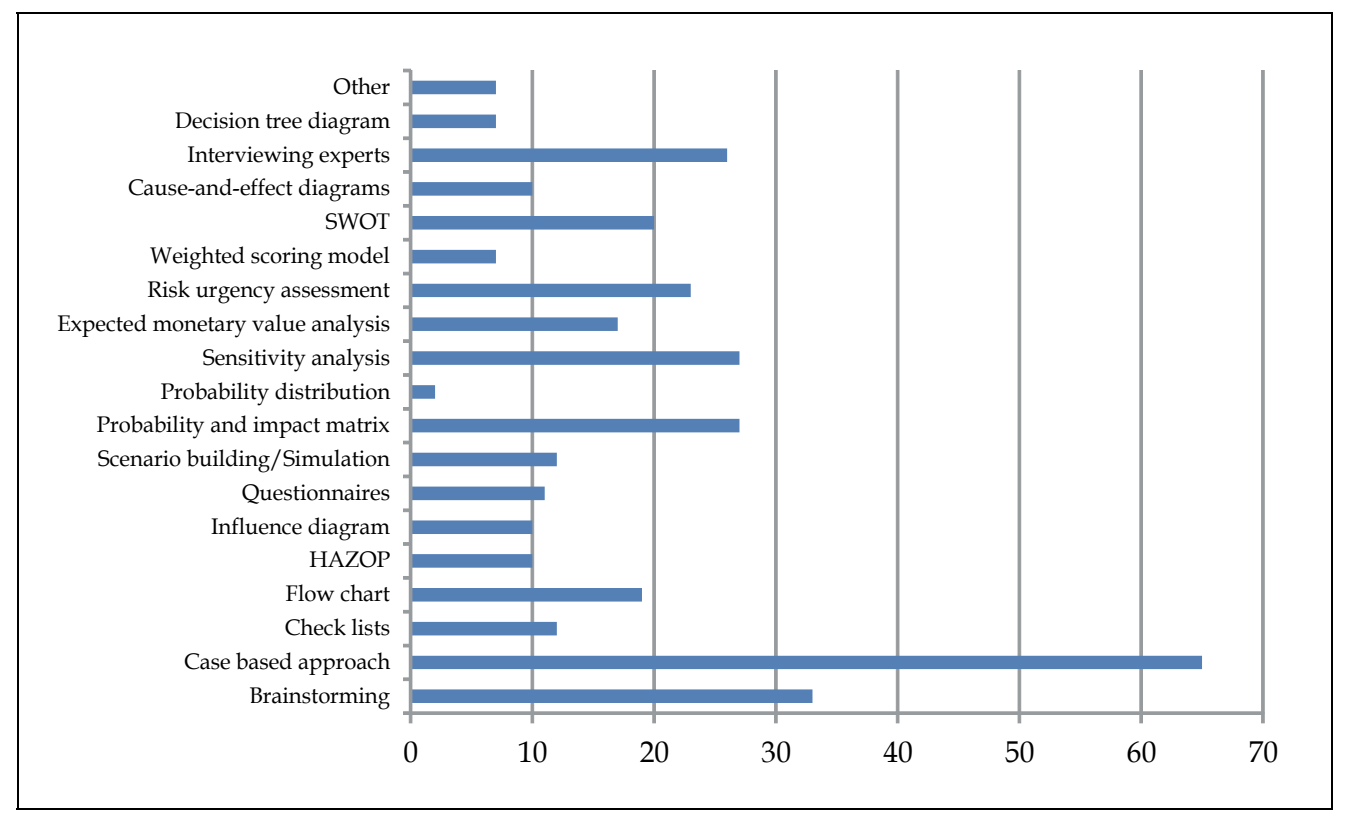

Fig. 6. Usage of risk management tools 
included case based apporach and brainstorming. Consistent with the results of Lyons and Skitmores' survey of PRM in the Queensland engineering construction industry (2004), brainstorming was the most common technique used in risk identification. No single risk assessment technique is best for all cases which is possibly the reason why the respondents have opted for the simplest approach. Tools such as probability distribution and simulation analysis were used seldom. The interview also suggested that, practitioners prefer to use simple methods that do not take much time or effort. The quantitative risk analysis tools are not considered to be an effective method due to various reasons such as insufficient knowledge and experience in these analysis tools and techniques and the difficulty of finding the true probability distribution for risks in practice. Shen (1997), in addition, suggested that according to his survey of PRM in Hong Kong, quantitative analytical techniques have been rarely used due to limited understanding and experience.

From this study, it is clear that the practitioners used the tools which were known to them and the tools they considered as the most effective.

One survey respondant mentioned that a "bank performance letter" can be used as an effective tool for reducing risk in mining project investment as it shows the company credit reputation. For investment companies this document ensures their confidence in the mining company. Furthermore, as mentioned earlier, financial problems are one of the major risks of mining companies, which is a reason why the bank performance letter can be useful tool for obtaining reliable information.

\subsection{Risk learning}

One of the fundamental and major steps in PRM is to identify and assess the potential risks in the project. Every project contains some degree of risk; and yet, most project managers are ill prepared when it comes to identifying or adequately addressing potential risks (Wang et. al., 2004). Managers struggle to identify all the risks of projects because it is time-consuming and counterproductive. Attempts to consider every risk are doomed to failure (El-Sayegh, 2007). The trick is to identify the most critical risks and control them (Barkley, 2004). Thus, it is important to determine the most significant risks in the mining industry of the country where the project is planned to be implemented.

The identification of risk and the creation of a risk list are dependent upon many factors, such as past experience, personal tendency, and the possession of information. Therefore, almost no two risk analysts will make the same judgment when they identify risks from the same project (Ren, 1994).

For managers, an information database with exclusive information of the local risk characteristics of mining projects can be argued to be effective support for mining project managers.

\subsubsection{Project risk information database}

Generally, each project team performs risk management activities and retains what it learns within the project. Thus many of the things learned from various projects need to be reinvented in new projects (Varadharajulu \& Rommel, 2008). However, finding information of previous local projects with similar characteristics is time, effort and money consuming and could be avoided if there is a process and mechanism by which project learning is shared among other project managers. Consequently, an information database solution for risk management process for information sharing among project managers is required. 


\subsubsection{Creating the project risk information database}

Perhaps, previous literature, case studies and survey analysis are essential information for creating risk database. Commonly, large projects implementation takes time and gathering project learning and risk information from them will also take time. Therefore, in addition to the recently implemented project learning, previous studies will contribute as a lot of information of risk and the ways risk was managed (Figure 7). Companies which share similar project characteristics can create a joint risk database and distribute risk information for one another.

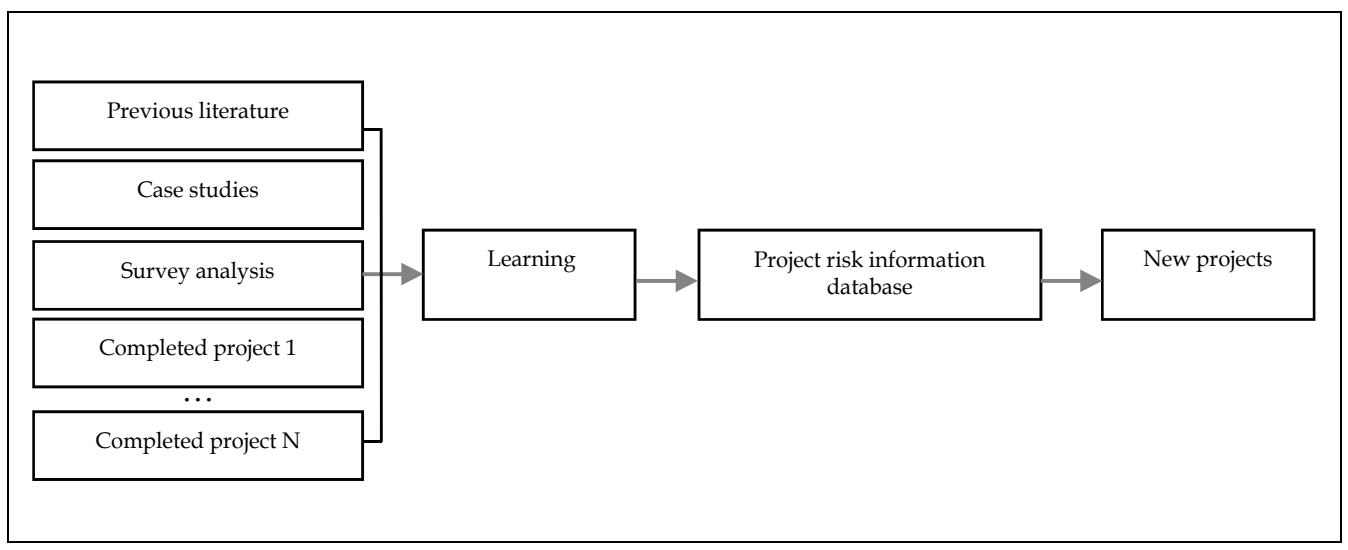

Fig. 7. Project risk information database

While providing inputs, a panel of specialists of the companies should review the submitted risk information and the appropriateness. Only the generic and practical information for future projects should be inserted.

\subsubsection{Using the project risk information database}

As the new project starts, project leader will go through the risk database. In order to save time assuming the information in the database is a great deal of amount the input needs to be categorized. The information in the database is categorized by the type of the projects such as construction or mining project. Then the information is further categorized into place of project implementation to find out the local risks with unique characteristics. Subsequently, the list of literature and project learning of the required project type and location which the project was implemented will be revealed (Figure 8). The risk database needs to have a good guideline on the risk description and how it was managed. The database is required to be maintained by a team appointed by the companies or the database creator. Additionally, the information can be utilized to perform various studies such as simulation analysis on the risk probability of occurrence and impact to project failure in the alleged countries in the supposed types of projects.

The database will help project managers to save effort, time and money and also find out the possible risks and understand them at an early stage. Furthermore, gathered information can be exploited for various project risk management researches which may be helpful for generating productive ideas and techniques that can be utilized in the modern project management. 


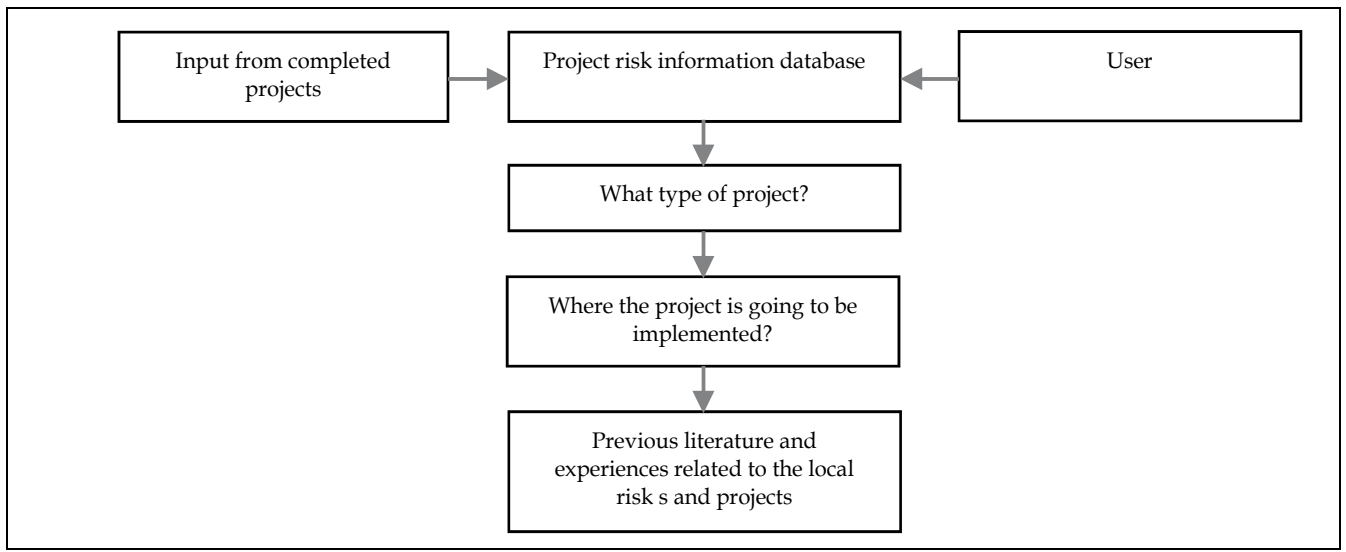

Fig. 8. Project Risk Information Database: Categorizing the Risks

\section{Conclusion}

The chapter describes risk management processes based on a study of the current views and practices of mining projects in Mongolia. Project risks and their relative contribution to project failure was studied. Moreover risk management tools used by those in the field were identified. The identified 30 risks which have highest contribution to mining project failure in Mongolia may be useful for project managers in their future project implementations and risk management processes.

The study shows a necessity for a risk management culture in organizations in the country. Additionally, a risk management method which is suitable for the Mongolian mining industry which is stipulated by a research and an analytic study is required. It may be simply impossible to predict the future of projects over a 10-15 year period of work. However, a framework for a risk management approach that is apt for the characteristics of the country and culture of the people can be suggested for future research.

Furthermore, creation of a risk management database will help project managers to save effort, time and money and also find out the possible risks and understand them at an early stage. The gathered information can be exploited for various project risk management researches which may be helpful for generating productive ideas and techniques that can be utilized in the modern project management.

Finally, some of the risks described in this study may also share same impact to other types of projects implemented in Mongolia, therefore, studies in this matter is also suggested for future researches.

\section{References}

Barkley, B. T. (2004). Project Risk Management, McGraw-Hill, New York, USA

Castle, G. R. (1985). Feasibility studies and other pre-project estimates: How reliable are they?, Proceedings of the Finance for the Minerals Industry, ISBN 0895204355, New York, February, 1985 
Chapman, C. (1997). Project risk analysis and management - PRAM the generic process, International Journal of Project Management, Vol. 15, No. 5, (October 1997), pp. 273281

Charette, R. (2002). The state of risk management 2002: Hype or reality, Industry Report, Cutter Consortium, Arlington, MA

Cooper, D.; Grey, S.; Raymond, G. \& Walker, P. (2005). Project Risk Management Guidelines: Managing Risk in Large Projects and Complex Procurements, John Wiley \& Sons Ltd., England

De Camprieu, R.; Desbiens, J. \& Feixue, Y. (2007). 'Cultural' differences in project risk perception: An empirical comparison of China and Canada. International Journal of Project Management, Vol. 25, pp. 683-693

Del Cano, A. \& de la Cruz, M. P. (2002). Integrated methodology for project risk management, Journal of Construction Engineering and Management, Vol. 128, No. 6, pp.473-485

Edwards, P. J. \& Bowen, P. A. (2005). Risk management in project organizations, Elsevier, Butterworth Heinemann

El-Sayegh, S. M. (2007). Risk assessment and allocation in the UAE construction industry. International Journal of Project Management, Vol. 26, pp. 431-438

Enshassi, A. \& Mosa, J. A. (2008). Risk management in building projects: owners' perspective. The Islamic University Journal (Series of Natural Studies and Engineering), Vol. 14, No.1, pp. 95-123

Fang, D.; Li, M.; Fong, P. S. \& Shen, L. (2004). Risks in Chinese construction market contractors' perspective. Journal of Construction Engineering and Management, Vol. 130, No.6, pp. 853-861

Floricel, S. \& Miller, R. (2001). Strategizing for anticipated risks and turbulence in large-scale engineering projects, International Journal of Project Management, Vol. 19, pp. 445-455

Fraser, D. C. (1984). An approach to major projects, Major Project Association, Oxford: Templeton College Press

Gardiner, P. D. (2005). Project Management: A Strategic Planning Approach, Palgrave Macmillan, New York

Gypton, C. (2002). How have we done? Feasibility study performance since 1980, Engineering and Mining Journal, Vol. 302, No. 1, pp. 41-46

Jacinto, C. M. C. (2002). Discrete event simulation for the risk of development of an oil field, Proceedings of the 2002 Winter Simulation Conference, ed. E. Yucesan, C. H. Chen, J. L. Showdon, and J. M. Charnes, pp. 1588-1592

Kartam, N. A. \& Kartam, S. A. (2001). Risk and its management in the Kuwaiti construction industry; a contractors' perspective. International Journal of Project Management, Vol. 19, pp. 325-335

Ling, F. Y. Y. \& Hoi, L. (2006). Risks faced by Singapore firms when undertaking construction projects in India. International Journal of Project Management, Vol. 24, pp. 261-270

Luu, V. T.; Kim, S.; Tuan, N. V. \& Ogunlana, S. O. (2009). Quantifying schedule risk in construction projects using Bayesian belief networks. International Journal of Project Management, Vol. 27, pp. 39-50 
Lyons, T. \& Skitmore, M. (2004). Project risk management in the Queensland engineering construction industry: a survey. International Journal of Project Management, Vol. 22, No.1, pp. 51-61

Mackenzie, W. \& Cusworth, N. (2007). The use and abuse of feasibility studies, Proceedings of the Project Evaluation Conference, pp. 1-12, Melbourne

Miller, R. \& Lessard, D. (2001). Understanding and managing risks in large engineering projects, International Journal of Project Management, Vol. 19, No. 8, pp. 437-443

Miranda, M.; Burris, P.; Bincang, J. F.; Shaerman, P.; Briones, J. O.; La Vina, A. \& Menard, S. (2003). Mining critical ecosystems: Mapping the risks, World Resource Institute, Washington DC

Noort, D. J. \& Adams, C. (2006). Effective mining project management systems, Proceedings of the International Mine Management Conference 2006, pp. 87-96

Perry, J. C. (1986). Risk management-an approach for project managers, International Journal of Project Management, Vol. 4, No. 4, pp. 211-216

Project Management Institute, Inc., (2008) A Guide to the Project Management Body of Knowledge: PMBOK guide - Fourth edition, Project Management Institute, Inc., ISBN 978-1-933890-51-7, Pennsylvania

Ren, H. (1994). Risk lifecycle and risk relationships on construction projects. International Journal of Project Management, Vol. 12, No.2, pp. 68-74

Roisenberg, M.; Schoeninger, C. \& da Silva, R. R. (2009). A hybrid fuzzy-probabilistic system for risk analysis in petroleum exploration prospects, Expert Systems with Applications, Vol. 36, pp. 6282-6294

Shen, L. Y. (1997). Project risk management in Hong Kong. International Journal of Project Management, Vol. 15, No.2, pp. 101-105

United States Environmental Protection Agency (1997). Office of air and radiation, Final report - Performance of selective catalytic reduction on coal-fired steam generating units

Varadharajulu, M. \& Rommel, C. (2008). Achieving yokoten in the process of risk management, BPM Enterprise.com. Retrived from http://www.bpmenterprise.com/content/c080623a.asp?action=print

Wang, M.; ASCE, M. \& Chou, H. (2003). Risk allocation and risk handling of highway projects in Taiwan. Journal of Management in Engineering, Vol. 19, No.2, pp. 60-68

Wang, S.Q.; Dulaimi, M.F. \& Aguria, M.Y. (2004). Risk management framework for construction projects in developing countries, Consturction Management Economics, Vol. 33, No.3, pp. 237-252

Ward, S. C. \& Chapman, C. (1991). Extending the use of risk analysis in project management, International Journal of Project Management, Vol. 9, No. 2, pp. 117-123

Williams, T. (1995). A Classified Bibliography of Recent Research Relating to Project Risk Management, European Journal of Operational Research, Vol. 85, pp. 18-38

Wyk, R.; van Bowen, P. \& Akintoye, A. (2008). Project risk management practice: The case of a South African utility company, International Journal of Project Management, Vol. 26, pp. 149-163

Ашигт малтмалын тухай хууль, [Minerals Law] (2003). Art. 11, Par. 11.1.6-8, (Mon). 


\title{
A Fuzzy Comprehensive Approach for Risk Identification and Prioritization Simultaneously in EPC Projects
}

\author{
R. Tavakkoli-Moghaddam ${ }^{1}$, S.M. Mousavi ${ }^{1}$ and H. Hashemi² \\ ${ }^{1}$ Department of Industrial Engineering, College of Engineering, University of Tehran, \\ ${ }^{2}$ Department of Civil Engineering, Faculty of Engineering, Zanjan University, \\ Iran
}

\section{Introduction}

Long lasting complicated processes and organizational features generate abundant risks in Engineering, Procurement and Construction (EPC) projects. Iran witnesses an unprecedented boom in engineering, procurement and construction activities at all levels with the government's goal of diversifying its income away from oil dependence to commercial and industrial activities based on the fourth economical development plan. The number, size and complexity of new EPC projects have created an extra burden on the participants and resulted in lots of risks. It is important to identify and prioritize the important risks in Iran to help local and international companies to consider these important risks. Hence, risk identification and prioritization are influential factors in risk monitoring decisions (Ebrahimnejad et al., 2009).

The risk management process aims to identify and assess project risks in order to enable them to be understood clearly and managed effectively. In fact, project risk management is a systematic way of looking at areas of risk and consciously determining how each area should be treated. It is a management tool that aims at identifying sources of risk and uncertainty, determining their impact, and developing appropriate management responses (Thomas, 2003.). There are many commonly used techniques for risk identification and prioritization separately. These techniques generate a list of risks that often does not directly assist the project manager in knowing where to focus risk management attention. Qualitative assessment can help to prioritize identified risks by estimating their probability and impact, exposing the most significant risks; this approach deals with risks one at a time and does not consider their possible correlations, and so also does not provide an overall understanding of the risk faced by the project as a whole (Hillson, 2002).

Project risk prioritization is usually affected by numerous factors including the human error, data analysis and available information. The great uncertainty in projects often causes difficulty in assessing risk factors. However, many risk assessment techniques currently used in EPC projects are comparatively mature, such as fault tree analysis, event tree analysis, monte carlo analysis, scenario planning, sensitivity analysis, failure mode and effects analysis, program evaluation and review technique (Carr \& Tah, 2001).

In this paper, an applicable approach in an uncertain environment that can identify and prioritize project risks simultaneously is introduced. A decision approach is proposed that 
consists of three sections. In the first section, data of project potential risks are gathered. In the second section, a group decision-making approach is used in a fuzzy environment in order to prioritize all potential risks. In the third section, identified and non-identified risks are separated by using an appropriate threshold concurrently. Finally, a case study in one EPC project in Iran is conducted to illustrate the applicability of the proposed fuzzy comprehensive approach in mega projects. Meanwhile, special attention is paid to the various subjective analyses in the selection and prioritization process by using triangular fuzzy numbers in an uncertain environment.

The paper is organized as follows: The related literature for mega projects is reviewed in Section 2. In Section 3, the researchers briefly introduce some basic concepts on fuzzy sets, including fuzzy arithmetic numbers. In Section 4, the theoretic descriptions for the fuzzy entropy and compromise ranking (known as VIKOR) techniques are presented respectively. In Section 4 , the researchers propose the project risk identification and prioritization approach in mega projects. Section 7 investigates a case study using the proposed model to illustrate their potential applications in one EPC project. The discussion of results is provided in Section 6. Finally, conclusions are offered in Section 8.

\section{Literature review}

The general consensus in the current literature in the field of risk management incorporates four core steps in the process of risk management (Al-Bahar \& Crandell, 1990; Ebrahimnejad et al., 2008b; Raftery, 1999). These are:

1. Risk identification and classification

2. Risk analysis

3. Risk response

4. Risk monitoring

The second step of the project risk management process, risk analysis is to measure the impact of the identified risks on a project. Depending on the available data, risk analysis can be performed qualitatively or quantitatively or semi quantitatively (Alborzi et al., 2008; Chapman, 1998, 2001; Mojtahedi et al., 2009).

The evolution of risk management in EPC projects has resulted in the development of various risk identification and prioritization techniques. These techniques are used in situations experiencing uncertainty in order to ease decision making regarding the project's future. These beneficial and practicable developments have resulted in EPC practitioners becoming progressively aware of the importance of using these techniques at various stages of a project to achieve a greater project success (Thevendran \& Mawdesley, 2004).

Risk identification and classification is the first step of the project risk management process, in which potential risks associated with an EPC project are identified. Numerous techniques exist for risk identification, such as brainstorming and workshops, checklists and prompt lists, questionnaires and interviews, Delphi groups or NGT, and various diagramming approaches, such as cause-effect diagrams, systems dynamics, influence diagrams (Chapman, 1998; Ebrahimnejad et al., 2008a). There is no any "best method" for risk identification, and an appropriate combination of techniques should be used (Ebrahimnejad et al., 2008a). As a result, it may be helpful to employ additional approaches to risk identification, which were introduced specifically as broader techniques in group decisionmaking field (Ebrahimnejad et al., 2010; Hashemi et al., 2011; Makui et al., 2007, 2010; Mojtahedi et al., 2009,2010; Mousavi et al., 2011; Tavakkoli-Moghaddam et al., 2009). 
As an integrative part of risk identification, risk classification attempts to structure the diverse risks affecting an EPC project. Several approaches have been suggested in the literature for classifying risks. Perry \& Hayes (1985) presented a list of factors extracted from several sources that were divided in terms of risks retainable by contractors, consultants and clients. Combining the holistic approach of the general system theory with the discipline of a work breakdown structure as a framework, Flanagan \& Norman (1993) suggested three ways of classifying risk: by identifying the consequence, type and impact of risk. Chapman (2001) grouped risks into four subsets, namely environment, industry, client and project. Shen et al. (2001) categorized them into six groups in accordance with the nature of the risks, i.e. financial, legal, management, market, policy and political, as well as technical risks. In a word, many ways can be used to classify the risks associated with oil and gas projects. Mojtahedi et al. (2008) presented a group decision-making approach for identifying and analyzing project risks concurrently. They showed that the project risk identification and analysis can be evaluated at the same time. Moreover, they applied the proposed approach in a mega project and rewarding results were obtained.

Insufficient information, uncertain project environment, and unique EPC projects lead to gain some benefits from the fuzzy set theory in risk assessment. In fact, there have been limited attempts to exploit fuzzy logic within the mega project risk management domain. Kangari (1988) presented an integrated knowledge-based system for construction risk management using fuzzy sets. This system, which is called Expert-Risk, performs the risk analysis in two situations, namely before construction and during construction. Chun \& Ahn (1992) proposed the use of the fuzzy set theory to quantify the imprecision and judgmental uncertainties of accident progression event trees. Peak et al. (1993) proposed the use of fuzzy sets for the analysis of bidding prices for mega projects. Tah et al. (1993) tried a linguistic approach to risk management during the tender stage for contingency allocation, using fuzzy logic. Ross \& Donald (1995) described a method for assessing risk based on fuzzy logic and similarity measures. This approach uses linguistic variables catering for vagueness and subjectivity to devise rules for assessing the management of hazardous waste sites. Ross \& Donald (1996) also used the fuzzy set theory for the mathematical representation of fault trees and event trees as used in risk analysis problems. Wirba et al. (1996) used linguistic variables. This approach considers a method, in which the probability of a risk event occurring, the level of dependence between risks, and the severity of a risk event, is quantified using linguistic variables and fuzzy logic. Carr \& Tah (2001) presented a formal model for the construction project risk analysis. This model involved the relationships between risk factors, risks, and their impacts based on cause and effect diagrams. They used fuzzy approximation and composition, the relationships between risk sources and the impacts on project performance measures.

Dikman et al. (2007) also proposed a fuzzy risk analysis for international construction projects. This methodology utilizes the influence diagramming method and estimate a cost overrun risk rating. Zeng et al. (2007) introduced a risk analysis model based on fuzzy reasoning and modified Analytical Hierarchy Process (AHP) to handle the uncertainties arising in the construction process. Makui et al. (2010) developed the concept of safety to risk identification and assessment simultaneously in a fuzzy environment. They focused not only on the time and cost criteria but also on the health, safety and environment critera. Then, the NGT and MAGDM techniques were utilized for identifying and assessing risks in a gas refinery plant construction with emphasizing the potential risk breakdown structure. Ebrahimnejad et al. (2009) introduced effective criteria for evaluating risks, and presented a 
fuzzy multiple criteria decision-making (MCDM) model for risk assessment with an application to an onshore gas refinery. In addition, Ebrahimnejad et al. (2010) identified the risks in build-operate-transfer power plant projects and designed a fuzzy multi-attribute decision-making model for analyzing important risks.

Going through the literature indicates that the risk identification and prioritization problem has not been considered concurrently in EPC projects; moreover, few studies had been performed mega projects in Iran (Ebrahimnejad et al., 2008a; Makui et al., 2007; Mojtahedi et al., 2008). The aim of this paper is to introduce a practical fuzzy comprehensive approach for identifying and prioritizing project risks by applying group decision-making approach concurrently. Moreover, fuzzy logic is used through the proposed approach because of existing ambiguous and uncertain data in projects' environment. Finally, one EPC project as a case study in Iran is conducted to illustrate the applicability of the proposed approach. Meanwhile, special attention is paid to the various subjective analyses in the selection and ranking process by using fuzzy numbers.

\section{Basic definitions}

In the following, a brief review of some basic definitions of fuzzy sets is presented (Zimmermann, 1996; Chen, 2000). These basic definitions and notations are used throughout the paper.

Definition 3.1. A fuzzy set $\tilde{A}$ in the universe of discourse $X$ is convex if and only if

$$
\mu_{\tilde{A}}\left(\lambda x_{1}+(1-\lambda) x_{2}\right) \geq \min \left(\mu_{\tilde{A}}\left(x_{1}\right), \mu_{\tilde{A}}\left(x_{2}\right)\right)
$$

for all $x_{1}, x_{2}$ in $X$ and all $\lambda \in[0,1]$, where min denotes the minimum operator (Zimmermann, 1996).

Definition 3.2. A fuzzy number is a fuzzy subset in the universe of discourse $X$ that is both convex and normal (Zimmermann, 1996).

Definition 3.3. A linguistic variable is a variable whose values are linguistic terms. Linguistic terms (\{not important, somewhat important, important, very important, extremely important\} have been found to be intuitively easy in expressing the subjectiveness and/or imprecision qualitative of a decision maker (DM)'s assessments (Zimmermann, 1996).

Definition 3.4. A fuzzy set $\tilde{a}$ in a universe of discourse $x$ is characterized by a membership function $\tilde{a}$ which associates with each element $x$ in $X$, a real number in the interval $[0,1]$. The function value $\mu_{\tilde{a}}(x)$ is termed the grade of membership of $x$ in $\tilde{a}$ (Zimmermann, 1996). Fig. 1 shows a fuzzy number $\tilde{a}$.

A triangular fuzzy number $\tilde{a}$ can be defined by a triplet $\left(a_{1}, a_{2}, a_{3}\right)$ shown in Fig. 2 . The membership function $\mu_{\tilde{a}}(x)$ is defined as given in Zimmermann (1996):

$$
\mu_{\tilde{a}}(x)= \begin{cases}0 & ; x \leq a_{1} \\ \frac{x-a_{1}}{a_{2}-a_{1}} & ; a_{1} \leq x \leq a_{2} \\ \frac{a_{3}-x}{a_{3}-a_{2}} & ; a_{2} \leq x \leq a_{3} \\ 0 & ; x \geq a_{3}\end{cases}
$$




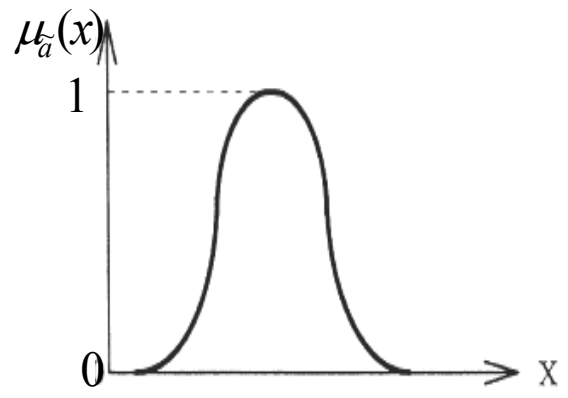

Fig. 1. A fuzzy number $\tilde{a}$.

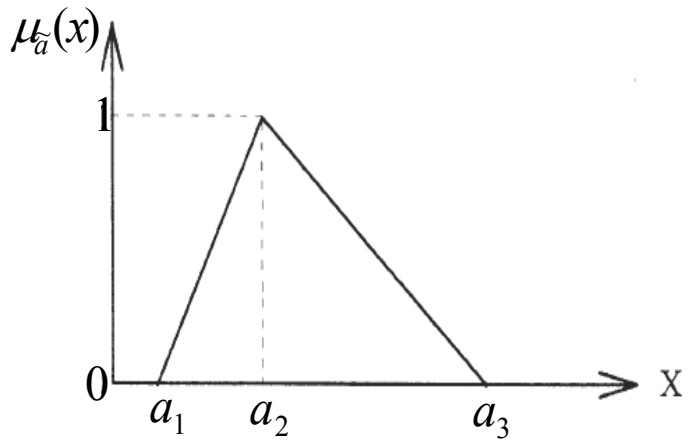

Fig. 2. A triangular fuzzy number $\tilde{a}$.

Definition 3.5. Let $\tilde{a}=\left(a_{1}, a_{2}, a_{3}\right)$ and $\tilde{b}=\left(b_{1}, b_{2}, b_{3}\right)$ be two triangular fuzzy numbers, then the vertex method is defined to calculate the distance between them, as Eq. (3):

$$
d(\tilde{a}, \tilde{b})=\sqrt{\frac{1}{3}\left[\left(a_{1}-b_{1}\right)^{2}+\left(a_{2}-b_{2}\right)^{2}+\left(a_{3}-b_{3}\right)^{2}\right]}
$$

Property 3.5.1. Assuming that both $\tilde{a}=\left(a_{1}, a_{2}, a_{3}\right)$ and $\tilde{b}=\left(b_{1}, b_{2}, b_{3}\right)$ are real numbers, then the distance measurement $d(\tilde{a}, \tilde{b})$ is identical to the Euclidean distance (Chen, 2000).

Property 3.5.2. Let $\tilde{a}, \tilde{b}$, and $\tilde{c}$ be three triangular fuzzy numbers. The fuzzy number $\tilde{b}$ is closer to fuzzy number $\tilde{a}$ than the other fuzzy number $\tilde{c}$ if, and only if, $d(\tilde{a}, \tilde{b}) \leq d(\tilde{a}, \tilde{c})$ (Chen, 2000).

The normalization method: To avoid the complicated normalization formula used in fuzzy MCGDM, the linear scale transformation is used here to transform the various criteria scales into a comparable scale. Therefore, we can obtain the normalized fuzzy decision matrix denoted by $\tilde{R}$.

$$
\tilde{R}=\left[\tilde{r}_{i j}\right]_{m \times n}
$$


where $B$ and $C$ are the set of benefit and cost criteria, respectively.

$$
\begin{aligned}
\tilde{r}_{i j}=\left(\frac{a_{i j 1}}{c_{j}^{*}}, \frac{a_{i j 2}}{c_{j}^{*}}, \frac{a_{i j 3}}{c_{j}^{*}}\right), \quad j \in B, \quad i=1,2, \ldots, m, j=1,2, \ldots, n ; \\
\tilde{r}_{i j}=\left(\frac{a_{j}^{-}}{a_{i j 1}}, \frac{a_{j}^{-}}{a_{i j 2}}, \frac{a_{j}^{-}}{a_{i j 3}}\right), \quad j \in C, \quad i=1,2, \ldots, m, j=1,2, \ldots, n ; \\
c_{j}^{*}=\max c_{i j} \quad \text { if } j \in B ; \\
a_{j}^{-}=\min a_{i j} \quad \text { if } j \in C .
\end{aligned}
$$

Definition 3.6. Let $\tilde{A}=\left(a_{1}, a_{2}, a_{3}\right)$ and $\tilde{B}=\left(b_{1}, b_{2}, b_{3}\right)$ be two positive triangular fuzzy numbers. Then basic fuzzy arithmetic operations on these fuzzy numbers are defined as (Dubois \& Prade, 1980; Kauffman \& Gupta, 1991):

$$
\begin{aligned}
& \text { Addition: } \tilde{A}+\tilde{B}=\left(a_{1}+b_{1}, a_{2}+b_{2}, a_{3}+b_{3}\right) \\
& \text { Subtraction: } \tilde{A}-\tilde{B}=\left(a_{1}-b_{3}, a_{2}-b_{2}, a_{3}-b_{1}\right) \\
& \text { Multiplication: } \tilde{A} \times \tilde{B} \approx\left(a_{1} b_{1}, a_{2} b_{2}, a_{3} b_{3}\right) \\
& \text { Division: } \tilde{A} \div \tilde{B}=\left(\frac{a_{1}}{b_{3}}, \frac{a_{2}}{b_{2}}, \frac{a_{3}}{b_{1}}\right)
\end{aligned}
$$

\section{Multiple criteria group decision making in a fuzzy environment}

MCGDM often involves DMs' subjective judgments and preferences, such as qualitative /quantitative criteria ratings and the weights of criteria. These problems will usually result in uncertain, imprecise, indefinite and subjective data being present, which makes the decision-making process complex and challenging. In other words, decision making often occurs in a fuzzy environment where the information available is imprecise/uncertain (Zadeh, 1975). In the last few years, numerous studies attempting to handle this uncertainty, imprecision, and subjectiveness have been carried out basically by means of the fuzzy set theory, as fuzzy set theory may provide the flexibility needed to represent the imprecision or vague information resulting from a lack of knowledge or information (Chen \& Hwang, 1992). Therefore, the application of the fuzzy set theory to multi-criteria evaluation methods under the framework of the utility theory has proven to be an effective approach (Carlsson, 1982; Zimmermann, 1996). Fuzzy multi-criteria evaluation methods are used widely in fields, such as tool steel material selection (Chen, 1997), evaluating investment values of stocks (Tsao, 2003), bridge conceptual design (Malekly et al., 2010; Mousavi et al., 2008), temporary storage design (Heydar et al., 2008). 


\subsection{Fuzzy entropy}

The concept of entropy in the context of the information theory was first introduced by Shannon, and it can be viewed as an order measure in the signal. Shannon entropy, quantifies the PDF of the signal and it can be computed by:

$$
H_{S h}=-\sum_{i} p_{i} \log p_{i}
$$

where $i$ goes over all amplitude values of the signal and is the $p_{i}$ probability that amplitude $a_{i}$ value occurs anywhere in the signal. This concept can be easily extended in a fuzzy environment.

\subsection{Fuzzy VIKOR}

The VIKOR method was developed by (Opricovic \& Tzeng, 2002). This method is based on the compromise programming of MCDM. We assume that each alternative is evaluated according to a separate criterion function; the compromise ranking can be reached by comparing the measure of closeness to the ideal alternative. The multi-criteria measure for the compromise ranking is developed from the $L_{P}$-metric used as an aggregating function for a compromise programming method (Opricovic \& Tzeng, 2002; Wu et al., 2010).

Matching MCDM methods with classes of problems will address the correct applications, and for this reason the VIKOR characteristics are matched with a class of problems as follows (Opricovic \& Tzeng, 2007):

- Compromising is acceptable for conflict resolution.

- The decision maker (DM) is willing to approve solution that is the closest to the ideal.

- There exist a linear relationship between each criterion function and a decision maker's utility.

- The criteria are conflicting and non-commensurable (different units).

- The alternatives are evaluated according to all established criteria (performance matrix).

- The DM's preference is expressed by weights, given or simulated.

- The VIKOR method can be started without interactive participation of the DM; but, the $\mathrm{DM}$ is in charge of approving the final solution and his/her preference must be included.

- The proposed compromise solution (one or more) has an advantage rate.

- A stability analysis determines the weight stability intervals.

The VIKOR method was introduced as one applicable technique to be implemented within MCDM problem and it was developed as a multi attribute decision-making method to solve a discrete decision making problem with non-commensurable (different units) and conflicting criteria (Opricovic \& Tzeng, 2002,2007). This method focuses on ranking and selecting from a set of alternatives, and determines compromise solution for a problem with conflicting criteria, which can help the decision makers to reach a final solution. The multicriteria measure for compromise ranking is developed from the $L_{P}$-metric used as an aggregating function in a compromise programming method (Aven \& Vinnem, 2005; Aven et al., 2007).

Assuming that each alternative is evaluated according to each criterion function, the compromise ranking can be performed by comparing the measure of closeness to the ideal alternative. The various $m$ alternatives are denoted as $A_{1}, A_{2}, \ldots, A_{m}$. For alternative $A_{i}$, the 
rating of the $j$ th aspect is denoted by $f_{i j}$, i.e. $f_{i j}$ is the value of $j$ th criterion function for the alternative $A_{i} ; n$ is the number of criteria. Development of the VIKOR method is started with the following form of the $L_{p}$-metric:

$$
L_{p i}=\left\{\sum_{j=1}^{n}\left[\left(f_{j}^{*}-f_{i j}\right) /\left(f_{j}^{*}-f_{j}^{-}\right)\right]^{p}\right\}^{1 / p} \quad 1 \leq p \leq \infty ; \quad i=1,2, \ldots, m .
$$

In the VIKOR method, $L_{1 . i}\left(\right.$ as $\left.S_{i}\right)$ and $L_{\infty . i}\left(\right.$ as $\left.R_{i}\right)$ are used to formulate the ranking measure. The solution obtained by $\min S_{i}$ is with a maximum group utility ("majority" rule), and the solution obtained by $\min R_{i}$ is with a minimum individual regret of the "opponent".

\section{Proposed fuzzy comprehensive approach}

The proposed fuzzy comprehensive approach is designed in three main sections and nineteen sub-steps as illustrated in Fig. 3. Project potential risk data gathering is described in the first section, the fuzzy MCGDM process based on the fuzzy entropy and VIKOR techniques is explained in details in the second section, and separation of identified and non-identified risks is discussed in the section three. The fuzzy theory importance in the proposed fuzzy comprehensive approach is described in following sub-section.

\subsection{Fuzzy theory importance in proposed approach}

In project risk management, the modelling process of the risks may not be performed sufficiently and exactly, because the available data and information are vague, inexact, imprecise and uncertain by nature. The decision-making process dealing with the modelling of project risks should be based on these uncertain and ill-defined information. To resolve the vagueness, ambiguity and subjectivity of human judgment, fuzzy sets theory can be applied to express the linguistic terms in risk decision making process.

The project risk experts or DMs can provide a precise numerical value, a range of numerical values, a linguistic term or a fuzzy number. Consequently, fuzzy linguistic terms are much easier to be accepted and adopted by the DMs to provide precise numerical judgments about the criteria of each risk event. Therefore, a linguistic term and a fuzzy number can be used in the proposed approach.

Fuzzy membership function: Through the commonly used fuzzy numbers, triangular fuzzy numbers are likely to be the most adoptive ones for their simplicity in modelling and interpreting. We figure out that a triangular fuzzy number can adequately represent the seven level fuzzy linguistic variables and thus it is used for the analysis hereafter. Table 1 illustrates the linguistic terms defined for the criteria of project risk event in this paper. Moreover, the fuzzy membership functions are illustrated in Fig. 4.

\subsection{Steps of the proposed fuzzy comprehensive approach}

\section{Section 1: Project potential risk data collection}

Step 1. In this step, project potential risks are gathered by applying historical information, lessons learned and NGT method in order to establish the potential risk breakdown 
structure (PRBS). Many approaches have been suggested in the literature for classifying risks (Chapman \& Ward, 2004; Perry \& Hayes, 1985; Shen et al., 2001). In this paper, a new practical approach based on Makui et al. (2010) is considered for classifying risks. Potential risks are grouped in adhere to the project work break down structure (WBS) in order to study potential risks in different levels of project and scope of work.

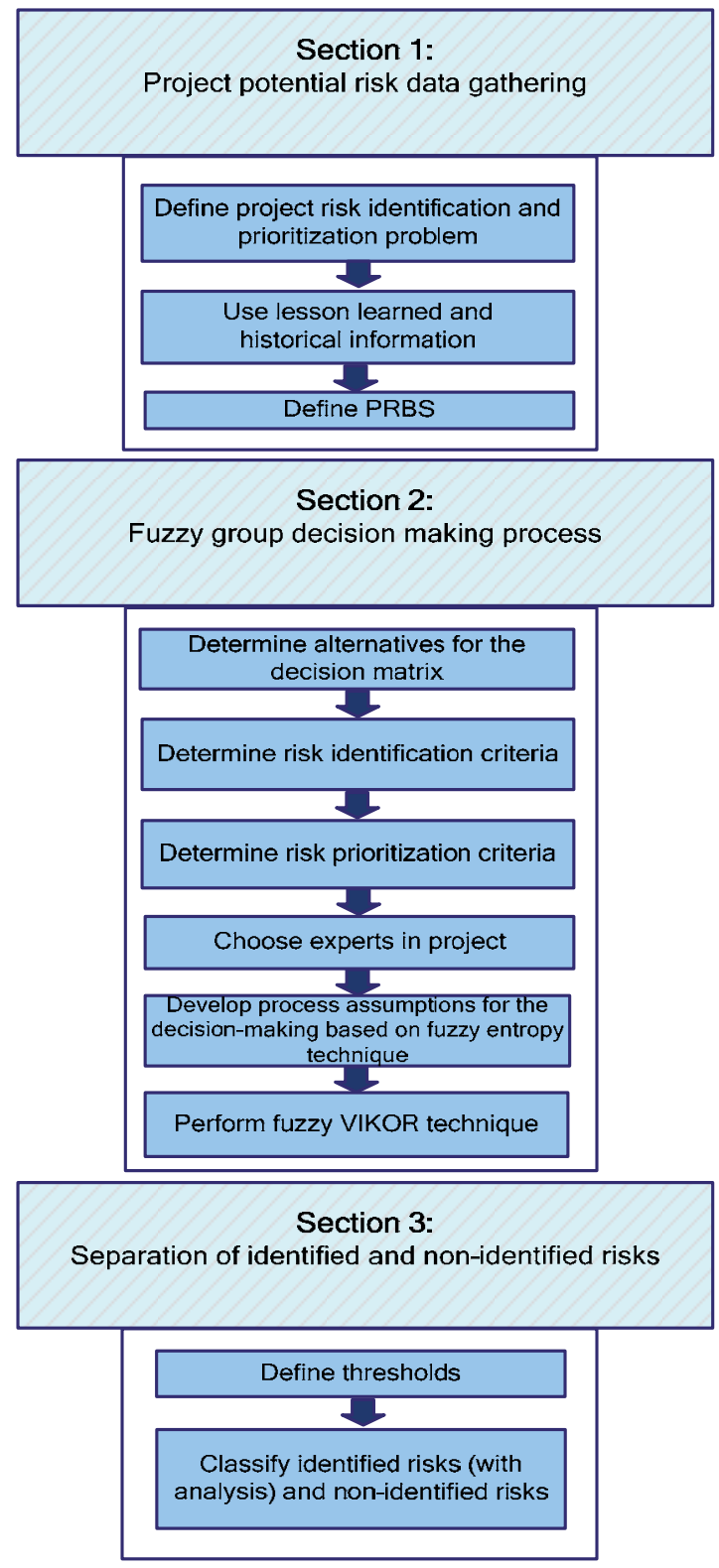

Fig. 3. Proposed fuzzy comprehensive approach for the risk identification and prioritization simultaneously 


\begin{tabular}{ccc}
\hline Description & Scale & Measure \\
\hline Almost Certain & AC & $(0,0,0.1)$ \\
Highly Likely & HL & $(0,0.1,0.3)$ \\
Likely & L & $(0.1,0.3,0.5)$ \\
Possible & P & $(0.3,0.5,0.7)$ \\
Unlikely & UL & $(0.5,0.7,0.9)$ \\
Rare & R & $(0.7,0.9,1)$ \\
Non-Identified & NI & $(0.9,1,1)$ \\
\hline
\end{tabular}

Table 1. Linguistic variables for the importance weight of each criterion.

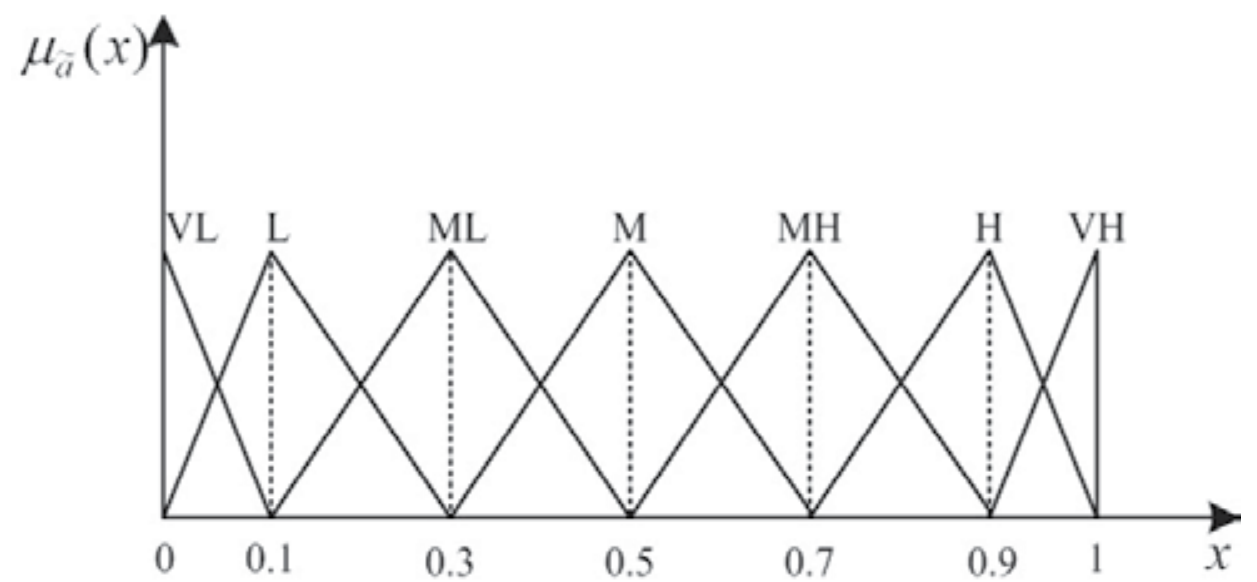

Fig. 4. Fuzzy membership triangular functions.

We propose a solution for structuring the risk management problem in order to adopt the full hierarchical approach used in the WBS, which as many levels as are required to provide the necessary understanding of risk exposure to allow effective management. Such a hierarchical structure of risk source should be known as a PRBS based on WBS. The proposed PRBS is defined here as a source-oriented grouping of project potential risks that organize and defines the total risk exposure of the project based on the WBS. Each descending level represents an increasingly detailed definition of sources of potential risk to the project based on the WBS.

\section{Section 2: Fuzzy group decision-making process}

This study aims to identify and prioritize project risks concurrently. Fuzzy entropy and fuzzy VIKOR techniques is used to identify risks from PRBS and prioritize them in the same time in a fuzzy environment.

Step 2. The lowest level of the PRBS constructs the alternatives of the fuzzy decision matrix. 
Step 3. Determine risk identification criteria as follows:

$\mathrm{C}_{1}$ : Existing and observing in other similar projects.

$\mathrm{C}_{2}$ : Disability to transfer the potential risk to client or employer.

$\mathrm{C}_{3}$ : Contract's disability to clarify the potential risk.

Step 4. Determine risk analysis criteria as below (Makui et al., 2010):

$\mathrm{C}_{4}$ : Probability, $\mathrm{C}_{5}$ : Time impact, $\mathrm{C}_{6}$ : Cost impact, $\mathrm{C}_{7}$ : Performance impact

Step 5. The DMs in the project:

The selection of experts for answering potential risk against criteria is very critical and it should be selected from project stakeholders.

Step 6. In order to take precise advantages form the fuzzy VIKOR method, some assumptions can be considered:

a. Criteria are the same for all DMs.

b. Criteria may have different weights but criteria's weights are the same for all DMs.

c. DMs have different weights.

Step 7. Construct fuzzy decision matrix $D,(p=1,2, \ldots, k)$ for each of the experts. The structure of the fuzzy matrix can be depicted by:

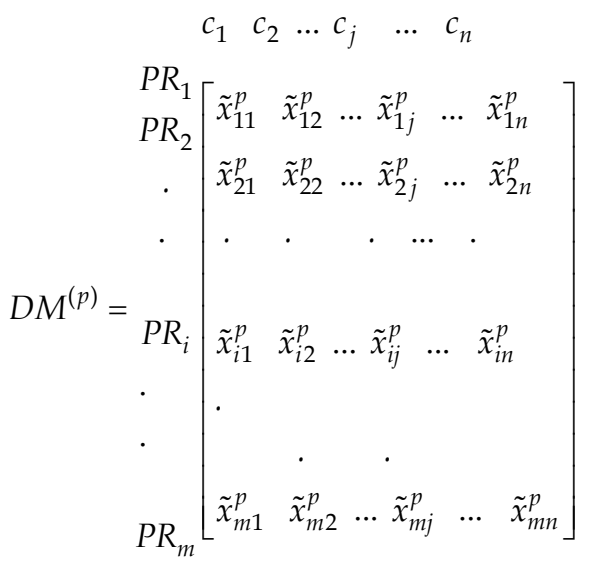

where $P R_{i}$ denotes the $i$ th potential risk, $\tilde{C}_{j}$; represents the $j$ th criterion or attribute, $(j=1,2, \ldots, m)$ (which are identified in Steps 3 and 4 ); with qualitative data. The element of $D M^{(p)}$ is $\tilde{x}_{i j}^{p}$, which indicates the perform rating of alternative $P R_{i}$ with respect to criterion $\tilde{C}_{j}$; by $D M(p=1,2, \ldots, k)$.

Please note that there should be $k$ fuzzy decision matrix for the $k$ members of a group. Observe that the DMs can also set the outcomes of qualitative or intangible criterion for each alternative as discrete values, or other linguistics values will be placed in the above decision matrix.

Step 8. Construct the fuzzy normalized decision matrix $\tilde{R}$, by each DM for $n$ criteria. The normalized value $\tilde{r}_{i j}^{p}$ in the decision matrix $\tilde{R}^{p}$ is calculated by Eq. (5); (all criteria are considered as benefit). 
Step 9. Construct the group decision matrix $\tilde{G}$ as follows:

$$
\begin{aligned}
& \begin{array}{llllll}
c_{1} & c_{2} & \ldots & c_{j} & \ldots & c_{n}
\end{array}
\end{aligned}
$$

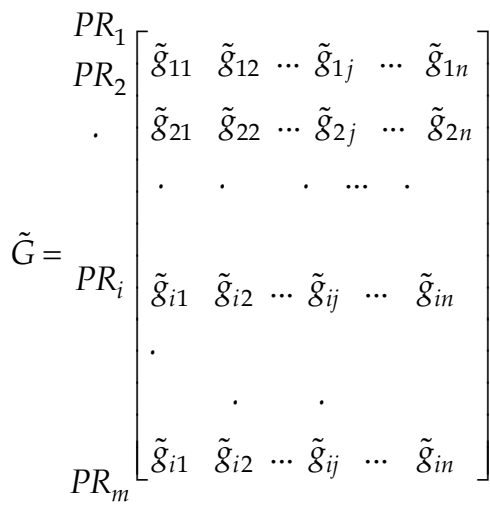

The grouping value for criterion $j$ can be as follows:

$$
\tilde{g}_{i j}=\sum_{p=1}^{k} \tilde{W}_{D}^{p} \times \tilde{r}_{i j}^{p} ; i=1,2, \ldots, m, j=1,2, \ldots, n
$$

$\tilde{W}_{D}{ }^{p}$ is the weight of each DM, where we have:

$$
\sum_{p=1}^{k} \tilde{W}_{D}^{p}=1
$$

Step 10. Change the evaluation index from different measurement to the same measurement.

$$
\tilde{p}_{i j}=\tilde{x}_{i j} / \sum_{j=1}^{n} \tilde{x}_{i j}
$$

Step 11. Calculate entropy of every index weight

$$
\tilde{e}_{i}=-k \sum_{j=1}^{n} \tilde{p}_{i j} \ln \tilde{p}_{i j}
$$

where $k>0, k=1 / \ln n, \tilde{e}_{i} \geq 0$.

Step 12. Define the difference coefficient $\tilde{g}_{i}=1-\tilde{e}_{i}$, the bigger the $\tilde{g}_{i}$, the more important the index is. Identifying the indexes' value and applying entropy weight method.

$$
\tilde{w}_{i}=\tilde{g}_{i} / \sum_{i=1}^{m} \tilde{g}_{i} \quad(i=1,2, \ldots, m)
$$

Weight vector is $\tilde{w}_{1}=\left(\tilde{w}_{1}, \tilde{w}_{2}, \ldots, \tilde{w}_{m}\right)$. 
There are many methods that can be employed to determine weights (Kuo et al., 2007; Wang et al., 2007). In this paper, the weights provided by the fuzzy entropy technique are used.

Step 13. Determine the best $f_{j}^{*}$ and the worst $f_{j}^{-}$values of all criterion functions $j=1,2, \ldots, n$.If the $j$ th function represents a benefit, then we have:

$$
\begin{gathered}
f_{i}^{*}=\max _{j} f_{i j} \\
\text { and } \\
f_{i}^{-}=\min _{j} f_{i j}
\end{gathered}
$$

Step 14. Compute the values $S_{i}$ and $R_{i} ; i=1,2, \ldots, m$, by these relations:

$$
\begin{gathered}
S_{i}=L_{1, i}=\sum_{j=1}^{m} w_{j}\left(f_{j}^{*}-f_{i j}\right) /\left(f_{j}^{*}-f_{j}^{-}\right), \\
R_{i}=L_{\infty, i}=\max _{j} w_{j}\left(f_{j}^{*}-f_{i j}\right) /\left(f_{j}^{*}-f_{j}^{-}\right),
\end{gathered}
$$

where $w_{j}$ are the weights of criteria, expressing their relative importance.

Step 15. Compute the values $Q_{i} ; i=1,2, \ldots, m$, by the following relation:

$$
Q_{i}=v\left(S_{i}-S^{*}\right) /\left(S^{-}-S^{*}\right)+(1-v)\left(R_{i}-R^{*}\right) /\left(R^{-}-R^{*}\right)
$$

Where

$$
\begin{array}{ll}
S^{*}=\min _{i} S_{i}, & S^{-}=\max _{i} S_{i} \\
R^{*} & =\min _{i} R_{i}, \quad R^{-}=\max _{i} R_{i}
\end{array}
$$

$v$ is introduced as weight of the strategy of "the majority of criteria" (or "the maximum group utility"), here suppose that $v=0.5$.

Step 16. Rank the alternatives, sorting by the values $S, R$ and $Q$ in decreasing order. The results are three ranking lists.

Step 17. Propose as a compromise solution the alternative $A^{\prime}$, which is ranked the best by the measure $Q$ (Minimum) if the following two conditions are satisfied:

C1. Acceptable advantage:

$$
Q\left(A^{\prime \prime}\right)-Q\left(A^{\prime}\right) \geq D Q
$$

where $A^{\prime \prime}$ is the alternative with the second position in the ranking list by $Q$; $D Q=1 /(m-1) ; m$ is the number of alternatives.

C2. Acceptable stability in decision making: 
Alternative $A^{\prime}$ should be also the best ranked by $S$ or/and $R$. This compromise solution is stable within a decision-making process, which can be "voting by majority rule" (when $v>0.5$ is needed), or "by consensus" $v \approx 0.5$, or "with veto" $(v<0.5)$. Here, $v$ is the weight of the decision-making strategy "the majority of criteria" (or "the maximum group utility"). If one of the conditions is not satisfied, then a set of compromise solutions is proposed, which consists of:

- Alternatives $A^{\prime}$ and $A^{\prime \prime}$ if only condition $\mathrm{C} 2$ is not satisfied, or

- Alternatives $A^{\prime}, A^{\prime \prime}, \ldots, A^{(M)}$ if condition $\mathrm{C} 1$ is not satisfied; $A^{(M)}$ is determined by the relation $Q\left(A^{(M)}\right)-Q\left(A^{\prime}\right)<D Q$ for maximum $M$ (the positions of these alternatives are "in closeness").

The best alternative, ranked by $Q$, is the one with the minimum value of $Q$. The main ranking result is the compromise ranking list of alternatives, and the compromise solution with the "advantage rate". VIKOR is an effective tool in MCDM, particularly in a situation where the DM is not able, or does not know to express his/her preference at the beginning of the system design. The obtained compromise solution can be accepted by the DMs because it provides a maximum "group utility" (represented by min $S$ ) of the "majority", and a minimum of the "individual regret" (represented by $\min R$ ) of the "opponent". The compromise solutions can be the basis for negotiations, involving the DM preference by criteria weights.

\section{Section 3: Separation of identified and non-identified risks}

Step 18. In this step, one threshold can be determined in order to separate identified risks from potential risks, moreover, some ranges could be developed to assess the identified risks into "Almost certain risks" up to "Rare risks", as shown in Fig. 5.

Step 19. Classify identified risks (with analysis) and non-identified risks.

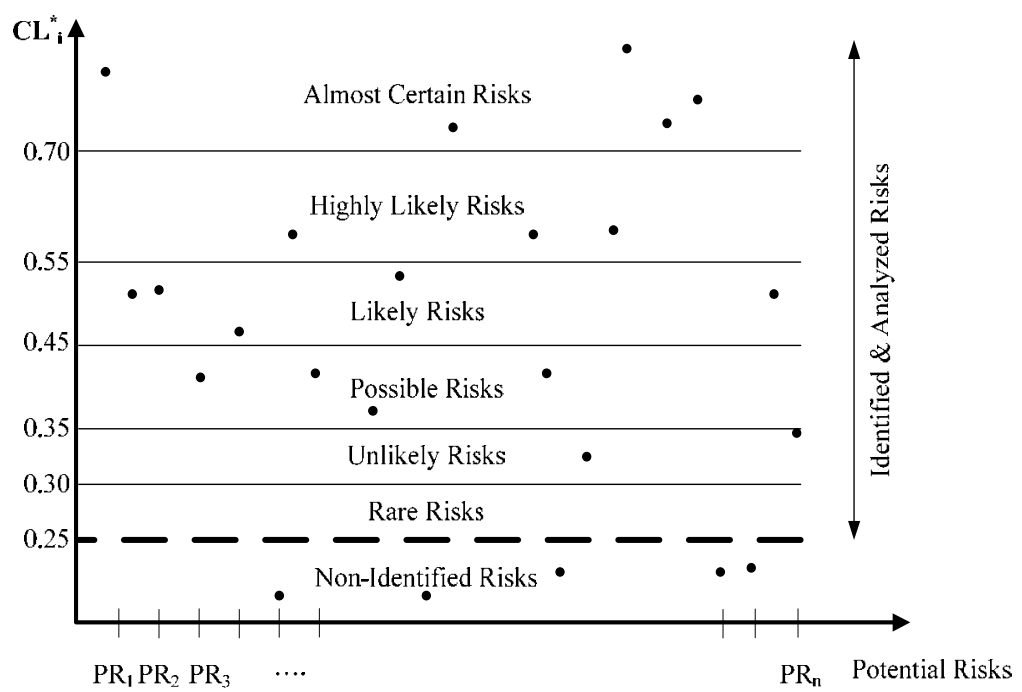

Fig. 5. Identifying and analysing project risks concurrently by defining appropriate thresholds. 


\section{Application to an EPC project}

In this section, the proposed comprehensive approach is applied in the engineering phase of an EPC project. A project, as defined in the field of project management, consists of a temporary endeavor undertaken to create a unique product, service or result (Cooper et al., 2005). Project management tries to gain control over project's variables, such as risk. Thus, a risk analysis is essential for all phases of projects particularly engineering phase because this phase is a commencement phase of project. Project promoters depend upon several project partners (e.g., consultants, architects and contractors) to convert their plans into reality. Among the project partners, EPC contractors play a crucial role in the actual implementation of projects. Depending upon the size of a project, an EPC contractor might execute the same solely or break the project into different categories and delegate it to a number of subcontractors.

Easy to manage by client, reduction of project time and cost, output guarantees, shortened project life cycle, improving contractors' abilities and financers' interests are the most advantages of EPC contracts. However, increasing contractor risk to perform the job, underestimating and quality of work are the major disadvantages of EPC contracts. Most engineering contracts can fall into four major scopes of services:

- $\quad$ Basic Engineering (BE)

- $\quad$ Front End Engineering Design (FEED)

- $\quad$ Detailed Engineering (DE)

- $\quad$ Field Engineering (FE)

The main deliverable of a "Conceptual Design", which elaborates project feasibility, is the Master Development Plan (MDP). A basic designer further develops the MDP and creates the necessary integrity in each functional department to aim the proper design for having such industrial complex. The FEED is the extension of BE in order to create Material Requisition (MR) for Long Lead Items (LLI) in the project procurement phase. The BE or FEED will be the input to start the DE. Huge amount of man-hours are spent in comparison to the BE and FEED. The DE produces required documents for the project procurement and construction phases. Although using powerful tools, such as modeling software, helps the designer to minimize construction problems; however, still some problems exist that need and aggressive solutions during construction at project's site. Nowadays companies try to mobilize a technical crew at their site to solve and mitigate such obstacles during construction. These people have both good knowledge of engineering and construction experience. This step mainly is called the FE.

DMs' weights are calculated by using the entropy technique and results as shown in Table 2 .

\begin{tabular}{|c|c|c|c|}
\hline Criteria & Weight & Decision Maker & Weight \\
\hline $\mathrm{C}_{1}$ & $(0.15,0.20,0.30)$ & \multirow{3}{*}{$\mathrm{DM}_{1}$} & \multirow{3}{*}{$(0.30,0.45,0.60)$} \\
\hline $\mathrm{C}_{2}$ & $(0,0.10,0.15)$ & & \\
\hline $\mathrm{C}_{3}$ & $(0,0.10,0.15)$ & & \\
\hline $\mathrm{C}_{4}$ & $(0.15,0.20,0.30)$ & \multirow[t]{2}{*}{$\mathrm{DM}_{2}$} & \multirow[t]{2}{*}{$(0.20,0.35,0.50)$} \\
\hline $\mathrm{C}_{5}$ & $(0.10,0.15,0.20)$ & & \\
\hline $\mathrm{C}_{6}$ & $(0.10,0.15,0.20)$ & \multirow[t]{2}{*}{$\mathrm{DM}_{3}$} & \multirow[t]{2}{*}{$(0.05,0.15,0.30)$} \\
\hline $\mathrm{C}_{7}$ & $(0,0.10,0.15)$ & & \\
\hline
\end{tabular}

Table 2. Weights of criteria and decision makers. 
Potential risks can be classified into two groups: 1) identified risks and 2) non-identified risks. Moreover identified risks can be classified into several analysis levels. These can be taken by defining appropriate thresholds as determined in Table 3.

The criteria of identified risks are rated on a six-point descriptive scale in terms of their crucial roles in identifying risks. Table 4 shows a suitable scale for identifying risks in EPC projects according to Makui et al. (2010).

\begin{tabular}{lcc}
\hline \multicolumn{2}{c}{ Identification \& analysis phases concurrently } & $Q_{i}$ \\
\hline Identified risks & Almost certain risks & $>0.75$ \\
& Highly likely risks & $0.60-0.75$ \\
& Likely risks & $0.45-0.60$ \\
& Possible risks & $0.40-0.45$ \\
& Unlikely risks & $0.35-0.40$ \\
Non-identified risks & Rare risks & $0.30-0.35$ \\
\hline
\end{tabular}

Table 3. Thresholds of identification and prioritization phases.

\begin{tabular}{|c|c|c|c|c|}
\hline Description & Scale & $\begin{array}{c}\text { Existing and observing in } \\
\text { other similar or related } \\
\text { projects }\left(C_{1}\right)\end{array}$ & $\begin{array}{l}\text { Disability to transfer the } \\
\text { potential risk to client or } \\
\text { employer }\left(C_{2}\right)\end{array}$ & $\begin{array}{c}\text { Contract disability to } \\
\text { clarify the potential } \\
\text { risk }\left(C_{3}\right) \\
\end{array}$ \\
\hline Almost Certain & $\mathrm{AC}$ & $\begin{array}{c}>8 \text { cases out of } 10 \text { similar } \\
\text { projects }\end{array}$ & $\begin{array}{l}\text { Contract disability is almost } \\
\text { certain to transfer the } \\
\text { potential risk to client or } \\
\text { employer. }\end{array}$ & $\begin{array}{l}\text { Contract disability for } \\
\text { clarifying the } \\
\text { potential risk is } \\
\text { almost certain. }\end{array}$ \\
\hline Highly Likely & HL & $\begin{array}{l}\text { 6-8 cases out of } 10 \text { similar } \\
\text { projects }\end{array}$ & $\begin{array}{l}\text { Contract disability is highly } \\
\text { likely to transfer the } \\
\text { potential risk to client or } \\
\text { employer. }\end{array}$ & $\begin{array}{l}\text { Contract disability for } \\
\text { clarifying the } \\
\text { potential risk is } \\
\text { highly likely. }\end{array}$ \\
\hline Likely & $\mathrm{L}$ & $\begin{array}{l}\text { 4-6 cases out of } 10 \text { similar } \\
\text { projects }\end{array}$ & $\begin{array}{l}\text { Contract disability is likely } \\
\text { to transfer the potential risk } \\
\text { to client or employer. }\end{array}$ & $\begin{array}{l}\text { Contract disability for } \\
\text { clarifying the } \\
\text { potential risk is likely. }\end{array}$ \\
\hline Possible & $\mathrm{P}$ & $\begin{array}{l}\text { 2-4 cases out of } 10 \text { similar } \\
\text { projects }\end{array}$ & $\begin{array}{l}\text { Contract disability is } \\
\text { possible to transfer the } \\
\text { potential risk to client or } \\
\text { employer. }\end{array}$ & $\begin{array}{l}\text { Contract disability for } \\
\text { clarifying the } \\
\text { potential risk is } \\
\text { possible. }\end{array}$ \\
\hline Unlikely & UL & $\begin{array}{l}1-2 \text { cases out of } 10 \text { similar } \\
\text { projects }\end{array}$ & $\begin{array}{l}\text { Contract disability is } \\
\text { unlikely to transfer the } \\
\text { potential risk to client or } \\
\text { employer. }\end{array}$ & $\begin{array}{l}\text { Contract disability for } \\
\text { clarifying the } \\
\text { potential risk is } \\
\text { unlikely. }\end{array}$ \\
\hline Rare & $\mathrm{R}$ & Nothing & $\begin{array}{l}\text { Contract disability is rare to } \\
\text { transfer the potential risk to } \\
\text { client or employer. }\end{array}$ & $\begin{array}{l}\text { Contract disability for } \\
\text { clarifying the } \\
\text { potential risk is rare. }\end{array}$ \\
\hline
\end{tabular}

Table 4. Measure of project risk identification criteria used within the contents of the EPC project. 
Table 5 shows an extended probability and impact scales developed for a multi-purpose set of the analysis. They are rated in terms of weekly occurrence and potential impact on the criteria on a six-point descriptive scale for probability and impact criteria, respectively. The scale in Table 5 is used successfully in the risk analysis for EPC projects. However, it can be adapted easily to smaller than less complex projects.

By considering above information (Tables 1 to 5) and fuzzy group decision-making techniques based on the fuzzy entropy and VIKOR (Steps 6 to 17), the computational results are shown in Table 6.

\begin{tabular}{cccccc}
\hline Description & Scale & Probability $\left(\mathrm{C}_{4}\right)$ & Time $\left(\mathrm{C}_{5}\right)$ & Cost $\left(\mathrm{C}_{6}\right)$ & Performance $\left(\mathrm{C}_{7}\right)$ \\
\hline Almost Certain & AC & $>0.9$ & $>20$ weeks & $>\$ 50 \mathrm{~m}$ & $\begin{array}{c}\text { Key performance criteria } \\
\text { cannot be achieved }\end{array}$ \\
Highly Likely & HL & $0.7-0.9$ & $15-20$ weeks & $\$ 30 \mathrm{~m}-\$ 50 \mathrm{~m}$ & $\begin{array}{c}\text { Very Significant reduction in } \\
\text { performance }\end{array}$ \\
Likely & $\mathrm{L}$ & $0.5-0.7$ & $10-15$ weeks & $\$ 10 \mathrm{~m}-\$ 30 \mathrm{~m}$ & $\begin{array}{c}\text { Significant reduction in } \\
\text { performance }\end{array}$ \\
Possible & $\mathrm{P}$ & $0.3-0.5$ & $5-10$ weeks & $\$ 1 \mathrm{~m}-\$ 10 \mathrm{~m}$ & $\begin{array}{c}\text { Some reduction in performance } \\
\text { Unlikely }\end{array}$ \\
Rare & $\mathrm{UL}$ & $0.1-0.3$ & $1-5$ weeks & $\$ 0.1 \mathrm{~m}-\$ 1 \mathrm{~m}$ & $\begin{array}{c}\text { Small reduction in performance } \\
\text { R }\end{array}$ \\
& $<0.1$ & $<1$ weeks & $<\$ 0.1 \mathrm{~m}$ & $\begin{array}{c}\text { Minimal or unimportant } \\
\text { performance impacts }\end{array}$ \\
\hline
\end{tabular}

Table 5. Measure of project risk analysis criteria used within the contents of the EPC project.

\section{Discussion of results}

In this paper, we identify and prioritize risks concurrently by using the fuzzy entropy and VIKOR techniques in the EPC project. The inference of the results is applicably feasible, appealing and interesting in the EPC project. We also classify potential risks in accordance with the work breakdown structure (WBS) in three levels and after applying the proposed fuzzy comprehensive approach, we calculate portion of each WBS levels from identified risks as shown in Fig. 6. For instance, $31.60 \%$ of identified and prioritized risks belong to the construction part.

The computational results show that management's risks are in the first priority for responding and further actions. Other ranks are illustrated in Table 7. Furthermore, by considering the defined thresholds in Table 3 and the obtained results from Table 4, the results of the EPC project risk identification and risk prioritization are classified in Table 6 . In addition, each portion is illustrated in Fig. 7. As it is evident $10.53 \%$ of risks are evaluated as possible risks and $5.26 \%$ of risks are evaluated as rare risks. Their ranks are shown in Table 8. 


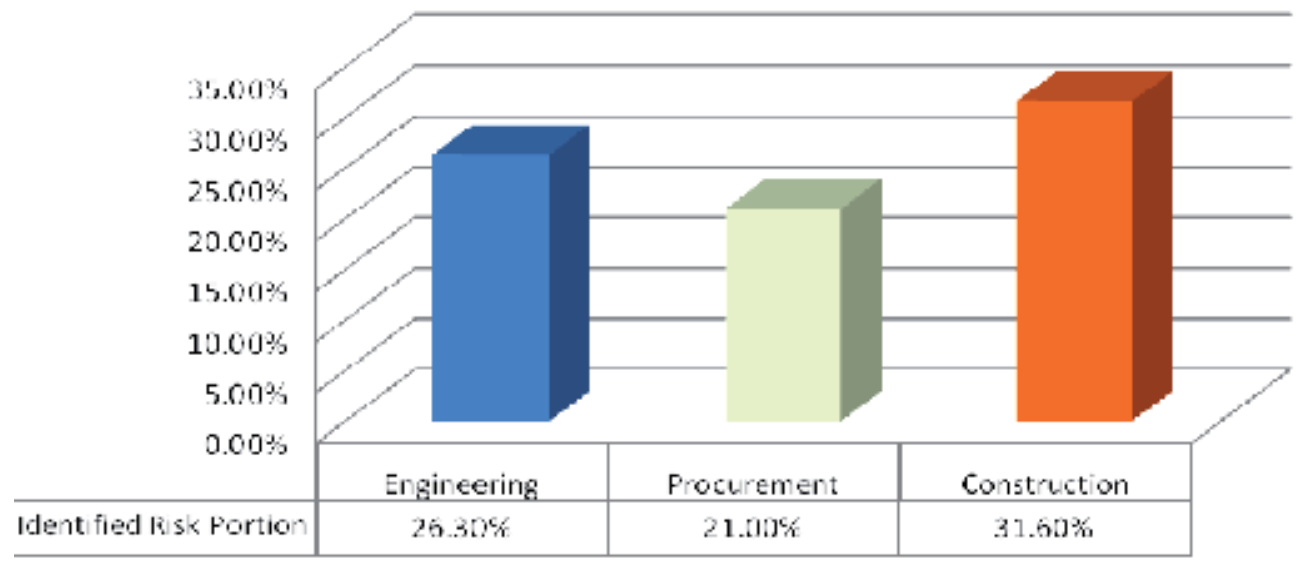

Fig. 6. Each WBS portion from identified risks in the EPC project.

\begin{tabular}{|c|c|c|c|}
\hline \multicolumn{4}{|c|}{ Fuzzy group weighted matrix } \\
\hline WBS & Potential risk code & Potential risk description & $Q_{i}$ \\
\hline \multirow{5}{*}{$\begin{array}{l}\text { Engineering } \\
\text { (E) }\end{array}$} & ENG-01-10 & Design failures & 0.338 \\
\hline & ENG-02-11 & Change in project scope of work & 0.432 \\
\hline & ENG-03-12 & $\begin{array}{c}\text { Data transition from basic to detail } \\
\text { design }\end{array}$ & 0.462 \\
\hline & ENG-04-13 & Lack of resources & 0.392 \\
\hline & ENG-05-14 & Inadequate design quality & 0.439 \\
\hline \multirow{6}{*}{$\begin{array}{l}\text { Procurement } \\
(\mathrm{P})\end{array}$} & PRO-01-15 & International relations & 0.919 \\
\hline & PRO-02-16 & Ambiguity in project cash injection & 0.540 \\
\hline & PRO-03-17 & Inappropriate vendor list & 0.362 \\
\hline & PRO-04-18 & Delay in purchasing & 0.504 \\
\hline & PRO-05-19 & $\begin{array}{c}\text { Imperfect data transmission to } \\
\text { vendors }\end{array}$ & 0.291 \\
\hline & PRO-06-20 & Inspection and forwarding problems & 0.278 \\
\hline \multirow{8}{*}{$\begin{array}{c}\text { Construction } \\
\text { (C) }\end{array}$} & CON-01-21 & Critical weather conditions & 0.662 \\
\hline & CON-02-22 & HSE matters & 0.707 \\
\hline & CON-03-23 & Workers riots & 0.369 \\
\hline & CON-04-24 & Poor team communication & 0.099 \\
\hline & CON-05-25 & Contagious diseases & 0.393 \\
\hline & CON-06-26 & Subcontractor interfaces & 0.549 \\
\hline & CON-07-27 & $\begin{array}{l}\text { Inadequate QA/QC inspections and } \\
\text { audits }\end{array}$ & 0.233 \\
\hline & $\mathrm{CON}-08-28$ & Delay in equipment delivery to site & 0.716 \\
\hline
\end{tabular}

Table 6. Fuzzy group decision matrix and ranking outcome for the EPC project risks. 


\begin{tabular}{ccc}
\hline WBS & Portion of $Q_{i}$ & Rank \\
\hline Engineering (E) & $26.30 \%$ & 2 \\
Procurement (P) & $21.00 \%$ & 3 \\
Construction (C) & $31.60 \%$ & 1 \\
\hline
\end{tabular}

Table 7. WBS leveling based on the portion of $Q_{i}$.

\begin{tabular}{ccc}
\hline Identified and analysis levels & Portion of $Q_{i}$ & Rank \\
\hline Almost certain risks & $5.26 \%$ & 4 \\
Highly likely risks & $15.79 \%$ & 2 \\
Likely risks & $21.05 \%$ & 1 \\
Possible risks & $10.53 \%$ & 3 \\
unlikely risks & $21.05 \%$ & 1 \\
Rare risks & $5.26 \%$ & 4 \\
Non-identified risks & $21.05 \%$ & 1 \\
\hline
\end{tabular}

Table 8. Ranking based on the portion of $Q_{i}$.

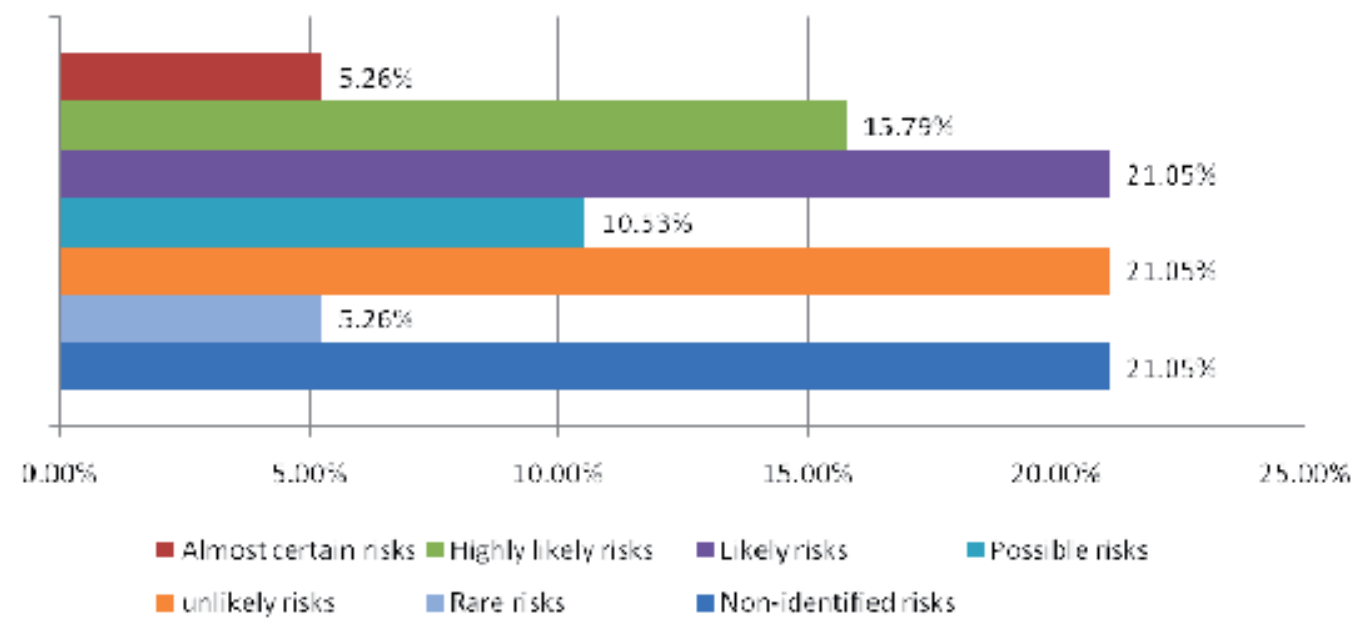

Fig. 7. Portion of each threshold from identified and non-identified project risks. 


\section{Conclusion}

Decisions are made today in increasingly complex environments. In more and more cases, the use of experts or decision makers in various fields is necessary. In many of such decision-making settings, the theory of group decision making can play crucial role. Group decision making in a fuzzy environment can overcome this difficulty as well. This paper has extended a new comprehensive approach for identifying and prioritizing risks of Engineering, Procurement and Construction (EPC) projects by using the Multiple Criteria Group Decision Making (MCGDM) in a fuzzy environment based on the fuzzy entropy and VIKOR techniques. In addition, this study has explored the use of two well-known fuzzy decision-making techniques for solving risk identification and prioritization concurrently. The fuzzy entropy has been utilized to obtain the weights of criteria, and the fuzzy VIKOR has been also used for ranking the potential risks as viable techniques for the problem. The fuzzy VIKOR is suitable for the use of precise performance ratings. When the performance ratings are vague and inaccurate, then the fuzzy MCDGM is the preferred approach. New criteria have been considered for risk management in EPC projects, in which they cover risk identification and risk prioritization concurrently. Then, a new method has been applied for classifying potential risks as PRBS. Furthermore, the techniques and experiences learned from the study can be valuable to future strategic planning for the company. The obtained results from the case study in the EPC project in Iran have shown that the proposed fuzzy comprehensive approach has been viable in solving the proposed risk identification and prioritization problems in EPC projects.

\section{Acknowledgment}

The authors would like to thank the EPC project's experts for their very valuable and helpful contributions on data collection for this study. The authors also thank Mr. S.M.H. Mojtahedi from School of Civil Engineering at the University of Sydney in Australia for his helpful comments and suggestions, which improve the primary version of the study.

\section{References}

Al-Bahar J.F. \& Crandell, K.C. (1990). Systematic risk management approach for construction projects. Journal of Construction Engineering and Management, Vol. 116, No. 3, pp. 533-556.

Alborzi, S.; Aminian, A.; Mojtahedi, S.M.H. \& Mousavi, S.M. (2008). An analysis of project risks using the non-parametric Bootstrap technique. Proc. of the IEEE International Conference on Industrial Engineering and Engineering Management, Singapore, 8-11 December 2008, pp. 1295-1299.

Aven, T. \& Vinnem J.E. (2005). On the use of risk acceptance criteria in the offshore oil and gas industry. Reliability Engineering and System Safety, Vol.90, pp. 15-24.

Aven, T.; Vinnem J.E. \& Wiencke, H.S. (2007). A decision framework for risk management with application to the offshore oil and gas industry. Reliability Engineering and System Safety, Vol.92, pp. 433-448.

Carlsson, C. (1982). Tackling an MCDM-problem with the help of some results from fuzzy set theory. European Journal of Operational Research, Vol.10, No.3, pp. 270-281. 
Carr, V. \& Tah, J.H.M. (2001). A fuzzy approach to construction project risk assessment and analysis: construction project risk management system. Advances in Engineering Software, Vol.32, No.10-11, pp. 847-857.

Chapman, C. \& Ward, S. (2004). Project risk management: processes, techniques and insights, Second ed., John Wiley and Sons Ltd.

Chapman, R.J. (1998). The effectiveness of working group risk identification and assessment techniques. International Journal of Project Management, Vol.16, pp. 333-343.

Chapman, R.J. (2001). The controlling influences on effective risk identification and assessment for construction design management. International Journal of Project Management, Vol. 19, pp. 147-160.

Chen, C.T. (2000). Extensions of the TOPSIS for group decision-making under fuzzy environment. Fuzzy Sets and Systems, Vol.114, pp. 1-9.

Chen, S.J. \& Hwang, C.L. (1992). Fuzzy multiple attribute decision making methods and applications, Springer, Berlin.

Chen, S.M. (1997). A new method for tool steel materials selection under fuzzy environment. Fuzzy Sets and Systems, Vol.92, pp. 265-274.

Chun M. \& Ahn, K. (1992). Assessment of the potential application of fuzzy set theory to accident progression event trees with phenomenological uncertainties. Reliability Engineering and System Safety, Vol.37, No.3, pp. 237-252.

Cooper, D.F.; Grey, S.; Raymond, G. \& Walker P. (2005). Project risk management guidelines: managing risk in large projects and complex procurements, John Wiley \& Sons, Chichester, England.

Dikmen, I.; Birgonul, M.T. \& Han, S. (2007). Using fuzzy risk assessment to rate cost overrun risk in international construction projects. International Journal of Project Management, Vol.25, pp. 494-505.

Dubois, D. \& Prade, H. (1980). Fuzzy sets and systems: theory and application, Academic Press, New York.

Ebrahimnejad, S.; Mousavi, S.M. \& Mojtahedi, S.M.H. (2008a). A fuzzy BOT project risk evaluation model in iranian power plant industry, The 5th of IEEE International Conference on Industrial Engineering and Engineering Management, Singapore.

Ebrahimnejad, S.; Mousavi, S.M. \& Mojtahedi, S.M.H. (2008b). A model for risk evaluation in construction projects based on fuzzy MADM, Proceedings of 4th IEEE International Conferences on Management of Innovation $\mathcal{E}$ Technology, Thailand, pp. 305-310,.

Ebrahimnejad, S.; Mousavi, S.M. \& Mojtahedi, S.M.H. (2009). A fuzzy decision making model for risk ranking with application to the onshore gas refinery. International Journal of Business Continuity and Risk Management, Vol.1, No.1, pp. 38-66.

Ebrahimnejad, S.; Mousavi, S.M. \& Seyrafianpour, H. (2010). Risk identification and assessment for build-operate-transfer projects: a fuzzy multi attribute decision making model. Expert Systems with Applications, Vol.37, No.1, pp. 575-586.

Flanagan, R. \& Norman, G. (1993). Risk management and construction, Blackwell Science Pty Ltd,Victoria, Australia. 
Hashemi, H.; Mousavi, S.M. \& Mojtahedi, S.M.H. (2011). Bootstrap technique for risk analysis with interval numbers in bridge construction projects, Journal of Construction Engineering and Management, doi:10.1061/(ASCE)CO.1943-862.0000344.

Heydar, M.; Tavakkoli-Moghaddam, R.; Mousavi, S.M. \& Mojtahedi, S.M.H. (2008). Fuzzy multi-criteria decision making method for temporary storage design in industrial plants. Proc. of the IEEE International Conference on Industrial Engineering and Engineering Management, Singapore, 8-11 December 2008, pp. 1154-1158.

Hillson D. (2002). Extending the risk process to manage opportunities. International Journal of Project Management, Vol.20, No.3, pp. 235-240.

Kangari, R. (1998). Construction risk management. Civil Engineering and System, Vol. 5, pp. 114-120.

Kauffman, A. \& Gupta, M.M. (1991). Introduction to fuzzy arithmetic: Theory and application, Van Nostrand Reinhold, New York.

Kuo, M.S.; Tzeng, G.H. \& Huang, W.C. (2007). Group decision-making based on concepts of ideal and anti-ideal points in a fuzzy environment. Mathematical and Computer Modelling, Vol.45, pp. 324-339.

Makui A.; Mojtahedi, S.M.H. \& Mousavi, S.M. (2007). Introducing new and practical risk identification methods in mega projects. In Proc. of the First International Congress on Risk Management, Iran, pp. 107-124.

Makui, A.; Mojtahedi, S.M.H. \& Mousavi, S.M. (2010). Project risk identification and analysis based on group decision making methodology in a fuzzy environment. International Journal of Management Science and Engineering Management, Vol.5, No.2, pp. 108-118.

Malekly, H.; Mousavi, S.M. \& Hashemi, H. (2010). A fuzzy integrated methodology for evaluating conceptual bridge design. Expert Systems With Applications, Vol.37, pp. 4910-4920.

Mojtahedi S.M.H.; Mousavi, S.M \& Aminian, A. (2009). A non-parametric statistical approach for analyzing risk factor data in risk management process. Journal of Appled Science, Vol.9, No.1, pp. 113-120.

Mojtahedi, S.M.H.; Mousavi, S.M. \& Makui, A. (2008). Risk identification and analysis concurrently: group decision making approach. Proceedings of 4th IEEE International Conferences on Management of Innovation \& Technology, pp. 299-304, Thailand.

Mojtahedi, S.M.H.; Mousavi, S.M. \& Makui, A. (2010). Project risk identification and assessment simultaneously using multi-attribute group decision making technique. Safety Science, Vol.48, No.4, pp. 499-507.

Mousavi, S.M.; Malekly, H.; Hashemi, H. \& Mojtahedi, S.M.H. (2008). A two phase fuzzy decision making methodology for bridge scheme selection", Proceedings of the IEEE International Conference on Industrial Engineering and Engineering Management, Singapore, 8-11 December 2008, pp. 415-419.

Mousavi, S.M.; Tavakkoli-Moghaddam, R.; Azaron, A.; Mojtahedi, S.M.H. \& Hashemi H. (2011). Risk assessment for highway projects using jackknife technique. Expert Systems With Applications, Vol.38, No.5, pp. 5514-5524. 
Opricovic, S. \& Tzeng, G.H. (2002). Compromise solution by MCDM methods: A comparative analysis of VIKOR and TOPSIS. European Journal of Operational Research, Vol.156, pp. 445-455.

Opricovic, S. \& Tzeng, G.H. (2007). Extended VIKOR method in comparison with out ranking methods, European Journal of Operational Research, Vol.178, pp.514-529.

Peak, J.H.; Lee, Y.W. \& Ock, J.H. (1993). Pricing construction risk-fuzzy set application. Journal of Construction Engineering and Management, Vol.119, No.4, pp. 743-756.

Perry, J.H. \& Hayes, R.W. (1985). Risk and its management in construction projects. in Proc. of the Institution of Civil Engineering, Part I, pp. 499-521.

Raftery J. (1999). Risk analysis in project management, E \& FN Spon.

Ross, T. \& Donald, S. (1995). A fuzzy multi-objective approach to risk management. Proc. of the Second Congress held in Conjunction with A/E/C Systems, ASCE, New York, Vol. 2, pp. 1400-1403,.

Ross, T. \& Donald, S. (1996). A fuzzy logic paradigm for fault trees and event trees in risk assessment. Proc. of the Third Congress, ASCE, New York, pp. 369-375.

Shen, L.Y.; Wu, G.W.C. \& Ng, C.S.K. (2001). Risk assessment for construction joint ventures in China. Journal of Construction Engineering and Management, Vol.127, No.1, pp. 7681.

Tah, J.H.M.; Thorpe, A. \& McCaffer, R. (1993). Contractor project risks contingency allocation using linguistic approximation. Computer Systems Engineering, Vol.4, No.2, pp. 281-293.

Tavakkoli-Moghaddam, R.; Mojtahedi, S.M.H.; Mousavi, S.M. \& Aminian A. (2009). A jackknife technique to estimate the standard deviation in a project risk severity data analysis. in Proc IEEE Int Conf Comput Ind Eng (CIE39), France, pp. 13371341.

Thevendran, V. \& Mawdesley, M.J. (2004). Perception of human risk factors in construction projects: an exploratory study. International Journal of Project Management, Vol. 22, pp. 131-137.

Thomas E.U. (2003). Programming and scheduling techniques, UNSW Press.

Tsao, C.T. (2003). Evaluating investment values of stocks using a fuzzy TOPSIS approach. Journal of Information E Optimization Sciences, Vol.24, No.2, pp. 373-396.

Wang, Y.M.; Luo, Y. \& Hua, Z.S. (2007). A note on group decision-making based on concepts of ideal and anti-ideal points in a fuzzy environment. Mathematical and Computer Modelling, Vol.46, pp. 1256-1264

Wirba, E.N.; Tah, J.H.M. \& Howes, R. (1996). Risk interdependencies and natural language computations. Engineering, Construction, and Architectural Management, Vol.3, No.4, pp. 251-269.

Wu, H.Y.; Chen J.K. \& Chen I.S. (2010). Innovation capital indicator assessment of Taiwanese Universities: A hybrid fuzzy model application. Expert Systems with Applications Vol.37, No.2, pp. 514-529.

Zadeh, L.A. (1975). The concept of a linguistic variable and its application approximate reasoning. Information Sciences, Vol.8, No.3, pp. 199-249. 
Zeng, J.; An, M. \& Smith, N.J. (2007). Application of a fuzzy based decision making methodology to construction project risk assessment. International Journal of Project Management, Vol.25, pp. 589-600.

Zimmermann, H.J. (1996). Fuzzy Set Theory and its Applications. second ed., Kluwer Academic Publishers. 


\section{Part 3}

Economy 



\title{
A Comprehensive Risk Management Framework for Approaching the Return on Security Investment (ROSI)
}

\author{
Elvis Pontes, Adilson E. Guelfi, Anderson A. A. Silva and Sérgio T. Kofuji \\ Laboratory of Integrated Systems, Polytechnic School at the University of São Paulo, \\ Brazil
}

\section{Introduction}

For designing cost-effective security strategies, organizations need practical and complete frameworks for security and risk management (RM), with methods for measuring and managing risks within organizations. In the recent years computer systems have become more present in all economic fields, improving activities in the industry, commerce, government, and researching areas. For the near future the same growing rate of cyber technology is projected for all those areas (Federal Information Security Management Act [FISMA], 2002). On the other hand, threats for this new way of doing business are also growing significantly: hackers, computer viruses, cyber-terrorists are making headlines daily (Internet Crime Complaint Center [IC3], 2008). Consequently, security has also become priority in all aspects of life, including business supported by computer systems (Sonnenreich et al, 2006).

In this reasoning line, some major points may worry researchers, technology implementers, decision makers and investors: 1) the framework to be adopted in organizations for making business secure; 2) managing security and risk levels in organizations for making business workable; 3) mainly, the return of security investment has to be measured to make business profitable.

For business, when the topic is security, it is hard not to consider the associated financial aspect, as any other costs (time, processing, electric power, throughput, etc.) (Pontes et al, 2009a, 2009b, 2009c, 2010). However, for the decision makers it does not matter whether firewalls or soldiers are going to protect the Enterprise Resource Planning (ERP) system and/or other servers. Instead, decision makers have to be aware of the costs related to security and the consequences on the bottom line, both for the present day and for the time yet to come (Sonnenreich et al, 2006). So, it is important that Information Technologic (IT) and Information Security (IS) professionals to be aware about how to justify costs and investments in IS (National Institute of Standards and Technology [NIST] SP800-65, 2005), (International Standardization Organization, [ISO] TR 13569, 2005). Besides, all the related security costs must be correctly presented faced to the real necessities. Risk Management (RM) and Risk Analysis (RA) are efficient means for both: to show the needs of protection and the impact in the overall business activity (ISO 13335, 2004), (ISO 27005, 2008). Usually employed together with RM, the Cost-Benefit Analysis (CBA) may identify the costeffectiveness for the security countermeasures, supporting the statements of the IT or IS 
professionals (e.g. technology implementers) during the approval process of implementations of IS controls, as Intrusion Detection Systems (IDS), biometric controls for access control, etc. In a software based environment, the CBA may similarly be used to apply one or more controls (Wei et al, 2002). The reason of CBA is to present the benefits of IS controls (countermeasures) that may be adopted, comparing to the costs of each IS mechanism.

When CBA is applied, it is intended to determine the intrinsic cost of the IS control, correlating it to the overall organizational environment and analyzing the systemic consequences of IS controls adoption. For instance, by the use of CBA it is possible to track hypothetical overhead because of IS controls employment, before the use of the controls. It is also important to emphasize that during the CBA of a IS control it is possible to assess the positives about the control, e.g.: the increment of selling due to the use of Public Key Infrastructure (PKI) in the electronic commerce.

Another important approach to assess IS mechanisms and IS controls is the Return on Security Investment (ROSI), which analyzes different points if compared to CBA. ROSI concerns the idea about historical series of incidents that were problem to productivity rates to the organizations (Sonnenreich et al, 2006). ROSI concerns also the cost avoidance resulting from resistance, recognition, and reconstitution efforts for the IT infrastructure in the organization (O'Neil, 2007), based on the Annualized Loss Expectancy (ALE) and the number of incidents (Wei et al, 2001), (Government Chief Information Office [GCIO], 2004), (O'Neil, 2007). In spite the fact that ROSI may be used to justify costs and investments in organizations (GCIO, 2004), ROSI is partially accepted in IS. (Heiser, 2002) mention that there is no way for calculating an effective ROSI, but superficial estimations may be done. While regular ROSI methods consider the likelihood of security incidents (ALE), they do not approach studies about forecasts and trends of incidents or unwanted events, like unwanted Internet traffic (Pontes et al, 2009a, 2009b, 2009c, 2010).

The goal of this chapter is to propose a comprehensive RM framework, in which the traditional approach (with the establishment of risk levels to attend the business requirements) is extended to add a new phase for handling variables concerning ROSI statements. As a result we intend to address the impact of the comprehensive RM framework over the traditional RM in IS, in order to obtain cost-effectiveness of IS controls, reducing uncertainties and risks in IT environment, and finally improving the probability of positive rates of ROSI.

The comprehensive RM framework includes the CBA (Wei et al, 2001) and ROSI (GCIO, 2004), (O'Neil, 2007), which analyzes the incidents history, ALE, and productivity rates. This chapter is organized as follows: RM is presented in section 2. Section 3 regards ROSI models. The description of the comprehensive RM framework is in the section 4 . Section 5 and 6 summarizes analysis and conclusions respectively.

\section{Risk management (RM) - traditional frameworks}

Traditional frameworks for RM regard models that do not consider phases to handle ROSI issues in IS environments. Generally, traditional RM frameworks deals with the needs of protection and the impact in the overall business activity.

Government and society are more and more concerned about eventual loss of data, theft of information and with possible loss of human life due to failures in computer systems. Consequently, IS and IT have been focused by diverse standardization organizations, as 
International Organization for Standardization (ISO), National Institute of Standards and Technology (NIST), British Standards (BSi), Australian/New Zealand Standard (AS/NZS), Project Management Institute (PMI), Brazilian Society for Technical Standards (ABNT), Information Security Forum (IFS), among others. The main recommendations about IS reinforce the adoption of good practices for RM in IT systems. The most well known recommendations for IS are the BS 7799 series (British Standards Institute [BSi], 1999), (BSi, 2002) and (FISMA, 2004). The BS 7799 series were developed by the British Government and are cited as good practices for managing IS systems. Lately, the first documents from the BS 7799 were revised and reorganized in the ISO17799 series (ISO 27005, 2008).

The public American law 107-347 (e-Government Act) 2002, recognizes the importance of IS to the interests of the economy and national security of United States (FISMA, 2002). The third title of the law, called FISMA, imposes that each federal agency has to develop, document and implement an extensive program for management IS. (FISMA, 2002) is supported by diverse NIST documents.

Currently, new efforts for revising IS standards are happening, and they are going to be reclassified in the ISO/IEC 27000 series. The objective is to align the IS management standards with the ISO 9000 and ISO 14000 series. The structure of ISO 27001 is likely FISMA, as they are cyclic models intending the ongoing Risk Management for identifying, evaluating, controlling, monitoring, reducing and/or accepting risks. Fig. 1 presents an overview of some RM and IS management standards, as the relation among each other.

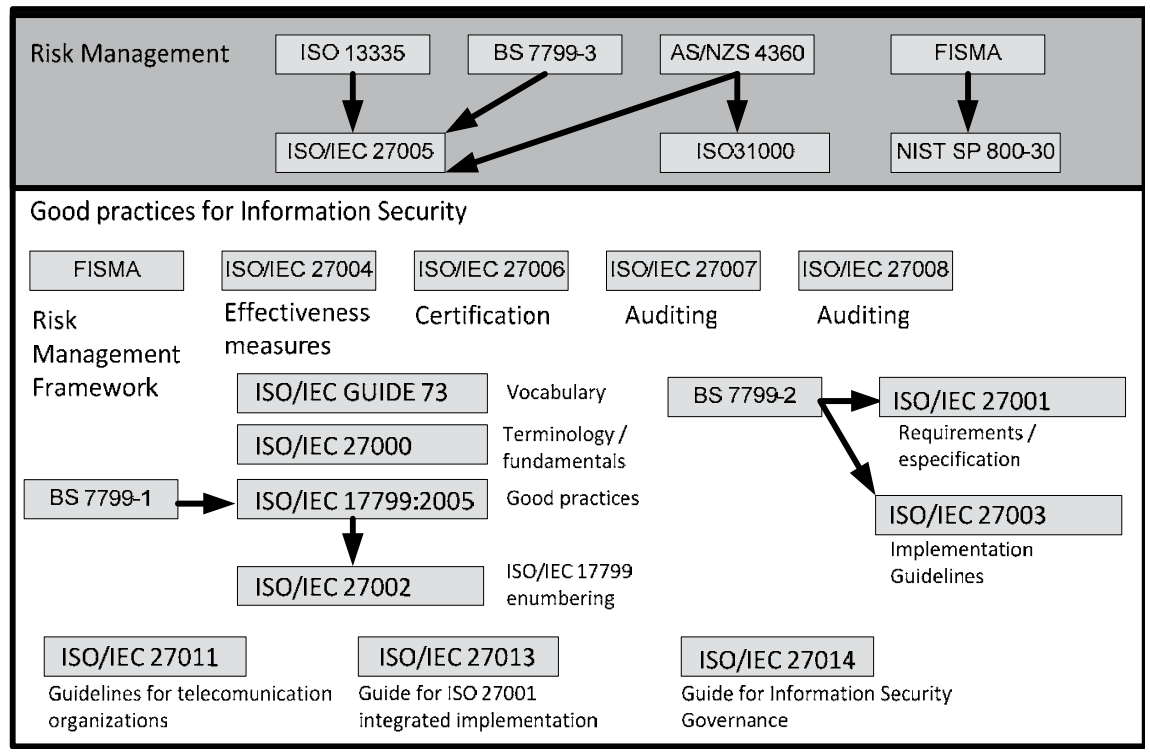

Fig. 1. Evolution of RM and IS Management

According to Fig. 1, some of the RM standards are the ISO 13335, BS 7799-3 AS/NZS 4360, FISMA, ISO/IEC 27005, ISO 31000 and NIST SP 800-30.

(BSi 7799-2, 2002) defines the fundamental concepts and the vocabulary for IS to be used in the documents of the ISO 27000 series. The adopted terminology in most of the IS standards derives from (ISO 73, 2009). (ISO 27001, 2006) and (ISO 27002, 2005) are based on BS 7799-2 and ISO 17799-1. The recommendation ISO 27001 introduces a model to establish, 
implement, operate and supervise, to analyze critically, to maintain and to improve a IS management system. ISO 27002 (formed ISO 17799:2005) introduces IS concepts and discusses about motivations for establishing IS management within organizations. In most parts of the document, the IS best practices are detailed and associated to the objectives of the IS controls mentioned in the ISO 27001. The preliminary version of ISO 27003 is derived from the BS 7799-2 annex B, and is basically a guide to implement the management IS system.

$\mathrm{RM}$ is founded on principles and good practices for management and security, to support the decision making processes (NIST SP800-30). More details about the RM standards can be found in the following subsections.

\subsection{AS/NZS 4360, ISO 31000, ISO 13335 and ISO 27005}

(Australian and New Zealand [AS/NZS], 2004) and (ISO 31000, 2009) define risk as everything that deviates from de main objective. This concept is directly associated to the strategic goals of organizations. ISO 31000 offers an integrated RM model to the organizations, providing a holistic view about risks to the RM members (stakeholders) to improve the decision making process. Fig. 2 illustrates the constant integration among each stage of (AS/NZS, 2004) and (ISO 31000, 2009), and each stage can be described as follows:

- Communication and consultation: this planning stage concerns any stakeholder involved with the RM, in both cases: internal and external to the organization. During the planning stage, all problems related to risks, consequences of impacts and the management actions must be presented;

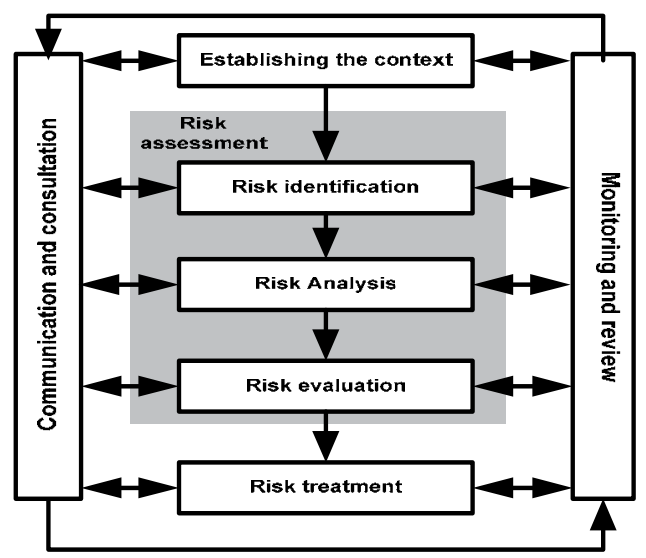

Fig. 2. RM - ISO 31000 and AS/NZS 4360

- Establishing context: stage to align the RM with the organizational culture, internal and external processes and other criteria (as risks criteria, roles and responsibilities, likelihood metrics, levels of acceptance, etc.).

- $\quad$ Risk Assessment: integrated process for identification of risks, RA and risks evaluation. It includes: 1) Risks identification: based on the objectives and criteria defined during the context establishment, relevant risks to the organization are identified throughout this stage; 2) RA: phase for determining causes and sources of risk, as well as occurrence likelihood and impact; 3) Risk Evaluation: based on the results of the 
previous $\mathrm{AR}$, this phase proposes a comparison between the estimated risks and the risk criteria to determine the risk level.

- Risk Treatment: process regarding selection and implementation of safeguards to modify risks;

- Monitoring and review: refers the changing analysis and / or trend tracking, periodic auditing, incident registering and maintaining security logs.

AS/NZS 4360 and ISO 31000 are cyclic models, with constant feedback done during the monitoring and reviewing, as well during the communication and consultation stages. In other hand, as Fig. 3 depicts, the RM model proposed by the (ISO 27005, 10) is very similar to the model presented by Fig. 2, having few nuances which can be noted, e.g., the decision points and the risk acceptance phase which trigger the beginning of the model and/or the monitoring/communication phases. Even though, ISO 27005 has one stage for risk treatment, neither ROSI, nor hypothetical closing situations (sunset in accordance with (NIST SP800-21, 2005)) are deeply commented or recommended in these standards.

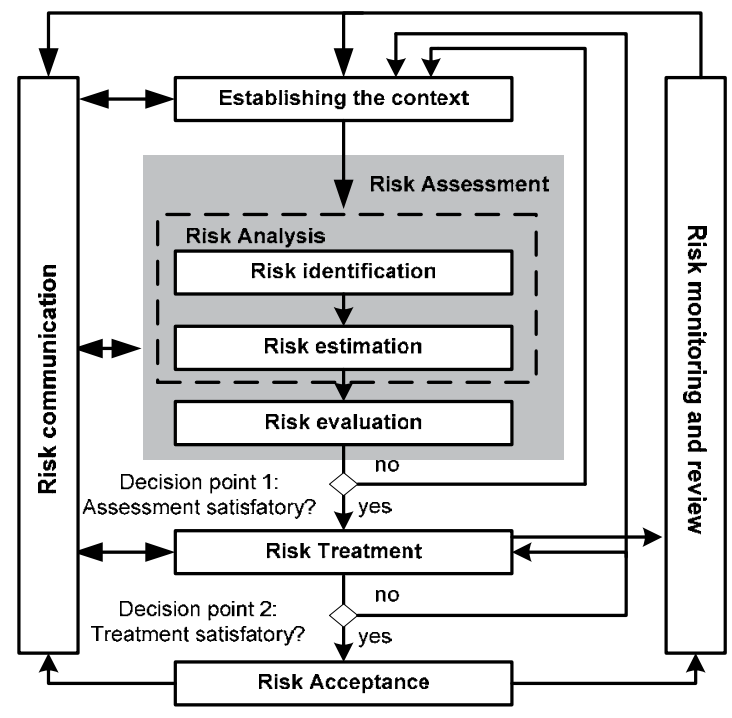

Fig. 3. RM - ISO 27005

\subsection{FISMA and NIST SP800-30}

The risk-based approach to security control selection and specification considers effectiveness, efficiency, and constraints due to applicable laws, directives, executive orders, policies, standards, or regulations (FISMA, 2002). The following activities related to managing organizational risk (also known as the NIST RM Framework) are paramount to an effective IS program and can be applied to information systems within the context of the enterprise architecture (see Fig. 4):

Step 1: CATEGORIZE the information system and the information resident within that system based on impact. FIPS 199 and NIST SP 800-60;

Step 2: SELECT an initial set of security controls for the information system based on the security categorization (FIPS 199) and the minimum security requirements (FIPS 200); apply tailoring guidance as appropriate; and supplement the tailored baseline security controls 
based on an assessment of risk and local conditions including organization-specific security requirements, specific threat information, cost-benefit analyses (NIST SP800-30 and NIST SP 800-53).
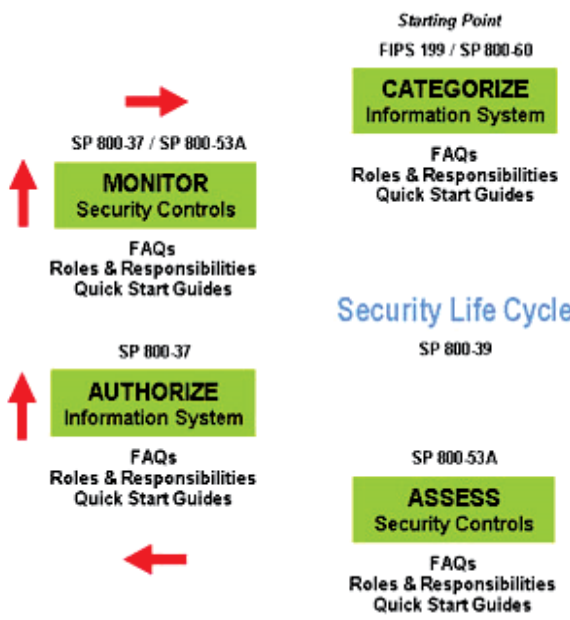

Fig. 4. RM - FISMA

Step 3: IMPLEMENT the IS controls.

Step 4: ASSESS the security controls using appropriate methods and procedures to determine the extent to which the controls are implemented correctly, operating as intended, and producing the desired outcome with respect to meeting the security requirements for the system. NIST SP 800-53A

Step 5: AUTHORIZE information system operation based upon a determination of the risk to organizational operations, organizational assets, or to individuals resulting from the operation of the information system and the decision that this risk is acceptable. (NIST SP800-37, 2010)

Step 6: MONITOR and assess selected security controls in the information system on a continuous basis including documenting changes to the system, conducting security impact analyses of the associated changes, and reporting the security status of the system to appropriate organizational officials on a regular basis. NIST SP 800-37 and SP 800-53A.

Among the standards and for the NIST's RM Framework, NIST SP800-30 (RM Guide for IT) provides guidelines for RM with definitions and necessary directions to assess and lessen identified risks in IT systems (NIST SP800-30, 2002). NIST SP800-30 comprises in two phases: risk assessment (system characterization, threat identification, vulnerability identification, control analysis, likelihood determination, impact analysis, risk determination, control recommendations, results documentation) and risk mitigation (prioritizing, evaluating, and implementing the appropriate risk-reducing controls recommended from the risk assessment process). But, neither ROSI, nor hypothetical closing situations is referred in any (FISMA, 2002) and (NIST SP800-30,2002).

\subsection{Project management body of knowledge PMBOK}

PMBOK approaches RM in a project matter, including processes related to conducting RM plans, identifying risks, risks analysis, response, monitoring and control (PMBOK, 2008). 
Most of processes are updated during the project life cycle. The RM objectives are: to increase the probability and impact of positive events, to reduce de probability and impact of negative events to the project. According to Fig. 5, RM concerns the following steps:

1) RM planning (decisions about how to approach and to execute the activities during the $\mathrm{RM}$ in a project; 2) Identifying risks (to determine which risks may affect the project, documenting the risks' characteristics); 3) Qualitative RA (prioritizing risks for further analysis or action by assessing and combining their probability of occurrence and impact);4) Quantitative Analysis (process of numerically analyzing the effect of identified risks on overall project objectives); 5) Plan Risk Responses (process of developing options and actions to enhance opportunities and to reduce threats to project objectives). 6) Monitor and Control Risk Responses (the process of executing risk response plans, tracking identified risks, monitoring residual risks, identifying new risks, and evaluating risk process effectiveness throughout the project).

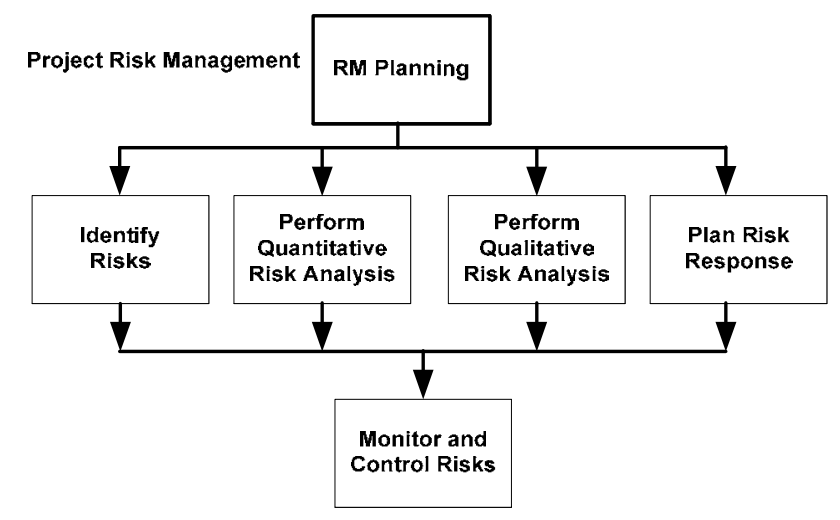

Fig. 5. RM - PMBOK

Even though (PMBOK, 2008) considers forecasting for other areas of projects (as evolution performance, estimative about finalization - time and cost), neither ROSI, nor forecasting of incidents trends, nor hypothetical closing situations for RM are referred in (PMBOK, 2008).

\section{Return on security investment (ROSI)}

ROSI concerns the idea about historical series of incidents that were problem to productivity rates for the organizations, the cost avoidance resulting from resistance, recognition, and reconstitution efforts for the IT infrastructure in the organization (Wei et al, 2001), based on the ALE (Pontes et al, 2009a), (GCIO, 2004), (O'Neil, 2007). ROSI with forecasting combines the conventional ROSI with hybrid prediction techniques (Pontes et al, 2009a, 2009b, 2009c, 2010). Some models for conventional ROSI and ROSI with forecasting are shown in this section.

\subsection{ROSI - cost-benefit model}

This model was developed to handle intrusions and unwanted traffic with an IDS, considering the cost-effectiveness of the countermeasure.

Most of the current ROSI methods refer to the work of (Wei et al, 2001), about cost-benefit analysis in IDS, considering it as one of the bases for the ROSI methods (Sonnenreich et al, 2006), (GCIO, 2004), (O'Neil, 2007). 
(Wei et al, 2001) says that a cost -effective analysis about the IS controls with a study of the costs is the first step toward to the cost-benefit analysis in the IT environment. Then, the major intention of (Wei et al, 2001) was to build a methodology with a cost-benefit model, based on investigation of cost factors and categorization of some variables of the environment. The proposal could be used either for quantitative estimative, or qualitative costs, to determine the best choice for the cost-effectiveness (cost-benefit).

This methodology needs a previous RA to define the scope and the needs of IS controls to the organization assets, taking into account the values and vulnerabilities of each asset and the relevant threats. Lastly, the methodology includes likelihood about the incidents occurrence - when risk becomes impacts to the organization. This prognostic must be managed and controlled. Then, the ALE is calculated. The cost-benefit analysis is the next step: it works like a tool for the IDS, helping to determine whether, or not, the IDS adopts countermeasures to stop the intrusion. According to (Wei et al, 2001), it is not suggested to employ an extremely restrictive posture, as the cost of such posture is going to be more expensive then the benefit it could bring. The cost factors are determined from the RA and are divided as damage cost, operation costs and response costs. Then these costs are combined to determine the total cost for each intrusion.

The damage cost represents the maximum amount of damages that an attack may cause to an asset, when the IDS and other controls are not effective. The response cost relates to actions taken against the intrusions, including actions to stop the intrusion and to reduce damages. These actions, or controls, must be defined in the RA, according to the mapped threats. Operation cost is the processing of the event flow being monitored and analyzed in the IDS. After the cost factors definition, the cost values can be acquired when the RA is executed, leading the complementation of the cost matrix. Finally, the cost model may be applied as in (1):

$$
\text { Cost_total }(e)=\sum_{i=1}^{N}(\operatorname{CostC}+\operatorname{CostOper}(e))
$$

The Cost_total(e) is the total cost, $\mathrm{N}$ is the number of the event and CostC is the consequent cost of the prognostic for a intrusion event and for the IDS, that is determined for the damage cost and response cost. There are five types of prognostics: 1) FN (false negative); 2) TP (true positive); 3) FP (false positive); 4) TN (true negative) 5) Misclassified hit.

So, it was created a model to analyze multiple hosts as (2):

$$
\text { Cost_total }(e)=\sum_{i=1}^{N}\left(\sum_{j=1}^{H} \operatorname{Cos} t_{-} \operatorname{Dam}(i)+\operatorname{Cost}_{-} \operatorname{Res}(e)+\operatorname{Cos} t_{-} \text {Oper }(e)\right)
$$

$\mathrm{H}$ is the number of attacked hosts. The cost model may be implemented in the IDS context as shown in Fig. 6.

According to Fig. 6, the Message Server collects data from other tools, managing the messages, verifying the intrusion and the log messages. If an intrusion incurs, the Message Server reports the intrusion, status, attacked asset and other important information to the Cost Model. The Cost Model analyzes the information and calculates the cost, comparing to other alternatives. Then, a message is sent back to the Message Server. If the cost to respond the intrusion is larger than the benefit, the Message Server labels the received information, but does not send it to the Alert Server. Otherwise, the information is sent to the Alert 
Server and the Response Server. The message is shown in display. The Response server acts according to the Cost Model advice.

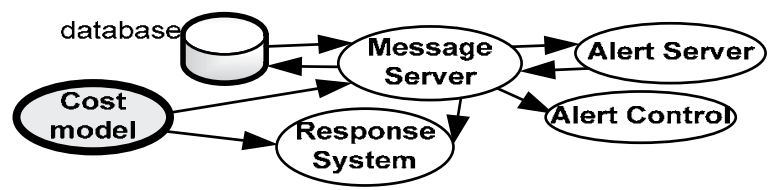

Fig. 6. Cost Model

This model has not yet undergone extensive enough training to be used in commercial applications. In addition to cost modeling and intrusion detection functions, the automatic response function is very important to the network intrusion detection system. With the cost model and automatic response system, a network IDS can both detect an attack and decide if it is worth stopping. If it is worth stopping the attack, the network IDS can automatically employ countermeasures. Even though (Wei et al, 2001) recommends a previous RA before applying the cost-benefit model, RM frameworks are not approached.

\subsection{ROSI - GCIO Australia}

This framework uses diverse approaches to obtain cost-benefit in SI countermeasures. Then, it is proposed a hybrid tool, combining ALE (Wei et al, 2001) with the Australian standard Threat and Risk Assessment framework (GCIO, 2004). The hybrid tool has also an extension to "Monte Carlo" statistical analysis (in electronic spreadsheet) of the possible spread in cost-benefit results arising - as security incidents vary randomly in their rate of occurrence and their severity (GCIO, 2004). "Monte Carlo" involves introducing variability into one or more parameters of a complex model, re-running the calculations many times and studying the ranges of resulting outputs

The framework also transforms qualitative judgments of likelihood and severity into quantitative appraisals of loss expectancy (ALE), with and without security. Fig. 7 presents the sequence of steps for running the (GCIO, 2004) framework. Each step has, in matter of fact, an electronic spreadsheet to be fulfilled, with some simple qualitative definitions and some estimative equations to transform qualitative into quantitative criteria.

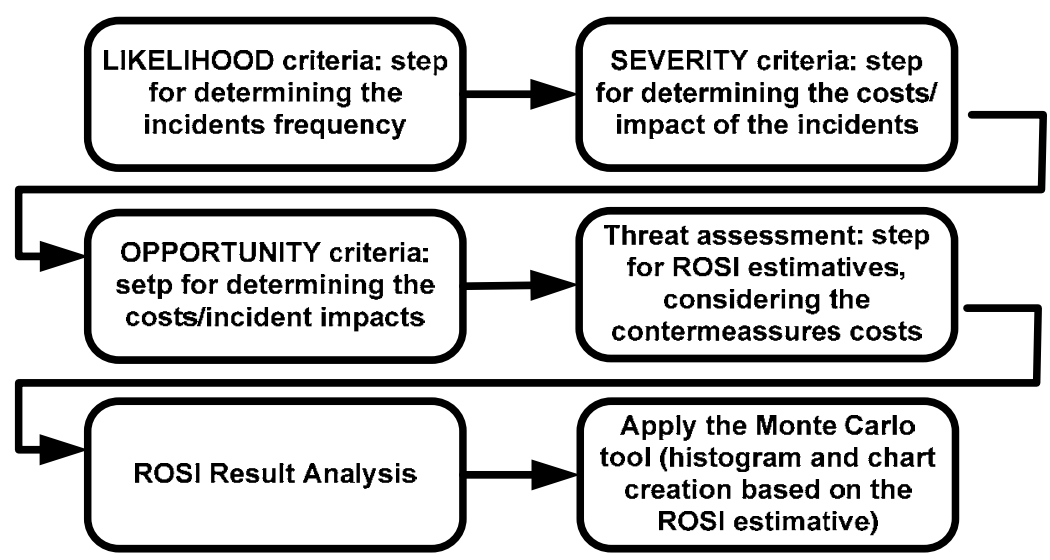

Fig. 7. GCIO ROSI framework 
Even though the framework is easy to implement, it has some limitations, as follows: 1) Difficult to separate effects of countermeasures; 2) Restricted sources of randomness; 3) Difficult to predict how countermeasures affect severity; 4) Security incidents are not necessarily independent; 5) Hard to implement in a real time system.

Although steps of RA are performed in (GCIO, 2004), RM frameworks are not considered.

\subsection{ROSI - Carnegie mellon and US department of homeland and security}

The objectives of this method are to make a more real estimate about the ROSI, considering the absence of actual data on the number of incidents and to better assess the impact of an individual incident. According to ( $\mathrm{O}^{\prime}$ Neil, 2007), ROSI savings is divided by costs as (3):

$$
\text { ROSI }=\frac{\text { Savings }}{\text { Cost }}
$$

Savings is cost avoidance resulting from resistance, recognition, and reconstitution efforts. Cost includes preparation and incident cost. Incident cost is cleanup, lost opportunity, and critical infrastructure impact.

This model estimates if the expected number of incidents is low, the security readiness investment will be recouped; for a higher number of cyber attack incidents, what are the minimum factors needed to fully recoup security investment; if there is an equitable scheme for sharing security readiness costs among the project, the enterprise, and the government; and what are the guidelines for public-private collaboration and cost sharing. The method is divided in three different phases, with different steps for each one:

1. ROI 1

a. $\quad$ Savings $=($ Resistance Savings + Recognition Savings + Reconstitution Savings $)$

b. $\quad$ Cost $=($ Total Preparation + Total Cleanup + Total Lost Opportunity + Total Critical

2. ROI 2 Infrastructure Impact)

a Savings $=($ Full Cost Incurred - Cost with Avoidance $)$

b Cost $=$ (Preparation + Cost with Avoidance $)$

3. ROI 3

a Savings $=($ Full Cost Incurred $)$

b Cost $=$ (Preparation + Cost with Avoidance $)$

Each one of the variables in the cost and savings, for ROI 1, ROI 2 and ROI 3, has a long definition and estimative to reach the correspondent value. The aim of this chapter is not to describe such procedure. Because of the long analysis for each variable, this method may not be effective in real time systems. This method does not consider RM frameworks.

\subsection{ROSI - British computer society and Australian computer society}

For this approach, the ROSI estimative has a direct relation to the productivity rates (Sonnenreich et al, 2006). Determining expected returns for security investments involves estimating the risk exposure and the amount a solution will mitigate the risk. As the security incidents are not successfully tracked in most organizations, the incidents history is an item not as important in this approach as it is in others.

A meaningful ROSI can be calculated by focusing on the impact security has on productivity. The productivity lost due to security incidents can have a serious impact on the bottom line. For many organizations the cost of lost productivity associated with a 
security incident is far greater than the cost of data recovery or system repair, as it is shown in (4):

$$
\text { ROSI }=\frac{\text { Expected_Returns }- \text { Cost_investment }}{\text { Cost_investment }}
$$

The cost of a solution must include the impact of the solution on productivity, since this number is often large enough to make or break the viability of a given solution.

The problem with this approach is that isolating security's impact on productivity from other factors (such as poor performance) is impossible. If the survey is correctly constructed, there will be a strong correlation between the survey score and financial performance. Specifically if a department shows a decrease in perceived downtime, it should also show an increase in productivity on the internal balance sheets. However, with a good survey and scoring system for productivity, combined with external measurements of intellectual property value, it becomes possible to quantify risk exposure in a repeatable and consistent manner.

Risk exposure is measured as the productivity loss due to existing security issues. This approach assumes that serious disasters are rare and hard to quantify but everyday incidents create a significant amount of aggregate loss. Solving these problems provides real returns and improves security at the same time, which has the side-effect of preventing some of those major disasters. This approach does not consider or RM frameworks.

\subsection{ROSI - North Carolina A\&T State university}

Accordingly with (Al-Humaigani et al, 2003), it is necessary to evaluate security planning and security solutions, analyzing business needs and security controls to be employed. In this sense, ROSI must present the lowest possible values to address costs of security breaches and costs of security controls. Security controls can be classified in two types of costs: 1) relative cost for acquisition, implementation and maintenance; 2) costs from the limitations of users, environments and tools.

The objective of (Al-Humaigani et al, 2003) is to examine security costs, in order to detail ROSI analysis and thereafter to propose a model for quantifying the referred ROSI analysis. According to (Al-Humaigani et al, 2003), (Heiser, 2002), there is no a safe way to quantify ROSI, and the best argument is that the investment in security can prevent losses.

The usual justification for conducting risk assessments is to protect integrity, confidentiality and availability of information. Moreover, due to difficulties in quantifying security investment, often the justification is rooted in Fear, Uncertainty and Doubt (FUD). However, ROSI can be a tool for decision making process: 1) the ROSI analysis numbers can be used to justify the investment in security; 2) the ROSI can be used to indicate the type of investment required, such as technology or people; 3 ) the ROSI analysis numbers also can be used to set ranges and insurance values (eg. based on what is invested in security organizations).

Although, ROSI takes place before the implementation of security controls and lies on empirical data. The model proposed by (Al-Humaigani et al, 2003) includes several factors that may be related in obtaining ROSI, considering both the pre as post implementation and demonstrating which elements affect the assessments in ROSI. Qualitative justifications for investments in security should incorporate quantitative measures, producing robust ROSI numbers. The model should answer the following questions:

1. How much is for an organization to invest in information security? 
2. How much is for an organization not to invest in information security spending.

The solutions presented by (Al-Humaigani et al, 2003) assess each one of the following varriables:

- CTI: The cost of procuring the security tool or software, its licenses, and upgrades.

- CT2: The cost of the extra physical hardware, rooms, and facilities needed.

- $\quad$ CT3: The cost of the training and the time of the human resources forcing the security policies and implementing the security tool.

- CT4: The losses due to the limitations placed on the business and the users.

- CT5: The cost of adopting secured-by-design strategy while designing network infrastructure, configuration of operating systems and databases, or application development.

- CT6: The financial cost of items, equipment, facilities, or systems in order to recover from a security incident / threat.

- CT: The losses due to business interruption.

- CT8: The losses in human casualties or injuries.

- CT9: The losses in loss of data from business and legal aspects.

- CTIO: The losses in the reputation and goodwill.

- CTI1: The amount that the insurance pays due to the loss caused during an incident.

- KT: The probability of the security incident/breach to happen (without implementing any security control system I solution).

One of the difficulties in ROSI is to estimate values. CT1, CT2, CT3, CT5, CT6, CT7, CT8 and CT11 may be obtained or calculated from market prices, payroll and benefits, price schedules, security policies or historical financial data. CT4, CT9, CT10 and KT can be deduced from information security, consumer satisfaction surveys, surveys for advice or reports made by employees. Given these values, ROSI can be calculated over all security controls in (5):

ROSI $=\mathrm{E}[\mathrm{KT}$. ( CT6 + CT7 + CT8 + CT9 + CTIO $)+\mathrm{CTI}$ I-(CTI + CT + CT3 + CT4 + CTS) $](5)$ Where $\mathrm{T}$ value refers to the type of risk that the security control or system is exposed (intrusion, industrial espionage, DoS, information theft, malicious code, etc.). Although, (AlHumaigani et al, 2003) approach risks to express ROSI, there are no considerations regarding RM frameworks extended to the ROSI analysis.

\subsection{Evaluating ROSI using game theory}

(Cavusoglu, et al 2004) advocates about a comprehensive and analytical model to evaluate security investment decisions considering the: 1) analyzes of individual security technologies used in the layers of the security infrastructure, which allows managers to assess the interaction among different security tools, as well as the use of this technology in ROSI; 2) conception of a target for deciding priorities for investment in technologies; 3 ) users decision for selecting and optimizing settings for security technologies, in addition allowing developers to design and evaluate security systems.

The proposed model does not act directly on the employed technologies, as it is not possible to assess how firewalls' vulnerabilities affect the expectation of losses. However, the model allows comparisons between different layers of IT security infrastructure. According to (Cavusoglu, et al 2004), one of the goals of IT security infrastructure is to reduce the risk to a point where the marginal cost of implementing controls is equal to additional gains coming from security incidents. The IT security infrastructure should be appropriate in order to 
provide a plan for ensuring confidentiality, integrity and availability of information resources. Such plan consists of: 1) Risk assessment to determine the level of security risks in the organization; 2) Quantitative risk analysis concerned with the values of risk, as costs of potential damages and cost-effectiveness of security controls.

IT architectures should consist of several layers, with various security controls which are complementary to each other. The values of the controls are different and are also dependent on each other on each level. This requires a design that acts simultaneously on all layers. The model of (Cavusoglu, et al 2004) proposes creation of three layers: 1) Preventive layer: where firewall acts; 2) Detection layer: where IDS acts; 3) Answer layer: composed by manual monitoring.

With the creation of infrastructure in layers, the model uses game theory to analyze strategic decisions on security. Game theory is used to analyze problems in which the outcome of a situation depends on the strategy used by players. Regarding the ROSI issue, both organizations and hackers are players; the organizations' decision making processes for whether approving or not a ROSI depends on the amount of cyber attacks. Analogously, cyber attacks to succeed depend on the implemented security controls in the company. Fig. 8 illustrates the game tree, which is based on infrastructure layer, created by (Cavusoglu, et al 2004) to demonstrate its model to evaluate ROSI:

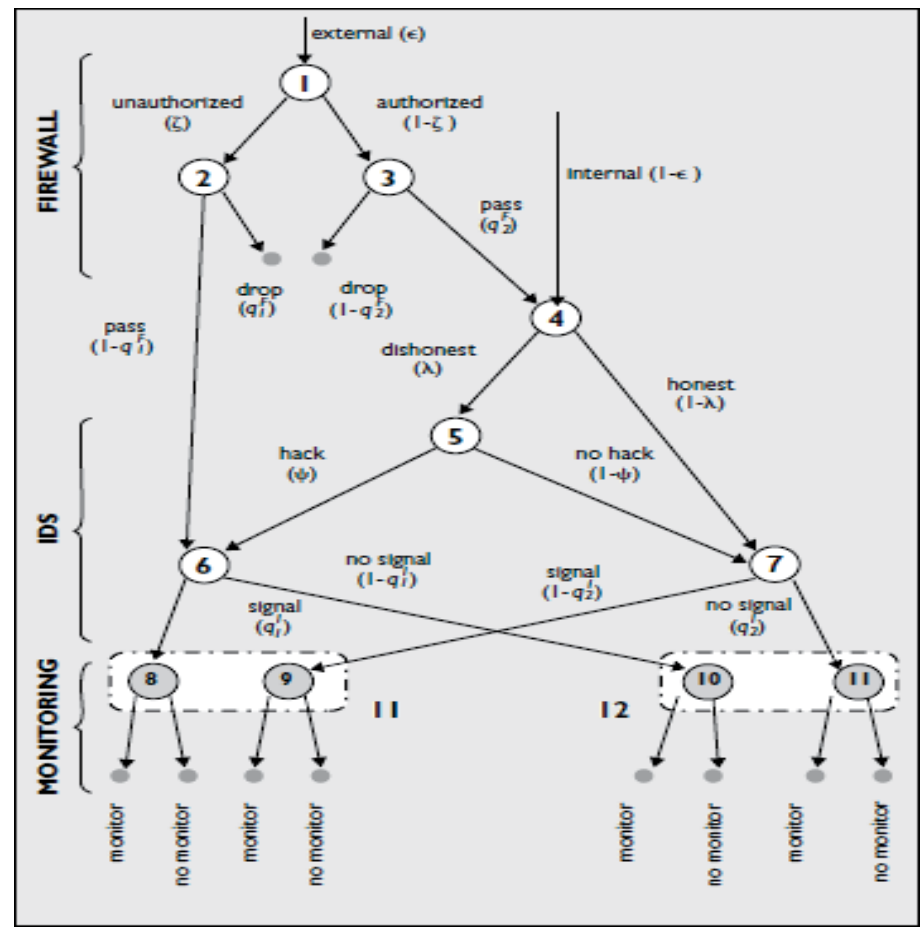

Fig. 8. The game tree

Items of Fig. 8 are:

- $\quad$ node 1 - receives external traffic;

- $\quad$ node 2 - receives unauthorized traffic;

- node 3 - receives external traffic allowed; 
- $\quad$ node 4 - receives traffic internal and external authorized;

- $\quad$ node 5 - featuring authorized access to an internal network;

- $\quad$ node 6 - gets unauthorized access to external and internal users;

- $\quad$ node 7 - gets authorized access to external and internal users;

- d: expected damage to a security breach;

- $\varepsilon$ : external traffic;

- $(1-\varepsilon)$ : internal traffic;

- $\quad \zeta$ : external traffic unauthorized that can be blocked by firewalls;

- $\quad \mathrm{qF} / 1$ : Probability of the firewall to stop unwanted traffic;

- (1-qF / 1): probability that the firewall does not stop unwanted traffic;

- $\quad \mathrm{qF} / 2$ : probability of the firewall to pass traffic you want;

- $\quad$ (1-qF / 2): probability that the firewall does not pass the desired traffic;

- $\sigma$ : cost that occurs when the unwanted traffic is caught by the firewall;

- $\lambda$ : honests Internet users;

- $(1-\lambda)$ : dishonests Internet users:

- $\quad \mu$ : fraction of dishonest users who gained access to the system;

- $\quad(1-\mu)$ : fraction of dishonest users who did not gain access to the system;

- $\quad$ II/1: probability of the IDS to signal a malicious operation coming of $\mu$ or coming of (1$\mathrm{qF} / 1)$;

- (1-qI/1: probability of the IDS does not signal a malicious operation coming of $\mu$ or coming of $(1-\mathrm{qF} / 1)$;

- $\quad$ : cost that occurs when the monitoring layer indicates a possible intrusion;

- a: probability of the IDS detects a real threat due to the imperfection of monitoring;

- $\varphi$ : fraction of the damages recovered when the intruder is detected by manual monitoring;

- $\quad \beta$ : fixed cost of an intrusion or malicious event;

- $\quad y d$ : cost of an intrusion (variable value proportional to the harm caused);

- $\quad$ p1: when there is a signal coming from the IDS;

- $\quad$ 2: when there is no signal coming from the IDS;

- Fs: expected results when there is a signal coming from the IDS;

- Fn: expected outcomes when there is no signal coming from the IDS;

With the use of (Cavusoglu, et al 2004)'s model it is possible for the organizations to make decisions about what to monitor (nodes 8 to 11) according to the status (named sign) of the analyzed traffic in the game tree. Using Bayesian rules, the company can determine the probability of intrusion when there is and when there is no signal coming from IDS.

The maximization of the company's expectations can be given by (6), (7) and (8):

$$
\begin{gathered}
F=[P(\text { signal }) F S+P(\text { nosignal }) F N+P(\text { drop }) \sigma] \\
\text { Where FS }=\{-\rho 1 c-\eta 1(1-\rho 1) d-\eta 1 \rho 1[(1-a) d+a(1-\varphi) d]\} \\
\text { Where FN }=\{-\rho 2 c-\eta 2(1-\rho 2) d-\eta 2 \rho 2[(1-\alpha) d+a(1-\varphi) d]\}
\end{gathered}
$$

The maximization of the hacker's expectations can be given by (10):

$$
H=P(\text { hacking })(\text { Benefit }- \text { Cost })=\psi \mu-\psi \alpha(\beta+\gamma d)[\rho 1 q 1 I+\rho 2(1-q 1 I)]
$$


Therefore, the proposed model is useful for some aspects of ROSI: 1) it helps to understand different parameters which affect the investment in security, as it is possible to simulate values in the game tree; 2) security controls can always be customized or configured. The process of setting changes parameters of quality, which influences the gains accounted in global security; 3) allows the choice of specific security technology. For instance, we can simulate the model as follows: step 1 - to select security technologies for deployment consideration, step 2 - to collect data about quality parameters q1I, q2I, q1F, Q2F, and costs of the concerning technologies, step 3 - to estimate cyber attacks and firm specific parameters such as $d, \gamma, \lambda, \varphi, \varepsilon, \sigma, c, \mu, \alpha$, and $\beta$, step 4 - to run the model for each security control and to determine the cost savings and step 5 - to choose the technology that yields the maximum savings.

Even though (Cavusoglu, et al 2004) recommends a previous RA before applying the ROSI model, RM frameworks are not approached

\subsection{Forecasting for ROSI - Institute for technological research of São Paulo}

As far as our knowledge extends, ROSI with forecasting was first applied by (Pontes et al, 2009a, 2009b, 2009c, 2010), which implemented a hybrid forecasting methodology combined with the cost-model of (Wei et al, 2001) for cyber attacks in the Internet. Fig. 9 shows the forecasting for ROSI, which generates two charts with two techniques (Fibonacci sequence and moving averages).

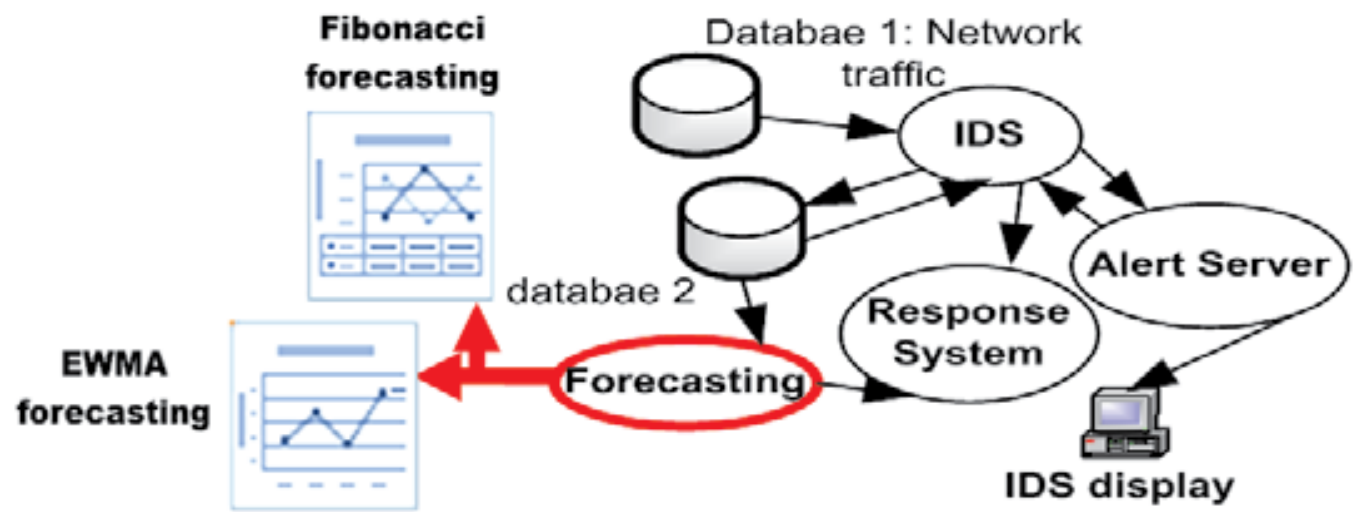

Fig. 9. Forecasting Methodology and Forecasting Generated Charts

(Pontes et al, 2009a, 2009b) used the datasets of (DARPA, 2009) representing the network traffic and an IDS (Snort, 2009) as a tool to analyze the network traffic. All security incidents (the intrusions attempts, alerts and logs) were lately recorded in another database. ROSI with forecasting collects the data from the second database; analyzes the information and then creates the trend charts, in accordance with the adopted techniques (Fibonacci sequence and moving average). However, in (Pontes et al, 2009a, 2009b) the forecasting for ROSI didn't approach three major gaps in forecasting techniques for IS: a) the use of few sensors and/or sensors employed locally; b) the use of just one forecasting technique; and c) lack of information sharing among sensors to be used for correlation.

Intending to improve the previous works, the goal of (Pontes et al, 2009c, 2010) was to propose the Distributed Intrusion Forecasting System Architecture (DIFSA) with prediction approaches and sensors acting in different network levels (host, border and backbone), 
which enables the use of different forecasting techniques, the cooperation among points of analysis and the correlation of predictions. As results it was possible to increase reliability of attack predictions, to prevent attacks in a proactive manner and to improve RM employed for defense of the homeland cyberspace. (Pontes et al, 2009c, 2010) applied the DIFSA for sites geographically divided, with both usual and simulated traffic for normal and malicious activities (cyber attacks). Fig. 10 depicts the DIFSA and the forecasting levels.

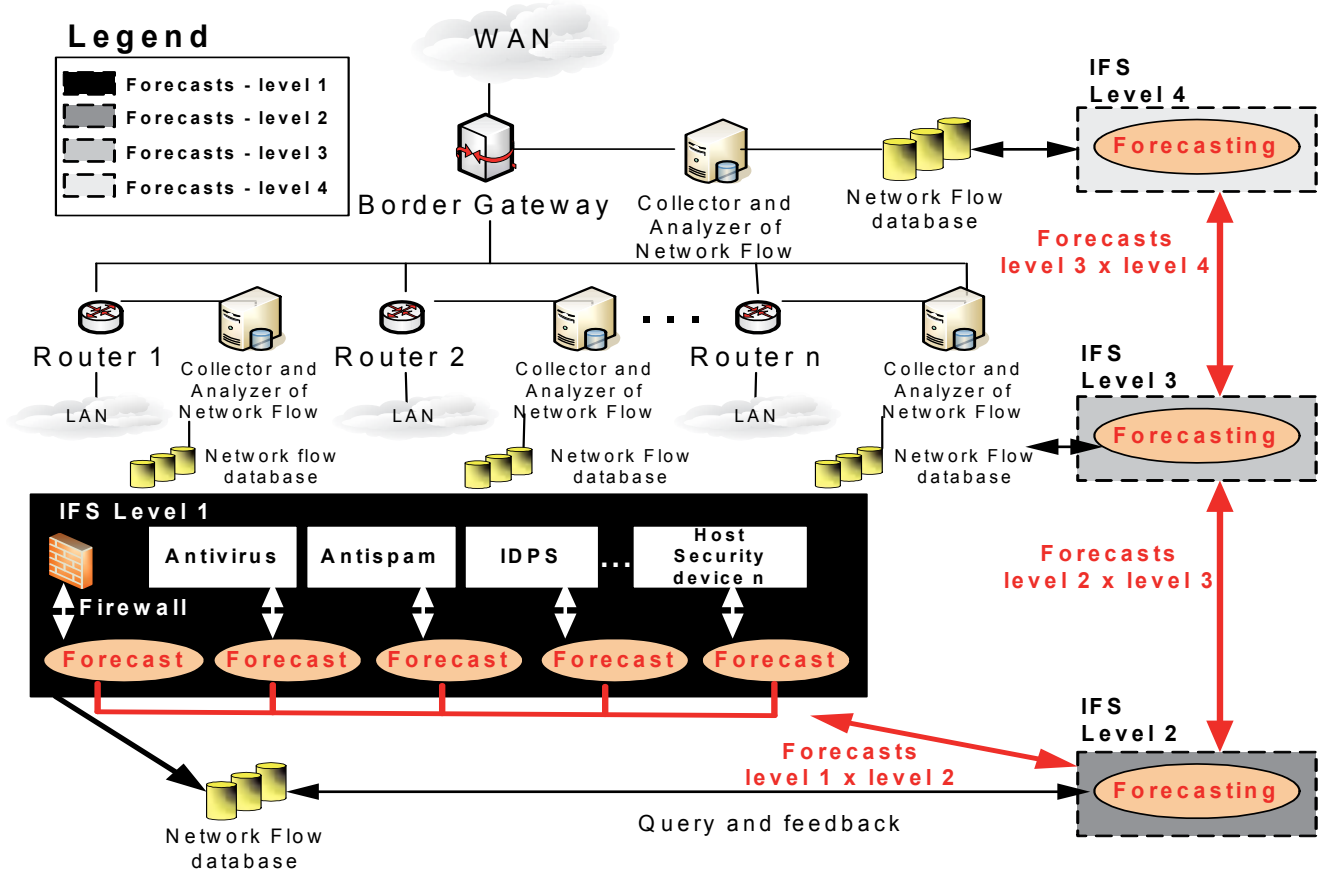

Fig. 10. IFS Architecture

Similarly to forecasting methodologies used in other fields, DIFSA also spreads agents and/or sensors widely to make predictions about the different kinds of cyber attacks. There are four levels of the IFS: level 1 - independent security devices of hosts; level 2 - integrated security devices of hosts; level 3 - the network level; and level 4 - the backbone level. All levels have some communication degree among each other. In other words, the forecasts obtained from level 1 are shared and correlated to the forecasts of the other levels. Lower levels work as sensors to higher levels; consequently feedback about the cyber attacks trends may be exchanged from one level to another.

Other prediction methods that may be employed with ROSI concern programming techniques, Markov chain, Fractal Analysis, stochastic processes, data mining, among others (Haslum et al, 2008). (Pontes et al, 2009a, 2009b, 2009c, 2010) did not approach RM frameworks in their works.

\section{The comprehensive risk management framework}

We hereby classify the comprehensive framework as the one which concerns each of the fundamentals of the traditional RM frameworks and, additionally, implements purposely a 
ROSI phase. The comprehensive RM framework is composed of 5 phases and diverse steps, as Fig. 11 illustrates. The phases are:

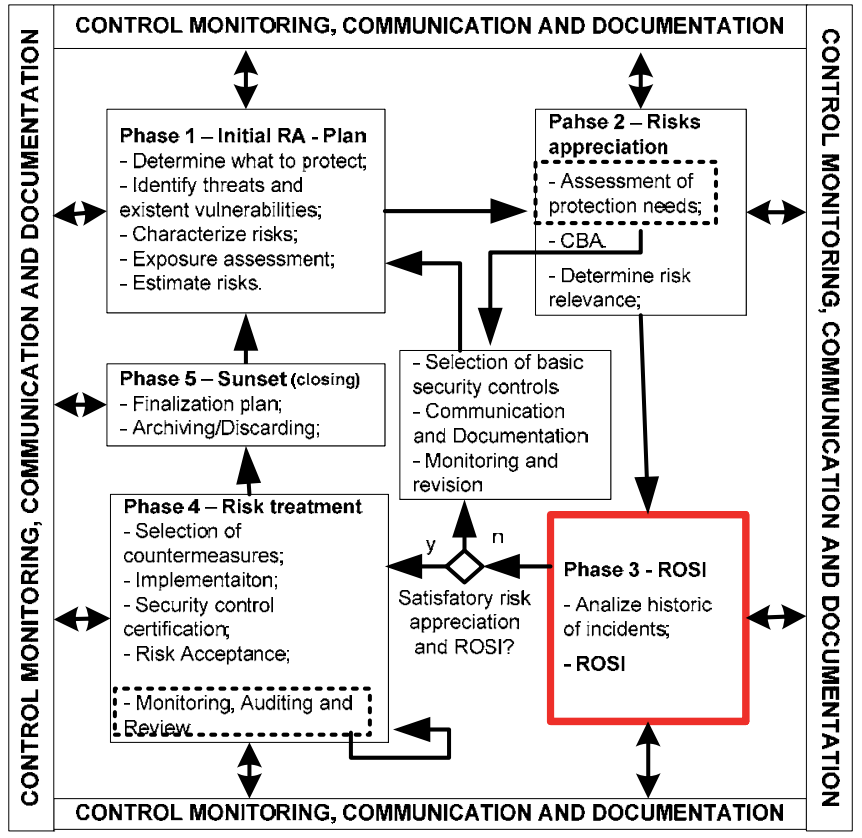

Fig. 11. The Comprehensive RM Framework - Extension to ROSI

Phase 1 - Initial RA: in this phase it is designed the plan for conducting the management activities, as defining scope for the RM environment (detailed description of the context and boundaries), defining the purpose of the RM. In addition, the first steps for RA are in this phase (threats identification, vulnerability analysis, assets identification, estimative about risk and the assessment of the exposure level for the assets);

Phase 2 - Risk appreciation: specific security requirements for organizations are defined in this phase, assessing and analyzing the protection needs by the use of CBA methods, estimating the ALE and the likelihood of the threats that may explore vulnerabilities;

Phase 3 - ROSI: this phase regards the analysis of the incidents history, adding 1) deeper financial analysis phase in the selection of controls, incorporating criteria such as loss of productivity, business organizational interruption, loss of intangible assets, depreciation, devaluation, reconstruction, recovery, monitoring of investment compensation; 2) evaluating security planning and security solutions, 3) analyzing business needs and security controls to be employed, 4) presenting the lowest possible values to address costs of security breaches and costs of security controls;

Phase 4 - Risk treatment: this phase concerns the selection of safeguards, as well as the implementation of countermeasures, certification of IS controls and the risk acceptance.

Phase 5 - Sunset (closing): phase performed to finalize all activities across the RM. This phase considers the hypothetical situation for transferring responsibilities, as archiving and/or discarding confidential information regarding third parties.

Phase 5 may happen whether for organization merging or when the activities of an organization come to end. 
The comprehensive RM framework illustrated by Fig. 11 is cyclic, but in some phases the cycle may be interrupted, returning to the first phase. Because of the dynamic nature of risks, threats and vulnerabilities (GCIO, 2004), (ISO 31000, 2009), monitoring and communication plans must be described, defining the stakeholders (involved parties), as their roles and responsibilities properly delimited. As well as the countermeasures and risks' monitoring, communication and documentation must be constant during the entire $\mathrm{RM}$, allowing each one of the stakeholders to know the progress of every processes and to provide subsidy for developing RM.

Phase 1 derives from (PMBOK, 2008), as it refers plan conception for conducting RM. However, in this phase there is extension to (FISMA, 2002), (ISO 27005, 2008), (NIST SP800$30,2002)$, as the scope identification, context and boundaries definition, identification of assets, threats and vulnerabilities, assessment of the exposure and risks estimative.

During phase 2, after assessing the protection requirements, it is possible to identify imminent risks with potential impacts and, therefore, the need of risk treatment with immediate countermeasures implementation. At this moment, it is suggested interruption of the RM cycle, remitting to the selection of tailored baseline security controls to mitigate risks, followed by documentation and communication and lastly by monitoring and revision of the implemented controls and/or other security controls to be implemented.

In organizations which RM is executed for the first time, it is usual the cycle to be interrupted during phase 2, like the implementation of basic security controls (ISO 13335, 2004). Although CBA and ROSI are essential for IS controls selection, at this moment the priority is to protect the organizational assets which might be at serious risk, as it was previously appointed by the first phase of RM and by the assessment of protection needs. Phase 2 is analogous to the risk assessment of 27005, as procedures for the protection requirements; the risks level determination and $\mathrm{ACB}$ are performed.

Phase 3, ROSI, represents the main proposed extension for RM. In this phase the risk assessment previously performed is complemented by tracking and predicting the incidents flow for the near future. In the case the risk assessment or ROSI had not been satisfactory, because of lack of related data, the cycle will be redirected to the first phase again. In this case, it is essential to select basic IS controls, to communicate and document, monitoring and revision of existing controls. Otherwise, in the case ROSI and risk assessment had been successfully concluded, phase 4 will be initiated. In the comprehensive RM framework, ROSI approaches the analysis of historical series of incidents that were problem to productivity rates (Sonnenreich et al, 2006). ROSI concerns also the cost avoidance resulting from resistance, recognition, and reconstitution efforts for the IT infrastructure in the organization, based on the ALE and the number of incidents (Wei et al, 2001), (GCIO, 2004), (O'Neil, 2007); 2) ROSI may also include techniques to identify incident trends (Pontes et al, 2009a, 2009b, 2009c, 2010). Phase 4, risk treatment, is the moment for minimizing risks, selecting effective controls, implementing, accepting risks and certifying IS countermeasures (FISMA, 2002), (NIST SP800-30, 2002). Phase 4 considers options for risk reduction, risks retention, risk avoidance and risk transferring.

Although the control monitoring is constant during the proposed model, in this phase the process is complemented by auditing and control revision. Eventually auditing and/or revision may indicate that the implemented controls are not enough, and then phase 4 is restarted, but preceded of communication and documentation. When the IS controls correspond the audit requirements phase 5, sunset, is initiated. Phase 5 is aligned to the SDLC (System Development Life Cycle) (NIST SP800-21, 2005) and it contemplates the 
hypothesis of finalization (extinction) or transposition or RM environment (e.g. organization merging) with archiving and/or discarding. Even though phase 5 is occasional, closing procedure is recommended to be planed, as follows:

Transposition: it happens during merging process of organizations, for instance. In this context, it is necessary to plan the closing, archiving and transfer process of RM. Documentation and communication are essential in this phase, as well controls monitoring. Phase 1 is retaken when transfer is concluded; Finalization: it happens when a company is closed. As RM is generally linked to third parties (governmental, private organizations), information disposal concerns treatment of sensitive data, as confidential information. Phase 1 is not retaken after closing.

Notice that the comprehensive framework is based on characteristics of other RM models, but ROSI with introduces an important increment for decision making process (Pontes et al, 2009a, 2009b, 2009c, 2010).

\section{Analysis of ROSI application in risk management (RM)}

Within the traditional RM (i. e., the one that deals with threats, vulnerabilities, probability of adverse events, impacts, risks and security controls for handling risks) the inclusion of ROSI provides a more discerning evaluation for selecting and acquiring IS controls in IT. The discerning evaluation is mainly due to the following factors:

- A ROSI approach in risk management (RM) adds a deeper financial analysis phase in selecting the most appropriate security control to address a specific risk, incorporating not only criteria of the technological feasibility and costs of acquisition, but also other touchstones such as loss of productivity, business organizational interruption, loss of intangible assets, depreciation, devaluation, reconstruction efforts, recovery efforts, monitoring of investment compensation in a control by minimizing or eliminating losses etc. Thus, a ROSI approach deepens and complements a cost/benefit analysis made in a RM, providing a more wide and appropriate evaluation of a given security control to be applied;

- Monitoring the investment compensation, regarding IS controls, is important for having a real perspective about the expected time for a given control to compensate its investments, by eliminating or minimizing losses which could occur if the control was not applied. Therefore, by the applied IS control, it is possible to keep the workability of business in order to make profit. Investment compensation in a given IS control can be understood as the savings generated by the protection of the business;

- $\quad$ ROSI approach in RM for IT enhances investments savings, as more efficient controls are required to protect and maintain the business of organizations;

- By the use of cyclic RM framework all together with the definition and collection of measures (metrics) associated with the applied controls in a given system, it is possible to reach the continuous improvement of these controls in a system, and it is also possible to verify whether the planning done for a given control will be fulfill or will require adjustments to its complete execution.

Notwithstanding, including ROSI approach in RM may also come out with some shortcomings. The first limitation is that the ROSI for an IT environment will always deal with the minimization or elimination of financial losses through the use and maintenance of one or more IS controls, thus generating savings. However, revenue or dividends are not 
generated over the invested financial value. This is the limit that a ROSI approach provides to an organization.

The second shortcoming: ROSI approach will always generate an additional work phase on the traditional RM framework, thus making this model more complex and quantitative. Consequently, it is common to observe that, not only the ROSI approach, but often also the cost/benefit analysis, may simply be ignored in the RM process when critical or high risk issues are identified.

The third shortcoming: ROSI approach for deploying an IS control is based on events or incidents which have occurred in the past, or on the notion of the current protection level for an IT environment. Therefore, when deploying an adequate IS control at a given moment, it is not possible to assess the future trend of the attacks to see whether the investment compensation can occur for the short, medium or long term. That is, a ROSI approach can only wait for the real behavior of the next attacks to see whether the planning for investment compensation in IS controls was anticipated, fulfilled or postponed. In addition, the ROSI approach addresses the description of costs to avoid problems of IS in IT, regarding losses or damages estimated at a given time.

Finally, the traditional RM in IT can produce a reduced amount of satisfactory results when financial criteria is not evaluated in depth for the selection and implementation of appropriate IS controls. However, ROSI should not be applied individually for the IS controls selection process; ROSI should always be placed within cyclical RM framework, as controls can be better justified, monitored and periodically evaluated to generate larger savings in business.

\section{Conclusion}

As a conclusion this study has investigated some of the RM standards and good practices, proposing an extension to those common RM frameworks: RM with ROSI and the closing phase for RM. The implementation of the proposed framework is simple and easy to interpret. Our discussions indicate that such a framework is practical for protecting assets, which are at risks, prone to threats or misuse

Within the context of RM in information security, it is important 1) to define the risk levels, select and implement appropriate security controls; 2 it is also important to justify costs and investments and monitoring processes when such investments will be compensated by the prevention of losses and damages. In this reasoning line, the goal of this chapter was to propose a RM framework more comprehensive than the traditional ones, deepening the importance of using ROSI as a way to monitor and measure the compensation of fulfilled investments in security controls.

As mentioned in section 2, several traditional RM approaches, such as the ISO/IEC 27000 family, AS / NZS 4360, NIST SP 800-30, among others, deal more clearly with the risk identification and analysis, risk treatment, CBA, monitoring and reviewing of implemented controls. However, the traditional RM approaches refer furthermost to ROSI in a secondary and superficial way within their texts. Then, section 3 discussed a number of proposals made to calculate the ROSI associated with security controls in IT. The works done by (Sonnenreich et al, 2006), (Wei et al, 2001), (O'Neil, 2007), (GCIO, 2004), and (Al-Humaigani et al, 2003) have two characteristics in common: a) the ROSI calculations are always based on savings (loss prevention) and on investment value for a given control; and b) the ROSI calculations should take into account not only the values of fulfilled investments, but also the values related to the maintenance of the implemented control. 
In the sequence, to meet the goal of the chapter, section 4 presented as proposal a comprehensive RM framework, extending the traditional approaches in two phases clearly stated: planning and monitoring of ROSI (phase 3); and closing or extinction of the IT environment resulting in the archiving or discarding activities within the system (Phase 5 aligned to the SDLC addressed in NIST SP 800-21 (NIST SP800-21, 2005)). Finally, section 5 has shown an analysis of ROSI application in RM, including:

- Key Benefits:

- ROSI adds a deeper financial analysis phase in the selection of controls, incorporating criteria such as loss of productivity, business organizational interruption, loss of intangible assets, depreciation, devaluation, reconstruction, recovery, monitoring of investment compensation in a control etc;

- ROSI allows to potentiate the saving of investments and cost-effectiveness for the controls;

- With the collection of measures (metrics) associated with the controls, it is possible to verify if the planning done for a given control will be fulfill or not;

- Major limitations:

- ROSI generates savings, but neither revenue nor dividends arise from the invested financial value;

- ROSI brings up an additional work phase on the traditional risk management model, therefore making this framework more complex and quantitative;

- ROSI is based on events or incidents have occurred in the past or on the notion of the current protection level for an IT environment, thus it is not possible to assess the future trend of the attacks to verify if the investment compensation can occur in the short, medium or long term.

The following future works may be suggested: an experimental analysis of ROSI approaches applied in IT environments; to use forecasting techniques to know the behavior and volume of the security attacks, thus helping to verify if the planning done for the ROSI will be confirmed before or after the defined deadline; to prepare a formal proposal for the implementation of ROSI taking into account the life cycle of IT systems; among others.

\section{References}

Al-Humaigani, M.; Dunn, D.B., A model of Return on Investment for Information Systems Security, Proceeding of 2003 IEEE International Symposium on Micro-NanoMechatronics and Human Science, pp. 483, ISBN 0-7803-8294-3, Cairo, 2003.

Cavusoglu, H., Mishra, B., Raghunathan, S., A Model of Return on Investment for Information Systems Security, (2004), Journal Communications of the ACM, Volume 47 Issue 7, July 2004, ACM New York, NY, USA.

DARPA, Defense Advanced Research Projects Agency, DARPA, (1998), Massachusetts Institute of Technology (MIT) - Lincoln Laboratory, 1998, Available from http://www.ll.mit.edu/mission/communications/ist/corpora/ideval/data/index .html.

Haslum, K, Abraham, A., Knapskog, S., Fuzzy Online Risk Assessment for Distributed Intrusion Prediction and Prevention Systems, Proceedings of IEEE UKSIM 2008 10th International Conference on Computer Modeling and Simulation, pp. 216, ISBN 0-76953114-8, Cambridge, UK, April 2008. 
IC3 - Internet Crime Complaint Center, (2008), 2008 Internet Crime Report, Bureau of Justice Assistance and National White Collar Crime Center, 2008, Available from: www.ic3.org.

ISO 13335, International Standardization Organization, ISO/IEC TR 13335. Information Technology - Guidelines for the management of IT Security - part 1: Concepts and Models for IT Security, Geneva, 2004.

ISO 27001, International Standardization Organization, ISO/IEC 27001. Information technology -- Security techniques -- Specification for an Information Security Management System, Geneva, 2006.

ISO 27002, International Standardization Organization, ISO/IEC 27002. Information technology -- Security techniques -- Code of Practice for Information Security Management, Geneva, 2005.

ISO 27005, International Standardization Organization, ISO/IEC 27005. Information technology - Security techniques -- Information security risk management, Geneva, 2008.

ISO 31000, International Standardization Organization, ISO/IEC 31000. Risk management Guidelines on principles and implementation of risk management, Geneva, 2009.

ISO 73, International Standardization Organization, ISO/IEC Guide 73. Risk management Risk Management Vocabulary, Geneva, 2009, Geneva, 2009.

NIST SP800-21, National Institute of Standards and Technology, (2005), Guideline to Implement Cryptograph in the Federal Government, USA, 2005.

NIST SP 800-30, National Institute of Standards and Technology, (2002), Risk Management Guide for Information Technology Systems, USA. 2002

NIST SP 800-37, National Institute of Standards and Technology, (2010), Guide for Applying the Risk Management Framework to Federal Information Systems, USA, 2010

PMBOK, Project Management Institute, (2008), PMBOK - Project Management Body of Knowledge, A Guide to the Project Management Body of Knowledge, Forth Edition, Paperback, PMI, December, 2008.

Pontes, E. \& Geulfi, A., (2009), IDS 3G - Third Generation for Intrusion Detection: Applying Forecasts and ROSI to Cope With Unwanted Traffic, Proceedings of 2009 4th IEEE ICITST International Conference for Internet Technology and Secured Transactions, pp. 1, ISBN 978-1-4244-5647-5, London, UK, November 2009.

Pontes, E. \& Guelfi, IFS - Intrusion Forecasting System Based on Collaborative Architecture, Proceedings of 2009 4th IEEE ICDIM International Conference on Digital Information Management, pp. 1-8, ISBN 978-1-4244-4253-9, University of Michigan, Ann Arbor, USA, November 2009.

Pontes, E. \& Zucchi, W., (2010) Fibonacci Sequence and EWMA for Intrusion Forecasting System, Proceedings of 2010 5th IEEE ICDIM International Conference on Digital Information Management, pp. 404-412, ISBN 978-1-4244-7572-8, Lakehead University, Thunder Bay, Ontario, Canada, July 2010.

Pontes, E., Guelfi, A. \& Alonso, E., (2009), Forecasting for Return on Security Information Investment: New Approach on Trends in Intrusion Detection and Unwanted Traffic, Journal IEEE Latin America Transactions, Vol. 7, Issue 4, (December 2009), pp. 438-446, ISSN 1548-0992, São Paulo, Brazil.

SNORT, 2009, Available from http:/ / www.snort.org.

United States Government, (2002), Federal Information Security Management Act of 2002 FISMA, USA, Dec. 2002, Available from: http://csrc.nist.gov/groups/SMA/fisma.

W. Sonnenreich, , J. Albanese, and B. Stout, (2006), A practical approach to return on security investment, Journal of Research and Practice in Information Technology, Vol. 38, No. 1, pp. 45-56, ISSN 1443-458X, Australia, February 2006. 


\title{
Market Risk Management with Stochastic Volatility Models
}

\author{
Per Solibakke \\ Molde University College, Specialized University in Logistics, Molde, \\ Norway
}

\section{Introduction}

Risk assessment and management have become progressively more important for enterprises in the last few decades. Investors diversify and find financial distress and bankruptcy among enterprises not welcome but expected in their portfolios. Some enterprises do extremely well and keep expected profits (and realised) at a satisfactory level above risk free rates. In contrast, corporations should be run at its shareholders best interest inducing project acceptance with internal rates of return greater than the risk adjusted cost of capital. These considerations are at the heart of modern financial theories. However, often not stressed enough, for the survival of a corporation financial distress and bankruptcy costs can be disastrous for continued operations. Every corporation has an incentive to manage their risks prudently so that the probability of bankruptcy is at a minimum. Risk reduction is costly in terms of the resources required to implement an effective risk-management program. Direct cost are transactions costs buying and selling forwards, futures, options and swaps - and indirect costs in the form of managers' time and expertise. In contrast, reducing the likelihood of financial distress benefits the firm by also reducing the likelihood it will experience the costs associated with this distress. Direct costs of distress include out-ofpocket cash expenses that must be paid to third parties. Indirect costs are contracting costs involving relationship with creditors, suppliers, and employees. For all enterprises, the benefits of hedging must outweigh the cost. Moreover, due to a substantial fixed cost element associated with these risk-management programs, small firms seem less likely to assess risk than large firms ${ }^{1}$. In addition, closely held firms are more likely to assess risk because owners have a greater proportion of their wealth invested in the firm and are less diversified. Similarly, if managers are risk averse or share ownership increases ${ }^{2}$, the enterprises are more likely to pursue risk management activities. Stringent actions from regulators, municipal and state ownership and scale ownership (>10-15\%), may therefore force corporations to work even harder to avoid large losses from litigations, business disruptions, employee frauds, losses of main financial institutions, etc. leading to increased probability for financial distress and bankruptcy costs.

\footnotetext{
1 See Booth, Smith, and Stolz (1984), DeMarzo and Duffie (1995), and Nance, Smith and Smithson (1993). The improvements in use of information technology have made it more likely that smaller companies use sophisticated risk-management techniques Moore et al. (2000).

2 Tufano (1996) finds that risk management activities increase as share ownership by managers increases and activities decreases as option holdings increases (managerial incentives hypotheses).
} 
Energy as all other enterprises must take on risk if they are to survive and prosper. This chapter describes parts of the portfolio of risks a European energy enterprise is currently taking and describes risks it may plan to take in the future. The three main energy market risks to be managed are financial, basis and operational risk. The financial risks are market, credit and liquidity risks. For an energy company selling its production in the European energy market, the most important risk factor is market risk, which is mainly price movement risks in Euro $(€)$. The credit risk is the risk of financial losses due to counterparty defaults. The Enron scandal made companies to review credit policies. Finally, the liquidity risk is market illiquidity which normally is measured by the bid-ask spread in the market. In stressed market conditions the bid -ask spread can become large within a certain time period. The next main risk category for energy companies is basis risk ${ }^{3}$ which is risk of losses due to an adverse move or breakdown of expected price differentials. Price differentials may arise due to factors as weather conditions, political developments, physical events or changes in regulations. Some markets operate with area prices that differ from the reference prices and contract for differences (CfD) are established to allow for basis risk management. The last main risk category is operational risk which is divided into legal, operational and tax risks. Legal risks are related to non-enforceable contracts. Operational risk is the risk of loss resulting from inadequate or failed internal processes, people, and systems or from external events. Tax risk can occur when there are changes to taxation regulations. Importantly, all these risks interrelate and affect one another making the use of portfolio risk assessment and management relevant. Basis and operational risk measures contribute to total relevant risk and some of the basis risk is related to market risk (CfDs). In many ways, the key benefit of a risk management program is not the numbers that are produced, but the process that energy companies go through producing the risk related numbers.

Economic capital is defined as the amount of capital an energy corporation needs to absorb losses over a certain time horizon (usually one year) with a certain confidence level. The confidence level depends on the corporation's objectives. Maintaining an AA credit rating implies a one-year probability of default of about $0.03 \%$. The confidence level should therefore be $99.97 \%$. For the measurement of economic capital the bottom up approach is often used. In this method the loss distributions are estimated for different types of risks (market and operational) over different business units and then aggregated. For an energy corporation the loss distributions for market risks can be divided into for example price and volume risk, basis risk into location and time risks and operational risks into business and strategic risks (related to an energy company's decision to enter new markets and develop new products/line of business). A final risk aggregation procedure should produce a probability distribution of total losses for the whole corporation. Using for example copulas, each loss distribution is mapped on a percentile-to-percentile basis to a standard wellbehaved distribution. Correlation structures between the standard distributions are defined and this indirectly defines correlation structures between the original distributions. In a Gaussian copula the standard distributions are multivariate normal. An alternative is a multivariate $t$ distribution. The use of the $t$ distribution leads to the joint probability of extreme values of two or more variables being higher than in the Gaussian copula. When many variables are involved, analysts often use a factor model: $U_{i}=a_{i} \cdot F+\sqrt{\left(1-a_{i}^{2}\right)} \cdot Z_{i}$, where $F$ and $Z$ have standard normal distributions and $Z_{i}$ are uncorrelated with each other

\footnotetext{
3 Three components of basis risk: location basis (area supply/demand factors), time basis (grid problems) and some mixed basis issues.
} 
and uncorrelated with $F$. Energy corporations use both risk decomposition and risk aggregation for management purposes. The first approach handles each risk separately using appropriate instruments. The second approach relies on the power of diversification of reducing risks.

The chapter is concerned with the ways market risk can be managed by European enterprises. Several disastrous losses ${ }^{4}$ would have been avoided if good risk management practices had been enforced. The current financial crises may have been avoided if risk management had reached a higher understanding at the level of the CEO and board of directors. Normally, corporations should never undertake a trade strategy that they do not understand. If a senior manager in a corporation does not understand a trading strategy proposed by a subordinate, the trade should not be approved. Understanding means instrument valuations. If a corporation does not have the in-house capability to value an instrument, it should not trade it. The risks taken by traders, the models used, and the amount of different types of business done should all be controlled, applying appropriate internal controls. If well handled, the process can sensitize the board of directors, CEOs and others to the importance of market, basis and operational risks and perhaps lead to them thinking about them differently and aggregately.

\section{Energy markets, financial market instruments and relevant hedging}

The main participants in financial markets are households, enterprises and government agencies. Surplus units provide funds and deficit units obtain funds selling securities, which are certificates representing a claim on the issuer. Every financial market is established to satisfy particular preferences. Money markets facilitate flow of short-term funds, while those that facilitate flow of long-term funds are known as capital markets. Whether referring to money market or capital market securities, the majority of transactions are pertained to secondary markets (trading existing securities) and not primary markets (new issuances). The most important characteristic of secondary markets is liquidity (the degree a security can be liquidated without loss of value). If a market is illiquid, market participants may not be able to find a willing buyer and may have to sell the security at a large discount just to attract a buyer. Finally, we distinguish between organised markets (visible marketplace) and the over-the-counter market (OTC), which is mainly a telecommunication network. All market participants must decide which markets to use to achieve their goals or obtain financing.

Europe's power markets consist of more than half a dozen exchanges, most of which offer trading in both spot, futures and option contracts, giving a dauntingly complex picture of the markets. Moreover, the markets are fragmented along national lines. The commodity itself is impossible to store, at least not on the necessary scale, and is subject to extreme swings in supply and demand. And critical information about such key factors as the level of physical generation is incomplete or not available at all in certain markets. The Nordic market was one of the leaders on electricity liberalization, with Nord Pool becoming Europe's first international power exchange in 1996. Liquidity and volume have grown significantly. Nord Pool trades and clears spot and financially settled futures in Finland,

\footnotetext{
${ }^{4}$ Recent examples are Orange County in 1994 (US), Barings Bank (UK) (Zang, 1995), Long-Term Capital Management (Dunbar, 2000), Enron counterparties, and several Norwegian municipals in 2007-2008.
} 
Sweden, Denmark and Norway, listing day and week futures, three seasonal forwards, a yearly forward, contracts for difference and European-style options. Volume in its financial power market in 2009 totaled 2,162 terawatt hours, valued at 68.5 billion euros. Cleared OTC volumes in 2009 reached 942 TWh from 1,140 TWh in 2008. The European Energy Exchange (EEX) in Germany is Europe's fastest growing power futures market. EEX offers trading in physically-settled German and French power futures as well as cash-settled futures based on an index of power prices. On 1st April 2009, the Powernext SA futures activity was entrusted to EEX Power Derivatives AG. The exchange also offers trading in German, Austrian, French and Swiss spot power contracts, emission allowances and coal, and launched trading in natural gas in 2009/2010. On 1st January 2009, Powernext SA transferred its electricity spot market to EPEX Spot SE and on 1st September 2009 EPEX Spot merged with EEX Power Spot. The exchange has more than 160 members from 19 countries, including banks such as Barclays, Deutsche Bank, Lehman Brothers and Merrill Lynch. Eurex owns 23\% of the exchange and supplies its trading platform. In 2009 the volume of futures traded on EEX was 1,025 TWh, and the value of futures trading was 61 billion euros. The number of transdactions at the end of 2009 was approximately 114,250. France's Powernext exchange was established in 2002 as a spot market for electricity. Futures trading were launched in 2004 and until 2009 traded physically-settled contracts with maturities from three months to three years. In 2009 the exchange entrusted the futures activity to EEX Power Derivatives AG. Moreover, 1st January 2009, Powernext SA transferred its electricity spot market to EPEX Spot SE and on 1st September 2009 EPEX Spot merged with EEX Power Spot. The transfer of activity was due to the implementation of France's TRTAM "return to tariff" law, which reinstates regulated tariffs for industrial users from EDF, France's main electricity supplier, which limits competition and is seen to distort exchange prices. Liquidity was severely dented and trading volume plunged and open interest sank from around 14 TWh in June 2006 to 11 TWh at the end of 2005. The European Energy Derivatives Exchange (Endex) is funded by financial players and Benelux energy market participants, including Fortis Bank, Endesa and RWE. It incorporates the Endex Futures Exchange, an electronic market for Dutch and Belgian power futures, and Dutch gas futures. Electrabel, Essent and NUON act as liquidity providers. Since the exchange launched in 2004 the major interest has been in Dutch power futures, though Belgian power markets have also grown. Combined, they rose $156 \%$ in year one and grew from 327 TWh in 2008 to 412 TWh in 2009. Number of transactions in Dutch power for 2009 was 45,900. In November 2009, the Endex and Nord Pool take the first steps towards a integrated crossborder intra-day electricity market. There are many other markets changing rapidly, or where futures markets may develop. The U.K., for instance, is currently building a new trading model to combat declining liquidity. A considerable amount of spot and forward trading takes place on APX Power UK, but all attempts to create a futures market for U.K. electricity have failed to attract significant volume. Most market participants have relied instead on bilateral contracts traded on the over-the-counter market. The latest initiative is Nord Pool and the N2EX market initiative started in 2009/2010. Volume is still an issue also for this initiative. European markets are moving towards greater physical integration, with more market coupling to increase the efficiency of cross-border interconnectors. Coupling between Denmark and Germany is due, with EEX and Nord Pool party to an existing agreement. Similarly, the 700MW NorNed interconnector links the Dutch APX market with Nord Pool via Norway. The future could well see consolidation among exchanges, particularly as cross-border integration becomes more widespread. 


\begin{tabular}{|c|c|c|c|c|c|c|c|c|c|}
\hline & & \multicolumn{2}{|c|}{ Power Futures (TWh) } & \multicolumn{2}{|c|}{ Carbon Trading (tonnes) } & \multicolumn{2}{|c|}{ Spot Power (TWh) } & \multicolumn{2}{|c|}{ Cleared OTC power (TWh) } \\
\hline & & 2008 & 2009 & 2008 & 2009 & 2008 & 2009 & 2008 & 2009 \\
\hline Nord Pool & Transactions & 158815 & 136030 & 6685 & 3792 & $70 \%$ & $72 \%$ & 51575 & 40328 \\
\hline EEX & Transactions & 128750 & 114250 & 4398 & 1959 & $54 \%$ & $56 \%$ & $\mathrm{n} / \mathrm{a}$ & $\mathrm{n} / \mathrm{a}$ \\
\hline \multirow[t]{2}{*}{ Powernext } & Volume (TWh) & 79 & 87 & $\mathrm{n} / \mathrm{a}$ & $\mathrm{n} / \mathrm{a}$ & 203.7 & 196.3 & $\mathrm{n} / \mathrm{a}$ & $\mathrm{n} / \mathrm{a}$ \\
\hline & Transactions & $\mathrm{n} / \mathrm{a}$ & $\mathrm{n} / \mathrm{a}$ & $\mathrm{n} / \mathrm{a}$ & $\mathrm{n} / \mathrm{a}$ & $\mathrm{n} / \mathrm{a}$ & $\mathrm{n} / \mathrm{a}$ & $\mathrm{n} / \mathrm{a}$ & $\mathrm{n} / \mathrm{a}$ \\
\hline APXIEndex & Transactions & 36150 & 45900 & $\mathrm{n} / \mathrm{a}$ & $\mathrm{n} / \mathrm{a}$ & $\mathrm{n} / \mathrm{a}$ & $\mathrm{n} / \mathrm{a}$ & $\mathrm{n} / \mathrm{a}$ & $\mathrm{n} / \mathrm{a}$ \\
\hline
\end{tabular}

* On 1st January 2009, Powernext SA transferred its electricity spot market to EPEX Spot SE and on 1st September 2009 EEXPower Spot merged with EPEX Spot.

* On 1st April 2009, the Powernext SA futures activity was entrusted to EEXPower Derivatives AG.

Table 1. Volume (TWh) and Number of Transactions for European Power markets

A financial futures contract is a standardised agreement to deliver or receive a specified amount of a specified financial instrument at a specified price and date. The instruments are traded on organised exchanges, which establish and enforce rules of trading. Futures exchanges provide an organised market place where contracts are traded. The marketplaces clear, settle, and guarantee all transactions that occur on their exchange. All exchanges are regulated and all financial future contracts must be approved and regulations imposed before listing, to prevent unfair trading practices. The financial future contracts are traded either to speculate on prices of securities or to hedge existing exposure to security price movements. The obvious function of commodity future markets is to facilitate the reallocation of the exposure to commodity price risk among market participants. However, commodity future prices also play a major informational role for producers, distributors, and consumers of commodities who must decide how much to sell (or consume) now and how much to store for the future. By providing a means to hedge the price risk associated with the storing of a commodity, futures contracts make it possible to separate the decision of whether to physically store a commodity from the decision to have financial exposure to its price changes. For example, suppose it is Wednesday week 9 and a hydro electricity producer has to decide whether to produce his $10 \mathrm{MW}$ maximum capacity of electricity from his water reservoir, which has a normal level for the time of year, next week at an uncertain spot price of $S_{1}$ or selling short a future contract to day at $F_{0}^{1}$. By selling the future contract, the producer has obtained complete certainty about the price he will receive for his energy production. Anyone using a future contract to reduce risk is a hedger. But much of the trading of futures contracts are carried on by speculators, who take positions in the market based on their forecasts of the future spot price. Hence, speculators typically gather information to help them forecast prices, and then buy or sell futures contracts based on those forecasts. There are at least two economic purposes served by the speculator. First, commodity speculators who consistently succeed do so by correctly forecasting spot prices and consequently their activity makes future prices better predictors of the direction of change of spot prices. Second, speculators take then opposite site of a hedger's trade when other hedgers cannot readily be found to do so. The activity makes futures markets more liquid than they otherwise would be. Finally, future prices can provide information about investor expectations of spot prices in the future. The reasoning is that the future prices reflects what inspectors expect the spot price to be at the contract delivery date and, therefore, one should be able to retrieve that expected future spot price. Options are broader class securities called contingent claims. A contingent claim is any security whose future 
payoff is contingent on the outcome of some uncertain event. Commodity options are traded both on and off organised exchanges all around the world. Therefore, any contract that gives one if the contracting parties the right to buy or sell a commodity at a pre-specified exercise price is an option. European Energy Enterprises are all able to trade these securities on organised exchanges and OTC markets. Traders and portfolio managers use each of the "Greek Letters" or simply the Greeks, to measure a different aspect of the risk in a trading position. Greeks are recalculated daily and exceeded risk limits require immediate actions. Moreover, delta neutrality $(\Delta=0)$ is maintained on a daily basis rebalancing portfolios ${ }^{5}$. To use the delta concept, obtain delta neutrality and managing risks can be shown assuming a electricity market portfolio for company TK AS in Table 2. One way of managing the risk is to revalue the portfolio assuming a small increase in the spot electricity price from $€ 65.27$ per MW to $€ 65.37$ per MW. Let us assume that the new value of the portfolio is $€ 65395$. A $€ 0.1$ increase in price decreases the value of the portfolio by $€ 1000$.

\begin{tabular}{crrr} 
Portfolio of Electricity Products in Tafjord Kraft book (daily): & & \\
& Number of MW (000) & Spot Prices $(€)$ & Value $€(000)$ \\
\hline Spot position (long normal production): & 1000 & 65.27 & 65270 \\
Forward contracts & & & \\
One Year Forward Contracts & -100 & 52.5 & -5250 \\
One Quarter Forward Contracts & 50 & 68.23 & 3411.5 \\
Two Quarter Forward Contracts & -200 & 52.5 & -10500 \\
Four Quarter Forward Contracts & 150 & 75.7 & 11355 \\
One Month Forward Contracts & 50 & 64.55 & 3227.5 \\
$\quad$ Three Month Forward Contracts & -10 & 58.25 & -582.5 \\
Future Contracts & & & \\
$\quad$ One Week Future Contracts & 100 & 67.25 & 6725 \\
$\quad$ Two Weeks Future Contracts & -50 & 65.21 & -3260.5 \\
Options & & & -10000 \\
$\quad$ Call One Year Forward Options & & & 5000 \\
$\quad$ Put One Year Forward Options & & & 65396 \\
\hline & & &
\end{tabular}

Table 2. Portfolio of Electricity Products in TK AS trading book (daily)

The sensitivity of the portfolio to the price of electricity is the delta: $\Delta=\frac{-1000}{+0.1}=-10000$. Hence, the portfolio loses (gains) value at a rate of $€ 10000$ per $€ 1$ increase (decrease) in the spot price of electricity. Elimination of the risk is to buy for example an extra one year (month) forward contract for 10000/8250h (10000/740h) MW. The forward contracts gains (loses) value of $€ 10000$ per $€ 1$ increase in the electricity price. The other "Greek letter" are the Gamma $\left(\gamma=\frac{\partial^{2} \text { Portfolio }}{\partial S^{2}}\right)$, Vega $\left(v=\frac{\partial \text { Portfolio }}{\partial \sigma}\right)$, Theta $\left(\varsigma=\frac{\partial^{2} \text { Portfolio }}{\partial T}\right)$, and Rho $\left(\rho=\frac{\partial^{2} \text { Portfolio }}{\partial i}\right)$. Corporations in any market must distinguish between market, basis and operational risk. The relevant risk is the market risk and the other risks are those over

${ }^{5}$ Gamma and Vega neutrality on regular basis is in most cases not feasible. 
which the company has control6 (internal risk). In classical corporate finance textbooks we find the separation theorem (the separation of ownership and management), which defines all relevant risk as the market (external) risk while all other risk (internal) is diversified away building diversified portfolios. Hence, the trade-off between return versus risk (higher expected returns for higher risks) for investors must be separated from risk and return for corporations. For an investor the relevant risk is $\sigma_{j} \cdot \rho\left(R_{j}, R_{m}\right)$, which divided by $\sigma_{m}$ for scaling purposes, defines the $\beta$ measure (often interpreted as market sensitivity). Investors are therefore compensated only for market (systematic) risk. All other risks can be diversified away building asset portfolios 7 . For corporations the assumptions of shareholder wealth maximization are imposed. Every investment project with a positive net present value (NPV) discounted with the risk adjusted cost of capital using the Capital Asset Pricing Model (CAPM) approach ${ }^{8}$, should be accepted. Operational (non-systematic) risk is irrelevant ${ }^{9}$. However, there are two important arguments among more (in an imperfect world) that can be extended to apply for all risks; that is, bankruptcy costs (product reputations, service products, accountants and lawyers) and managerial performance. The bankruptcy costs can be disastrous for a corporation's continued operations. It makes therefore sense for a company that is operating in the best interest of its shareholders to limit the probability of this value destruction occurring. Managerial performance evaluates company performance that can be controlled by the executives in the organisation. Idiosyncratic risks not possible to control by company executives should therefore be controlled. Hence, limiting total risk may be considered a reasonable strategy for a corporation. Many spectacular corporate failures can be traced to CEOs who made large levered acquisitions that did not work out. Corporate survival is therefore an important and legitimate objective, where both financing and investment decisions should be taken so that the possibility of financial distress (bankruptcy costs) is as low as possible. To limit the probability of possible destructive occurrences, energy corporations monitor market risks (mainly the correlated price and volume risks), basis, and operational risk. Even though a corporation manage its Greek letters (delta, gamma, theta and vega) within certain limits, the corporation is not totally risk free. At any given time, an energy corporation will have residual risk exposure to changes in hundreds or even thousands of market variables such as interest rates, exchange rates, equity markets, and other commodity market prices as oil, gas and coal prices. The volatility of one of these market variables measures uncertainty about the future value of the variable. Monitoring volatility to assess potential losses for the corporation is therefore crucial for risk management.

\footnotetext{
${ }^{6}$ All internal risks are included as for example the rogue trader risk and the risk of other sorts of employee fraud.

7 The Arbitrage Pricing Theory (APT) extends the one-factor model (CAPM) to dependence of several factors (Ross, 1976).

${ }^{8}$ The CAPM was simultaneously and independently discovered by Lintner(1965), Mossin (1966), and Sharpe(1964).

9 Some companies in an investor's portfolio will go bankrupt, but others will do extremely well. The overall result for the investor is satisfactory.
} 


\section{Value at risk, expected shortfall, volatility, correlations and copulas}

\subsection{Value at risk and expected shortfall}

Value at Risk (VaR) is an attempt to provide a single number that summarizes the total risk in a portfolio. VaR is calculated from the probability distribution of gains during time $T$ and is equal to minus the gain at the $(100-X)$ th percentile of the distribution. Hence, if the gain from a portfolio during six months is normally distributed with a mean of $€ 1$ million and a standard deviation of $€ 2$ million, the properties from a normal distribution, the onepercentile point of the distribution is $1-2.33 * 2=€ 3.66$ million. The VaR for this portfolio with a time horizon of six months and confidence level of $99 \%$ is therefore $€ 3.66$ million. However, the VaR measure has some incentive problems for traders. A measure with better incentives encouraging diversification (Artzner et al., 1999) is expected shortfall also called conditional VaR (CVaR). As for the VaR, the CVaR is a function of two parameters: $T$ (the time horizon) and $X$ (the confidence interval). That is, the expected loss during time $T$, conditional on the loss being less than the $X$ th percentile of the distribution. Hence, if the $X$ $=1 \%, T$ is one day, the CVaR is the average amount lost over 1 day assuming that the loss is greater than the $1 \%$ percentile. The $\mathrm{CVaR}$ measure is a coherent risk measure while the VaR is not coherent.

The marginal $\mathrm{VaR} / \mathrm{CVaR}$ is the sensitivity of $\mathrm{VaR} / \mathrm{CVaR}$ to the size of the $i$ th sub-portfolio $\left(\frac{\partial V a R}{\partial x_{i}}\right.$ and $\left.\frac{\partial C V a R}{\partial x_{i}}\right)$ and is closely related to the capital asset pricing model's beta $(\beta)$. If a sub-portfolio's beta is high (low), its marginal VaR/CVaR will tend to be high (low). In fact, if the marginal $\mathrm{VaR} / \mathrm{CVaR}$ is negative, an increase of the weight of a particular subportfolio, will reduce overall portfolio risk. Moreover, incremental VaR/CVaR is the incremental effect on $\mathrm{VaR} / \mathrm{CVaR}$ of the $i$ th sub-portfolio. An approximate formula of the $i$ th sub-portfolio is $\left(\frac{\partial V a R}{\partial x_{i}} x_{i}\right.$ and $\left.\frac{\partial C V a R}{\partial x_{i}} x_{i}\right)$. Finally, using the Euler theorem: $\operatorname{VaR}=\sum_{i=1}^{N} \frac{\partial V a R}{\partial x_{i}} x_{i}$ and $\quad C V a R=\sum_{i=1}^{N} \frac{\partial C V a R}{\partial x_{i}} x_{i}$ where $N$ is the number of sub-portfolios. The component $\mathrm{VaR} / \mathrm{CVaR}$ of the $i$ th portfolio is defined as $C_{i}^{V a R}=\frac{\partial V a R}{\partial x_{i}} x_{i}$ and $C_{i}^{C V a R}=\frac{\partial C V a R}{\partial x_{i}} x_{i}$. Component VaR/CVaR is often used to allocate the total VaR/CVaR to subportfolios - or even to individual traders.

Back-testing is procedures to test how well the $\mathrm{VaR}$ and CVaR measures would have performed in the past and is therefore an important part of a risk management system. Var/ CVaR back-testing is therefore used for reality checks and is normally easier to perform the lower the confidence level. Test statistics for one and two-sided tests have been proposed (Kupiec, 1995). Bunch test statistics (not independently distributed exceptions) are also proposed in the literature (Christoffersen, 1998). Weaknesses in a model can be indicated by percentage of exceptions or to the extent to which exceptions are bunched.

\subsection{Volatility, Co-variances/correlations and copulas}

Volatility and correlation modelling of financial markets combined with appropriate forecasting techniques are important and wide-ranging topics. Volatility is defined as the 
standard deviation of variable $i^{\prime}$ s return $\left(y_{i, t}=\ln \left[\frac{P_{i, t}}{P_{i, t-1}}\right] \cdot 100\right)$ per unit time $(t-1, t)$, where $P_{i, t}$ is the price of asset $i$ at time $t$. Relative to time horizons, the uncertainty measured by the standard deviation increases with the square root of time $(\sqrt{t})$. There are approximately 252 (trading) days $(t)$ per year. Volatility estimates can normally be obtained from two alternative approaches. The first is directly from the Black \& Scholes option pricing formula $(1973,1976)$ (implied volatility) and the second is to estimate volatility from historical data series and make conditional forecasts. Implied volatility estimates assume an actively traded market for the derivatives and therefore an up-to-date price.

Observing the price in the market, the volatility can be estimated by use of a NewtonRaphson technique. This technique's $\sigma$-measure is used extensively by market traders (the vega-measure). However, risk management is largely based on historical volatilities. The $s_{i}$ estimate of standard deviation of returns $\left(y_{i}\right)$ is: $s_{i}=\sqrt{\left[\frac{1}{n-1} \cdot \sum_{i=1}^{n}\left(y_{i, t}-\bar{y}_{i}\right)^{2}\right]}$, where $\bar{y}_{i}$ is the mean for asset $i$ of the $y_{i, t}$ and $n$ is the number of periods. The $s_{i}$ variable is therefore an estimate of $\sigma_{i} \sqrt{t}$. It follows that $\sigma_{i}$ itself can be estimated as $\hat{\sigma}_{i}$, where $\hat{\sigma}_{i}=\frac{s_{i}}{\sqrt{t}}$ and the standard error of this estimate can be shown to be approximately $\frac{\hat{\sigma}_{i}}{\sqrt{2 n}}$. A corporation that has exposure to two different market variables will have gains and losses non-linearly related to the correlation between the changes in the variables. The correlation coefficient $(\rho)$ between two variables $R_{1}$ and $R_{2}$, is defined as $\rho_{l, 2}=\frac{E\left(R_{1} R_{2}\right)-E\left(R_{1}\right) E\left(R_{2}\right)}{S D\left(R_{1}\right) S D\left(R_{2}\right)}$, where $E()$ denotes expected value and $S D()$ denotes standard deviation. As the covariance between $R_{1}$ and $R_{2}$ can be defined as $E\left(R_{1} R_{2}\right)-E\left(R_{1}\right) E\left(R_{2}\right)$ the correlation between $R_{1}$ and $R_{2}$ can be written as $\rho_{l, 2}=\frac{\operatorname{cov}\left(R_{1}, R_{2}\right)}{S D\left(R_{1}\right) S D\left(R_{2}\right)}$. Two variables are defined as statistically independent if knowledge about one of them does not affect the probability distribution for the other. That is, if $f\left(R_{2} \mid R_{1}=y\right)=f\left(R_{2}\right)$ for all $y$, where $f()$ is the probability density function. However, a correlation coefficient of zero between two variables does not imply independence. The correlation coefficient measures only linear dependence. There are many other ways in which two variables can be related. For example, for the values of $R_{1}$ normally encountered, there is very little relation between $R_{1}$ and $R_{2}$. However extreme values of $R_{1}$ tend to lead to extreme values ${ }^{10}$ of $R_{2}$. The marginal distribution of $R_{1}$ (sometimes also referred to as the unconditional distribution) is its distribution assuming we know nothing about $R_{2}$ and vice versa. To define the joint distribution between $R_{1}$ and $R_{2}$, how can we make an assumption about the correlation structure? If the marginal distributions are normal then the joint

${ }^{10}$ The quote is: "During a crisis the correlations seem all to go to one"! 
distribution of the variables are bivariate normal11. In the bivariate normal case a correlation structure can be defined. However, often there is no natural way to define a correlation structure between two variables. It is here copulas come to our rescue. Regardless of probability distribution shapes, copulas are tools providing a way of defining default correlation structures between two or more variables. Copulas therefore have a number of applications in risk assessment and management. Formally, a Gaussian copula can be defined for the cumulative distributions of $R_{1}$ and $R_{2}$, named $F_{1}$ and $F_{2}$, by mapping $R_{1}=r_{1}$ to $U_{1}=u_{1}$ and $R_{2}=r_{2}$ to $U_{2}=u_{2}$, where $F_{1}\left(r_{1}\right)=N\left(u_{1}\right)$ and $F_{2}\left(r_{2}\right)=N\left(u_{2}\right)$ and $N$ is the cumulative normal distribution function (Cherubini et al., 2004).. This means $u_{1}=N^{-1}\left[F_{1}\left(r_{1}\right)\right], u_{2}=N^{-1}\left[F_{2}\left(r_{2}\right)\right]$ and $r_{1}=F_{1}^{-1}\left[N\left(u_{1}\right)\right], r_{2}=F_{2}^{-1}\left[N\left(u_{2}\right)\right]$. The variables $U_{1}$ and $U_{2}$ are then assumed to be bivariate normally distributed. The key property of a general copula is that it preserves the marginal distribution of $R_{1}$ and $R_{2}$ while defining a correlation structure between them. In addition to the Gaussian copula we also have the Student- $t$ copula (the tail correlation is higher in a bivariate Student-t-distribution than that in a bivariate normal distribution). For more than two variables a multivariate Gaussian copula can be used. Alternatively, a factor model for the correlation structure between the $U_{\mathrm{i}}$ can be used: $U_{i}=a_{i} \cdot F+\sqrt{\left(1-a_{i}^{2}\right)} \cdot Z_{i}$ where $F$ and the $Z_{i}$ have standard normal distributions and the $Z_{i}$ are uncorrelated with each other and uncorrelated with $F$. Other distributions can be used to obtain for example a Student- $t$ distribution for $U_{i}$ (Demarta and McNeil, 2004). Copulas will is this paper be used to apply a simple model for estimating the value at risk on a portfolio of electricity accounts (households/firms) and to value credit derivatives and for the calculation of economic capital.

To illustrate and implement these market risk management concepts for the European energy markets, the Nord Pool and EEX energy markets are quite evolved and liquid markets for energy in Scandinavia and central Europe, respectively. In both markets, prices for energy are established seven days a week for the spot market and from Monday to Friday (not holidays) for the front week/month futures/forwards contracts. Hence, to establish the necessary concepts and define volatilities, co-variances and copulas fir these markets we use the financial EEX and Nord Pool base and peak load prices from Monday to Friday. We use all available prices from Monday to Friday for front week and front month contracts in the two energy markets. The price series are shown in Figure 1 (note the change in currency from NOK to Euro $(€)$ for contracts with physical delivery after December $31^{\text {st }}$ 2005). Prices seem to move randomly over time for both markets and contracts and is clearly non-stationary. The prices seem to show movements similar to other commodity markets and Solibakke (2006) have shown that energy markets seem to exhibit similar features to other markets. The EEX markets show a much higher frequency of price spikes and after adjusting for NOK and Euro differences the EEX market seem to have higher peak prices than the Nord Pool market. Due to the obvious non-stationary prices we calculate the returns in percent (logs) and these return series will be the main objects of our investigations.

${ }^{11}$ There are many other ways in which two normally distributed variables can be dependent on each other. There are similar assumptions for other marginal distributions. 
When distributions from energy market time series are compared with the normal distribution, fatter tails are observed (excess kurtosis). The standardized fourth moment is much higher than the normal distribution postulates ${ }^{12}$. Hence, distributions with heavier tails, such as Paretian and Levy are proposed in the international literature for modelling price changes. Moreover, the time series from energy markets show sometimes too many observations around their mean value and the tails show different characteristics at the negative (left) side relative to the positive (right) side of the distribution. In particular, the spikes at the EEX market may give some positive skewness to the EEX markets price changes.
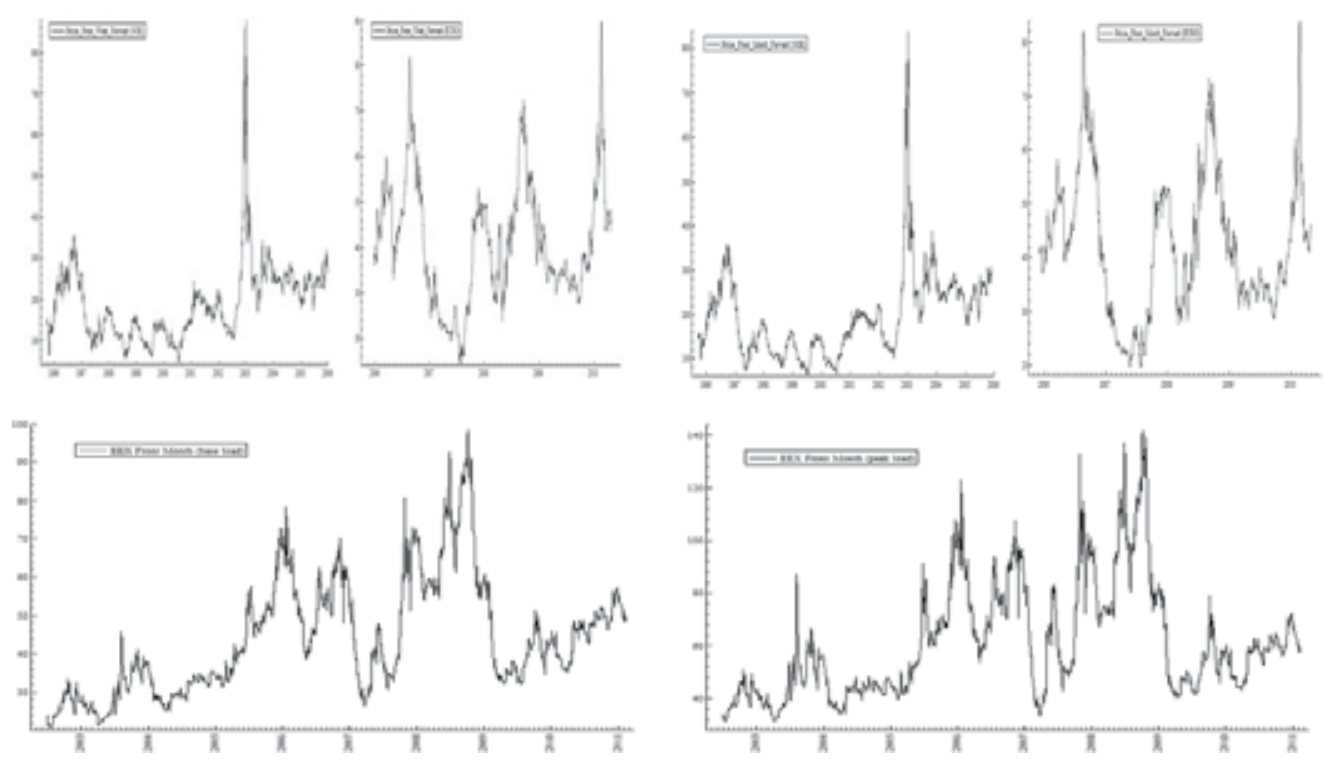

Fig. 1. Price series for Nord Pool and EEX. Nord Pool Front Week and Front Month (base). EEX front Month (base load) and Front Month (peak load).

Uni-variate and bi-variate return characteristics, densities (frequency distribution, normal distribution and the Epanechnikov kernel), volatilities and correlations for the Nord Pool front Week and Month contracts and the EEX Front Month base and peak load contracts are reported in Figure 2. For all the density plots (panel A-D) we distinguish three main arguments: the middle, the tails, and the intermediate parts (between the middle and the tails). When moving from a normal distribution to the heavy-tailed distribution, probability mass shifts from the intermediate parts of the distribution to the tails and the middle. As a consequence, small and large changes in a variable are more likely than they would be if a normal distribution were assumed. Intermediate changes are less likely. The QQ-plots confirm this non-normal story for all return distributions. The contract volatilities (panel E-F) show clearly different shapes between Nord Pool and EEX. However, the products within the same market show similar volatility patterns. The asymmetry (panel G-H) is much clearer at EEX than at Nord Pool. In particular, the EEX market seems to exhibit much more

${ }^{12}$ See the first studies of this feature: Mandelbrot $(1963)$ and Fama $(1963,1965)$. 


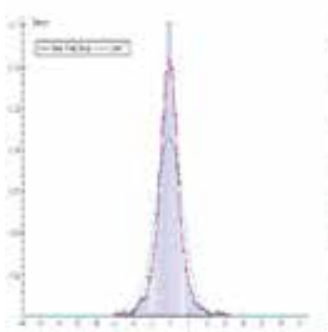

A: Nord Pool Front Week
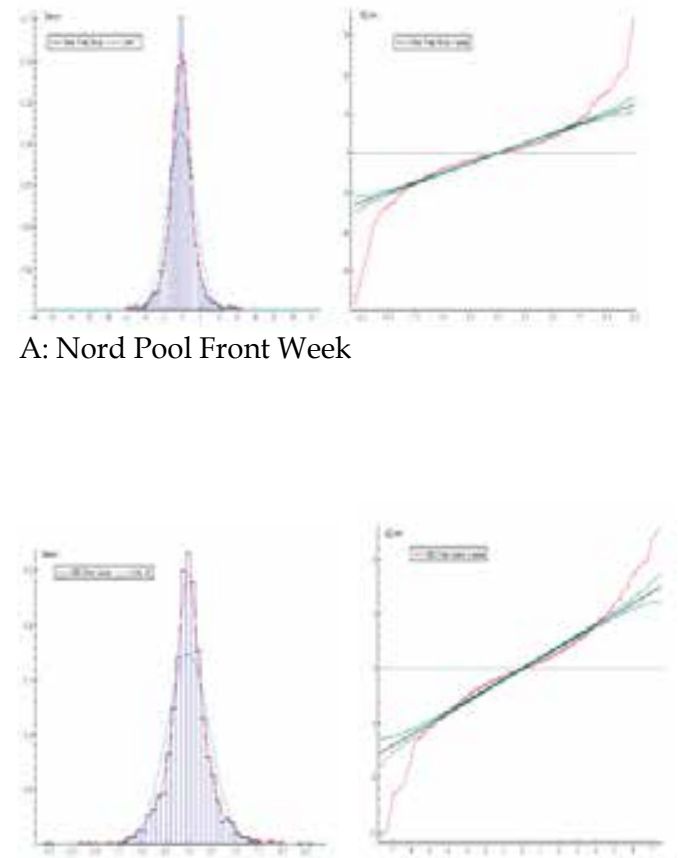

C: Nord Pool Front Month (base load)
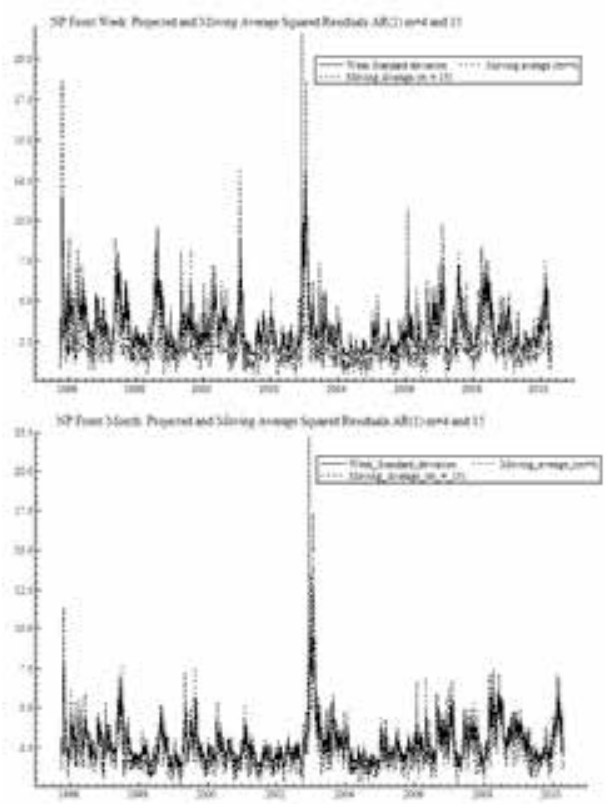
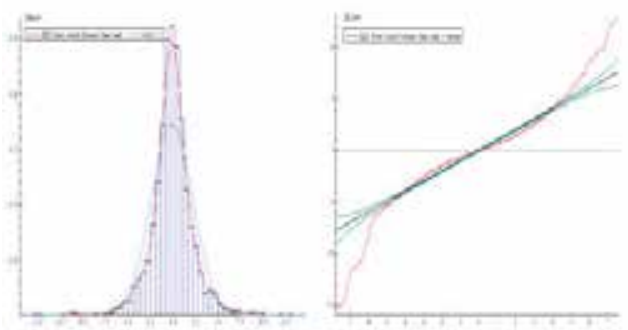

B: EEX Front Month (base load)
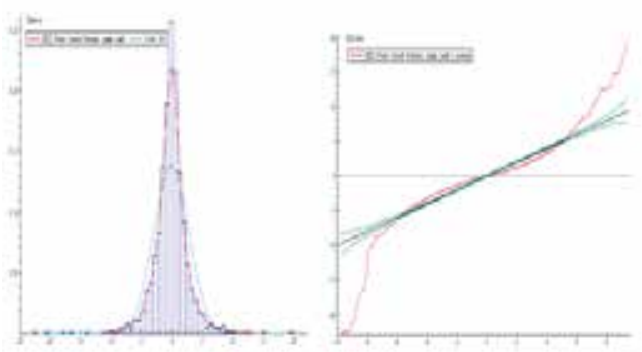

D: EEX Front Month Peak Load
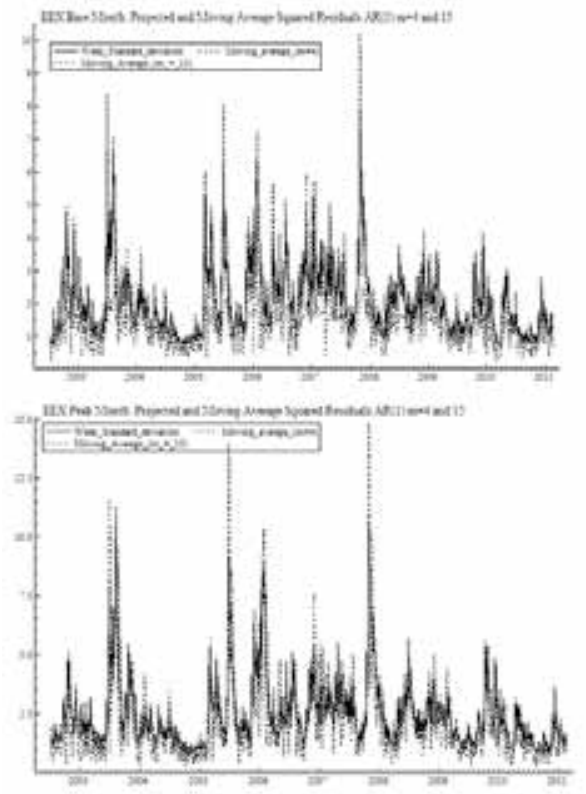

E: Nord Pool volatility clustering (conditional volatility) F: EEX volatility clustering (conditional volatility) 

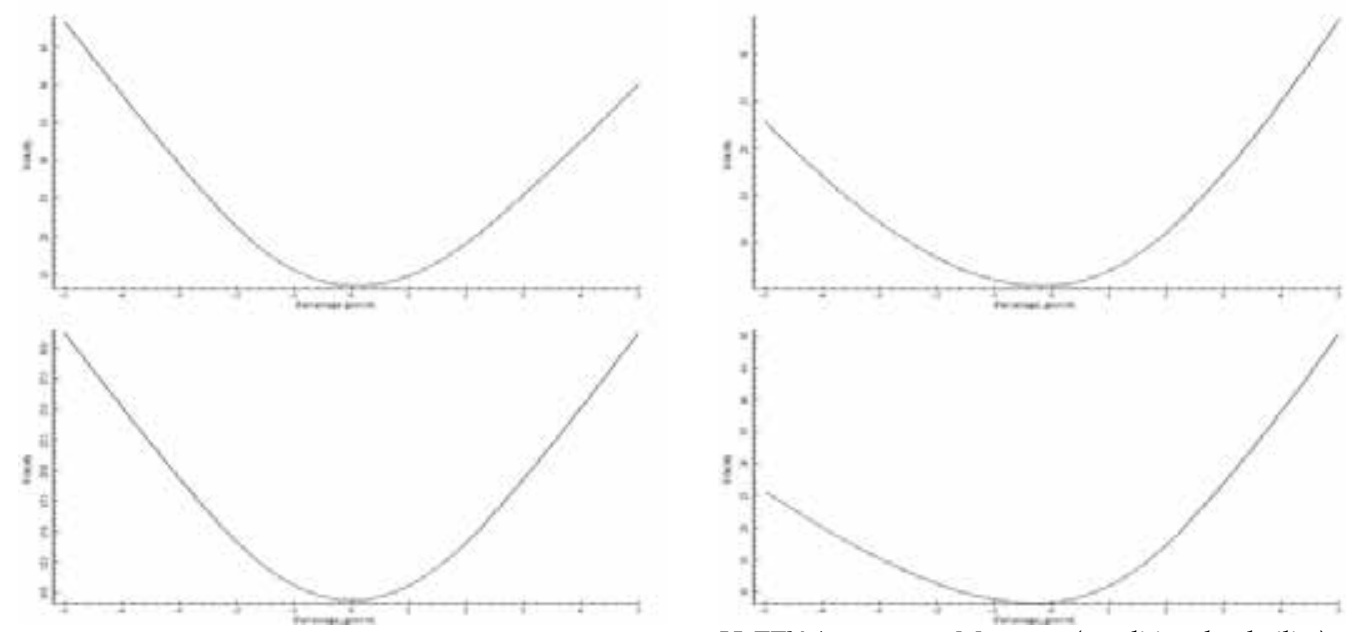

G: Nord Pool Asymmetry Measures (conditional volatility)

H: EEX Asymmetry Measures (conditional volatility)
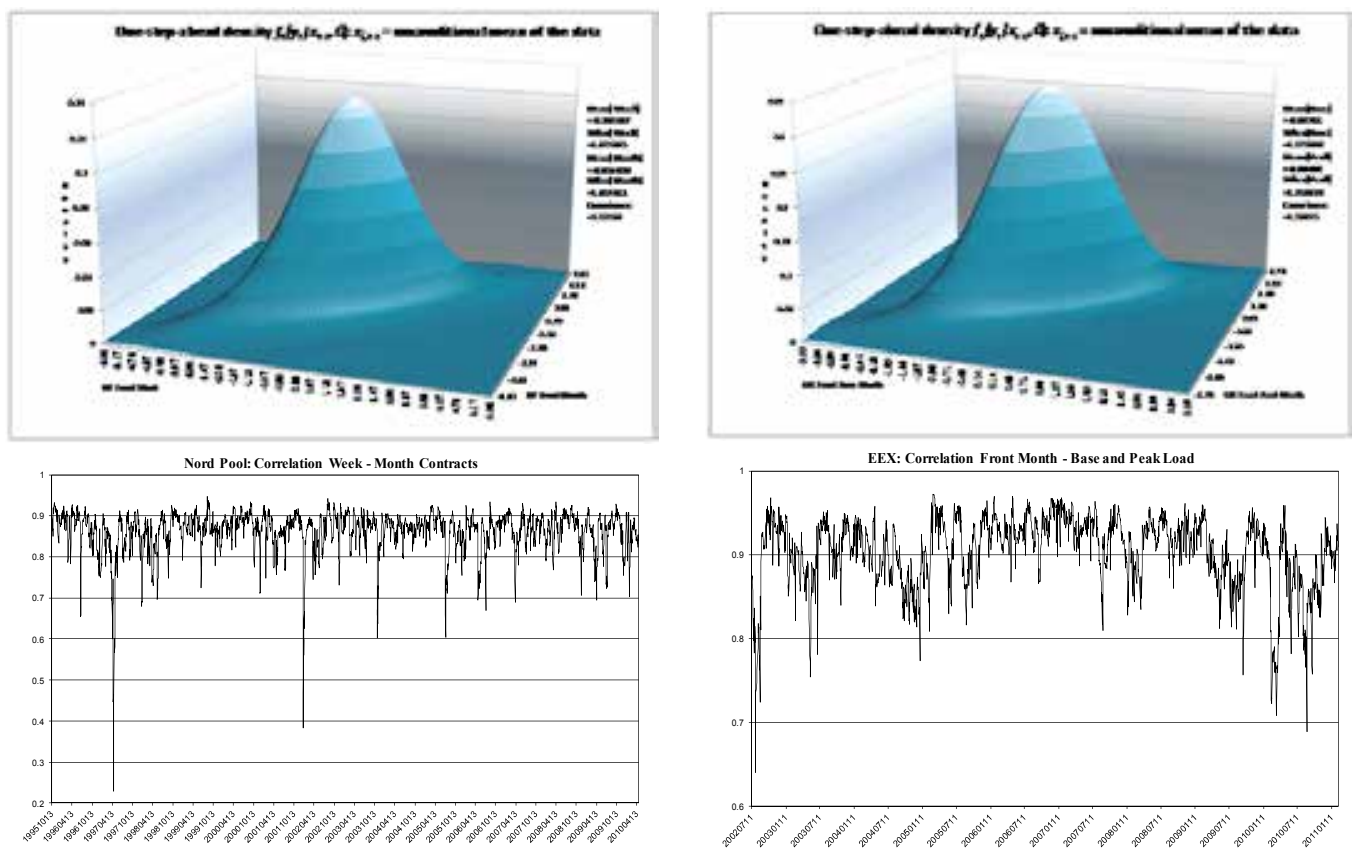

I: Nord Pool: Bivaraite Week-Month Density and Correlation J: EEX: Bivariate Months Density and Correlation

Fig. 2. Characteristics of Nord Pool and EEX Front Week/Month Forward/Future Contracts Nord Pool (www.nordpool.no) and EEX (www.eex.de)

positive asymmetry, that is - higher volatility from positive than negative price changes. In contrast, the Nord Pool week future contract report a low but significant negative asymmetry, in line with equity markets where the asymmetry is well known under "the leverage effect". Finally, panels I-J in Figure 2 report the bi-variate relationships in the Nord Pool and EEX markets. The distributions for the two markets show similar densities but 
clearly different mean and standard deviations. The correlations seem at a higher level in the Nord Pool bi-variate front week and month contracts relative to the EEX bi-variate front month base and peak load contracts. However, in some time periods the correlations are as low as $0.23 / 4$ for the Nord Pool market. Generally, the correlation seems high between financial instruments within the two energy markets.

The densities for the energy markets returns suggest heavy tail distributions that have relative to the normal distribution, more probability mass in the tails and in the middle, and less mass in the intermediate parts of the distribution. That is, small and large price changes are more likely and intermediate changes are less likely, relative to a normal distribution. An alternative to the normal distribution is the power law. The power law asserts that it is approximately true that the value $v$ of a variable has the property that, when $x$ is large $\operatorname{Prob}(v>x)=K \cdot x^{-\alpha}$ where $K$ and $\alpha$ are constants. The extreme Power Law has been found to be approximately true for variables at many and diverse applications. The equation is useful when we use extreme value theory for risk management purposes and is valuable for $\mathrm{VaR}$ and $\mathrm{CVaR}$ calculations. Extreme value theory can be used to improve VaR estimates and to deal with situations where the $V a R$ confidence level is very high. The theory provides a way of smoothing and extrapolating the tails of an empirical distribution.

Gnedenko (1943) stated that, for a wide range of cumulative distributions $F(x)$, the distribution of $F_{u}(y)=\frac{F(u+y)-F(u)}{1-F(u)}$ converges to a generalised Pareto distribution as the threshold $u$ is increased. The generalised Pareto distribution is defined with the formula $G_{\xi, \beta}(y)=1-\left(1+\xi \frac{y}{\beta}\right)^{-\frac{1}{\xi}-1}$. The distribution has two parameters that have to be estimated from the data set $(\xi, \beta)$. The $\xi$ parameter is the shape parameter and determines the heaviness of the tail of the distribution (a normal distribution has $\xi=0$ ). The parameter $\beta$ is the scale parameter. Estimating $\xi$ and $\beta$ can be done with maximum likelihood methods. We first differentiate the cumulative distribution function with respect to $y$ and obtain the probability density function $g_{\xi, \beta}(y)=\frac{1}{\beta}\left(1+\xi \frac{y}{\beta}\right)^{-\frac{1}{\xi}-1}$. We choose first $u$ close to the $95 \%$ percentile point of the empirical distribution. The focus is for observations $x>\mathrm{u}$. We now assume that there are $n_{u}$ such observations and they are $v_{i}\left(1 \leq i \leq n_{u}\right)$. The likelihood function becomes: $\prod_{t=1}^{n_{u}} \frac{1}{\beta}\left(1+\frac{\xi\left(v_{i}-u\right)}{\beta}\right)^{-\frac{1}{\xi}-1}$. Finally maximize its logarithm: $\sum_{t=1}^{n_{u}} \ln \left[\frac{1}{\beta}\left(1+\frac{\xi\left(v_{i}-u\right)}{\beta}\right)^{-\frac{1}{\xi}-1}\right]$. The probability that $v>u+y$ conditional on $v>u$ is $1-G_{\xi, \beta}(y)$. The probability that $v>u$ is $1-F(u)$. The unconditional probability that $v>x(x>u)$ is now $[1-F(u)]\left[1-G_{\xi, \beta}(x-u)\right]$. If $n$ is the total number of observations, an 
estimate of $[1-F(u)]$ calculated from the empirical data is $\frac{n_{u}}{n}$. The unconditional probability that $v>x$ is therefore $\operatorname{Prob}(v>x)=\frac{n_{u}}{n}\left[1-G_{\xi, \beta}(x-u)\right]=\frac{n_{u}}{n}\left[1+\xi \frac{(x-u)}{\beta}\right]^{-\frac{1}{\xi}}$.

For the equivalence to the power law, set $u=\frac{\beta}{\xi}$ and the equation reduces to $\operatorname{Prob}(v>x)=\frac{n_{u}}{n}\left[\xi \frac{x}{\beta}\right]^{-\frac{1}{\xi}}$ so that the probability of the variable being greater than $x$ is $K x^{-\alpha}$ (the power law) where $K=\frac{n_{u}}{n}\left[\frac{\xi}{\beta}\right]^{-\frac{1}{\xi}}$ and $\alpha=\frac{1}{\xi}$, implying that the $\operatorname{Prob}(v>x)$ is consistent with the power law. To calculate the $\mathrm{VaR}$ with a confidence level of $q$ it is necessary to solve the equation: $\quad F(V a R)=q$. We now use $q=1-\frac{n_{u}}{n}\left[1+\xi \frac{V a R-u}{\beta}\right]^{-\frac{1}{\xi}} \quad$ so that $\operatorname{VaR}=u+\frac{\beta}{\xi}\left[\frac{n}{n_{u}} \cdot(1-q)^{-\xi}-1\right]$. Finally, the expected shortfall ${ }^{13}(\mathrm{CVaR})$ becomes $C V a R=\left[\frac{V a R+\beta-\xi u}{1-\xi}\right]$.

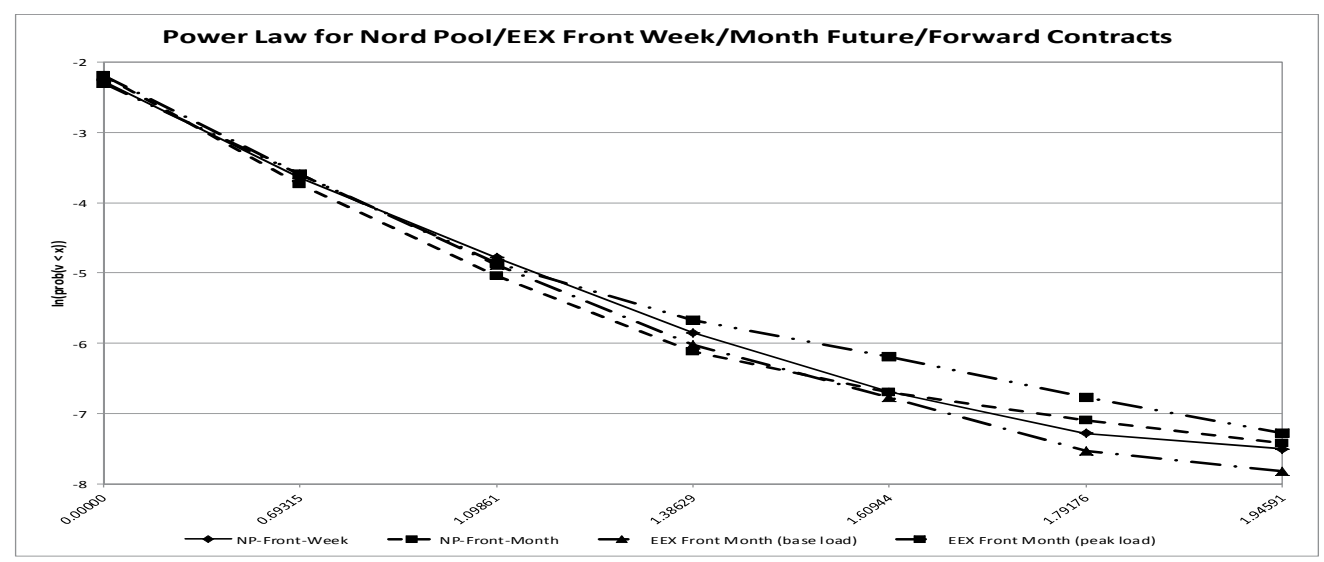

Fig. 3. The Power Law: Log plot for Electricity price increases: $x$ is the number of standard deviations; $v$ is the electricity price increase/decrease4. Stochastic volatility and risk assessment/management

${ }^{13}$ The choice of $u$ does not influence the estimate of $\operatorname{Prob}(v>x)$ much. $u$ should be approximately equal to the $95^{\text {th }}$ percentile of the empirical distribution. 
A test of whether the power law ${ }^{14}$ holds for the energy markets is to plot $\ln [\operatorname{Prob}(v>x)]$ against $\ln x$. For the time series from the energy markets Nord Pool and EEX, define $x$ as the number of standard deviations by which electricity prices decreases in one day. Figure 3 shows that the logarithm of the probability of the electricity price decreasing by more than $x$ standard deviations is approximately linearly dependent on $\ln x$ for $x>3$. The power law therefore seems to hold for energy market applications and we can therefore apply the extreme value theory for $\mathrm{VaR}$ and $\mathrm{CVaR}$ calculations.

\section{Stochastic volatility and risk assessment/management}

\subsection{The stochastic volatility model}

The model building approach implies a need for a scientific model for the mean and volatility using the MCMC (Markov Chained Monte Carlo) methodology to generate distributions for $y=\delta P$. A stochastic volatility (SV) model provide alternative models and methodologies to EWMA and (G)ARCH models. SV models specify a process for volatility and in the form used by Gallant et al. (1997) is formulated as:

$$
\begin{aligned}
& y_{t}=a_{0}+a_{1}\left(y_{t-1}-a_{0}\right)+\exp \left(v_{1 t}+v_{2 t}\right) \cdot u_{1 t} \\
& v_{1 t}=b_{0}+b_{1}\left(v_{1, t-1}-b_{0}\right)+u_{2 t} \\
& v_{2 t}=c_{0}+c_{1}\left(v_{2, t-1}-c_{0}\right)+u_{3 t} \\
& u_{1 t}=z_{1 t} \\
& u_{2 t}=s_{1}\left(r_{1} \cdot z_{1 t}+\sqrt{1-r_{1}^{2}} \cdot z_{2 t}\right) \\
& u_{3 t}=s_{2}\left(\sqrt{1-r_{2}^{2}-\left(\left(r_{3}-\left(r_{2} \cdot r_{1}\right)\right) / \sqrt{1-r_{1}^{2}}\right)^{2}} \cdot z_{3 t}\right)
\end{aligned}
$$

where $z_{i t}, i=1,2$ and 3 are standard Gaussian random variables. The parameter vector is $\rho=\left(a_{0}, a_{1}, b_{0}, b_{1}, s_{1}, c_{0}, c_{1}, s_{2}, r_{1}, r_{2}, r_{3}\right)$. The $r_{i}^{\prime}$ s are correlation coefficients from a Cholesky decomposition; enforcing an internally consistent variance/covariance matrix. Early references are Rosenberg (1972), Clark (1973) and Taylor (1982) and Tauchen and Pitts (1983). More recent references are Gallant, Hsieh, and Tauchen (1991, 1997), Andersen (1994), and Durham (2003), see Shephard (2004) and Taylor (2005) for more background and references. The model has three stochastic factor and extensions to four and more factors can be easily implemented through the model setup. The inclusion of a Poisson distribution to model jumps with the use of intensities, are applicable. Long memory can be formulated. The long-memory stochastic volatility model can be described as $u_{l t}=(1-L)^{-d} \cdot z_{\omega t}$ and $z_{\omega t}=\sum_{j=1}^{L_{\omega}} a_{j} \cdot z_{\omega t-j}+z_{1 t}$, valid for $|d|<1 / 2$, as described by Sowell (1990). Other extensions

14 The power law can be rewritten as: $\ln [\operatorname{Prob}(v>x)]=\ln K-\alpha \ln x$ very useful for regressions and the observing the possibility of empirically estimating $\ln K$ and $\alpha$ when the measure $\ln [\operatorname{Prob}(v>x)]$ can be calculated. 
of stochastic volatility models for better data fit are possible. Splines and t-errors have for example been applied (Gallant and Tauchen, 1997). Liquid financial market normally reports a much better model fit introducing three (or more) stochastic factors. The applicable extensions will be called upon when needed.

Note that writing the variance rate (volatility) as: $\sigma_{n}^{2}=\frac{1}{m} \sum_{i=1}^{m} y_{i-1}^{2}$ where $y_{i}^{2}$ is observation $i^{\prime}$ s squared return, is a particularly simple model for updating volatility estimates over time. The Exponentially Weighted Moving Average (EWMA) model, where weights $\alpha_{i}$ decrease exponentially as we move back through time $\left(\alpha_{i+1}=\lambda \cdot \alpha_{i}, 0 \leq \lambda \leq 1\right)$ is such a simple model. The formula becomes 15 : $\sigma_{i}^{2}=\lambda \cdot \sigma_{i-1}^{2}+(1-\lambda) \cdot y_{i-1}^{2}$ and can relatively easy be implemented by using for example the Excel spreadsheet and the Solver routine. Adding a constant term to this equation establish the (G)ARCH (generalised autoregressive conditional heteroscedastic) model. However, the number of EWMA/GARCH model reports/papers and the simple fact that both methodologies have limited theoretical justifications, the chapter will focus exclusively on the scientific SV model implementation for the Nord Pool and EEX energy markets. In fact, it is only the SV-model estimation and simulation that makes a bivariate Nord Pool - EEX market density estimation possible. The SV-model implementation use the computational methodology proposed by Gallant and McCulloch (2010) for statistical analysis of a stochastic volatility model derived from a scientific process. The scientific stochastic volatility model cannot generate likelihoods (latent variables) but it can be easily simulated. The VaR can now be calculated as the appropriate percentile of the distribution. The one-day $99.9 \% \mathrm{VaR}$ for a $100 k$ simulation $\triangle P$ series is the value for the $100^{\text {th }}$-worst outcome. The $99.9 \% \mathrm{CVaR}$ measure is the average of observations below the $99.9 \%$ percentile; that is, the average of the 100 observations.

\subsection{The Nord Pool and EEX front week/month stochastic volatility models}

The $y_{i, t}^{3644}\left(i=N P\right.$ Front Week / Month) and the $y_{i, t}^{2189}$ ( $i=$ EEX Front Month Base / Peak Load) is the percentage change (logarithmic) over a short time interval (day) of the price of a financial asset traded on an active speculative market. The SV model implementation established a mapping between a statistical model and a scientific model and the adjustment for actual number of observations and number of simulation must be carefully logged for final model assessment. For the SV model implementation reasonable starting values are important. The implementation of the scientific model is a lengthy sequential process which is finalized with a $25 \mathrm{CPU}$ parallel computing run applying the Open-message passing interface $^{16}$ (Open-MPI).

${ }^{15}$ To understand why this equation corresponds to weights that decrease exponentially, substitute $\sigma_{i-1}^{2}$ with $\lambda \cdot \sigma_{i-2}^{2}+(1-\lambda) \cdot u_{i-2}^{2}$. The substitution produce: $\sigma_{i}^{2}=(1-\lambda) \cdot \sum_{j=1}^{m}\left(\lambda^{j-1} \cdot u_{i-j}^{2}\right)+\lambda^{m} \cdot \sigma_{i-m}^{2}$. For large $m$ the last term $\lambda^{m} \cdot \sigma_{i-m}^{2}$ is small enough to be ignored.

16 Open-MPI is a high-performance, freely available, open source implementation of the MPI standard that is researched, developed, and maintained at the Open System Lab at Indiana University (www.open-mpi.org). 
SV model extensions are condition specific. The extensions are analysed from both the score model $\left(f_{k}()\right)$ and from characteristics of the EMM implementation. The $f_{k}()$ indicates the starting values and active SV model parameters for the EMM estimation. The normalised scores quasi t-statistics indicate score failures and need for SV model extensions. Finally, the Bayesian $\log$ posterior $\chi^{2}$ test statistic and the Epanechnikov kernel density plots of parameters and functional statistics (stats) assesses SV model optimality or fit. These optimization routines together with an associated 25 iterative run for a comprehensive model assessments, establish the empirical foundation of the Bayesian MCMC estimation reports. The implementation of the 3x8-/2x12-core CPUs generates 240,000 simulated paths for the stochastic volatility model. The Bayesian MCMC M-H algorithm $\alpha^{*}$ optimal model from the 24-core CPU parallel run model is reported in Table 3. The mode, mean and standard errors are reported for the four series. For all models the optimal Bayesian log posterior value is reported together with the $\chi^{2}$ test statistic. Moreover, all the score diagnostics (not reported) are all well below 2.0 in value 17 . The first important observation from Table 3 is the four $\chi^{2}(\mathrm{df})$ rejection statistics for the multifactor SV models. None of the SV models are rejected at the 5\% significance level. Moreover, the model diagnostics do not identify score moments that are rejected $(>2)$. The SV models are therefore found accepted for extended commodity market analyses. Table 3 suggests some important differences between Nord Pool and EEX. The Nord Pool week contracts show the largest negative drift, inducing a positive risk premium that is traded the last week before contract maturity. The three other monthly forward products show all lower but negative drift. The volatility seems highest for the Nord Pool week contracts (which also have the shortest time to maturity) ${ }^{18}$. Finally, the analysis shows interesting mean - volatility correlation structures for the EEX market. The asymmetry is found for both volatility factors. The first factor report a positive asymmetry (largest) and the second volatility factor reports a negative factor. From the initial plots in Figure 2, the positive factor seems to dominate asymmetry for EEX. For the Nord Pool the correlation structure seems close to zero and insignificant. That is, asymmetry and non-linearity seems higher for the EEX market than for Nord Pool, which is close to negligible.

The multi-equation SV model reported in Table 3 can now be easily simulated at any length. First, Figure 4 reports plot of standard deviation versus returns for the original series with 3644 observations for Nord Pool (left: panel A and B) and 2189 observations for EEX (right: panel $C$ and D) in the upper part of the figures and a simulated series with $100 k$ observations right below. From these plots we can find signs of positive volatility asymmetry for the EEX market, while Nord Pool shows little or no volatility asymmetry. However, the standard deviations over time $(t)$ seem quite symmetric around negative and positive returns for all contracts. The asymmetry coefficients in Table 3 , where we find that Nord Pool shows close to zero and insignificant asymmetry while the EEX market reports significant and positive asymmetry.

In particular, note that relative to the negative asymmetry found for equity markets the asymmetry for the EEX energy market is positive. The positive asymmetry can be explained by production/grid capacity constraints. Figure 5 shows volatility scatter plots which are

${ }_{17}$ The standard errors are biased upwards (Newey, 1985 and Tauchen, 1985) so the quasi t-ratios are downward biased relative to 2.0. Hence, a quasi-t-statistic above 2.0 indicates failure to fit the corresponding score.

${ }^{18}$ See Samuelson (1965) for the volatility hypothesis. 
plots of $y_{\mathrm{t}}-y_{\mathrm{t}-1}$ versus $y_{\mathrm{t}-1}$. The raw data (Nord Pool: 3644 and EEX: 2189 points) are plotted in the upper part and a simulated data set (100 k points) is plotted in the lower part of each plot. Interestingly, the SV specification seems to mimic the general characteristic of the raw time series.

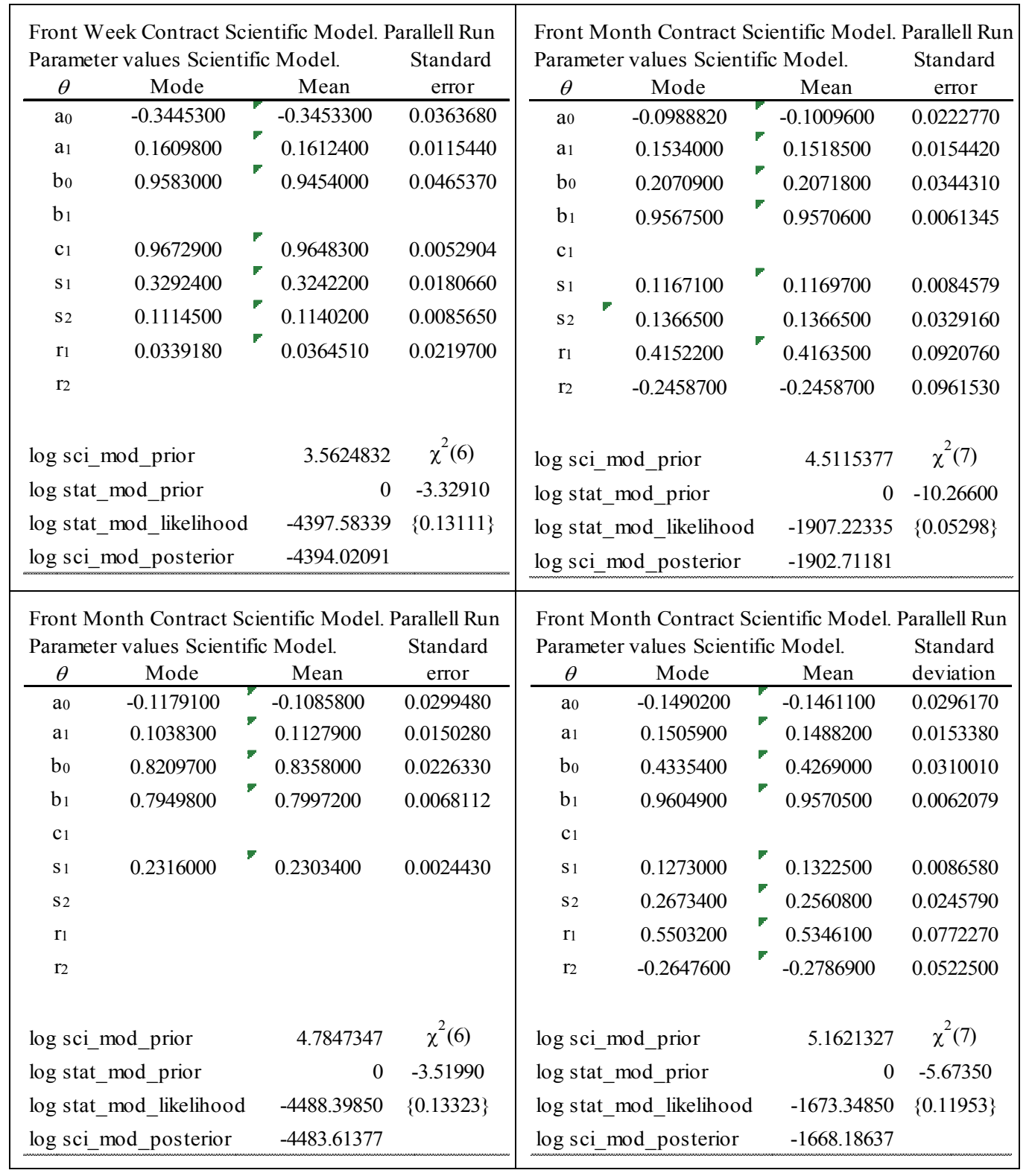

Table 3. Scientific Stochastic Volatility Characteristics for Nord Pool/EEX: the $\theta$-parameters 
The mean and variance results for the Nord Pool and EEX energy market contracts are summarised below. The Nord Pool week future contracts show a negative daily mean of 0.323 inducing a yearly negative drift of $-81.4 \%(-0.323 * 252$ days $)$. That is, a strategy of selling futures Friday the week before maturity and buying back/closing out the last day of trading/ at maturity seem to be a very profitable strategy. The high negative drift (risk premium) suggests a high yearly return. However, the volatility measured by the daily standard deviation is $3.49 \%$ indicating a yearly volatility of $55.44 \%$. The Nord Pool onemonth forward contracts have a mean daily drift of $-0.134 \%$ ( $-33.85 \%$ per year). The volatility measured by the daily standard deviation is $2.61 \%$ indicating a yearly volatility of $41.5 \%$. Generally, both the mean and standard deviation numbers from these Nord Pool contracts are high for financial markets. The drift numbers for the EEX contracts are for the front month base (peak) $-0.089(-0.168)$ inducing a yearly negative drift of $-22.36 \%(-42.22 \%)$. The EEX base (peak) month volatility measured by the daily standard deviation is $1.48 \%$ $(2.04 \%)$ indicating a yearly volatility of $23.52 \%$ (32.41\%).
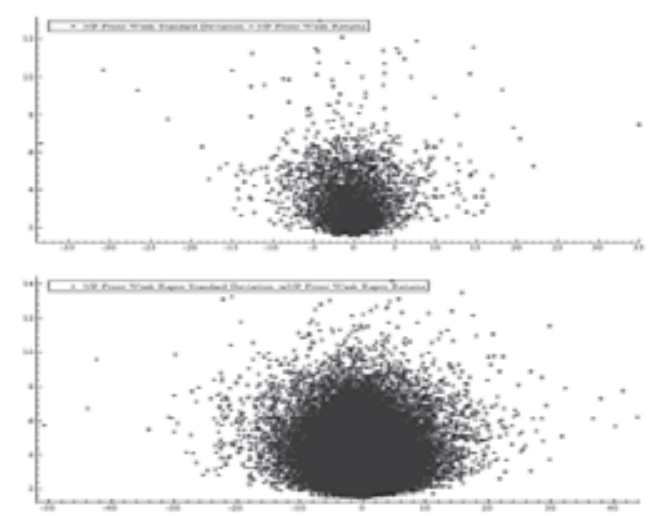

A: Nord Pool Std Deviation vrs Returns Week
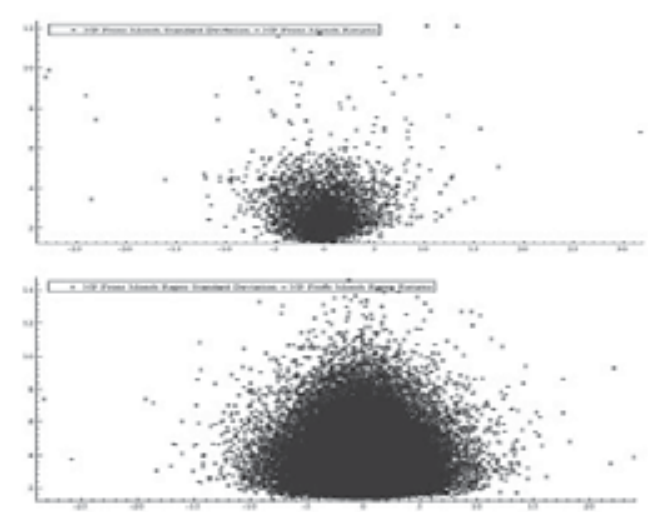

B: Nord Pool Std Deviation vrs Returns Month

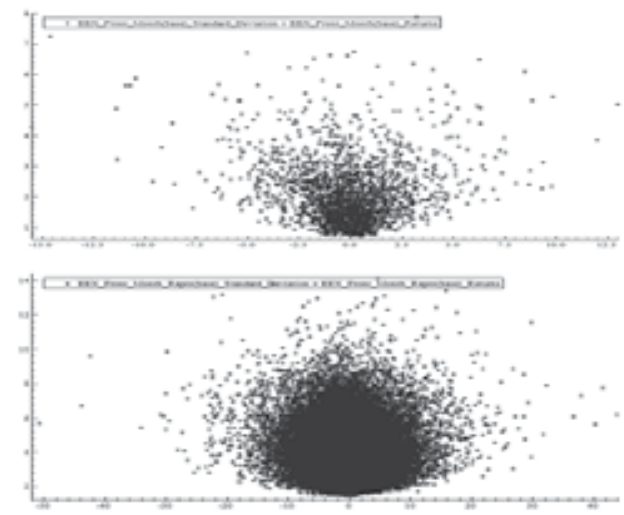

C: EEX Std Deviation vrs Returns Month (base)
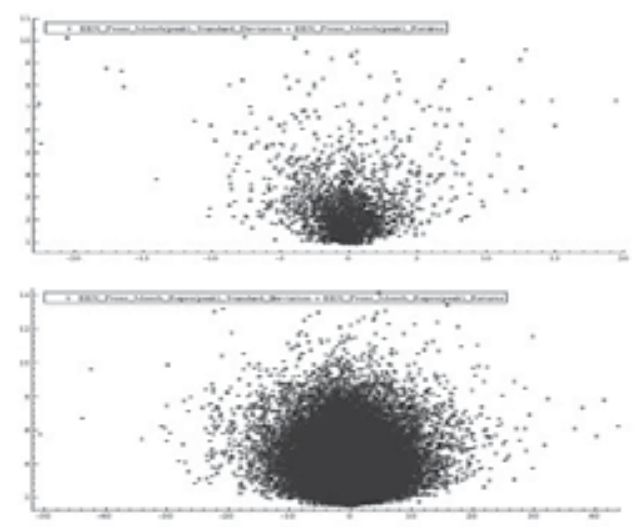

D: EEX Std Deviation vrs Returns Month (peak)

Fig. 4. Nord Pool and EEX Standard deviations versus Returns. 


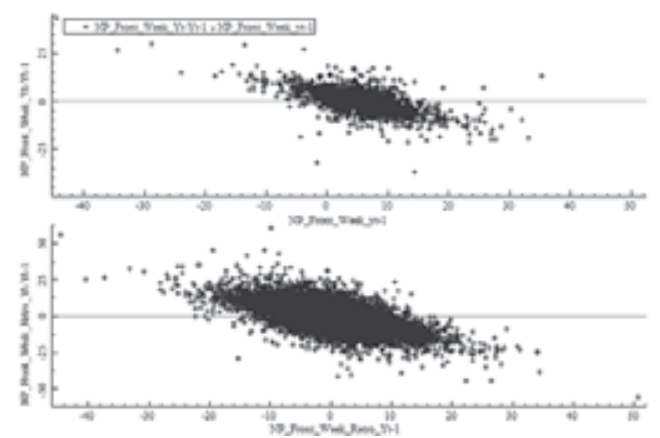

A: Nord Pool Front Week Yt-1-Yt vrs Yt-1
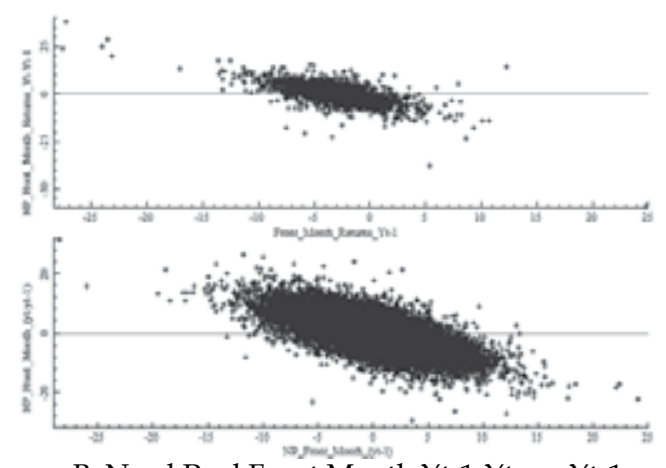

B: Nord Pool Front Month Yt-1-Yt vrs Yt-1
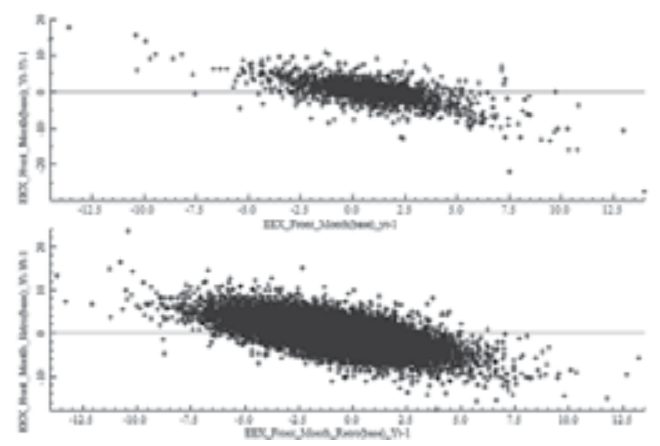

C: EEX Front Month (base load) Yt-1-Yt vrs Yt-1
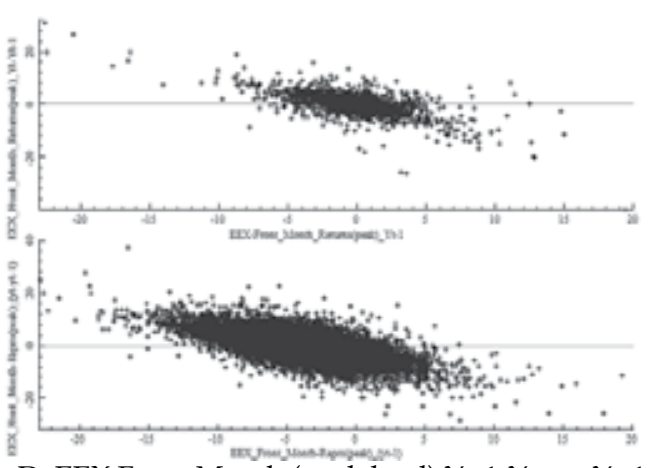

D: EEX Front Month (peak load) Yt-1-Yt vrs Yt-1

Fig. 5. Nord Pool and EEX Return differences $y_{t}-y_{t-1}$ versus Returns $y_{t-1}$. 

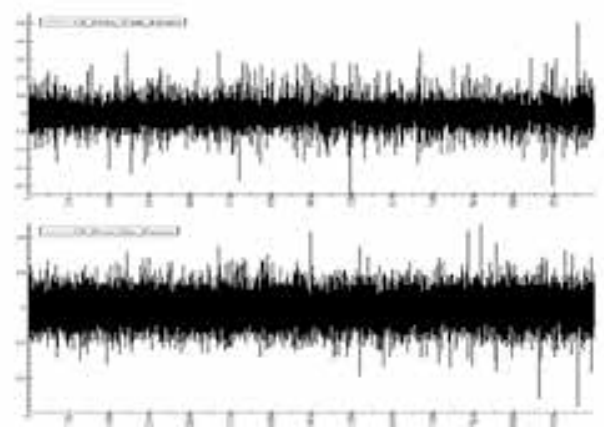

A: Mean Simulations (100 k)
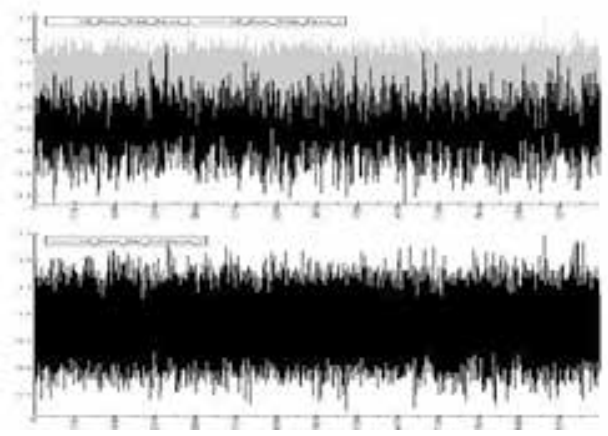

C: Volatility Factor Simulations (100 k)
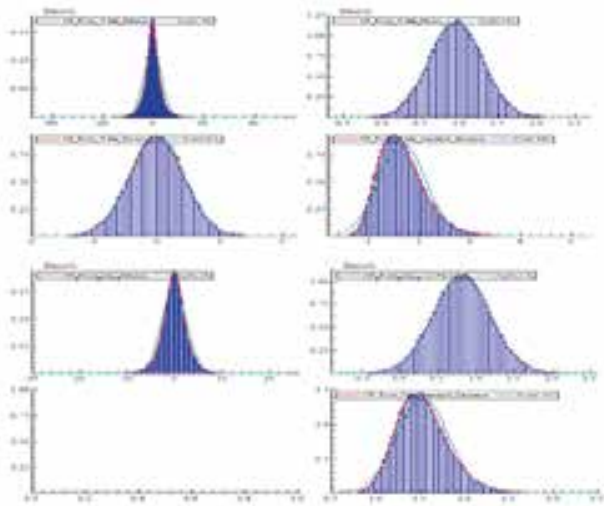

E: Distributional Density Characteristics (100 k)

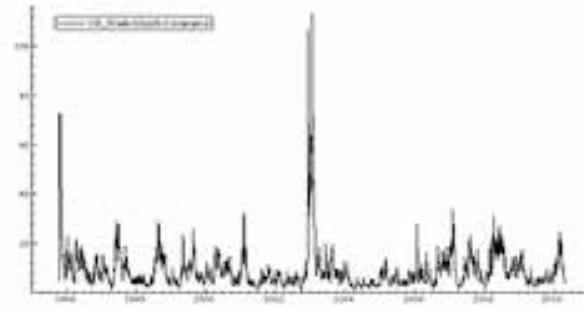

Nord Pool Covariance Week - Month Contracts
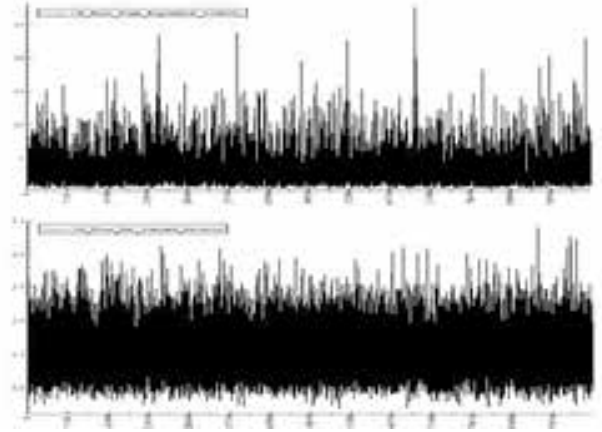

B: Exponential Volatility Simulations (100 k)
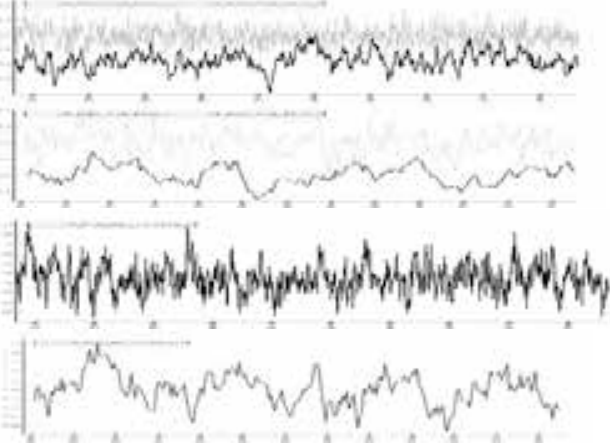

D: Subsamples Volatility Factor Simulations (100 k)
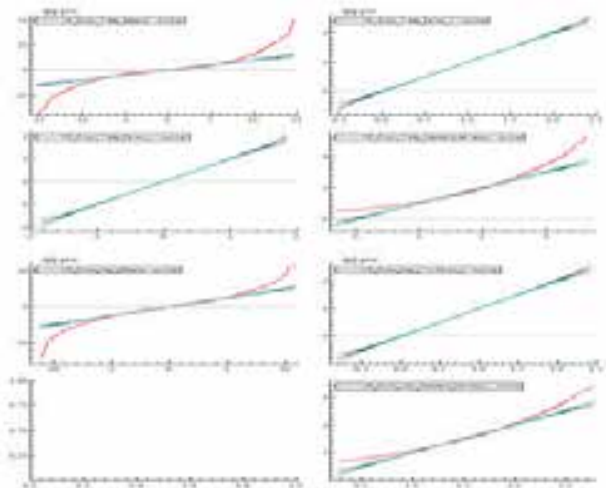

F: QQ-plot Characteristics (100 k)

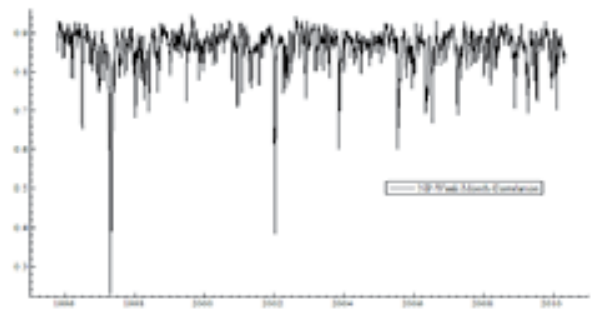

H: Nord Pool Correlation Week - Month Contracts

Fig. 6. Nord Pool SV model Characteristics for Future Week and Forward Month Contracts 

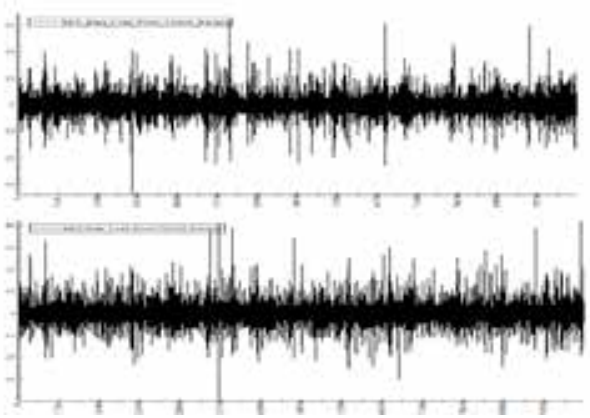

A: Mean Simulations $(100 \mathrm{k})$
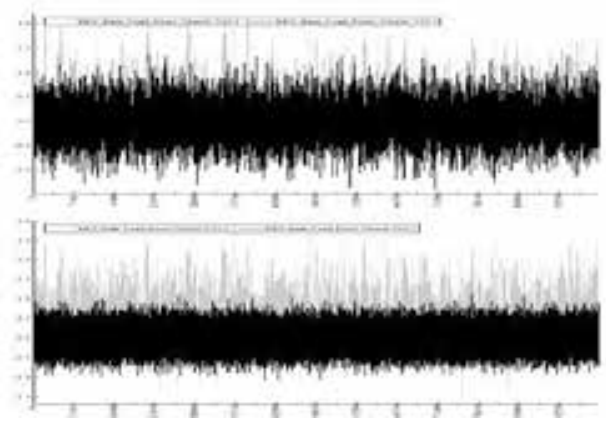

C: Volatility Factor Simulations (100 k)

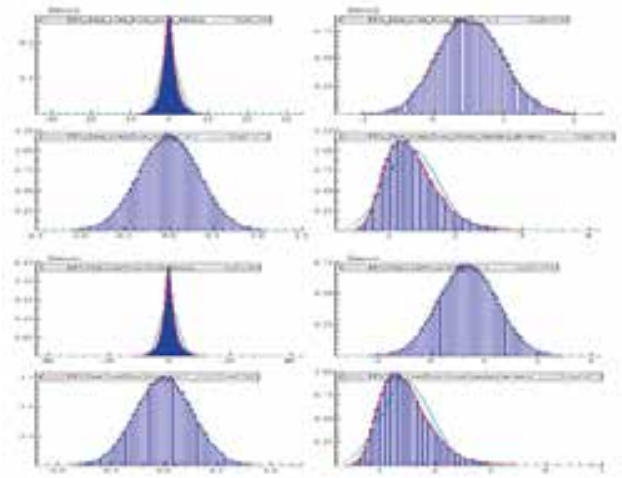

E: Distributional Density Characteristics (100 k)

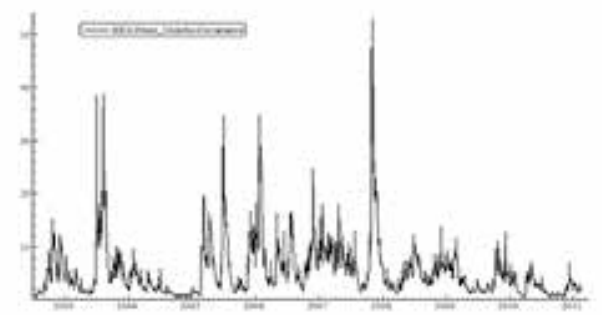

G: EEX Covariance Month Base-Peak Contracts
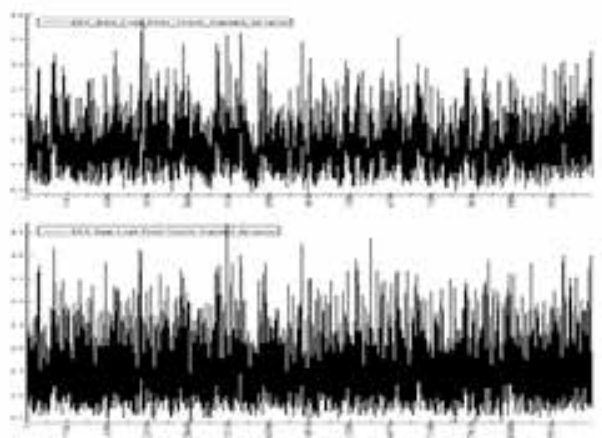

B: Exponential Volatility Simulations (100 k)

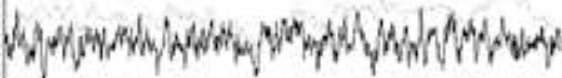

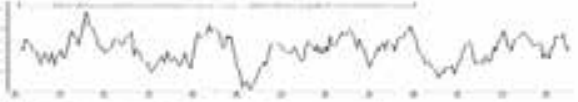

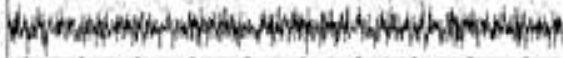

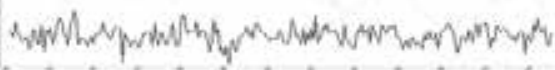

D: Subsamples Volatility Factor Simulations (100 k)
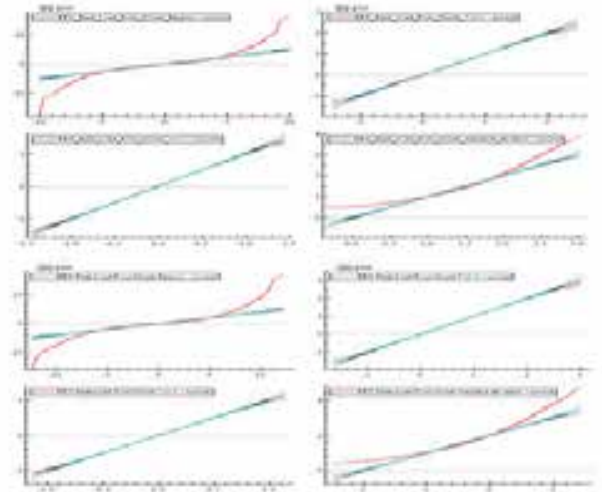

F: QQ-plot Characteristics (100 k)

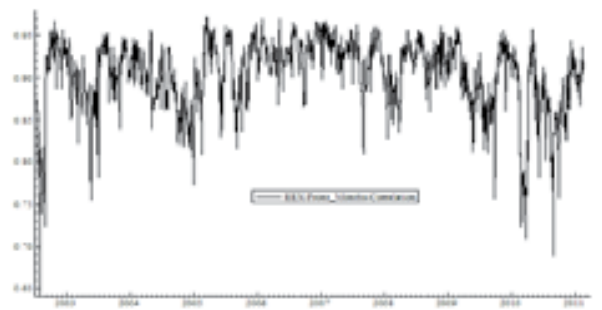

H: EEX Correlation - Month Base-Peak Contracts

Fig. 7. EEX SV model Characteristics for Future Month Contracts (base and peak load) 
Distributional features of the mean and volatility equations from a functional simulation $(100 k)$ of the Nord Pool and EEX commodity markets are reported in Figure 6 (Nord Pool) and Figure 7 (EEX). The top plots report a full-simulation of the mean (left) and the exponential volatility (right); the middle report the full-sample paths of the two volatility factors together with sub-samples for the two volatility factors (right). From the plots to the right we see that the first factor reports a quite choppy behaviour with lower persistence (solid-line) while the second factor is smoother with higher persistence (dotted-line). The result confirms the interpretation of Table 3. The two factors seem to represent quite different processes inducing volatility processes that originate from informational flow from several sources. In the middle bottom plots (panel E and F) we have reported the densities (left) and the $Q Q$-plots (right) for the mean, the two volatility factors and the exponential volatility (standard deviation). The one/two volatility factors seem normally distributed while the mean have inherited the non-normal features from the original plots in Figure 2 and the exponential volatility seem log-normal distributed as would be expected using the exponential functions for normally distributed variables. Finally in the bottom plots (panel $\mathrm{G}$ and $\mathrm{H}$ ) the co-variance is reported in the left plot and the correlation to the right. For both markets the correlation seems high with only minor exceptions towards a correlation of 0.25 for the Nord Pool market and toward 0.5 for the EEX market.

Irrespective of markets and contracts, Monte Carlo Simulations should lead us to a deeper insight of the nature of the price processes that can be described by stochastic volatility models. The results are close to the moment based (non-linear optimizers) techniques adjusting for a more robust model specification (but at a higher dimension). The Bayesian $\mathrm{M}-\mathrm{H} \alpha^{*}$ technique also helps to keep the model parameters in the region where the predicted shares are positive.

\subsection{Market risk management measures and the conditional moments forecasts}

For the mean and volatility forecasting we can simply use the fitted SV model in each iteration to generate samples for the forecasting period. Point forecasts of the return $\left(y_{t+1}\right)$ and volatility $\left(e^{v_{1, t+1}+v_{2, t+1}}\right)$ are simply the sample means of the two random samples.

Similarly, the sample standard deviations can be used as the standard deviations of forecast errors. The MCMC method produces a predictive distribution of the mean and volatility. The predictive distributions are more informative than simple point forecasts. Quartiles are readily available for $\mathrm{VaR}$ and $\mathrm{CVaR}$ calculations for example. Figure 8 reports densities for the mean and the exponential volatility for a $100 k$ simulation of the optimally estimated SV models. The percentiles of the densities can be extracted and associated VaR and CVaR values are therefore also reported in Figure 8 using percentage notation. From Figure 8 and for the Nord Pool week contracts (long positions) the $99.9 \% \mathrm{VaR}(\mathrm{CVaR})$ is $-0,1729(-0,2165)$, giving an average daily loss of $€ 172,919$ (€216,509) for a 1 million Euro portfolio. The $99.9 \%$ $\mathrm{VaR}$ and $\mathrm{CVaR}$ for an EEX peak front month contract portfolio of 1 million Euro is $€ 103,044$ and $€ 124,408$, respectively. The SV-model results give us also immediate access to the Greek Letters (a contract with an exercise price must be quoted). Hence, as VaR and Greek letters are accessible for every stochastic run both methods will be available for reporting in distributional forms. The $\mathrm{VaR}$ and $\mathrm{CVaR}$ is calculated using extreme value theory (EVT ${ }^{19}$ )

${ }^{19}$ For applications of the EVT, it is important to check for log-linearity of the Power Law $(\operatorname{Prob}(v>x)=$ $\mathrm{Kx}-\alpha$ ). See section 3.2 above. 
for smoothing out the tail results. Applying the estimated SV-model for $10 k$ simulations and 1 million Euro invested in the front contracts, a maximum likelihood optimization of $97.5 \%$, 99.0\%, 99.5\% and 99.9\% $\mathrm{VaR}$ and expected shortfall (CVaR) calculations are reported in Figure 9. The VaR and CVaR densities using EVT are credible, are clearly related to the VaR and $\mathrm{CVaR}$ values reported using the optimal SV-model percentiles in Figure 8, and the density means seem higher. In fact, optimal forecast percentiles are only in the left part of the EVT-tails. The EVT-tails of the VaR and CVaR densities must be of considerable interest to risk managers engaged in commodity markets. The mean and standard deviation for the EVT calculated $\mathrm{VaR}(\mathrm{CVaR})$ can be extracted from the underlying distributions. For example, from Figure 9, the Nord Pool week future contracts Var (CVaR) numbers with associated standard errors becomes $0.1809 ; 0.0217 \quad(0.2239 ; 0.0332), \quad 0.1243 ; 0.0115$ $(0.1604 ; 0.0183), 0.1026 ; 0.0084(0.1363 ; 0.0139)$, and $0.0763 ; 0.0052(0.1069 ; 0.0093)$ for $99.9 \%$, $99.5 \%, 99.0 \%$ and $97.5 \%$ percentiles, respectively. SV model simulations and the EVT calculated $\mathrm{VaR}$ and $\mathrm{CVaR}$ numbers seem to indicate higher values for both markets and all contracts relative to SV optimal forecast model. High volatilities induce risky instruments and rather high $\mathrm{VaR} / \mathrm{CVaR}$ values for the European energy market.
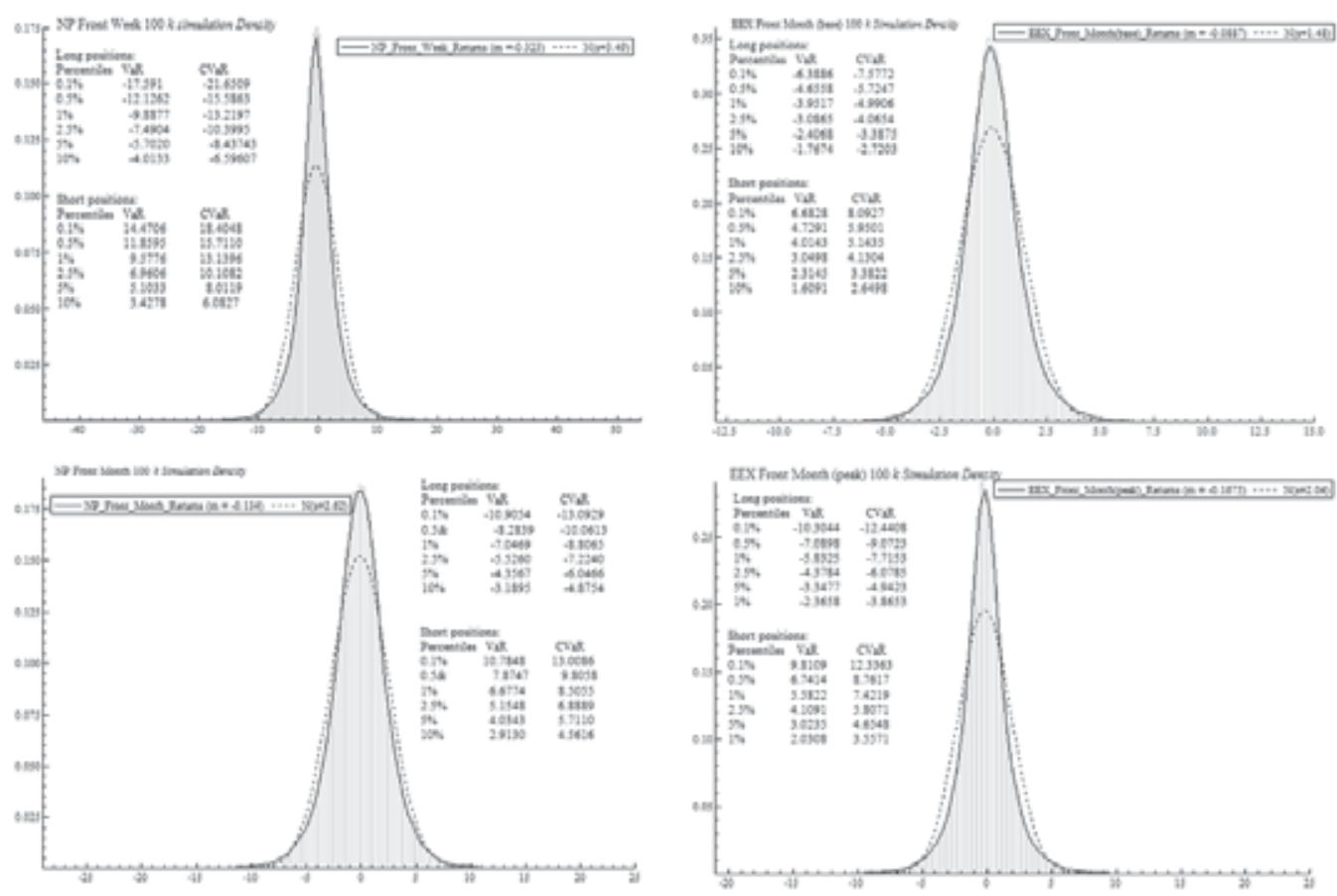

A: Nord Pool Forecasted Mean Densities

B: EEX Forecasted Mean Densities

Fig. 8. Forecasted Densities with associated VaR and CVaR values for Nord Pool and EEX 

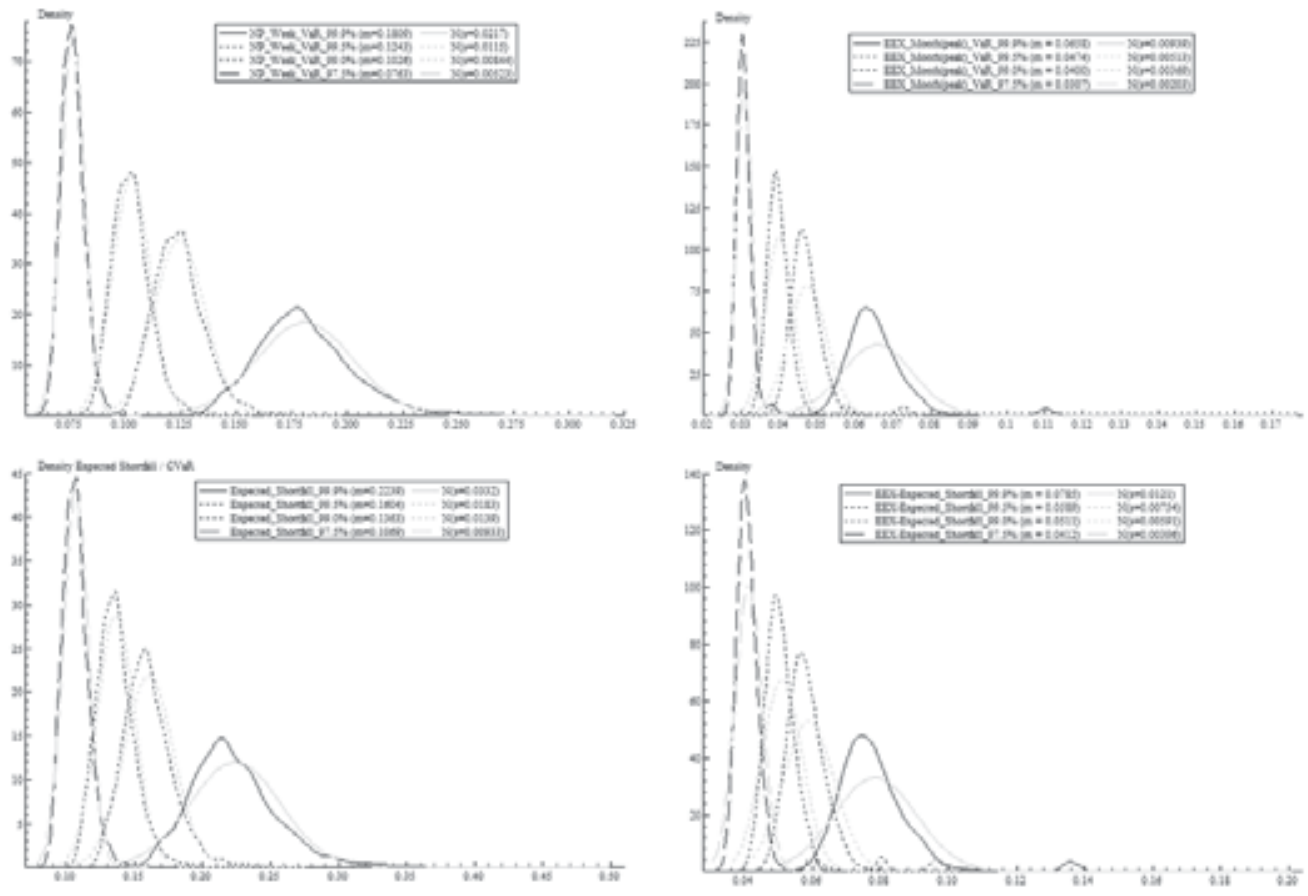

A: NP Front Week VaR and CVaR Densities

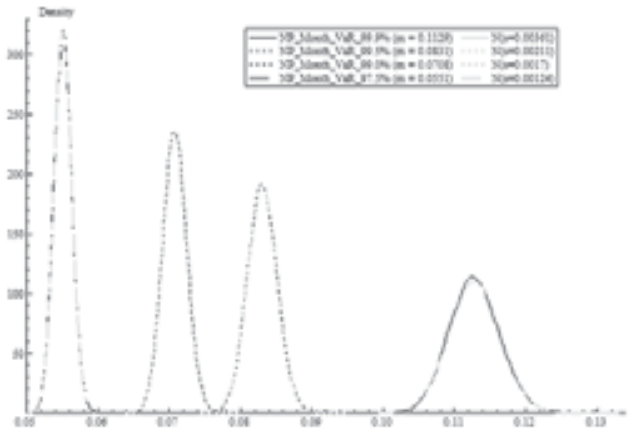

C: EEX FM (base load) VaR and CVaR Densities
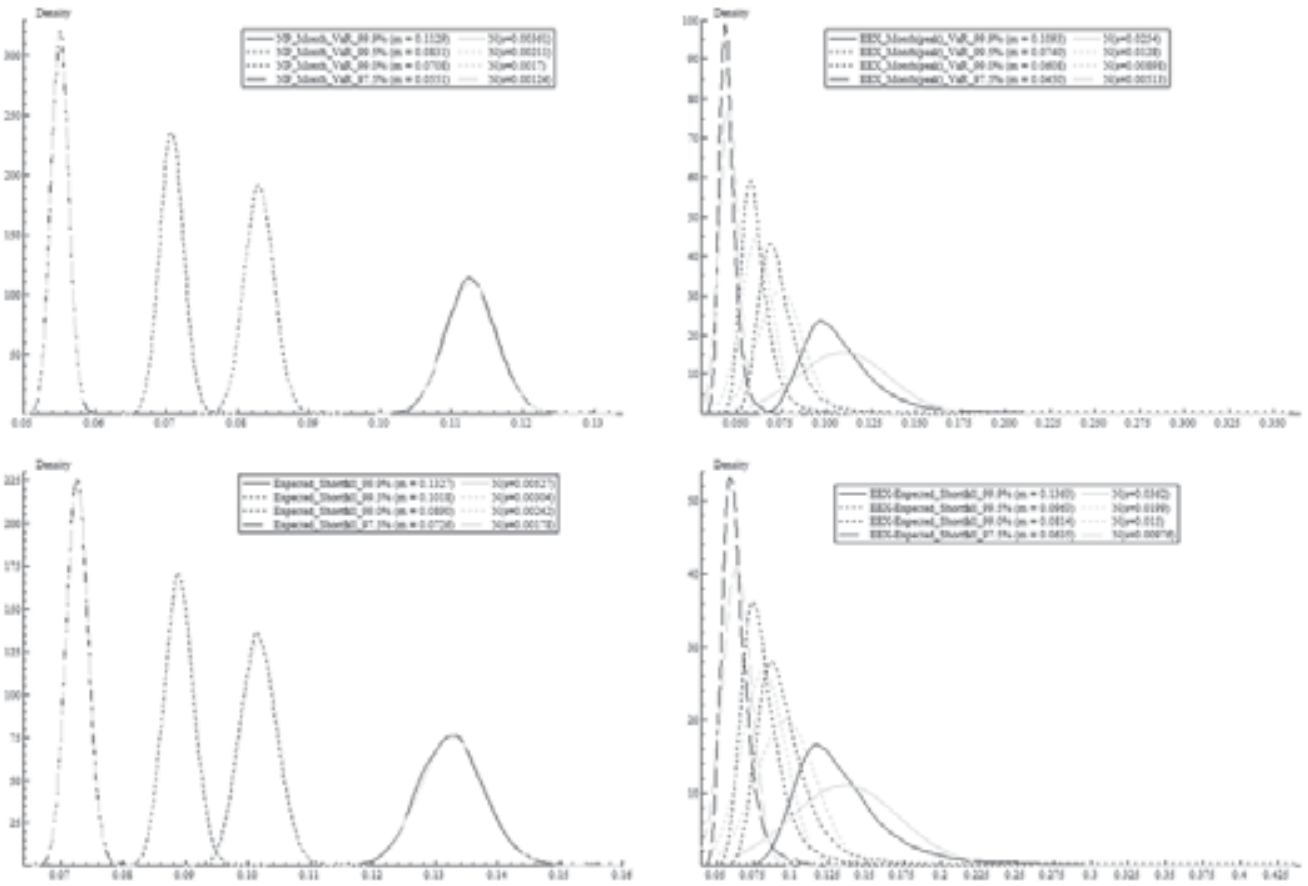

B: NP Front Month VaR and CVaR Densities

D: EEX FM (peak load) VaR and CVaR Densities

Fig. 9. VaR and CVaR (expected shortfall) Densities Nord Pool and EEX using EVT 
The Greek letters can be calculated for all stipulated contract prices using the Broadie and Glasserman formulas (1996). The Gamma ( $\gamma$ ) letter is not stochastic but deterministic and can be derived using the classical deterministic formula. Applying the estimated SV-model for $10 \mathrm{k}$ simulations, the Greek letter densities (delta, (gamma), rho and theta) are reported in Figure 10 for ATM call and put options (only the delta density is reported). The Nord Pool front week call-option delta density for example has a mean of 0.4484 (below 0.5 due to negative drift) with associated standard error of 0.0078 . Gamma is deterministic and becomes 0.3742 . The values for rho and theta are 6.5592 and 1.2582 with associated standard errors of 0.1110 and 0.1653, respectively. Considering the relatively high values for $\mathrm{VaR}$ and $\mathrm{CVaR}$ in these commodity markets there may be some value in a procedure helping the risk management activities. Fortunately, a procedure for post estimation analysis and forecasting is accessible. The post estimation analysis we will apply is the final and third step described by Gallant and Tauchen (1998), the re-projection step (see appendix I). The step brings the real strengths to the methodology in building scientific valid models for commodity markets.

The re-projection methodology gets a representation of the observed process in terms of observables that incorporate the dynamics implied by the non-linear system under consideration. The post estimation analysis of simulations entails prediction, filtering and general SV model assessment. Having the GSM estimate of system parameters for our models, we can simulate a long realization of the state vector. Working within this simulation, univariate as well as multivariate, we can calibrate the functional form of the conditional distributions. To approximate the SV-model result using the score generator $\left(\hat{f}_{K}\right)$ values, it is natural to reuse the values of the previous projection step. For multivariate applications, the optimal BIC/AIC criterion (Schwarz, 78) would be a sufficient criterion. The dynamics of the first two one-step-ahead conditional moments (including co-variances) may contain important information for all market participants. Starting with the univariate case, Figure 11 shows the first moment $\left(E\left[y_{0} \mid x_{-1}\right]\right)$ densities to the left and the second moment $\left(\operatorname{Var}\left[y_{0} \mid x_{-1}\right]\right)$ densities to the right. The first moment information conditional on all historical available data shows the one-day-ahead density. This is informative for daily risk assessment and management ${ }^{20}$. To calculate the one-step-ahead $\mathrm{VaR}$ and CVaR we again use the extreme value theory to smooth out the tails. VaR (CVaR) numbers for the contracts are reported in Table 4. For the Nord Pool front week for example the VaR (CVaR) for $99.9 \%$, and $97.5 \%$ are $3.33(4.10)$ and 1.55 (2.06), respectively. The one-day-ahead forecasts conditional on all history of price changes and volatilities reduces in this case, the

\footnotetext{
${ }^{20}$ We use a transformation for lags of $x t$ to avoid the optimisation algorithm using an extreme value in $\mathrm{xt}-1$ to fit an element of yt nearly exactly and thereby reducing the corresponding conditional variance to near zero and inflating the likelihood (endemic to all procedures adjusting variance on the basis of observed explanatory variables). The trigonometric spline transformation is:$$
\hat{x}_{i}=\left\{\begin{array}{lr}
1 / 2\left\{x_{i}+4 / \pi\left(\arctan \left[\pi / 4\left(x_{i}+\sigma_{t r}\right)\right]\right)-\sigma_{t r}\right\} & -\infty<x_{i}<-\sigma_{t r} \\
x_{i} & -\sigma_{t r}<x_{i}<\sigma_{t r} \\
1 / 2\left\{x_{i}+4 / \pi\left(\arctan \left[\pi / 4\left(x_{i}-\sigma_{t r}\right)\right]\right)+\sigma_{t r}\right\} & \sigma_{t r}<x_{i}<\infty
\end{array}\right. \text {. The transform has negligible effect }
$$

on values of xi between $-\sigma \operatorname{tr}$ and $+\sigma \operatorname{tr}$ but progressively compress values that exceed $\pm \sigma \operatorname{tr}$ so they can be bounded by $\pm 2 \sigma$ tr. 


\begin{tabular}{|c|c|c|c|c|c|c|c|c|}
\hline \multirow{3}{*}{$\begin{array}{l}\text { Confidence } \\
\text { levels: }\end{array}$} & \multicolumn{4}{|c|}{$\begin{array}{l}\text { Univariate (long positions) } \\
\text { Nord Pool }\end{array}$} & \multicolumn{4}{|l|}{ EEX } \\
\hline & $\overline{\text { Front We }}$ & eek & Front $\mathrm{Mo}$ & onth & Base Mc & onth & Peak Mo & onth \\
\hline & VaR & CVaR & VaR & CVaR & VaR & CVaR & VaR & CVaR \\
\hline & 0.0333 & & 0.0240 & & 0.0195 & & 0.0246 & 0.0302 \\
\hline & & & & & & & & \\
\hline & & & & & & & & \\
\hline $97.50 \%$ & 01 & 0.02 & & & 0.00 & & & \\
\hline $95.00 \%$ & .0124 & 0.01 & & 0.0 & 0.0060 & & 0.0080 & \\
\hline $90.00 \%$ & 0.0096 & 0.0140 & 0.0082 & 0.0112 & 0.0043 & 0.0070 & 0.0059 & 0.0093 \\
\hline
\end{tabular}

\begin{tabular}{|c|c|c|c|c|c|c|c|c|c|c|c|c|}
\hline \multirow{3}{*}{$\begin{array}{l}\text { Confidence } \\
\text { levels: }\end{array}$} & \multicolumn{4}{|c|}{$\begin{array}{l}\text { Bivariate (long positions) } \\
\text { Nord Pool }\end{array}$} & \multicolumn{4}{|c|}{ EEX } & \multicolumn{4}{|c|}{ Nord-Pool \& EEX } \\
\hline & \multicolumn{2}{|c|}{ Front Week } & \multicolumn{2}{|c|}{ Front Month } & \multicolumn{2}{|c|}{ Base Month } & \multicolumn{2}{|c|}{ Peak Month } & \multicolumn{2}{|c|}{ Front Month } & \multicolumn{2}{|c|}{ Base Month } \\
\hline & VaR & CVaR & VaR & CVaR & VaR & CVaR & VaR & CVaR & VaR & CVaR & VaR & CVaR \\
\hline $99.90 \%$ & 0.0378 & 0.0464 & 0.0343 & 0.0416 & 0.0228 & 0.0285 & 0.0307 & 0.0379 & 0.0150 & 0.0178 & 0.0220 & 0.0275 \\
\hline 99.50 & & & & & 0.0 & & 10 & & & & & \\
\hline 99.00 & 0220 & 0.0289 & & 0.0261 & 0.0123 & & 0.0 & 0.0 & & & 119 & \\
\hline $97.50 \%$ & 0.0170 & 0.0230 & 0.0155 & 0.0209 & 0.0090 & 0.0128 & 0.0125 & 0.0178 & 0.0079 & 0.0101 & 0.0087 & 0.0124 \\
\hline $95.00 \%$ & 0.0133 & 0.0190 & 0.0122 & 0.0173 & 0.0068 & 0.0103 & 0.0094 & 0.0143 & 0.0064 & 0.0086 & 0.0066 & 0.0099 \\
\hline $90.00 \%$ & 0.0098 & 0.0152 & 0.0092 & 0.0139 & 0.0048 & 0.0080 & 0.0067 & 0.0111 & 0.0048 & 0.0070 & 0.0047 & 0.0077 \\
\hline
\end{tabular}

Table 4. Univariate and Bivariate VaR and CVaR measures for Conditional First Moments ${ }^{21}$

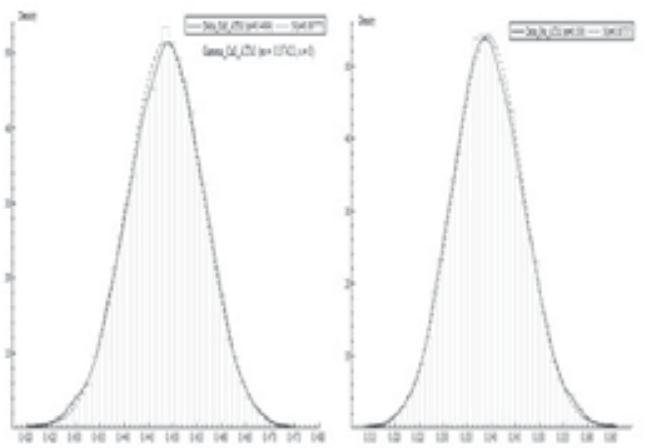

A: NP Front Week Delta Call/Put_ATM Densities
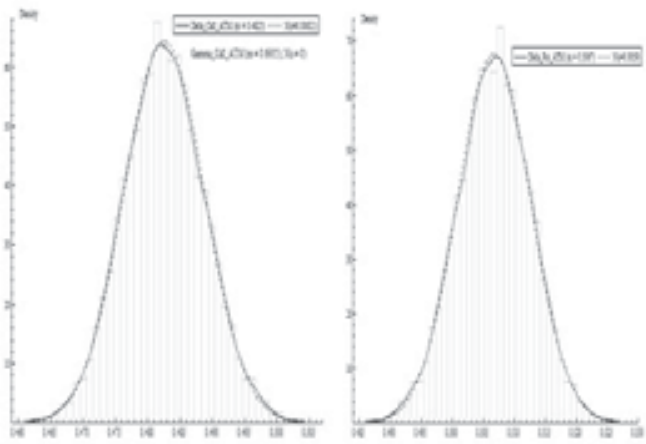

B: NP Front Month Delta Call/Put_ATM Densities

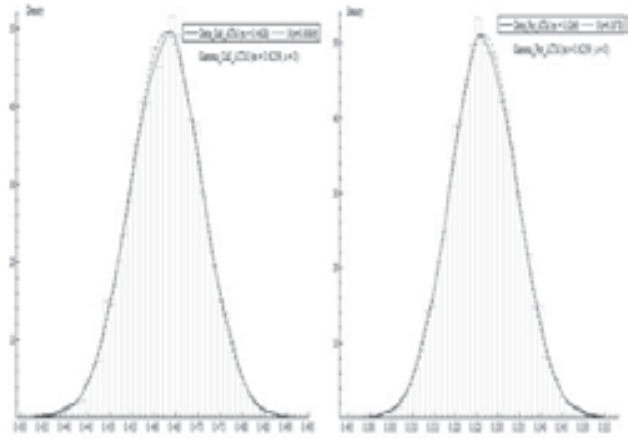

C: EEX FM (base) Delta Call/Put_ATM Densities
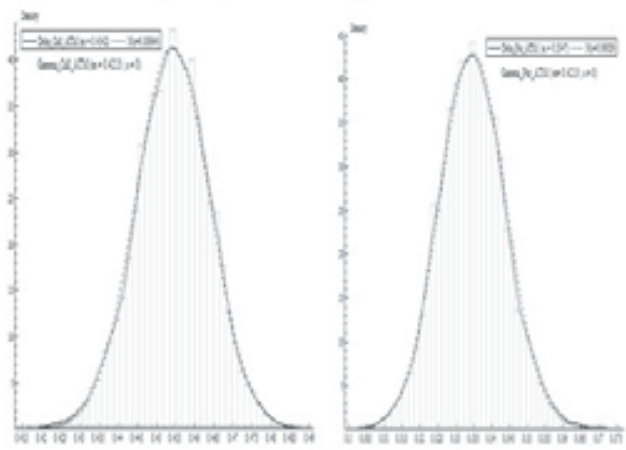

D: EEX FM (peak) Delta Call/Put_ATM Densities

Fig. 10. Greek letter densities (delta, (gamma), rho theta) for Nord Pool and EEX

${ }^{21}$ Greek letters (delta, gamma, rho and theta) are also available from univariate and bivariate conditional first moments. For the front week series the delta for a call (put) ATM option contract is 0.1999 (0.7868). 
VaR and CVaR numbers to approximately $20 \%$ of the original unconditional forecasts. Moreover, the three bivariate return distributions may add some information to the market participants. The bivariate distributions for the Nord Pool and the EEX are plotted to the right in Figure 11 and Figure 12 reports the bivariate density for the front month (base load) contracts at Nord Pool and EEX. The general conclusions from the bivariate densities of the Nord Pool and EEX markets in Table 4 are increased VaR and CVaR numbers. The exception is the front month contracts (base load) between the Nord Pool and EEX markets where we find that the Nord Pool market shows a relative strong decrease for the VaR and CVaR numbers while the EEX market show a small increase from the univariate analysis. Hence, comparing with classical forecasting in Figures 8 and 9, the use of the whole history of observed data series implies a significant reduction in the relevant risk indicating relevant information from the history of the time series. The use of forecasted conditional first moment reduces the $\mathrm{VaR}$ and $\mathrm{CVaR}$ values with a factor of 0.2 . The other side of the picture is the daily calculations with often very computer intensive algorithms.
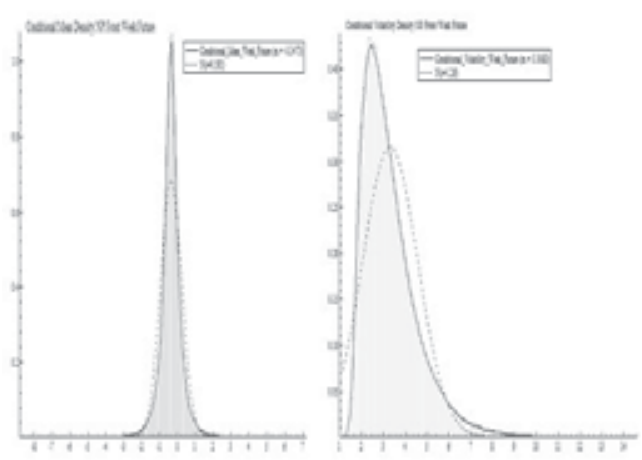

A: Re-projected Mean and Volatility NP Week
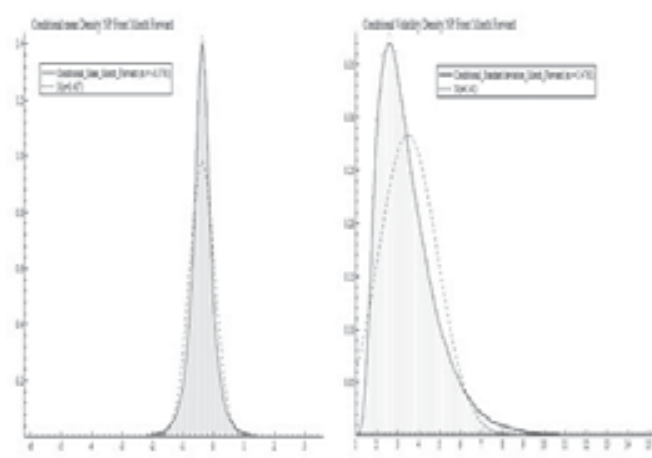

B: Re-projected Mean and Volatility NP Month
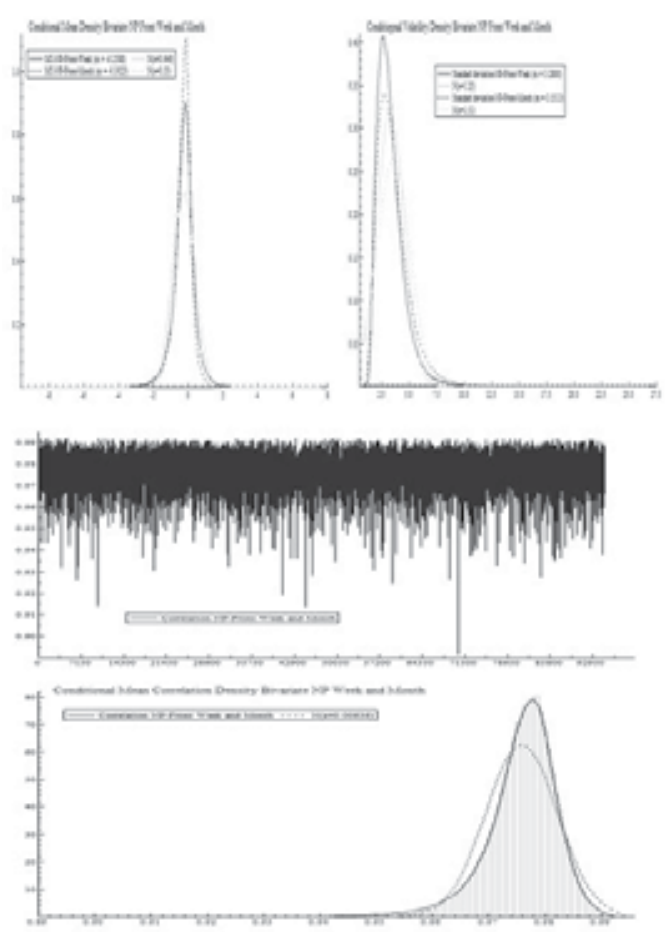

E: Bivariate Re-projected NP Week-Month 

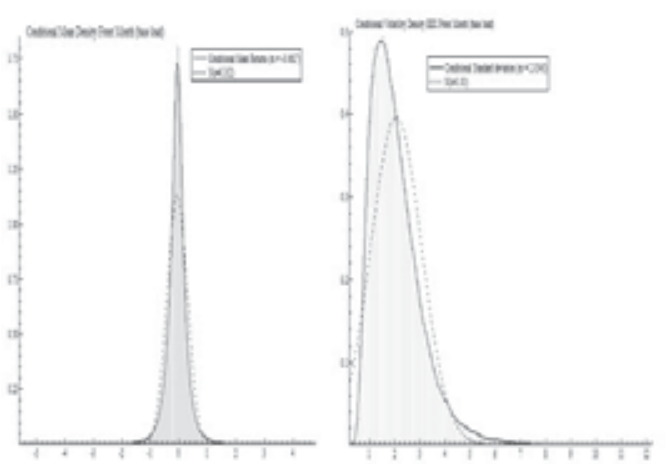

C: Re-projected EEX Month (base load)
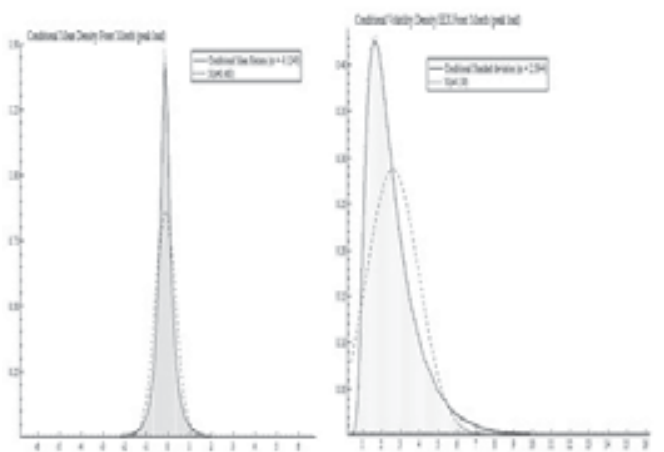

D: Re-projected EEX Month (peak load)
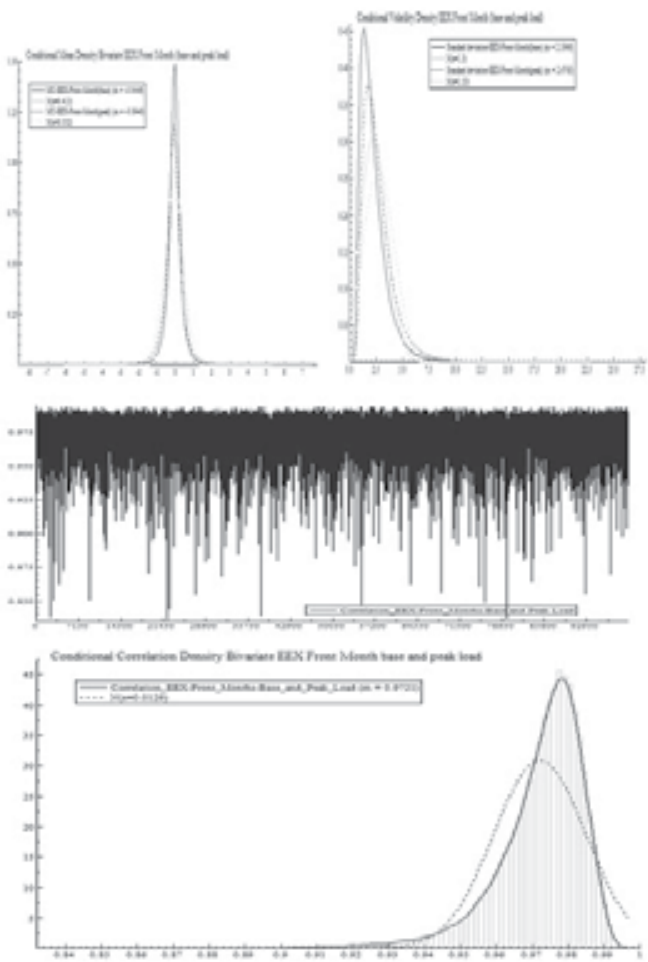

F: Bivariate Re-projected EEX F-M (base and peak ld)

Fig. 11. Univariate and Bivariate Characteristics for Nord Pool and EEX contracts
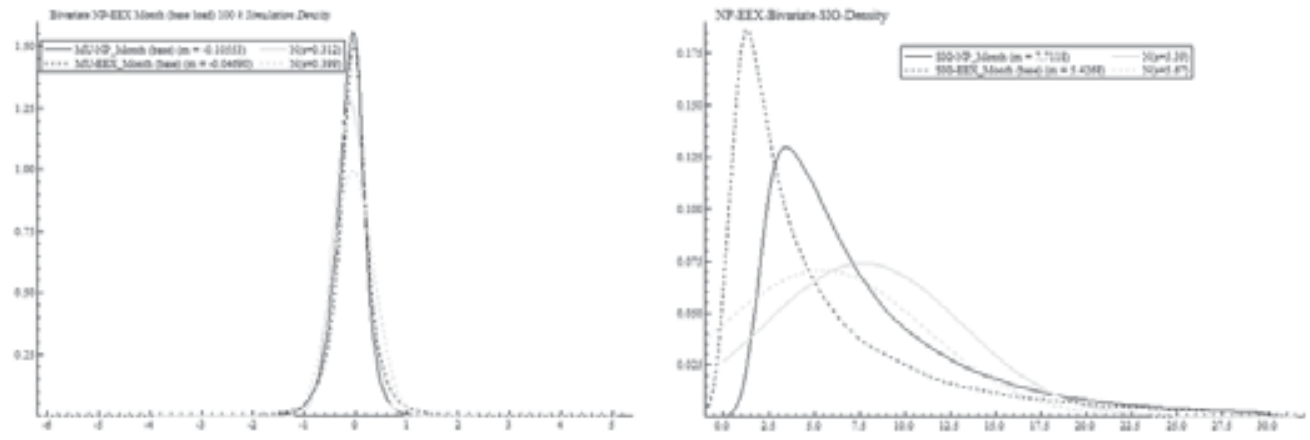

Fig. 12. Bivariate Characteristics between Nord Pool and EEX. Month (base load) contracts

For the second moment we find a log-normal distribution. The explicit variance and standard deviation distributions are interesting for several applications with a special emphasis on derivative computations. However, as we could expect the volatility does not change much from the original simulated SV model. The volatility is assumed latent and stochastic. However, the filtered volatility, the one-step-ahead conditional standard deviation evaluated at data values $\left(x_{t-1}\right)$, may give us some extra information. The filtered volatility is a result of the score generator $\left(f_{K}\right)$ and therefore volatility with a purely ARCH- 
type meaning. Figure 13 shows a representation of the filtered volatility at the unconditional mean of the data series. The density displays the typical shape for data from a financial market: peaked with fatter tails than the normal with some asymmetry. Figure 13 also plots the distributions for several data values $\left(x_{t-1}\right)$ from $-5 \% /-5 \%$ and $+5 \% /+5 \%$. Interestingly, the largest values in absolute terms of $x_{t-1}$ have the widest densities. That is, conditional mean densities are dependent on the $x_{t-1}$ observations making one-day-ahead VaR and $\mathrm{CVaR}$ dependent on historical information. Alternatively, a Gauss-Hermite quadrature rule $^{22}$ can be used and is also reported in Figure 13. Hence, the one-step-ahead filtered volatility seems therefore to contain more information than the general SV-model. Based on the observation day $t$ it is therefore of interest to use the one-step-ahead standard deviation for several applications. The filtered volatility and the Gauss-Hermite quadrature can be used for one-step-ahead price of any derivative.

Figure 13 also reports the conditional variance functions. The conditional variance functions are reported for both univariate and bivariate simulated data series. We can interpret the conditional variance graphs as representing the consequences of a shock to the system that comes as a surprise to the economic agents involved. From the plots we see that the EEX responses from positive shocks are higher than from negative shocks. The SV model positive $\rho$ signals positive mean and volatility correlation inducing positive asymmetry (higher volatility from positive price changes). As noted earlier in this chapter, the asymmetry seems close to zero for the Nord Pool market but the EEX market reports clearly positive asymmetry.
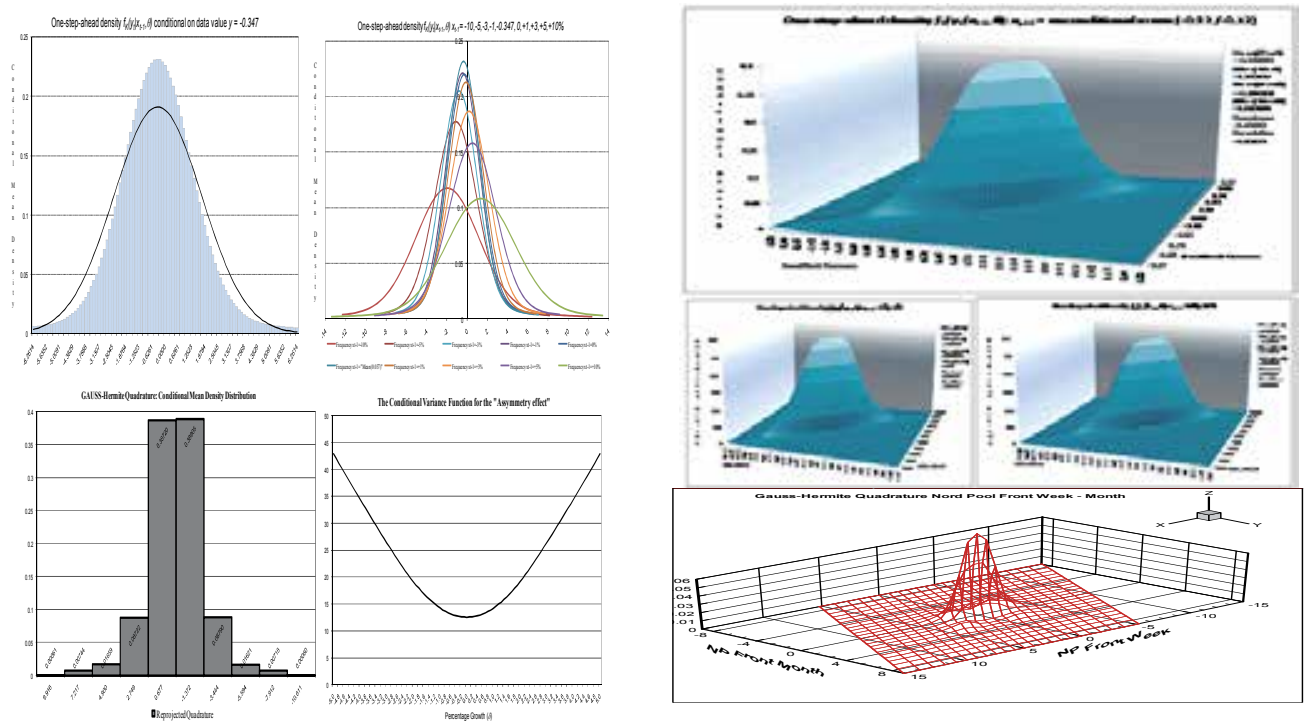

A: Re-projected Filtered Volatility NP Week

22 A Gaussian quadrature over the interval $(-\infty,+\infty)$ with weighting function $W(x)=e^{-x^{2}}$ (Abramowitz and Stegun 1972, p. 890). The abscissas for quadrature order $n$ are given by the roots $x_{i}$ of the Hermite polynomials $H_{n}(x)$, which occur symmetrically about 0 . An expectation with respect to the density can be approximated as: $E(g(y))=\sum_{j=1}^{n p t s} g($ abcissa $[j]) \cdot$ weight $[j]$. 

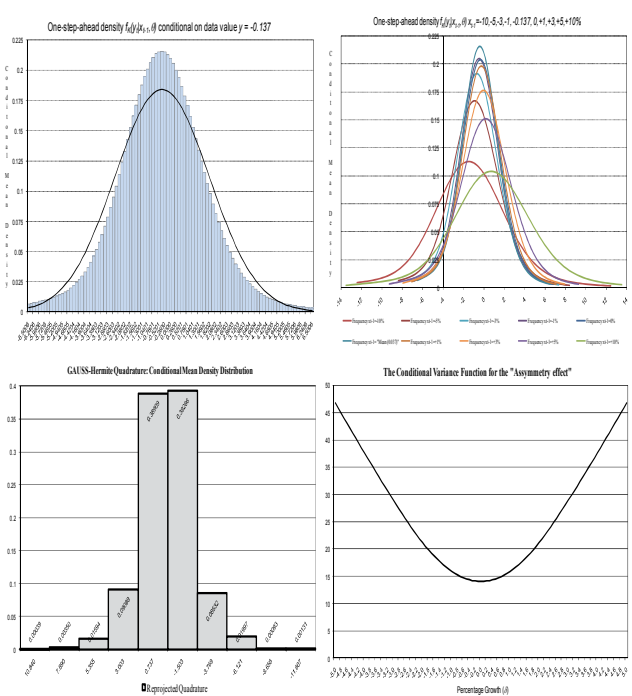

B: Re-projected Mean and Volatility NP Month
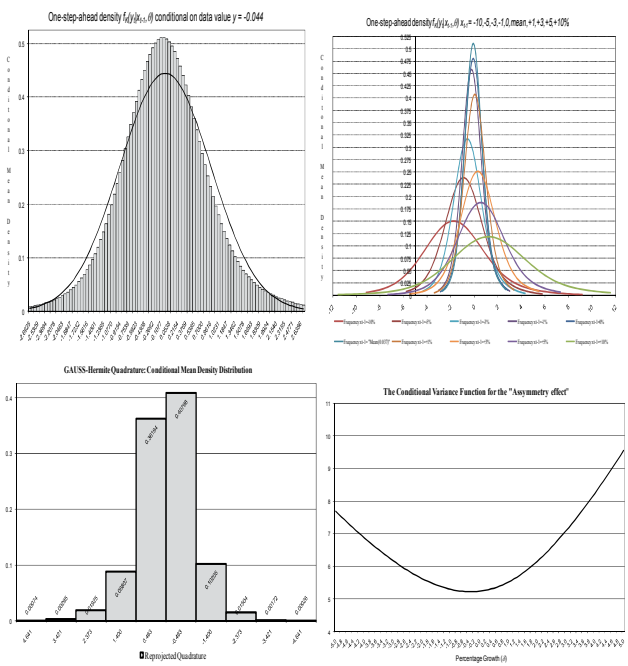

C: Re-projected EEX Month (base load)
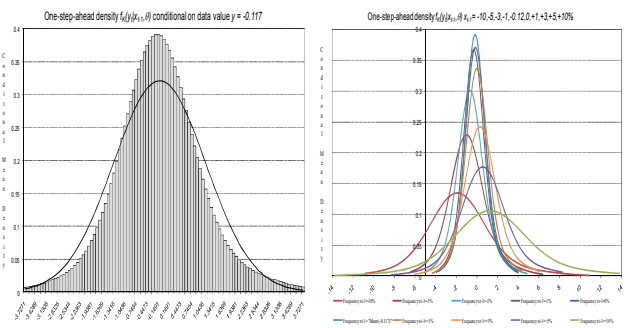

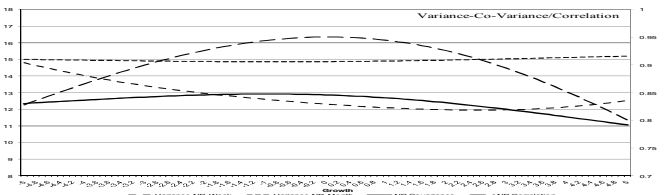

E:Bivar Filtered Volatility NP Week-Month
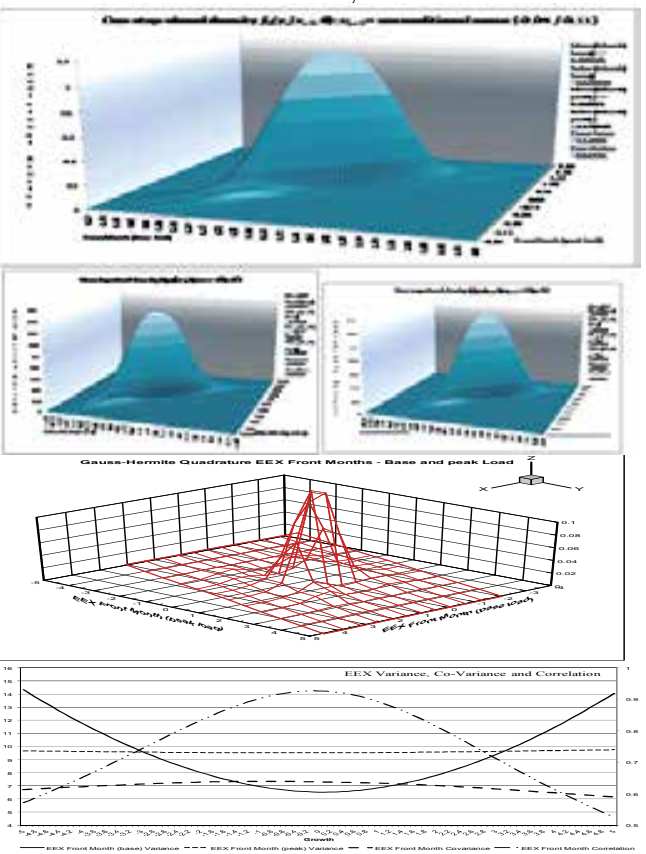

F:Bivar Filtered Volatility EEX Month(base-peak)
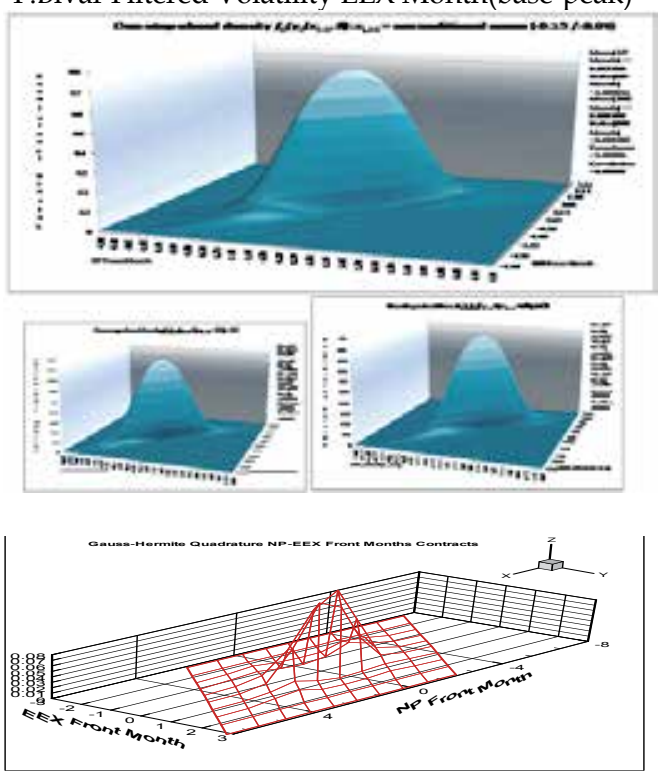


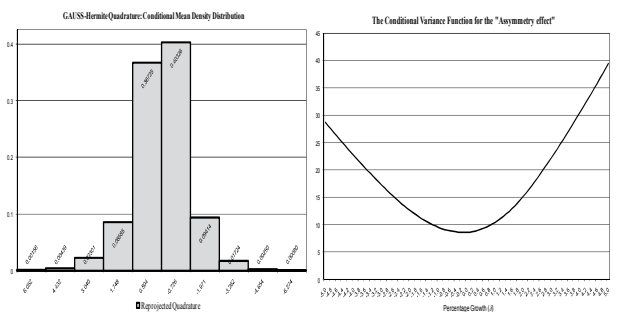

D: Re-projected EEX Month (peak load)

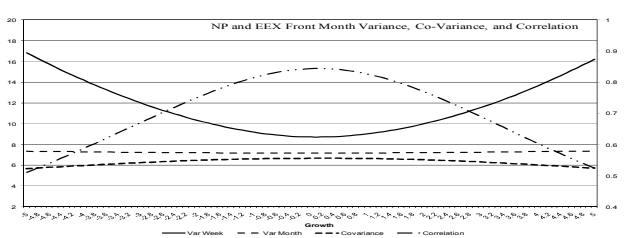

G:Bivar Filtered Volatility NP - EEX Month (base)

Fig. 13. Bivariate Contract Characteristics between Nord Pool and EEX

The multivariate post estimation analysis gives access to covariances/correlations for any simulated series combinations. The number of multivariate series is dependent on problem at hand. In this paper we analyse three bivariate $100 k$ simulated series: (1) the Nord Pool one-week future and one-month forward contracts; (2) the EEX base and peak one month future contracts, and (3) the Nord Pool and EEX front month (base load) contracts. Bivariate forecasts, one-step-ahead conditional mean, volatility and correlations are all interesting measures. Figure 13, middle part to the right (panel E, F and G), reports the bivariate conditional mean forecasts, dependent on changing historical information $\left(x_{t-1}\right)$. The GaussHermite quadrature adds to the mean density information and finally for all bivariate investigations, the conditional variance functions, co-variance functions and correlations are reported. The asymmetry story holds also for the bivariate analysis and the co-variances and correlations seem to decrease during high volatility periods. The correlation seems symmetric and is at its minimum when volatility and price changes (growth) are high either negative or positive. Hence, the quadrature and variance/covariance information from the post estimation analysis seems to add extra insight to scientifically valid models, the $\mathrm{VaR} / \mathrm{CVaR}$ measures for risk management and Greek letters for portfolio managment. Implicitly, Figure 13 panel G reports diversification effects between Nord Pool and EEX. The bivariate Nord Pool and EEX analysis report lower VaR and CVaR measures for all percentiles of the bivariate distributions relative to the two Nord Pool and EEX univariate analyses (front month (base load)).

Finally, for illustrative purposes and the use of EVT for conditional moments and the $\mathrm{VaR}, \mathrm{CVaR}$ and Greek letters density measures, we perform $5 k \mathrm{SV}$-model simulations for the Nord Pool Front week SV model, extract the conditional density using the $f_{k}(\theta)$ score model and calculate $\mathrm{VaR}, \mathrm{CVaR}$ and Greek letters density measures. It takes considerable time and computer resources to do this exercise. However, the $\mathrm{VaR} / \mathrm{CVaR}$ measures are interesting. Figure 14 upper right plot shows 30 subsamples of the $5 k$ front week SVmodel unconditional return density simulations. In the upper right plot, the front week conditional density returns are plotted. In the middle plots of Figure 14 the $\mathrm{VaR}$ and $\mathrm{CVaR}$ measures are reported for the conditional densities. Interestingly, the $\mathrm{VaR} / \mathrm{CVaR}$ density measures are at a considerably lower level than the same unconditional VaR/CVaR measures in Figure 9 above. The lower plots in Figure 14 report the Greek letter delta densities for call and put ATM options for front week contracts. Interestingly, the Greek letter density measures have also changed from the same unconditional measures in Figure 10 above. There seems to be some extra information in the conditional densities from the SV models. 

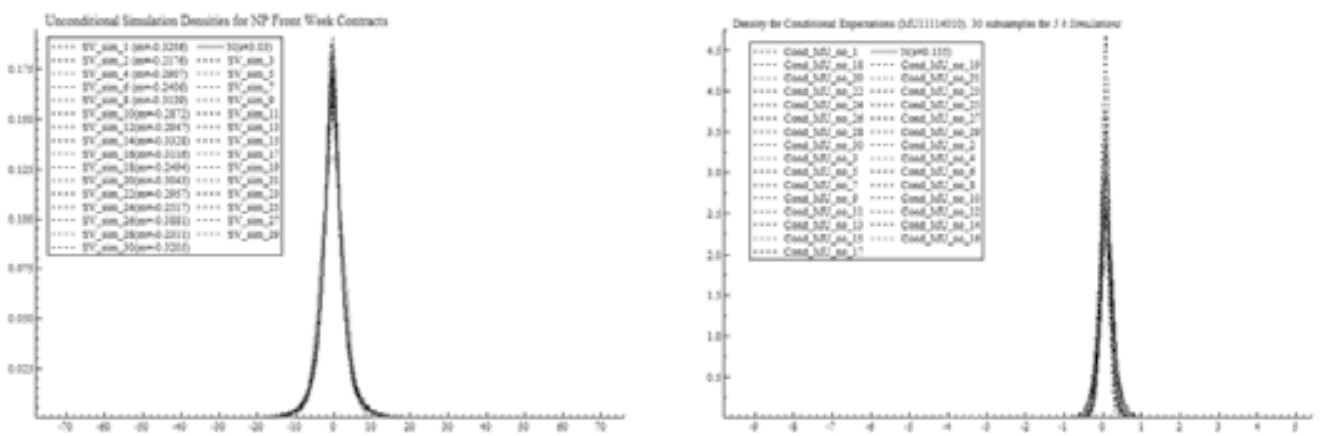

Panel A: Unconditional density plots (30 sub-samples) Panel B: Conditional density plots (30 sub-samples)
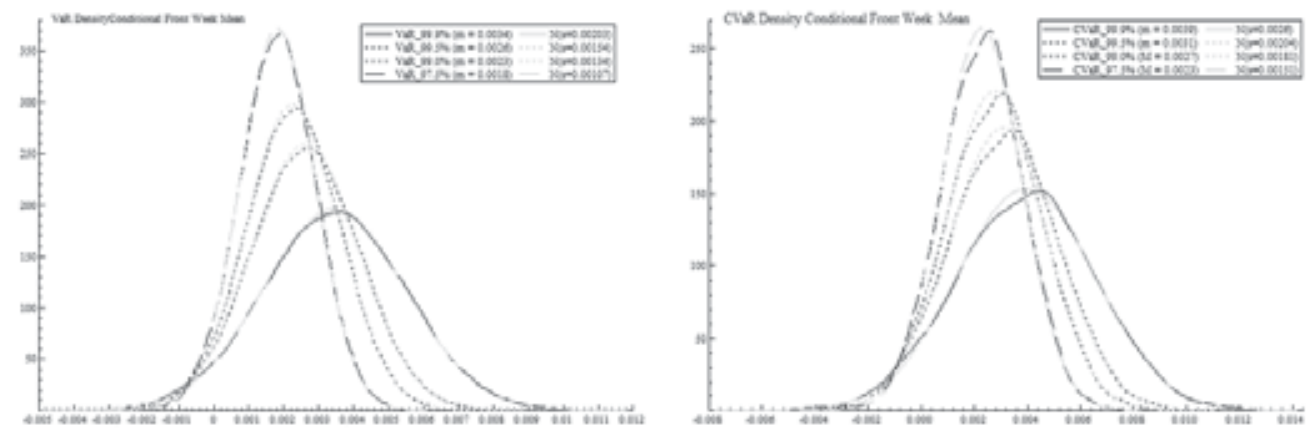

Panel C: VaR from $5 k$ conditional expectations

Panel D: CVaR from $5 k$ conditional expectations
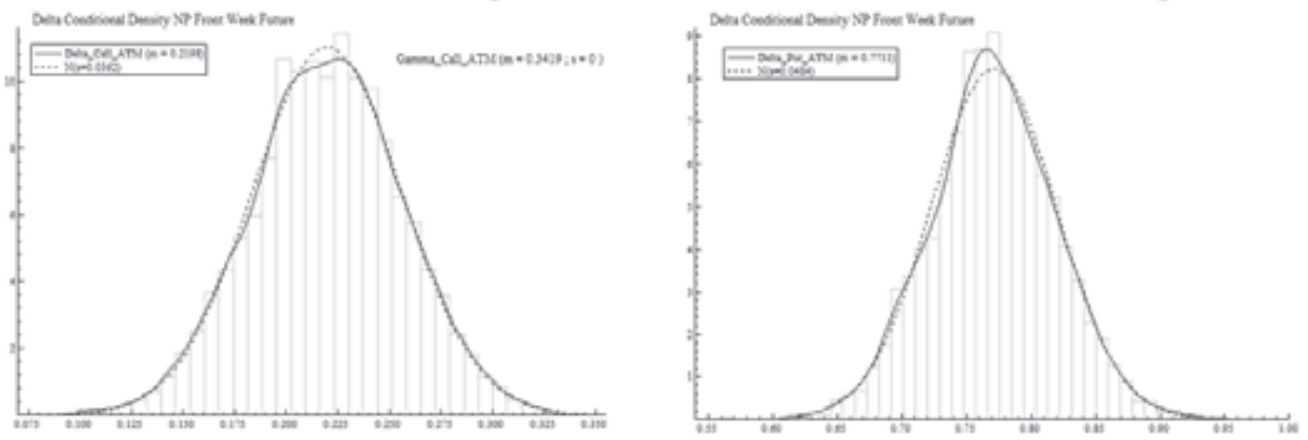

Panel E: ATM_4_Call $5 k$ conditional expectations

Panel F: ATM_A_Put 5 k conditional expectations

Fig. 14. (Un-)Conditional expectations, VaR/CVaR measures and Greek letters

\section{The credit and liquidity risks}

The chapter has focused mainly on stochastic volatility models. Other risks often found in energy will be briefly discussed and incorporated in the Economic Capital concept. For energy enterprises with a large number of customers we will use the one-factor Gaussian copula. A energy wholesale and retail company will have a portfolio of account payables for short electricity positions from households and industry. The risk for the energy company is default of these account payables. We define $T_{i}$ as the time customer $i$ defaults (we assume that all customers will default eventually, but the default time may be many years into the future.) We denote the cumulative probability distribution of $T_{i}$ by $Q_{i}$. In order to define a 
correlation structure between the $T_{i}$ using the one-factor Gaussian copula model, we map, for each $i$, the default time $T_{i}$ to a variable $U_{i}$ that has a standard normal distribution on a percentile-to-percentile basis. For the correlation structure between the $U_{i}$, we assume the factor model $U_{i}=a_{i} \cdot F+\sqrt{\left(1-a_{i}^{2}\right)} \cdot Z_{i}$ where $F$ and the $Z_{i}$ have standard normal distributions and the $Z_{i}$ are uncorrelated with each other. The mapping between the the $U_{i}$ and the $T_{i}$, imply that $\operatorname{Prob}\left(U_{i}<U\right)=\operatorname{Prob}\left(T_{i}<T\right)$, when $U=\mathrm{N}^{-1}\left[Q_{i}(T)\right]$. Now using the one factor model which we can write as $Z_{i}=\frac{U_{i}-a_{i} \cdot F}{\sqrt{\left(1-a_{i}^{2}\right)}}$, the probability that $U_{i}<U$ conditional on the factor value $\mathrm{F}$ is $\operatorname{Prob}\left(U_{i}<U \mid F\right)=\operatorname{Prob}\left(Z_{i}<\frac{U_{i}-a_{i} \cdot F}{\sqrt{\left(1-a_{i}^{2}\right)}}\right)=N\left(\frac{U_{i}-a_{i} \cdot F}{\sqrt{\left(1-a_{i}^{2}\right)}}\right)$.

Finally, $\operatorname{Prob}\left(T_{i}<T \mid F\right)=\operatorname{Prob}\left(Z_{i}<\frac{N^{-1}\left[Q_{i}(T)\right]-a_{i} \cdot F}{\sqrt{\left(1-a_{i}^{2}\right)}}\right)$. Assuming that the time to default $Q$, is equal for all $i$ and equal $Q$ and that the copula correlation between the default times of any two customers is the same and equal $\rho$., inducing that $a_{i}=\sqrt{\rho}$ for all $i$. Hence, we have $\operatorname{Prob}\left(T_{i}<T \mid F\right)=N\left(\frac{U_{i}-\sqrt{\rho} \cdot F}{\sqrt{(1-\rho)}}\right)$. When the customer portfolio is larger the expression provides a good estimate of the percentage of customers defaulting by time $T$ conditional on $F$. Therefore, we have defined the probability $Y$ that the default rate will be greater than $N\left(\frac{N^{-1}\left[Q_{i}(T)\right]-\sqrt{\rho} \cdot N^{-1}(Y)}{\sqrt{(1-\rho)}}\right)$ and therefore $\operatorname{VaR}(T, X)=A P \cdot(1-R) \cdot N\left(\frac{N^{-1}\left[Q_{i}(T)\right]+\sqrt{\rho} \cdot N^{-1}(X)}{\sqrt{(1-\rho)}}\right)$, where $X$ is the confidence level and $Y=1-X$, and $A P$ is accounts payable. The probability for an energy enterprise with $€ 250$ of retail exposures, probability of default is $4 \%$, the recovery rate averages $75 \%$ and the copula correlation parameter is $\rho=0.25$, is $N\left(\frac{N^{-1}[0.04]+\sqrt{0.25} \cdot N^{-1}(0.999)}{\sqrt{(1-0.25)}}\right)=0.40618$. Losses with one-year time horizon and a $99.9 \%$ confidence level when the worst case loss rate occurs are therefore: $\operatorname{VaR}(1,99.9 \%)=250 \cdot(1-0.75) \cdot 0.40618=€ 25.387$. For a confidence level of $97.5 \%$ the VaR will become $€ 11.672(250 \cdot(1-0.75) \cdot 0.18675)$. Several other methodologies for credit risk and default rates are available. For the default rate the Merton (1974) model, where we use equity prices and option theory to estimate default probabilities, is useful. The Credit Risk Plus software from Credit Suisse Financial ${ }^{23}$ Products and CreditMetrics from J.P. Morgan ${ }^{24}$ are commercial tools for the risk calculations.

\footnotetext{
${ }^{23}$ See www.credit-suisse.com/investment_banking/holt/

24 See www.jpmorgan.com/pages/jpmorgan/
} 
Finally, liquidity risk is the cost of liquidation in stressed market conditions within a certain time period. Bid-ask spread is normally a good measure for unwinding positions. If we define ai and si as the mean and standard deviation of the proportional bid-ask spread, we can write the cost of liquidation as $\sum_{i=1}^{n} \frac{1}{2}\left(\alpha_{i}+\lambda \sigma_{i}\right) \gamma_{i}$, where $\lambda_{i}$ is the required confidence level $(1 \%=2.33)$ and $\gamma_{i}$ is the size of the instrument/commodity. A liquidity adjusted VaR can therefore be calculated as $\operatorname{VaR}+\sum_{i=1}^{n} \frac{1}{2}\left(\alpha_{i}+\lambda \sigma_{i}\right) \gamma_{i}$.

\section{Economic capital and RAROC for European energy enterprises}

Economic or Risk Capital is defined as the amount of capital an energy company needs to absorb over a certain time horizon (usually one year) with a certain confidence level (Rosenberg and Schuermann, 2004). Confidence levels should be chosen based on credit ratings. An energy corporation usually wants to establish and maintain an AA-rating., which normally have a one-year probability of default of $0.03 \%$. That is, a confidence level of $99.7 \%$. Note that when we calculate the risk capital, this means that we want to have enough economic resources inside and outside the company to cover unexpected losses. Unexpected loss is the difference between expected and actual loss, so that expected losses are already priced in the corporation's capital structure. Hence, the risk capital for a corporation that want to maintain an AA rating is the difference between expected loss and the $99.7 \%$ point on the probability distribution of losses.

Due to the fact that energy companies are not publicly traded companies and equity prices therefore is rarely available for estimation of default probabilities, the approach most often used estimates different types of risk in different business units and then aggregates to measure total or overall risk. This mainly means that we calculate probability distributions for total losses per type or total losses per business unit. At the end a final aggregation gives a probability distribution of total losses for the whole corporation. For an energy corporation market risk (price and volume), basis risk (locational/time risk), and operational risk (operational and legal) is the three main risk classes.

We use two approaches. The first is the simple Hybrid approach the second is the use of copulas to facilitate correlation structure between market variables (the copula approach). For the remaining example we apply fictive capital estimates for the different risks/business units. We assume three business areas for example hydro-power productions with market (price and volume) and operational risk, a network division and telecommunication division with market and operational risk. Typical shapes of loss distributions for market risk is close to the normal distribution while the operational risk may have quite extreme shape. Most of the time losses are modest, but occasionally they are large. A distribution can be characterized by the second, third and fourth moments. The following table summarizes the properties of typical loss distributions:

The business mix is clearly the most important factor for the relative importance. For an energy company also trading derivatives market risk, basis risk and operational risk are all important. Moreover, we find interactions between market, basis and operational risk. When a derivative is traded for example, and the counterparty defaults, operational risk exists only if market variables have moved so that the value of the derivative to the financial 
institution is positive. A corporation in the energy sector has the following economic capital $(E)$ estimates (Panel A) and correlation (Panel B) between market, basis and operational risk for three business units in Table 5 :

\begin{tabular}{llll} 
& Second & Third & Fourth \\
& Moment & Moment & Moment \\
\cline { 2 - 4 } Market risk & High & Zero & Low \\
Basis risk & Low & High & Zero \\
Operational risk & Low & High & High \\
\hline
\end{tabular}

Panel A

Business Units (billion $€$ )

Hydro power Network Telephone

Economic Capital generation (B1) $\quad$ operation (B2) $\quad$ communication (B3)

\begin{tabular}{llll}
\hline Market risk (M) & 150 & 45 & 82
\end{tabular}

Basis Risk (B) $\quad 95 \quad 38 \quad 50$

Operational Risk $(\mathrm{O}) \quad 55 \quad 25 \quad 34$

\begin{tabular}{cccccccccc}
\hline Panel B Correlation & & & & & & & & & \\
Structure & MB1 & BB1 & OB1 & MB2 & BB2 & OB2 & MB3 & BB3 & OB3 \\
\hline MB1 & 1 & 0.35 & 0.2 & 0.4 & 0 & 0.1 & 0.3 & 0 & 0.05 \\
BB1 & 0.35 & 1 & 0.15 & 0.15 & 0.25 & 0.25 & 0.05 & 0.1 & 0 \\
OB1 & 0.2 & 0.15 & 1 & 0.15 & 0 & 0.2 & 0.1 & 0.1 & 0 \\
MB2 & 0.4 & 0.15 & 0.15 & 1 & 0.2 & 0.1 & 0 & 0 & 0.1 \\
BB2 & 0 & 0.25 & 0 & 0.2 & 1 & -0.1 & 0.1 & 0.2 & 0.05 \\
OB2 & 0.1 & 0 & 0.2 & 0.1 & -0.1 & 1 & 0 & 0.1 & 0 \\
MB3 & 0.3 & 0.05 & 0.1 & 0 & 0.1 & 0 & 1 & 0.1 & 0 \\
BB3 & 0 & 0.1 & 0.1 & 0 & 0.2 & 0.1 & 0.1 & 1 & 0.05 \\
OB3 & 0.05 & 0 & 0 & 0.1 & 0.05 & 0 & 0 & 0.05 & 1
\end{tabular}

Table 5. Economic Capital and Relevant Risk for a European Energy Enterprise

The correlation is checked for consistency using Cholesky decomposition. The hybrid approach involves calculating the economic capital for the individual risks using $E_{\text {total }}=\sqrt{\sum_{i=1}^{n} \sum_{j=1}^{n} E_{i} \cdot E_{j} \cdot \rho_{i j}}$ which is exactly correct if the distributions are normal. When they are non-normal, the hybrid approach gives an approximate answer - but one that reflects any heaviness in the tails of the individual loss distributions. Economic capital can be calculated in several ways. The market risk economic capital for the hydropower, network and telecommunication units: $\sqrt{150^{2}+45^{2}+82^{2}+2 \cdot(150 \cdot 45 \cdot 0.4+150 \cdot 82 \cdot 0.3+45 \cdot 82 \cdot 0)}$ and equals 233.41. The basis risk economic capital for the three business units becomes 159.37 and the operational risk becomes 98.32. The risk capital for the hydropower 
generation unit is 245.34. The total risk capital for the network unit is 108.19, the telecommunication unit is 133.94, and the total enterprise wide risk capital becomes: 299.73 . We find significant diversification benefits. The sum of the economic capital estimates for market, network and telecommunication risk is $233.41+159.37+98.38=491.09$ and the sum of the economic capital estimates for three business units are $245.34+108.19+133.94=487.48$. Both of these are greater than the total economic capital estimate of 299.73. These economic capital estimates are exactly correct.

The second approach is the use of copulas for the different risk measures. We will apply both normal copulas and Student- $t$ copulas for the calculation of Economic capital. In this example we assume the same correlation structures as for the hybrid approach and we consider nine factors (market, basis and operational risk for 3 business unit) represented with a mean and standard deviation. We perform Monte Carlo simulations assuming normal and for the illustration of heavy tails, student- $t$ distributions with 4 and 2 degrees of freedom for illustrational purposes. MC can also easily incorporate asymmetry (not reported). The procedure is as follows. From any original distribution each loss distribution is mapped on a percentile-to-percentile basis to a standard well-behaved distribution. A correlation structure between the standard distributions is defined and this indirectly defines a correlation structure between the original distributions. The copula therefore gives us well-behaved distributions classified as multivariate Gaussian or multivariate student-t. We simulate $100 k$ iterations for each $E_{\text {total }}$. For the normal distributions we find a $E_{\text {total }}$ of 305.06 with an associated standard deviation of 47.48. The student-t distribution with 4 degrees of freedom shows a mean of 304.21 with associated standard deviation of 51.82 . The student-t distribution with 2 degrees of freedom reports a mean of 318.58 with associated standard deviation of 222.41. Finally, we calculate the VaR and CVaR densities from $10 \mathrm{k}$ MCMC iterations. The VaR (upper) and CVaR (lower) for 99.9\% 99.5\%, 99.0\% and 97.5\% confidence levels are reported in Figure 15 for the normal, student-t with 4, and student-t with 2 degrees of freedom, respectively. For the normal distribution and VaR (CVaR) 99.9\% confidence level the mean is 453.08 (467.08) with associated standard deviation of 6.4 (8.4). For the student-t with $4 \mathrm{df}$ (2df) the VaR 99.9\% mean is 668.57 (2423.9) with associated standard deviation of 48.6 (512.9). The student-t distribution with 2 degrees of freedom shows quite a large $\mathrm{VaR} / \mathrm{CVaR}$ expected loss. Alternatively, the standard deviation of the total loss from $n$ sources of risk can be calculated directly from the relation $\sigma_{\text {total }}=\sqrt{\sum_{i=1}^{n} \sum_{j=1}^{n} \sigma_{i} \sigma_{j} \rho_{i j}}$ where $\sigma_{i}$ is the standard deviation of the loss from the $i$ th source of risk and $\rho_{i j}$ is the correlation between risk $i$ and $j$. For our example with three risks and 3 business units the $\sigma_{\text {total }}$ becomes 99.35 . From the relationships we can calculate the capital requirements. For example, the excess of the $99.9 \%$ worst case loss over the expected loss is 3.09 (normal distribution) times the number calculated for $\sigma_{\text {total }}$. The same worst-case loss numbers for a one-sided student-t-distribution is 7.17 and 22.33 for 4 and 2 degrees of freedom, respectively. For the normal distribution for example we get a worst case loss of 647.43 , which is $342.4\left(99.35^{*} 3.44\right)$ over the expected loss of 305.03 .

As for the Hybrid approach, the MC mean/mode economic capital (risk) shows considerable diversification effects also by using the copula approach. From an assumption of 574 separately for the total economic capital the correlation structure report 
diversification effects lowering the total economic capital to approximately 305 as the new risk measure for the corporation as a whole. Capital requirements at $99.9 \%, 99.5 \%$ and $99 \%$ worst-case loss scenarios for the corporation become 450.69, 434.64 and 414.88, respectively, for the normal distributions case. For the student-t distribution with two (four) degrees of freedom illustrating a medium (an extreme) heavy tail case, the excess $99.9 \%$ and $99.0 \%$ worst case losses grows to 1131.8 (931.4) and 464.1 (424.6), respectively.
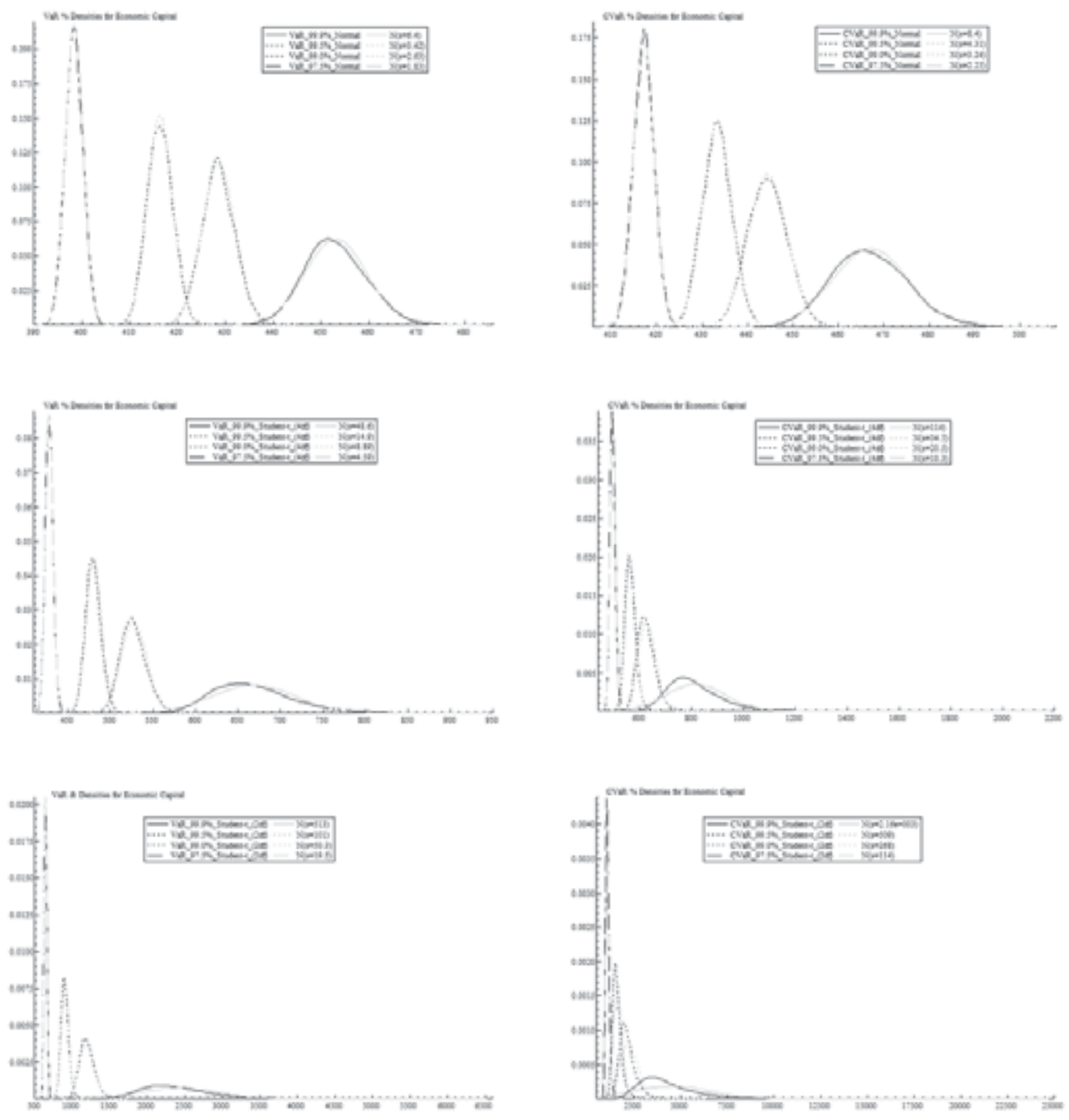

Fig. 15. Distributions of VaR and CVaR for Normal and Student-t distributions

The diversification benefits are to be allocated by an amount $x_{i} \cdot \frac{\partial E}{\partial x_{i}}$ to the $i$ th business unit, where $E$ is the total risk capital and $x_{i}$ is the investment in the $i$ th business unit. By using the Euler's theorem we ensure that the total of the allocated capital is E. Euler's theorem says: 
$\operatorname{VaR}=\sum_{I=1}^{N} \frac{\partial(\operatorname{VaR})}{\partial x_{i}} x_{i}$ where $N$ is the number of components. We can therefore set $C_{i}=\frac{\partial(\operatorname{VaR})}{\partial x_{i}} x_{i}$ where $C_{i}$ is the component $V a R$ for the $i$ th component. We define $\Delta E_{i}$ as the increase in the total risk capital when we increase $x_{i}$ by $\Delta x_{i}$. A discrete approximation for the amount allocated to business unit $i$ becomes: $\frac{\Delta E_{i}}{\Delta y_{i}}$ where $\operatorname{Prob}(v>x)$. When we increase the size of the hydropower generation by $1 \%$ its economic capital amounts for market, basis and operational risk increases to $151.5,95.95$, and 55.55, respectively. New economic capital (hybrid approach) becomes 301.75 , so that $\Delta E_{H P}=301.75-299.73=2.02$. Increasing the size of the network division by $1 \%$, implies an increase in the economic capital for market, basis and operational risk to $45.45,38.38$ and 25.25 , respectively. The total economic capital becomes 300.11, so that $\Delta E_{N T}=300.11-299.73=0.38$. The numbers for telecommunication is $\Delta E_{T C}=300.33-299.73=0.60$. The economic capital allocation gains are therefore divided between hydropower generation, network, and telecommunication by $2.02 / 0.01=202$, $0.38 / 0.01=3825$, and $0.30 / 0.01=60$, respectively.

\section{Summaries and conclusions}

The paper set out to measure volatility/correlation and market/operational risks for a general corporation in European energy markets. Starting with a relevant risk discussion the corporation may perform risk analysis based on either the argument of asymmetric information relative to owner or based on costs related to financial distress/bankruptcy costs.

For the Nordpool and the EEX energy markets the paper shows estimates of product and market volatility/correlations and makes one-step-ahead forecasts. The paper performs a model-building approach applying Monte Carlo simulation. Stochastic volatility models are estimated and simulated for risk management purposes. From the power law, the extreme value theory are used for $\mathrm{VaR}$ and $\mathrm{CVaR}$ calculations (smoothing out tails). The normal distribution assumptions make these analyses a relatively easy exercise for $V a R$ and CVaR distributions. Non-normality can be easily implemented applying Copulas. Finally, risk aggregation is shown for market and operational risk for normal as well as student- $t$ distributions.

\section{Appendix I: The theory of reprojection and the conditional mean densities}

Having the SV model coefficients estimate $\hat{\theta}_{n}$ at our disposal, we can elicit the dynamics of the implied conditional density of the observables $\hat{p}\left(y_{0} \mid y_{-L}, \ldots, y_{-1}\right)=p\left(y_{0} \mid y_{-L}, \ldots, y_{-1}, \hat{\theta}_{n}\right)$. Analytical expressions are not available, but an unconditional expectation $E_{\hat{\theta}_{n}}(g)=\int \ldots \int g\left(y_{-L}, \ldots, y_{0}\right) p\left(y_{-L}, \ldots, y_{0}, \hat{\theta}_{n}\right) d_{y_{-L}} \ldots d_{y_{0}}$ can be computed by generating an simulation $\left\{\hat{y}_{t}\right\}_{t=-L}^{N}$ from the system with parameters set to $\hat{\theta}_{n}$ and using

${ }^{25}$ Does not equal the total economic capital of 299.73 , because we approximated the partial derivatives. 
$E_{\hat{\theta}_{n}}(g)=1 / N \sum g\left(\hat{y}_{t-L}, \ldots, \hat{y}_{t}\right)$. With respect to unconditional expectation so computed, define $\hat{\theta}_{K}=\underset{\theta \in \mathfrak{R}^{\theta_{K}}}{\arg \max } E_{\hat{\theta}_{n}} \log f_{K}\left(y_{0} \mid y_{-L}, \ldots, y_{-1}, \theta\right)$, where $f_{K}\left(y_{0} \mid y_{-L}, \ldots, y_{-1}, \theta\right)$ is the SNP score density. Now let $\hat{f}_{K}\left(y_{0} \mid y_{-L}, \ldots, y_{-1}\right)=f_{K}\left(y_{0} \mid y_{-L}, \ldots, y_{-1}, \hat{\theta}_{K}\right)$. Theorem 1 of Gallant and Long (1997) states that $\lim _{K \rightarrow \infty} \hat{f}_{K}\left(y_{0} \mid y_{-L}, \ldots, y_{-1}\right)=\hat{p}\left(y_{0} \mid y_{-L}, \ldots, y_{-1}\right)$. Convergence is with respect to a weighted Sobolev norm that they describe. Of relevance here is that convergence in their norm implies that $\hat{f}_{K}$ as well as its partial derivatives in $\left(y_{-L}, \ldots, y_{-1}, y_{0}\right)$ converges uniformly over $\mathfrak{R}^{\ell}, \ell=M(L+1)$, to those of $\hat{p}$. They propose to study the dynamics of $\hat{p}$ by using $\hat{f}_{K}$ as an approximation. The result justifies the approach.

Hence, the conditional mean density is from $5 k$ iterated use of the re-projection procedure. For every simulation from the normally distributed coefficients, re-projected scores $\hat{f}_{K}\left(y_{0} \mid y_{-L}, \ldots, y_{-1}\right)$ are estimated and the conditional moments (mean and variance) and the filtered volatility are reported. The power law is also evaluated for the conditional mean series. Figure 16 report the power law test results for simulated and conditional mean $100 \mathrm{k}$ data series. The power law seems to work well for both markets and the four series.

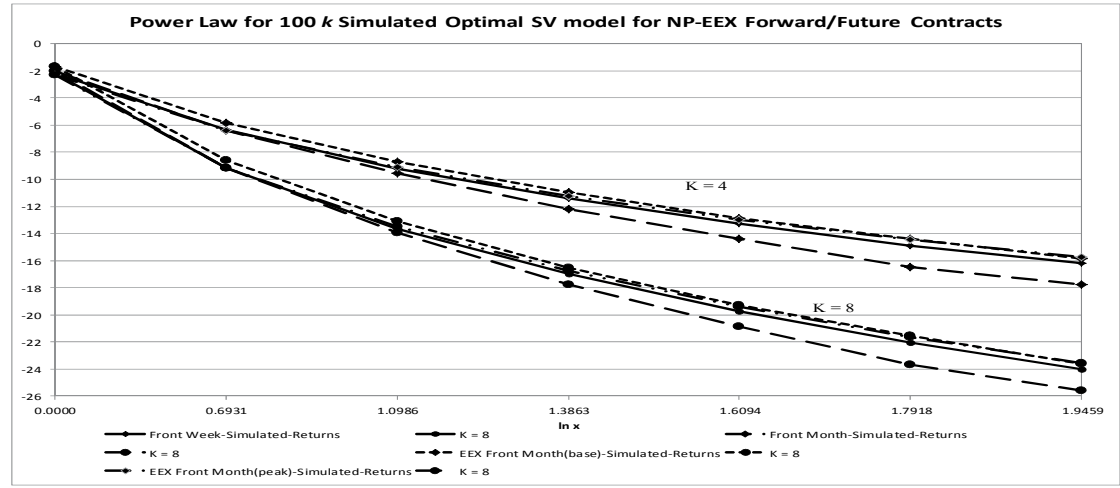

$$
\operatorname{Prob}(v>x)
$$

Fig. 16. The Power Law for SV-simulated and Conditional mean series: Log plots for return increases: $x$ is the number of standard deviations ; $v$ is the NP / EEX price increases/decreases.

\section{References}

Annual reports: www.nordpool.no, www.eex.de, www.apxendex.com, www.powernext.com. Abramowitz, M. and I.A. Stegun, 2002, Handbook of mathmatiical Functions with Formulas, Graphs, and Mathematical Tables, U.S. Department of Commerce (www.knovel.com/book_id=528) 
Andersen,, T.G., 1994, Stochastic autoregressive volatility: a framework for volatility modelling, Mathematical Finance, 4, pp. 75-102.

Artzner, P., F. Delbaen, J.-M. Eber, and D. Heath, 1999, Coherent Measure of Risk, Mathematical Finance, 9, pp. 203-228.

Black, F. and M. Scholes, 1973, The Pricing of Options and Corporate Liabilities, Journal of political Economy, 81, pp. 637-654.

Black, F, 1976, Studies in Stock Price Volatility Changes, Proceedings of the 1976 Meeting of the Business Economic Statistics Section, American Statistical Association, pp. 171-181.

Bollerslev, T., 1986, Generalized Autoregressive Conditional Heteroscedasticity, Journal of Econometrics, 31, pp. 307-327.

Booth, J.R., R.L. Smith and R.W. Stolz, 1984, The use of interest rate futures by fincial institutions, Journal of Bank Research, 15, pp. 15-20.

Boyle, P., and F. Boyle, 2001, Derivatives: The Tools that Changed Finance, London Risk Books.

Broadie, M. and P. Glasserman, 1996, Estimating Security Prices under Simulation, Management Science, 42(2), pp. 269-285.

Cherubini, U., E. Luciano, and W. Vecchiato, 2004, Copula Methods in Finance, Wiley.

Clark, P. K., 1973, A subordinated stochastic Process model with finite variance for speculative prices, Econometrica, 41, pp. 135-156.

Christoffersen, P. F., 1998, Evaluating Interval Forecasts, International Economic Review, 39, pp. 841-862.

Credit Suisse Financial Products, 1997, Credit Risk Management Framework

DeMarzo P.M. and D. Duffie, 1995, Corporate incentives for hedging and hedge accounting, The Review of Financial Studies, 24(4), pp. 743-771.

Demarta, S., and A.J. McNeil, 2004, The $t$ Copula and Related Copulas, Working paper, Department of Mathematics, ETH Zentrum, Zürich, Switzerland

Dunbar, N., 2000, Inventing Money, The Story of Long-Term Capital Management and the Legends Behind It, Chichester, UK: Wiley.

Durham, G., 2003, Likelihood-based specification analysis of continuous-time models of the short-term interestrate, Journal of Financial Economics, 70, pp. 463-487

Engle, R.F., 1982, Auto-regressive Conditional Heteroscedasticity with Estimates of the Variance of U.K. Inflation, Econometrica, 50, 987-1008.

Engle, R.F., and J. Mezrich, 1996, GARCH for Groups, Risk, pp. 36-40.

Faruqui, A. and K. Eakin (2000), Pricing in Competitive Electricity Markets, Springer.

Fama, E.F., 1963, Mandelbrot and the Stable Paretian Hypothesis, Journal of Business, 36, pp. $420-429$.

Fama, E.F., 1965, The Behaviour of Stock Market Prices, Journal of Business, 38, 34-105.

French, K.R. and R. Roll, 1986, Stock Return Variances: The Arrival of Information and the Reaction of Traders, Journal of Financial Economics, 17, 5-26.

Gallant, A.R., D.A. Hsieh and G. Tauchen, 1991, On fitting a recalcitrant series: the Pound/Dollar exchange rate, 1974-1983, in W.A. Barnett, J. Powell, and G.E. Tauchen (eds.), Nonparamettric and Semiparametric Methods in Econometrics and Statistics, Proceedings of the Fifth International symposium in Economic Theory and Econometrics. Cambridge: Cambridge University Press, Chapter 8, 199-240.

Gallant, A.R., D.A. Hsieh and G. Tauchen, 1997, Estimation of stochastic volatility models with diagnostics, Journal of Econometrics, 81, pp. 159-192. 
Gallant, A.R., and J. Long, 1997, Estimating stochastic differential equations efficiently by minimum chi-squared, Biometrika, 84, pp. 125-141.

Gallant, A.R. and G. McCulloch, 2010, Simulated Score methods and Indirect Inference for Continuous-time Models, in Y. AïT-Sahalia and L.P. Hansen, eds. Handbook of Financial Econometrics, Vol. 1, Elsevier B.V., 427-477

Gallant, A.R. and G. Tauchen, 2010, Simulated Score methods and Indirect Inference for Continuous-time Models, in Y. AïT-Sahalia and L.P. Hansen, eds. Handbook of Financial Econometrics, Vol. 1, Elsevier B.V., 427-477

Gnedenko, D.V., 1943, Sur la distribution limité du terme d'une série aléatoire, Ann. Math, 44, 423-453.

Hendricks, D., 1996, Evaluation of Value-at-Risk Models using Historical Data, Economic Policy Review, Federal Reserve Bank of New York, 2, 39-69.

Hull, J.C. and A. White, 1998, Incorporating Volatility Updating into the Historical Simulation method for Value at Risk, Journal of Risk, 1, 1, 5-19.

Jamshidian, F., and Y. Zhu, 1997, Scenario Simulation Model: Theory and methodology, Finance \& Stochastics

Jorion, P., 2001, Value at Risk, 2nd ed. New York: McGraw-Hill.

J.P:Morgan, 1997, CreditMetrics - Technical Document

Kristiansen, T., 2004, Risk management in Electricity Markets Emphasizing Transmission Congestion, NTNU..

Kupic, P., 1995, Techniques for Veryfying the Accuracy of Risk Management Models, Journal of Derivatives, 3, pp. 73-84.

Lintner, J. 1965, The Valuation of Risk assets and the Selection of Risky Investments in Stock Portfolios and Capital Budgets, Review of Economics and Statistics, pp. 13-37.

Mandelbrot, A., 1963, The Valuation of Vertain Speculative Prices, The Journal of Business, 36(4), pp. 394-419.

Markowitz, H., 1952, Portfolio Selection, Journal of Finance, 7, 1, pp. 77-91.

Moore, J., J. Culver and B. Masterman, 2000, Risk management for Middle Market Companies, Journal of Applied Corporate Finance, 12, (4) pp. 112-119.

Mossin, J., 1966, Equilibrium in a Capital Market, Econometrica, pp. 768-783.

Nance, D.C., C. Smith JR. and C. Smithson, 1993, Determinants of Corporate hedging, Journal of Finance, 48,pp. 267-284.

Neftci, S. N., 2000, Value at Risk Calculations, Extreme Events and Tail Estimation, Journal of Derivatives, 7, 3, pp. 23-38.

Newey, W., 1985, Maximum Likelihood specification testing and conditional moment tests, Econometrica, 2, pp. 550-566.

Noh, J., R.F. Engle, and A. Kane, 1994, Forecasting Volatility and Option Prices of the S\&P 500 Index, Journal of Derivatives, 2, 17-30.

Rich, D., 2003, Second Generation VaR and Risk Adjusted Return on Capital, Journal of derivatives, 10,4,51-61.

Rosenberg, B., 1972, The behaviour of random variables with nonstationary variance and the distribution of security prices. University of California, Berkeley

Rosenberg, J.V. and T. Schuermann, 2004, A General Approach to Integrated Risk Management with Skewed, Fat-Tailed Risks, Federal Reserve Bank of New York, Staff report No. 185.

Ross, S.A., 1976, The Arbitrage Pricing Theory of Capital Asset Pricing, Journal of Economic Theory,13,341-60 
Samuelson, P.A., 1965, Proof that properly anticipated prices fluctuate randomly, Industrial Management Review,6, pp. 41-49.

Schwarz, G., 1978, Estimating the Dimension of a Model, Annals of Statistics, 6, pp. 461-464.

Sharpe, W., 1964, Capital Asset Prices: A Theory of Market Equilibrium, Journal of Finance, pp. 425-442.

Shepard, N., 2004, Stochastic Volatility: Selected Readings, Oxford University Press.

Solibakke, Per Bjarte, 2007, Describing the Nordic Forward Electric-Power Market: A Stochastic Model Approach, Vol 4, pp 1-22.

Solibakke, Per Bjarte, 2009, EEX Base and Peak Load One-Year Forward Contracts. Stochastic Volatility adapting the $M-H$ Algorithm, Working Paper, Molde University College, pp, 1 -25.

Stulz, R.M., 2003, Risk Management and Derivatives, Southwestern.

Tauchen, G. and M. Pitts, 1983, The price variability-volume relationship on speculative markets, Econometrica, pp. 485-505.

Tauchen, G., 1985, Diagnostic Testing and Evaluation of Maximum Likelihood Models, Journal of Econometrics,30, pp. 414-430.

Taylor, S.J.,1982, Financial returns modelled by the product of two stochastic processes, a study of daily sugar prices 1961-79. In Time series Analysis: theory and practice 1 (ed. O.D. Anderson), pp. 203-226. Amsterdam: North-Holland.

Taylor, S,J. 2005, Asset Price Dynamics, Volatility, and Prediction, Princeton University Press.

Tufano, P., 1996, Who manages Risk? An empirical examination of risk management practices in the gold mining industry, The Journal of Finance, 51 (4), pp. 1097-1137.

Zang, P.G., 1995, Barings Bankruptcy and Financial Derivatives, Singapore: World Scientific Publishing. 



\section{Edited by Matteo Savino}

The term "risk" is very often associated with negative meanings. However, in most cases, many opportunities can present themselves to deal with the events and to develop new solutions which can convert a possible danger to an unforeseen, positive event. This book is a structured collection of papers dealing with the subject and stressing the importance of a relevant issue such as risk management. The aim is to present the problem in various fields of application of risk management theories, highlighting the approaches which can be found in literature. 